


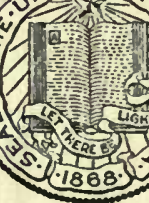

THE LIBRARY

OF

THE UNIVERSITY

OF CALIFORNIA

LOS ANGELES

IN MEMORY OF

EDWIN CORLE

PRESENTED BY

JEAN CORLE 
Huyis

Conule

Ber' 14 



\section{THE PRACTICAL BOOK OF OUTDOOR ROSE GROWING FOR THE HOME GARDEN}




\section{THE \\ PRACTICAL BOOKS}

EACH HANDSOMELY BOUND AND IN A SLIP COVER

THE PRACTICAL BOOK OF ORIENTAL RUGS

By DR. G. GRIFFIN LEWIS

New Edirion, Revised and EnLarged

20 illustrations in color, 93 in doubletone, 70 text designs in line. Folding chart of rug charac-

teristics and a map of the Orient Octavo. Cloth, $\$ 5.00$ Not

THE PRACTICAL BOOK OF GARDEN ARCHITECTURE By

PHEBE WESTCOTT HUMPHREYS

With frontispiece in color, designed title and 125 illus. trations from actual examples of garden architecture Octavo. Cloth, $85.00 \mathrm{Net}$

THE PRACTICAL BOOK OF PERIOD FURNITURE By

HAROLD DONALDSON EBERLEIN AND ABBOT MCCLURE

250 illustrations in color, doubletone and line of furniture of the Englisb, American Colonial and Post-Colonial, and principal French Periods Octavo. Cloth, \$5.00 Net

THE PRACTICAL BOOK OF OUTDOOR ROSE GROWING By GEORGE C. THOMAS, Jr.

96 perfect full-page reproductions in color and 8 halftone plates. Octavo. Cloth, $\$ 4.00 \mathrm{Net}$

UNIFORM IN SIZE AND STYLE THE CURIOUS LORE OF PRECIOUS STONES

By GEORGE FREDERICK KUNZ, PH.D., A.M., D.Sc.

With 76 illustrations in colors, doubletone and line Octavo. Cloth, $85.00 \mathrm{Net}$

J. B. LIPPINCOTT COMPANY PUBLISHERS PHILADELPHIA 



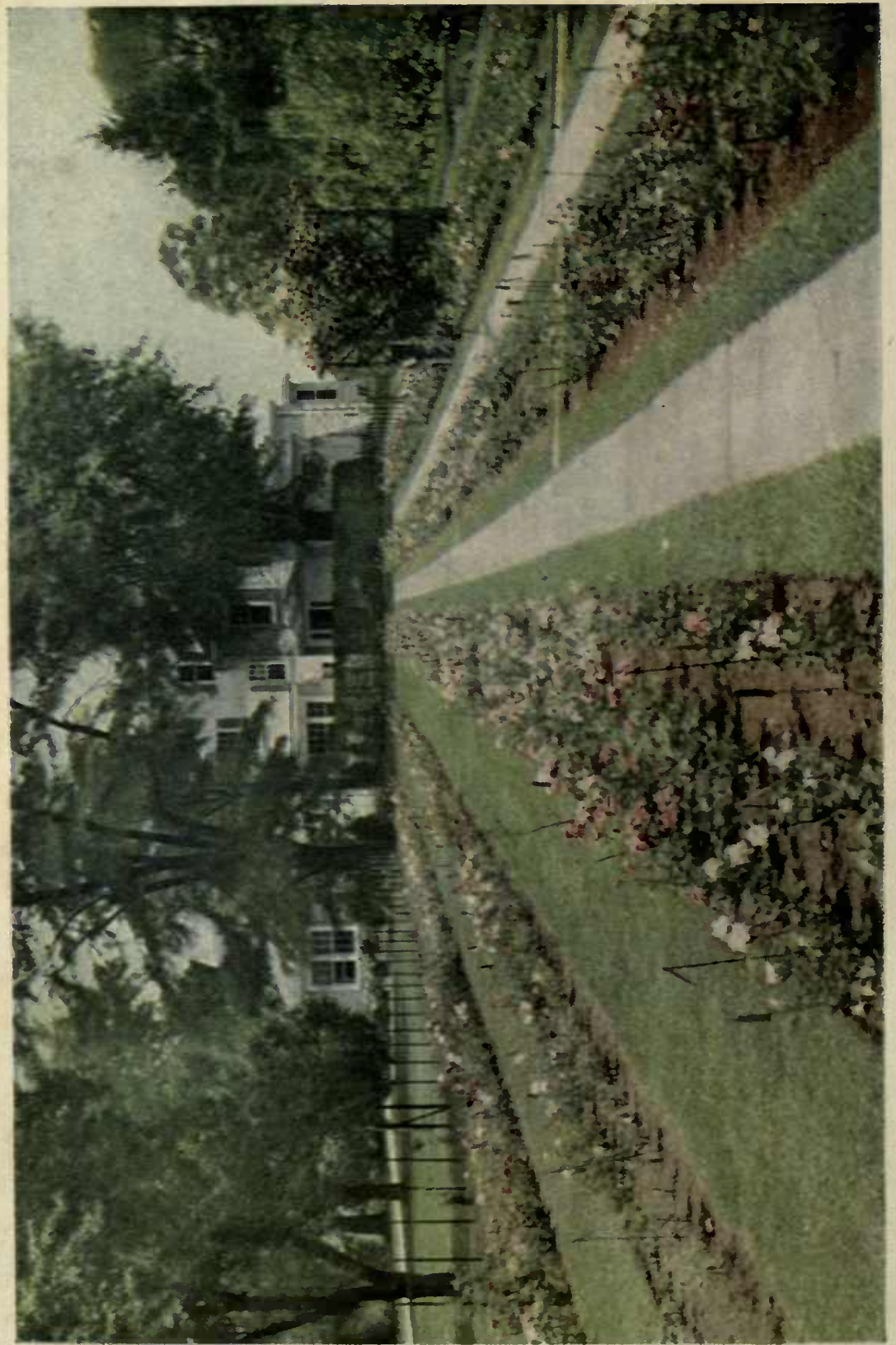




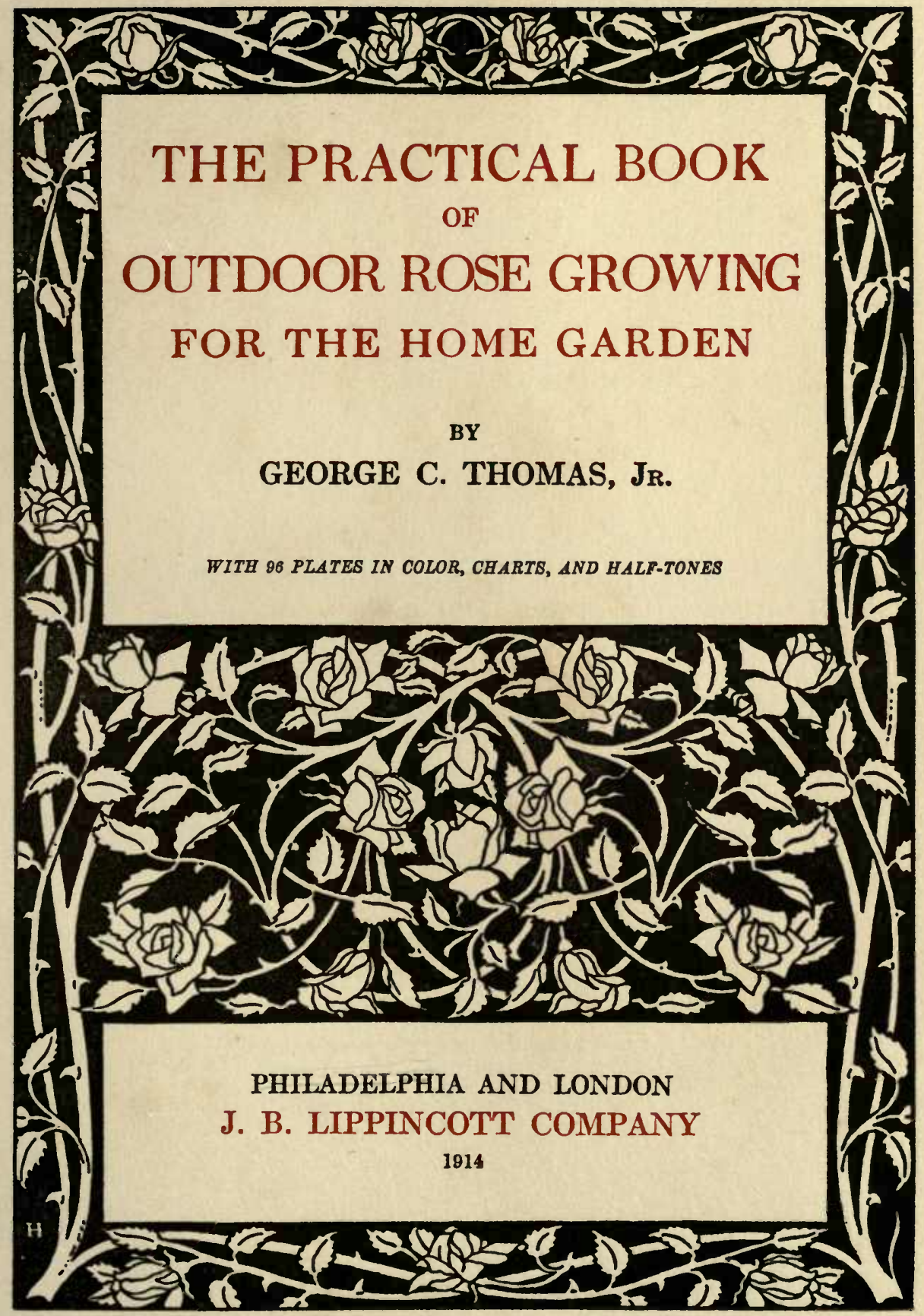


COPYRIGHT, 1914, BY J. B. LIPPINCOTT COMPANY

PUBLISHED NOVEMBER, 1914

PRINTED BY J. B. LIPPINCOTT COMPANY

AT THE WASHINGTON SQUARE PRESS

PHILADELPHLA, U.S. A. 
THIS BOOK IS AFFECTIONATELY

DEDICATED TO

DR. ROBERT HUEY

WHO GAVE ME MY FJRST INSPIRATION IN ROSE GROWING 



\section{FOREWORD}

THE author believes that there is need for a short, concise work on the best outdoor roses for our American climate, with practical working rules for their culture. It is his aim to supply this need in three ways:

First, by plain and carefully thought out rules, which have proven successful for many years in actual practice.

Second, by a list of roses made only after the entire catalogue list of varieties has been systematically tried for years in this country in testing beds.

Third, by illustrations in color reproduced from autochrome color photographs made from the varieties tested.

In addition, chapters devoted to general information are added as of interest, and books going further into detail on the various subjects are suggested.

The rules and arguments leading to their use, as herein set forth, have, as a base, rose growing in the approximate climate of the Middle Atlantic States, where the extreme temperature in winter does not often go below zero and the summer heat 


\section{FOREWORD}

seldom exceeds 95 degrees. This climate has rapid changes, all damaging to plant life, and it will readily be understood that, with the exception of climates where there is a more intense cold or heat, the list and rules, as hereafter given, will hold good. Suggestions are made for growing roses farther north and farther south.

In England and parts of Europe many roses flourish which when tried in America fail utterly.

We have used the words "failure" and "weak growers" to mean that our experiments in America with these varieties have been unsuccessful. Under more favorable conditions such varieties may do well.

This book does not pretend to be in any sense a complete scientific treatise on the rose or the more intricate details of its culture, such as hybridization, budding, grafting, etc., which the average amateur rose grower would not care to undertake and which are well and amply covered in standard works.

The author wishes to acknowledge, with great appreciation, the help of Dr. Robert Huey in all phases of his work.

Thanks are due to Messrs. Henry A. Dreer, Inc., Philadelphia, for their help in importing and securing new varieties, and also for giving data on roses tested by them. 


\section{FOREWORD}

The aid of Messrs. Williams, Brown \& Earle, Philadelphia, made possible the taking of the colored photographs.

The Japanese Multiflora which we recommend for certain varieties was first brought to our notice by the stock of George H. Peterson, of Fair Lawn, New Jersey.

September, 1914

G. C. T., Jr. 



\section{CONTENTS}

CBAPTER PAOE

I. The Propagation of Roses.............. 15

II. The Best Varieties, with their Characteristics...... 33

III. Chmbers..................... 67

IV. Location and Preparation............... 80

V. Ordering ....................... 91

VI. Plantina $\ldots \ldots \ldots \ldots \ldots \ldots \ldots \ldots \ldots \ldots \ldots \ldots \ldots$

VII. Prunina $\ldots \ldots \ldots \ldots \ldots \ldots \ldots \ldots \ldots \ldots \ldots \ldots \ldots \ldots$

Vili. Culmivation $\ldots \ldots \ldots \ldots \ldots \ldots \ldots \ldots \ldots \ldots \ldots \ldots \ldots$

IX. Some Genmal Information and Hints on Hrbridization 139

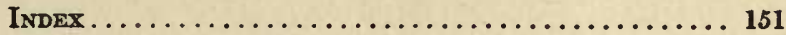





\section{ILLUSTRATIONS}

\section{COLOR PLATES}

Testina Beds-Author's Home............. Frontispiece

Killakney Brillitant.......................... 26

Reversion of Mrs. HARKNESS.................. 28

Sixteen Best Roses (Following Page 42)

Frad Kard Druschit....................... No. 1

Madame JUles Bodche....................... No. 2

ANTOINE ReVoIRe......................... No. 3

ElLen WiLmot........................ No. 4

KILARRNEY............................ No. 5

JonkheEr J. L. Mock....................... No. 6

Madame Leon PaIn....................... No. 7

Lady Alice Stanley....................... No. 8

Robert HUEY........................... No. 9

General MacArthdr....................... No. 10

Latrent Carle........................... No. 11

Grdss an Teplitz......................... No. 12

HARRY KIRK......................... No. 13

Duchess of Wellington..................... No. 14

Bетту................................. No. 15

Mrs. A. R. WAdDELl..................... No. 16

Christine Wright.............................. 69

Cummbing Kaiserin Augusta Victoria.................. 70

Aviatedr Bleriot............................ 76

Roses on Dr. Huey's Place..................... 82

First Bloom of a Hybrid Tea Seeding............ 145

Following last Page of Voldme, in Alphabetical Order Alex. Hill Gray

Auice Lemon

ANNie Besant

Beaute Inconstante 


\section{ILLUSTRATIONS}

BRTTISH QUEEN

Cardinal

CArine

Compesge Felicte Hoyos

Compesse Maggr Starzynsea

(On same plate with Mrs. Hubert Taylor)

CoUntess of Derby

(On same plate with Gartendirector Hartrath)

Charles J. Grahame

Creme Simon

C. W. CowaN

(On same plate with Elizabeth)

Dean Hole

Dorothy PAGe Roberts

DoROTHY RATCLIFFE

Duchess of Sutherland

DUChess OF WESTMINSTER

EARL OF WARWTCK

EdWARD MATLET

(On same plate with Eugene Boullet)

ELIzABEth

Edgene Bodllet

Evelyn DaUNTESEY

FARBEN Konigin

Freinerr Von Marschall

F. R. Patzer

GarTENDIRECTOR Hartrate

Geoffrey HensLow

George C. Ward

(On same plate with Lady Battersea)

George Dickson

Hermosa

Hugo RolLER

JosEPB HiLL

KaIser Wilhelm II

(On same plate with Charles J. Grahame)

LADY AsHTOWN

LADY BARHAM

LADY BATTERSEA

LADY DE BATHE 


\section{ILUUSTRATIONS}

\section{Ladt Greenall}

(On same plate with Comtesse Felicie Hoyos)

LADT HELEN VINCENT

LADY Hillingdon

LADX KaTHERINE ROSE

(On same plate with Lady Helen Vincent)

LadT Margaret Boscawen

LAdY MoYra Beadclere

LAdy Pirrie

LYON

MABEL DREW

Madame A. Tupinier

Madame Charles Lejeune

Madame Edodard Herriot

Madame Lucien Picard

(On same plate with Creme Simon)

MADAME MELANIE SOUPERT

Madame PaUL Rouchon

Madame Segond Weber

Madame Vermorel

Madame Wagram, Comtesse de Turenne

Mademoiselle Marie Mascurand

Mademoiselle Simone Beadmez

Mary, Countess of Ilchester

(On same plate with Lady Battersea)

Mart, Countess of Ilchester

Miss Alice DE ROTHSCHILD

Mrs. Arthur E. E. Coxhead

Mrs. Charles Custis Harrison

Mrg. Charles E. Aluhan

Mrs. Hubert Taylor

Mrs. James Craig

Mrs. Joseph H. WeLCH

Mrs. Leonard Petrie

Mrs. Richard Draper

Mrs. Waluace H. Rowe

(On same plate with Madame Charles Lejeune)

Mrs. Walter Easlea

NATAlie Botrner

Odette Pedriolle 


\title{
IILUSTRATIONS
}

\author{
OpHeLIA \\ Pharisaer \\ President William Howard Taft \\ Prince de Bulgarie \\ RADIANCE \\ Senatedr Mascurand \\ Souv. do President Carnot \\ St. HELENA \\ White KMLARNeY \\ W. R. SMITE
}

\section{HALFTONE PLATES}

Rose Cuttina Ready for Plantina................. ${ }^{\mathbf{p a x}}$

Hrbrid Tea and Manetti Folitage................. 21

Semdings Showing Varied Growths................ 29

Hybrid Tea Rose, Not Pruned but Allowed to Develop 116

Same Rose Properdy Pruned.................... 116

Rose with Petals Removed, Showing Stamens and ANthers 146

Same Rose with Most of Stamens and Anthers Removed. 146

Seed Pod on $\triangle$ Hrbrid Tra Rose which has been Hrbridized 148 


\section{THE PRACTICAL BOOK OF OUTDOOR ROSE GROWING}

\section{I \\ THE PROPAGATION OF ROSES}

\section{ESTABLISHED VARIETIES}

IN this chapter it is aimed to give the reader such general information as will enable him to comprehend the main principles of the propagation of the rose. In order that he may fairly understand the following chapters, and the general scheme of the selection of varieties and the ordering of the same, this chapter should be read carefully. It is not our intention, as explained in the introduction, to puzzle the home rose grower with all the scientific details of each phase of rose culture; but it is believed that the following paragraphs will give a good working idea of the methods employed. For those who may care to follow out such matters to their utmost conclusion the names of exhaustive works are given.

Established roses are propagated by the following methods: seeds, layering and suckers; cuttings, budding and grafting, the last three being the principal methods. 


\section{OUTDOOR ROSE GROWLNG}

\section{SEEDS}

In order to secure established varieties seeds are used only in special cases, because they can only be relied upon to reproduce plants of their own kind when they are taken from original species. Seeds of hybrids are useless for this end, as their seedlings do not conform to the parent stock. In other words, hybrids do not come true from seeds, and their seeds are only useful for new varieties. "Experiments with Plants," by Osterhout, goes further into the scientific treatment of seeds than any book we have seen.

\section{LAYERING}

Many plants and some roses increase by layering, that is, throwing out a branch which becomes rooted and in turn sends out its branches to root themselves and carry out nature's work of increase. Layering is not practised to any great extent, as it is a longer process than the others and requires not only more time to accomplish results, but also more space either in greenhouse or nursery.

Layering is now only used for some varieties which do not root well from cuttings. Ellwanger cites Persian Yellow as one of these.

It is a simple and easy operation, and is accomplished by bending down a rose cane of a growing 


\section{THE PROPAGATION OF ROSES}

plant, scientifically notching it with a knife (technically known as tongueing), and then putting the tongued portion into prepared ground, after which it is held in place by various methods. Roots are formed at the break and eventually the part so treated may be detached from the original plant, and becomes itself a complete plant.

Pemberton in "Roses-Their History, Development and Cultivation," gives very clear and explicit instructions on layering.

\section{SUCKERS}

Pemberton's description of suckers we quote as follows:

"Many of the species, such as Rugosa, Alpina, Spinosissima and Lucida, together with Provence and Damask hybrids, etc., increase by throwing out suckers, springing up at some distance from the parent plant, and forming roots at the place where they bend upwards. These rooted suckers, after being separated from the plant, should be pruned back to a foot or even less, and then treated as ordinary plants."

\section{CUTTINGS}

Cuttings are slips taken from plants which, when placed in sand and soil, grow roots of their own and become in turn rose plants, giving the same bloom 


\section{OUTDOOR ROSE GROWING}

as the plants from which they were cut. Very often they are given greenhouse care and while this is not necessary, it obtains, perhaps, surer and better results. In experimental work, cuttings have been carried so far that they have been made successfully even from rose leaves, although this method is of no practical use. No doubt many persons who have followed us to this point understand cuttings and have employed them not only in roses but in other plants, such as carnations and geraniums, which are propagated almost entirely by cuttings.

In their proper place (the greenhouse) cuttings as used in rose culture may be relied upon, but beyond this sphere their use is open to debate, as, in the opinion of nearly all the best authorities, they are not as satisfactory as budding. The main reason for their failure is that many of our new varieties are weak growers and cannot of their own accord win the fight for existence, even under favorable conditions. As conditions in our climate are most uncertain only the exceptionally hardy plant succeeds of itself on its own roots.

Cuttings are useful, however, when expense must be considered with certain of these hardy varieties. It would be easy for any one to make cuttings of his own, and this could be successfully done with the 


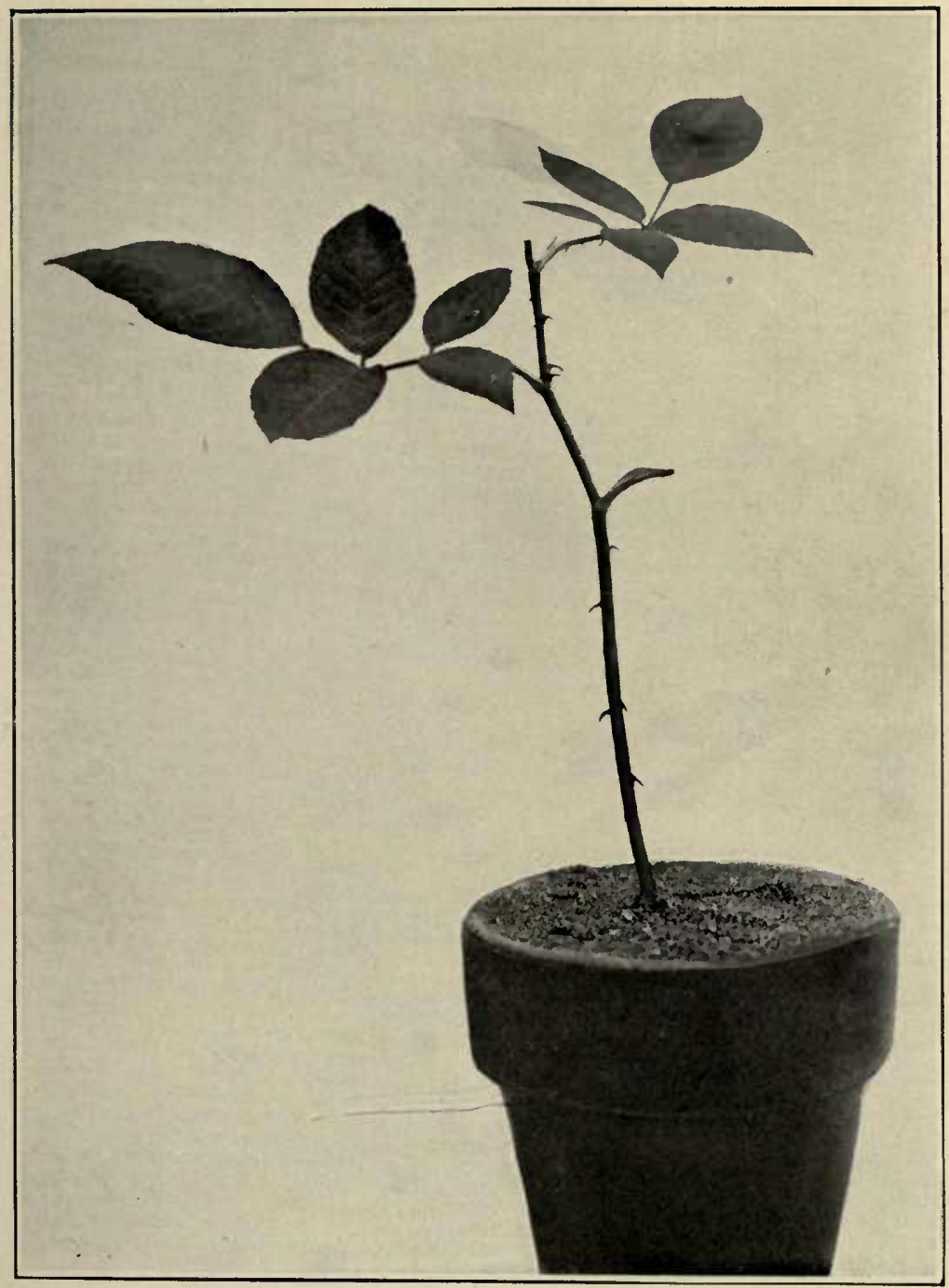

FIG. 1

ROSE CUTTING READY FOR PLANTING 



\section{THE PROPAGATION OF ROSES}

hardier kinds of roses, thereby saving the expense of purchasing. If roses are purchased, we strongly recommend buying budded plants, as the slight extra outlay would be fully justified.

While there are many good articles on cuttings, we consider that Pemberton's is the best, as it treats of cuttings under glass and also cuttings in the open.

\section{BUDDING}

In budding roses a strong stock is secured and the variety selected is budded upon this stock, eventually becoming a part of it. The actual operation of budding is merely to cut off the dormant bud from the variety which it is desired to perpetuate and, cutting a slit in the bark of the stock, to introduce the bud into the same. When the bud so transplanted becomes somewhat established, all growth above it is removed and the whole vitality of a proved stock is thrown into the bud, giving it the nourishment which a tried constitution insures.

In England the two stocks most commonly used are MANeTti and Briar. In the case of roses with a preponderance of Hybrid Perpetual blood the Manetti stock is generally used; for those containing much Tea blood the Briar has been found the better stock.

A few growers in this country are trying Japanese 


\section{OUTDOOR ROSE GROWING}

Multiflora, and with some varieties secure stronger and better stock than that grown from the ordinary stocks as generally used. Sometimes Rugosa stock is used for budding and a very few roses do quite well on it, the most noted of which is Molly Sharman Crawford.

Undoubtedly the ideal stock for all roses has not yet been discovered, and a great advance should be made in this most important section of rose culture. In order to secure a perfect rose list, budding on different stocks should be tried. If cuttings only are employed, very many roses will not succeed as well for outdoor culture.

There are two objections to budded roses. First, they occasionally break off at the bud, but this has so seldom occurred with us in actual practice that it is not worth consideration. The second and main reason is that the stocks upon which the roses are budded throw up shoots of their own below the bud, which, if left, take the entire nourishment of the roots and check the budded growth by crowding it out and taking its light and sunshine.

These shoots from below the bud may be very easily detected upon their appearance, because they come up from the ground outside the plant and also because of their different habit of growth, containing, as they do, seven and sometimes nine leaves on each 


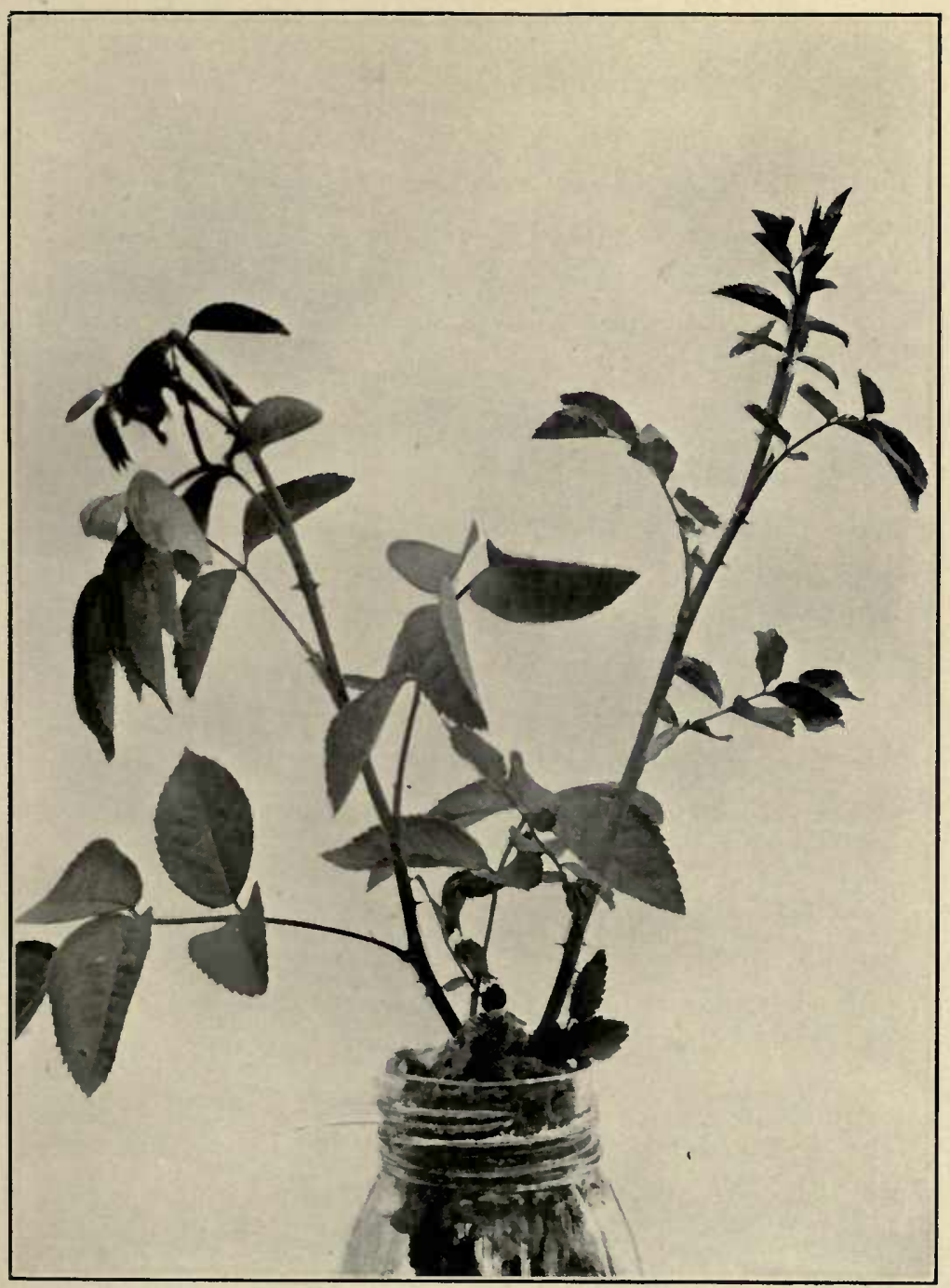

FIG. \&

IYYBRID TFA AND MANETTI FOLIAGE

At left, ordinary Hybrid Tea foliage showing five leaves on eaeh lateral. On the right, a shoot of Manetti, showing plainly seven leaves on the lower laterals. Note also the greater number of thorns on the Manetti 



\section{THE PROPAGATION OF ROSES}

lateral, instead of three and five as in most budded varieties. (Note illustration.) The foliage is of a much lighter shade of green than the shoots from the bud itself and its point of junction with the plant is below the bud. It is very easily removed by carefully digging up the ground, cutting it off with a knife at its union with the plant below the bud, and rubbing some earth over the cut. In addition, this main reason is not a valid objection, because it only happens with about one per cent. of the budded plants, and can even then be easily detected and the trouble removed. To keep this percentage down, roses must be planted with the bud two to three inches below the surface of the soil, as hereafter advocated. If planted less deeply they will throw a greater number of suckers.

Very often cuttings have only greenhouse growth when they are shipped to the purchaser. At best they are generally propagated under glass and have not had much outdoor growth, whereas budded plants are budded in the summer out-of-doors, and have even as yearlings a whole season's outside growth before being sold.

We have tested the own root plants, as cuttings are called, and in one particular instance made the following experiment which decided us once and for all as to the merits of the two methods. 


\section{OUTDOOR ROSE GROWING}

One bed was made, and over fifty roses on their own roots and fifty budded roses were planted in it side by side, all of old and established varieties, and, in the case of the own root plants, purchased from a grower who advocates their use. At the end of the first summer the difference was plainly apparent and was strongly in favor of the budded plants. At the end of two years there was no possible doubt as to the result; the budded plants were far superior. Experiments with other roses have endorsed this result, and budded roses are recommended for all outdoor work for the majority of roses contained in our main list, whether Hybrid Teas, Hybrid Perpetuals, or Teas.

In the case of climbers and some few very strong growers no doubt the own root roses would give good results, but as a working rule they cannot be recommended. In our garden are budded roses originally planted in the autumn of 1900 and moved from our first home to our present place in 1907. These plants are still strong and healthy and of the original lot less than two per cent. have died in over thirteen years.

We know of one case where budded roses planted over thirty years ago are still flourishing, and this certainly shows that their length of life is all that can be expected. 


\section{THE PROPAGATION OF ROSES}

In our testing of new roses the great majority has been budded plants and the percentage of deaths has naturally been greater in these new varieties than in established kinds. We have annually imported from three hundred to a thousand roses of new varieties, and yet twenty plants a year would cover all the deaths even of these new and untried kinds. Ordinarily, from one to two per cent. a year would more than cover the deaths of varieties marked "A" and "B" in our main list, under the column of "hardiness."

In other branches of horticulture budding and grafting have been tried with the greatest success; for example, apples, pears and peaches give very much better results for the reason that the kind of stock desired is supplied. It does seem that a tried stock is better than a different stock with each plant, viz., its own.

Undoubtedly better stocks will be discovered for certain roses which do not do well on the regular stocks; but surely it is going backward to grow inferior roses on their own roots and be satisfied with them, rather than by experimenting to ascertain the best stocks.

While all the better known rose books deal quite thoroughly with descriptions of budding, the "Nursery Book," by L. H. Bailey, should certainly be read by any one contemplating such work. 


\section{OUTDOOR ROSE GROWING}

For many strong growing plants and trees, where perfect results are obtained on the stock of the plant itself, budding is not necessary. With strong growing roses amateurs can take cuttings easily and increase their number of plants.

\section{GRAFTING}

Grafting is a modification of budding, and is a process which may give as good a result in the end with some outdoor roses; but for the first year, after planting outside, the plant does not make as much progress, and our death-rate has been much greater with grafted stock than with budded plants. Unfortunately grafts do not take very well on the Briar, therefore grafters use the Manetti which, as explained above, is not the best stock for Teas and Hybrid Teas.

Grafting is mostly used to increase new varieties which, if budded, would necessarily have to be operated upon in the late summer, the bud not developing until the following spring; whereas, in grafting, a part of the plant desired to be propagated is grafted upon the stock selected and growth at once begins; this is a very much quicker operation, but not so sure of success as budding for outdoor roses.

Grafting requires great skill and is used to obtain 


\section{THE PROPAGATION OF ROSES}

quick results. Seedlings to be tested are often grafted and a verdict quickly arrived at. There are numerous methods employed in grafting, but the principle is the same in all; the variety required is spliced on the stock and, as in budding, the strength of the stock all goes into the variety desired. Grafting roses is usually done under glass and requires expert handling, both during the actual operation and thereafter.

The books mentioned for cuttings and budding give the best articles on grafting, in addition to which "Parsons on the Rose" contains good, clear and explicit information on all these subjects.

\section{NEW VARIETIES}

New varieties of roses are developed in two ways: by sports and seedlings.

\section{SPORTS}

Sports are purely a matter of chance, and occur when any given variety shows a bloom or habit of growth different from the accepted plant. When this occurs propagation of the wood by cuttings, budding or grafting establishes the new variety.

As illustrations of sports, the two following are well known and are changes from the parent stock in the color of the bloom itself: 


\section{OUTDOOR ROSE GROWING}

La France, color silver rose, sported with Paul \& Sons, near London, in 1888, and gave the Duchess of Albany, called dark La France, a rich, deep pink. This was propagated and Duchess of Albany is now a well-established variety.

Camoens, pale rose color with the base of the petals yellow, sported with Boytard, in 1907, and the new rose was called Ecarlate, a brilliant scarlet.

With these two new varieties the habit of growth of the plants remained practically the same as their parent plents; it was only in the color of the rose that the change manifested itself.

In the past few years the old rose, Killarney, has sported three times, giving Killarney Brilliant, a rose of a deeper shade of pink; White Killarney, a rose, as the name implies, of a beautiful white; and Double Killarney, a rose of greater substance in petallage than the parent stock from which it sprang. These new roses will, no doubt, take their places in the list if they do as well as the old established Killarney, which there is every reason to believe they will do.

Before so many hybrids were cultivated, and when roses were not grown to as great an extent as now, sports were naturally less frequent. Of course varieties which are crosses, such as the hybrids of today, are very much more likely to give different 


\section{KILLARNEY BRILLIANT}

\section{Hrbrid TeA}

Alex. Dickson and Sons, 1914. See List. 


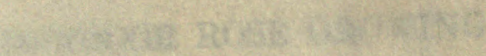

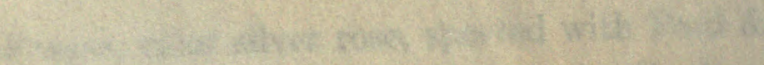

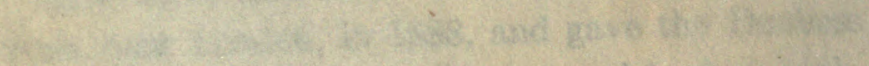

8.

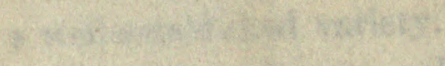

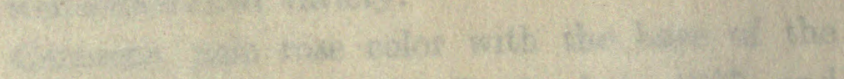

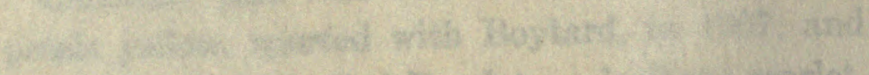

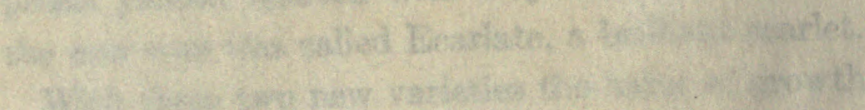

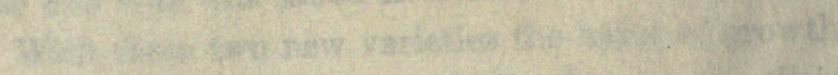

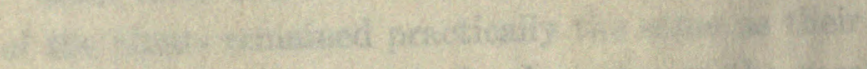

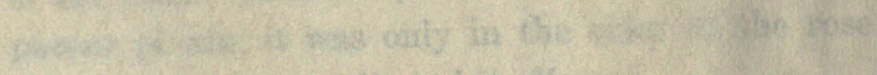

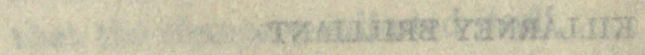

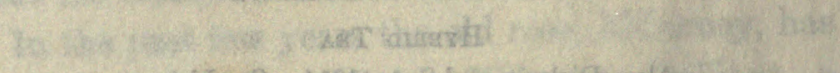

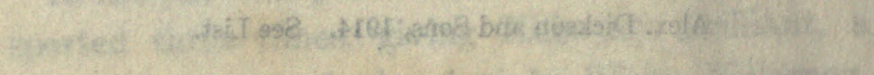

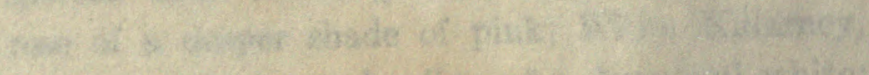
4.

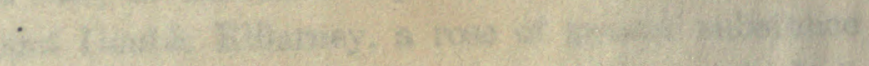

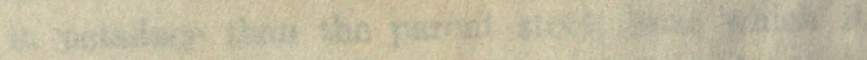

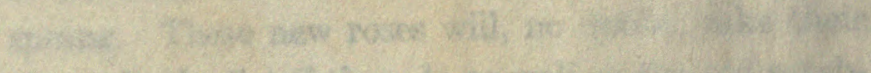

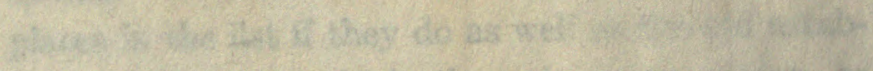

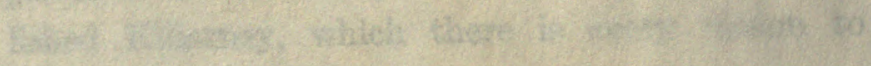

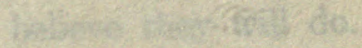

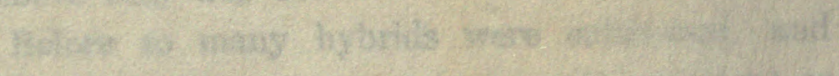

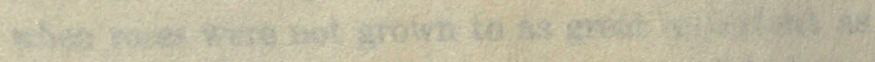

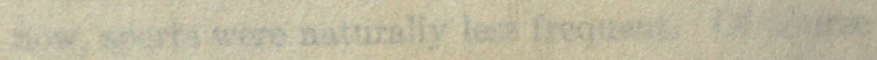

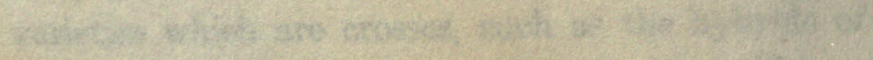

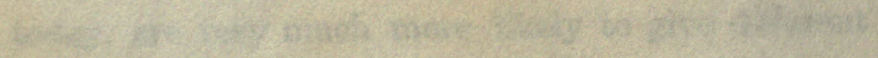




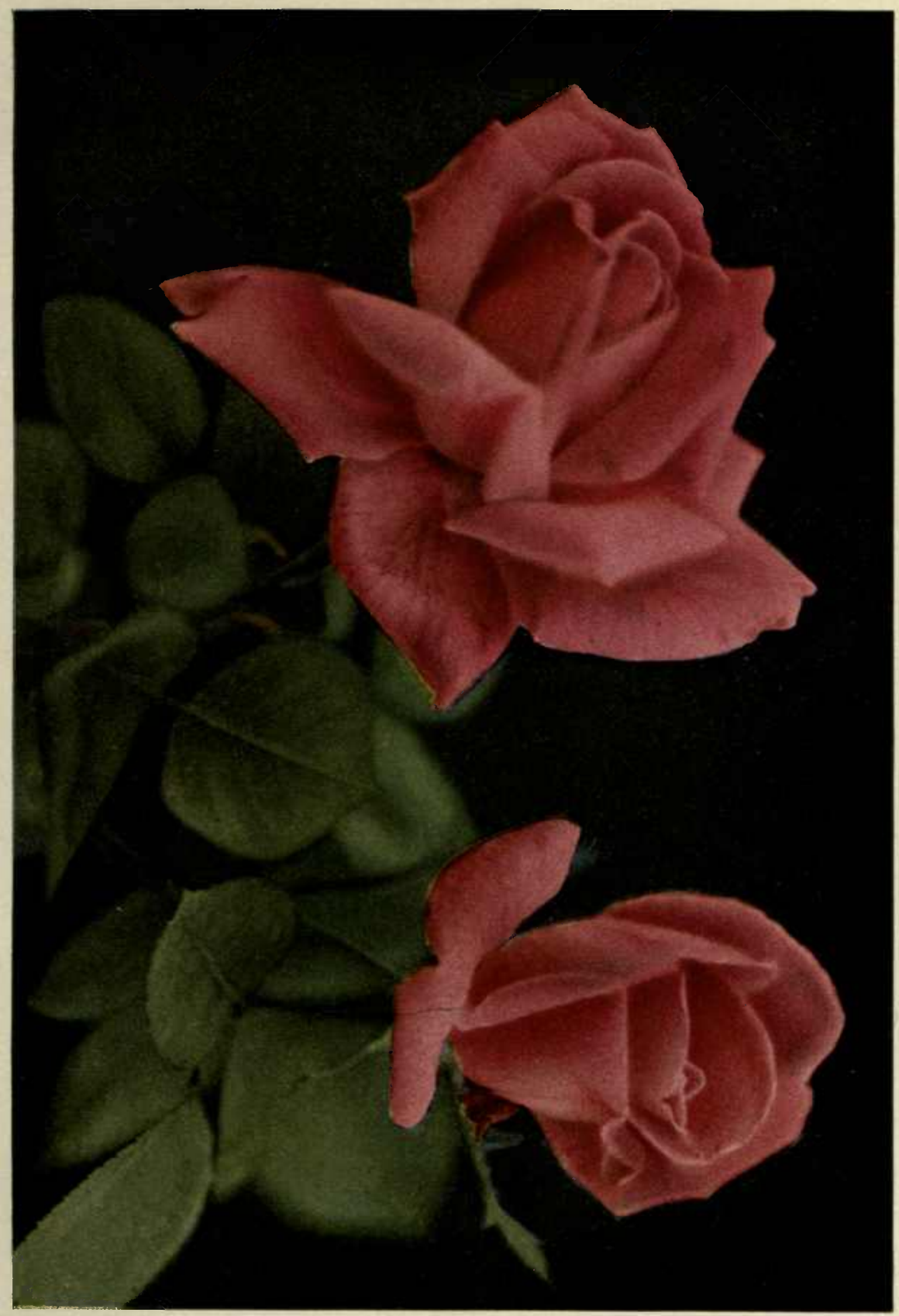





\section{THE PROPAGATION OF ROSES}

growth or different bloom than the old varieties, which were not so far removed from the original species.

Changes in habit of growth occur as well as changes in bloom, and a great many of the Hybrid Teas have produced sports which have much more of a climbing habit than the dwarf bush from which such new varieties originated. The bloom in form and color is practically identical with the parent stock, although its period of flowering is usually shorter and its bloom less profuse.

There is one very interesting illustration of a rose which sported, the new growth of which when propagated reverted to the original form of its parent stock. Heinrich Schultheis, a Hybrid Perpetual rose of deep, rosy pink, sported with Paul \& Sons, of London, and produced Paul's Early Blush, a light silvery pink. Again it sported with Alex. Dickson \& Sons, in Ireland, and produced another silvery pink, known as Mrs. Harkness. Both of these new roses were perpetuated and became quite popular before the Hybrid Teas came into general notice. In the year 1913 Dr. Robert Huey, of Philadelphia, still had plants of Paul's Early Blush and Mrs. Harkness. It was remarkable that specimens of both these plants partially reverted to the old form of Heinrich Schultheis, throwing up shoots 


\section{OUTDOOR ROSE GROWING}

with rose-colored blooms. If these had been propagated, some slight difference between them and Heinrich Schultheis might have been shown, but as the color and form of these roses were practically the same as specimens of Heinrich Schultheis growing in the same garden, the experiment was not tried.

Very often sports occur which are not noticed and of which advantage is not taken. Recently, while talking to the owner of a rose garden we were informed that one of her Killarney bushes had thrown out a red rose. There is a possibility that a plant might in some way have been misplaced, but the grower in question was quite sure that the red rose was a Killarney and that on one side it gave a flower of different color. We told her to watch the plant very carefully the coming spring, as she might have the pleasant experience of being the introducer of a new variety.

We do not wish to imply from this that sports are of frequent occurrence, for in all the years we have grown roses, and notwithstanding all the care we have lavished upon them, we have never had a sport manifest itself.

\section{SEEDLINGS}

Seedlings, as the name implies, come from seeds hybridized either by chance or by man's handiwork. 


\section{REVERSION OF MRS. HARKNESS}

Note deep rose-colored blooms of Heinrich Schultheis on right and Silver Pink of Mrs. Harkness on left. Prior to 1913 this plant gave nothing but the silver pink blooms of Mrs. Harkness. 


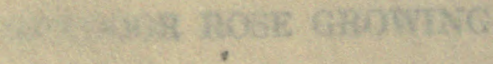

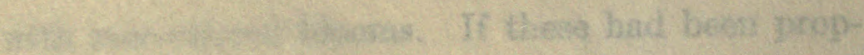

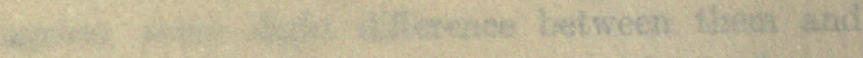

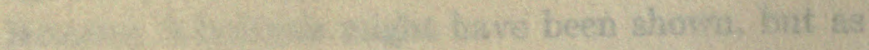
36.

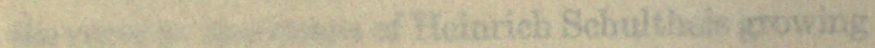

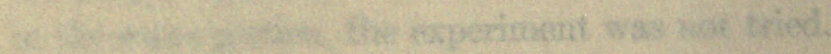

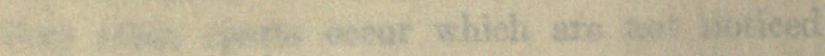

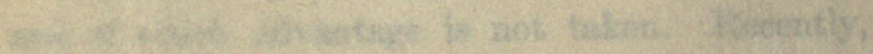

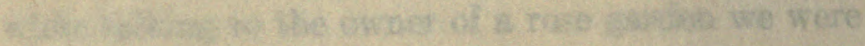

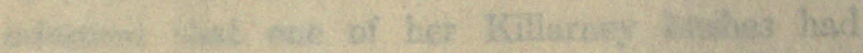

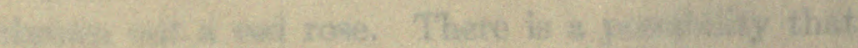

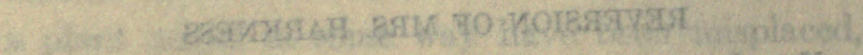

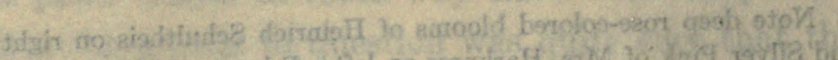

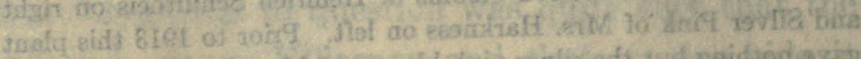

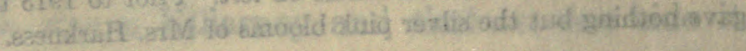

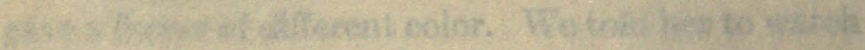

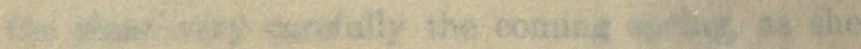

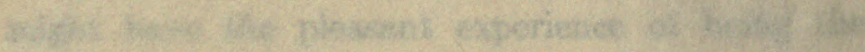

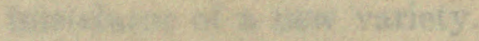

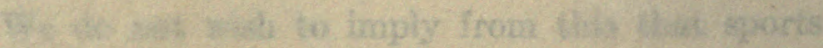

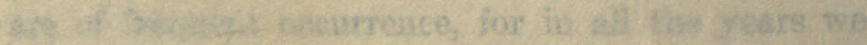

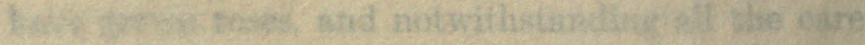

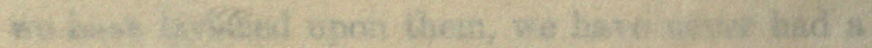

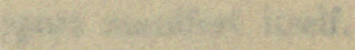

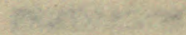

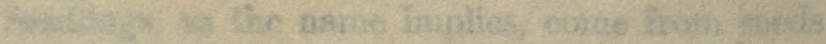

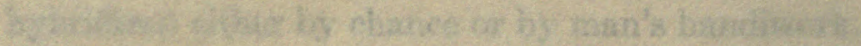




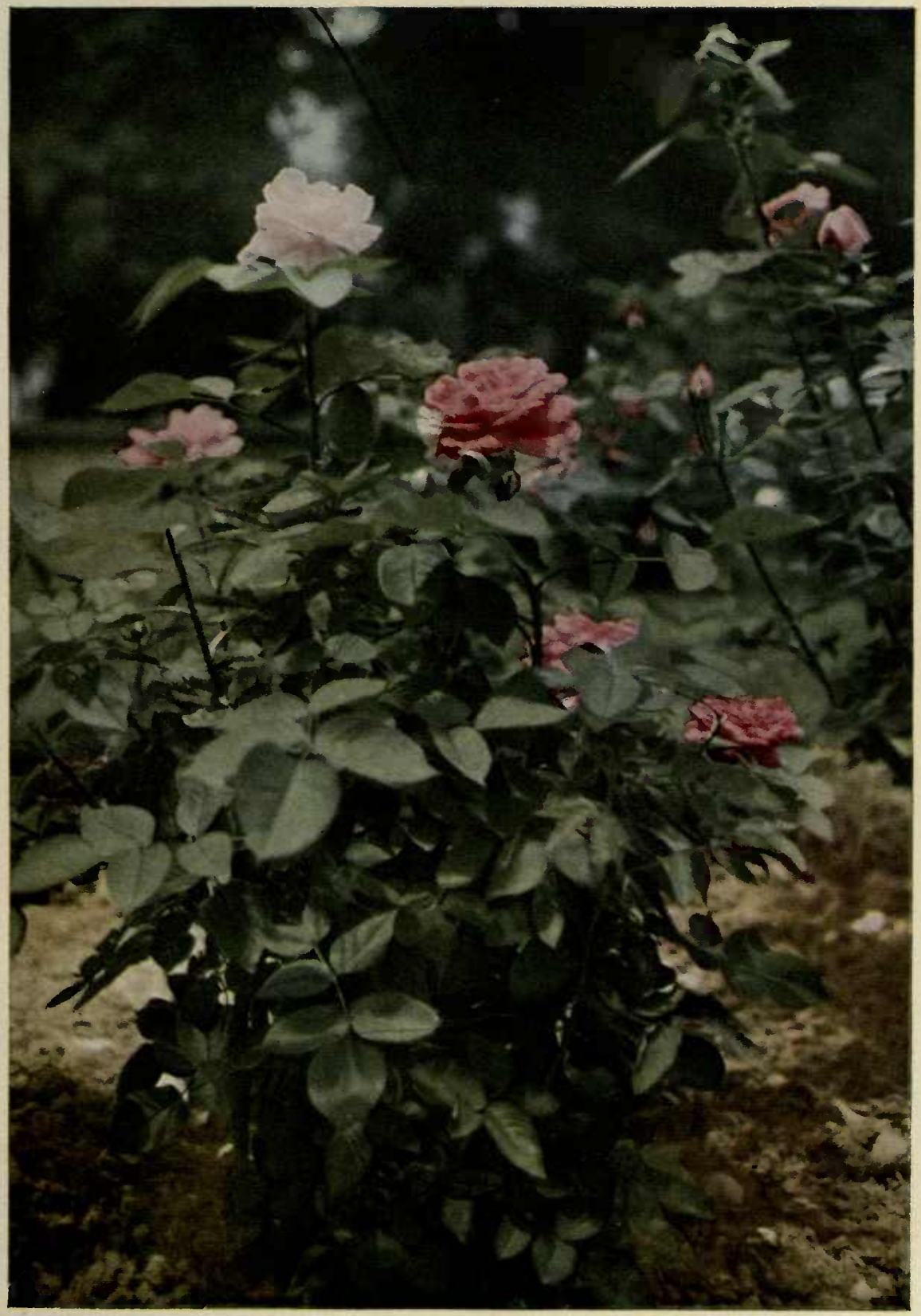





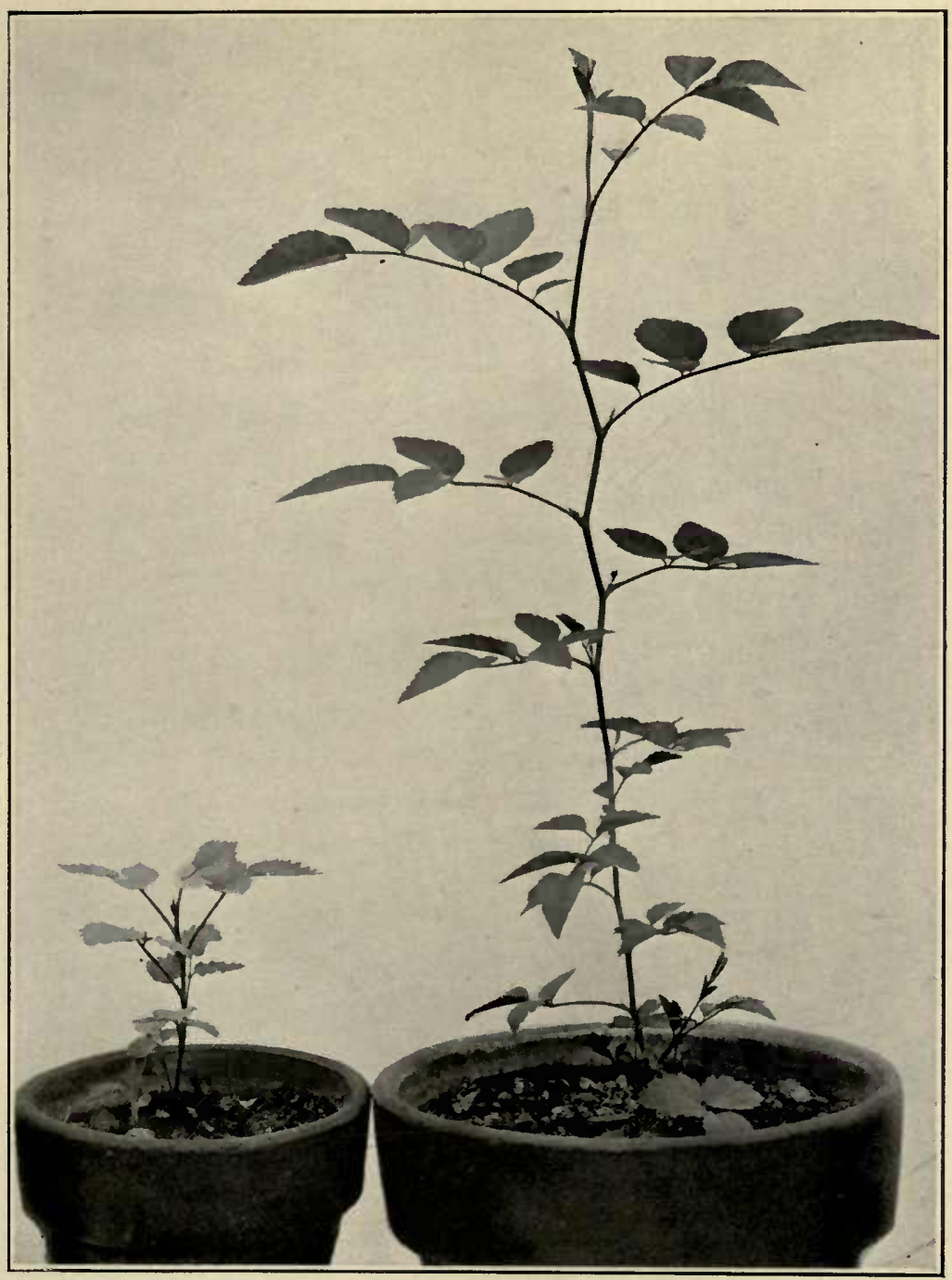

Fig. 3

SEEDLINGS SHOWING VARIED GROWTHS

On the left-hand side seedling of a Hybrid Tea. On the right-hand side seedling of a Wichuraiana. Both these plants are of the same age and have received identical care. Note different habit of growth even at this early stage in the life of the plants 



\section{THE PROPAGATION OF ROSES}

Nearly all the older rose growers gathered their heps containing the seeds in the autumn of each year and planted great numbers of these in nursery rows, hoping to secure new varieties; in this manner a great many of the Hybrid Perpetuals were discovered and introduced. However, of late years the commercial rose growers of Europe have hybridized different varieties of roses, and by careful selection and breeding for several generations are securing their new varieties.

In Europe this work is maintained on a very large scale. Thousands upon thousands of seedlings are raised each year, and only a very small percentage are of any practical use. In this country only a few men have achieved any great success in introducing new varieties-John Cook, of Baltimore, Maryland; E. G. Hill, of Richmond, Indiana; M. H. Walsh, of Woods Hole, Massachusetts; Dr. Van Fleet and W. A. Manda, of New Jersey. Cook introduced My Maryland and Radiance, and Hill has given us quite a number of good roses, the best perhaps for outdoor culture being General MacArthur, which is one of the finest all-round outdoor red roses grown in America today. Walsh, Manda and Van Fleet have been particularly successful in developing new Hybrid Wichuraiana-Walsh's most notable being Excelsa, Hiawatha, Sweetheart and 


\section{OUTDOOR ROSE GROWING}

Evangeline, all excellent additions and ranking with the best Wichuraiana climbers.

Following will be found a tabulated record of the breeding of the main varieties in which the Hybrid Perpetuals and Teas figure. It has not been arranged at all in conformity with the usual botanical analyses of species and sub-species, but the information given has been taken from such books as Pemberton's and placed together so that the history of the breeding of the different varieties may be seen at a glance. There are several authorities who have noted that the exact breeding of the Hybrid Perpetuals is to some extent problematical. The roses named as the Hybrid Perpetuals' immediate ancestors are generally accepted as such, but some few other varieties were used in the gradual evolution of this class from the first Hybrid Perpetual until the list was completed. At the present time there are fewer Hybrid Perpetuals bred, as the Hybrid Teas have entirely superseded them.

The work of hybridization is a most interesting one, but unless carried out on a scientific scale it is almost entirely a matter of chance whether or not anything of value may be secured. No doubt any one cultivating roses to a large extent would greatly enjoy trying to introduce a new variety of his own breeding. 


\section{THE PROPAGATION OF ROSES}

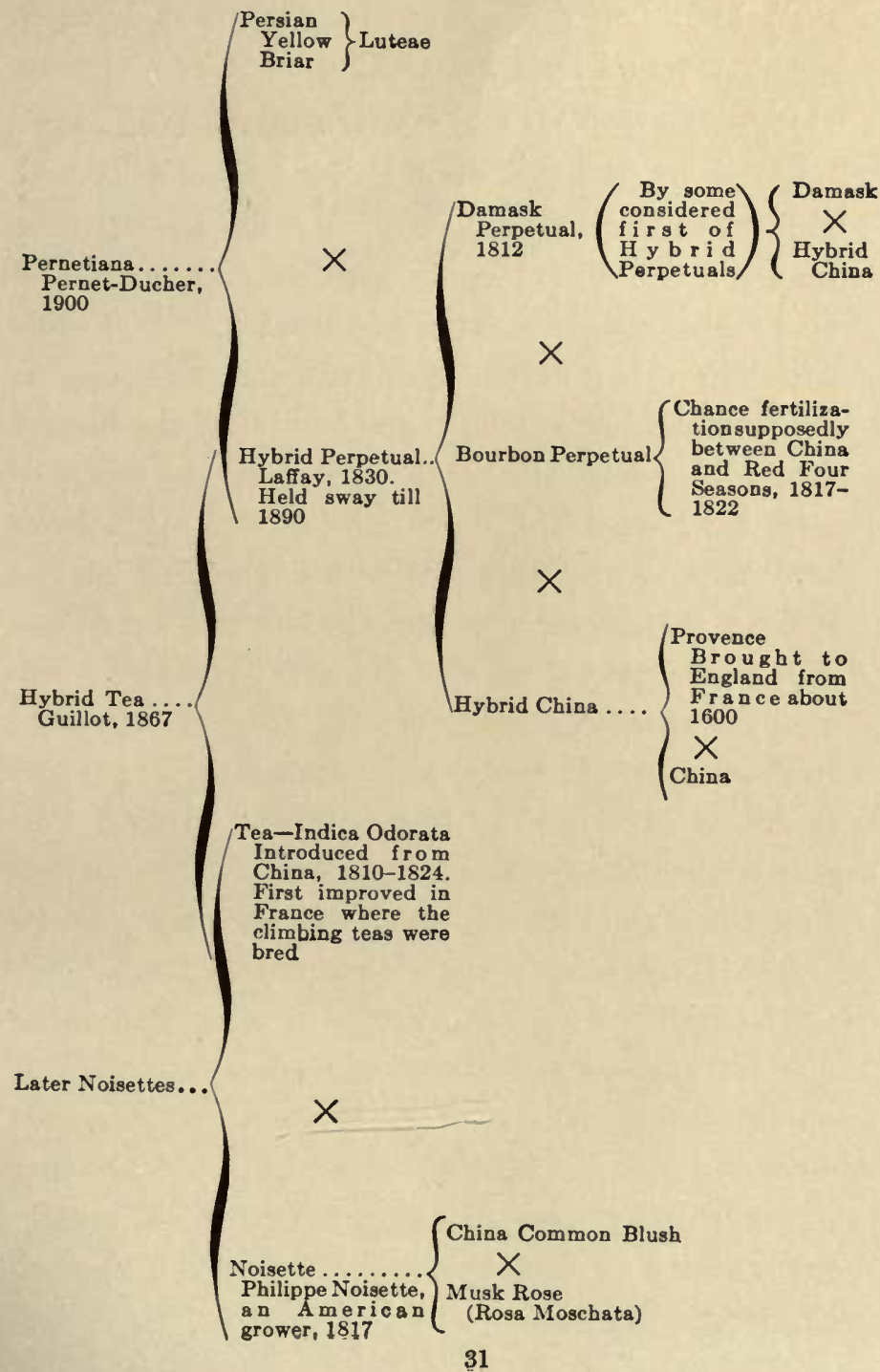




\section{OUTDOOR ROSE GROWING}

To hybridize roses properly one must have a greenhouse and it is astonishing what results may be obtained in a very small one.

Books on this subject which we have found to be most interesting and practical are:

"Plant Breeding," L. H. Bailey.

"Plant Breeding, Experiments of Nillson and Burbank," De Vries.

"Plant Life and Evolution," Campbell.

"New Creations in Plant Life," Harwood.

In Chapter IX will be found a few hints on hybridization taken from our own experiments. 


\section{II}

\section{THE BEST VARIETIES WITH THEIR CHARACTERISTICS}

ThE rose has been the Queen of Beauty among flowers as far back as records go. Down the ages she has held her position unchallenged. India, Persia, China, Japan, Greece, Italy and the rest of Europe all pay her homage in verse and story. The rose is a native of all these countries, and those of the twentieth century are the gradual evolution from the original types to our almost perfect flower. At first this evolution was slow and greatly due to chance. Hybridization was neither understood nor practised. New roses came from seed, or from some new variety thrown out by an old stock and noticed and propagated. Nature's friend, the bee, did most of the crossing of varieties, but such progress did not suit rose growers, and from the gambling methods of chance seeds systematic hybridization became the order of the day. At once the rose list increased by leaps and bounds, for the field was of extreme fascination and boundless possibilities.

Without going into the history of all the various steps, it is sufficient to say that about 1825 the 


\section{OUTDOOR ROSE GROWING}

Hybrid Perpetual began to take first place in the rose world. Perfectly hardy, of fine growth, having a longer period of bloom than its predecessors of equal growth and beauty, it became more and more popular, and held its sway until about 1890 . Its disadvantage was its short period of bloom compared with Teas and Chinas which, while very much smaller in growth, were more constant bloomers and, as a general rule, superior to the Hybrid Perpetuals in perfume and foliage.

Tea roses had existed in England and France from early in the nineteenth century, and yet after the cross of the Damask and Hybrid China, which gave the rose world the first Hybrid Perpetual, it was not until 1867 that the first cross of merit between the Teas and the Hybrid Perpetuals made its appearance. At once the rose world obtained what it had so long desired, combining in a seedling the best of both parents, a rose as hardy, or nearly as hardy as the Hybrid Perpetual-a rose that bloomed practically as often as the Tea and that had fine foliage and perfume. This rose, the first of the great army of Hybrid Teas which was to follow, was La France, introduced by Guillot fils, its parents being Madame Victor Verdier and Madame Bravy. Madame Victor Verdier was a Hybrid Perpetual, introduced by E. Verdier in 1863, 


\section{BEST VARIETIES WITH CHARACTERISTICS}

and Madame Bravy was a Tea raised by Guillot, of Pont Cherin, in 1848.

The next Hybrid Tea that appeared and stood the test of time was Reine Marie Henriette, raised by Levet, in 1878, from Madame Berard (of Gloire de Dijon) and General Jacqueminot; the first of Tea blood, and the second a Hybrid Perpetual. This rose is listed in English catalogues of today in the climbing section as a Hybrid Tea, although still considered by some as a Tea, and so listed in the Dutch Rozennaamlijst of 1909.

After the introduction of these two roses, La France and Reine Marie Henriette, the work went on still further and cross breedings of hybrids obtained by hybridization soon began to swell the list of new roses.

Roses so obtained are known as pedigree roses and very seldom is their breeding given, although it seems an open secret that three generations are often required before a new rose of merit is secured. The breeders and introducers of new roses naturally guard their breeding secrets with the greatest care, and little or no information as to their special methods is obtainable. This secrecy is really eminently proper, as it has taken years of patient effort, care, and great expense to bring out new varieties. It is the breeders' stoek in trade; they are entitled to 


\section{OUTDOOR ROSE GROWING}

hold the information they have acquired, and due credit should be given them for the wonderful strides they have made towards the perfect rose list.

While it is impossible, therefore, to give the breeding of the various pedigree roses, nevertheless a few examples of roses discovered by hybridization and cross breeding of one generation may be of interest.

In looking over the obtainable data it is at once noted that certain roses seem to stand out as having been the most successful parents, and of these Caroline Testout ranks among the first; bred with Souv. deM. Verdier, Aimeé Cochet was obtained; with Merveille de Lyon, Frau Karl Druschki was obtained; with Fisher Holmes, George Laing Paul was obtained; with Viscountess Folkstone, Konigin Carola was obtained; with Bridesmaid, La Detroit was obtained; with Ferdinand Jamin, Madame Edmée Metz was obtained.

In addition to this Caroline Testout has produced quite a number of sports, most noted of which are Admiral Dewey and Mrs. Longworth.

Another rose which stands out prominently is Lady Mary Fitzwilliam, a pedigree rose introduced in 1882, and one of the parents of Caroline Testout. In 1894 this rose with Dr. Grill produced Antoine Revoire, a rose that is holding its own among the 


\section{BEST VARIETIES WITH CHARACTERISTICS}

newer Hybrid Teas of today, and is still by far the best rose of its shade in this country. Crossed with La France, in 1894, Lady Mary Fitzwilliam gave Mrs. W. J. Grant (syn. Belle Siebrecht), a rose still popular; Kaiserin Augusta Victoria resulted when she was crossed with Coquette de Lyon. Kaiserin Augusta Victoria is unique in color and must be included in any large collection.

Ellwanger's chapter on "Seed Parents of Leading Roses," in his book "The Rose," gives some very interesting data on this subject.

About 1890, owing to its longer period of bloom, the Hybrid Tea had pushed the Hybrid Perpetual out of first place in popularity, and from that time on has held sway as the premier class. While at first much was to be desired in some of the Hybrid Teas, gradually they have become improved, until today there is no question about their being the best outdoor garden variety; yet, in so deciding on them as the most useful class, many must be discarded as worthless in the climate of the Middle Atlantic States. The best of the Teas and the Hybrid Perpetuals, and also others, must be included in a list which purports to include the best outdoor roses.

In addition to the hardy growth and long period of bloom common to the best of the Hybrid Teas, 


\section{OUTDOOR ROSE GROWING}

many of them have the long double bud on the stiff erect stem so much desired in roses, and the best varieties open slowly and keep well after being cut; therefore in the main list which follows we have put the best of the Hybrid Teas and have also included other roses which come up to a certain standard. In addition to these there are a great many which for large gardens should not be overlooked, some of them among the Perpetuals and Teas, and we have also added these varieties to our main list.

Unfortunately, it is almost impossible to find many roses absolutely perfect for our climate. The winters are more severe and the summers hotter than the conditions to which imported roses and their forbears have been accustomed, so that many of the roses which flourish in Europe are worthless with us.

The main classes include the Hybrid Perpetuals, Hybrid Teas and Teas, and are grown in two ways, as dwarfs and as standards. Standards differ from dwarfs or bushes (ordinary form), in that they are budded or grafted on strong briar and other stocks from two and one-half to four feet from the ground. They are most attractive and some are more easily reached than the dwarfs, as the blooms grow about the level of the eye, while all of them are adapted 


\section{BEST VARIETIES WITH CHARACTERISTICS}

to formal gardens and landscape work. However, we cannot recommend them unless absolute winter protection is given, and this is best accomplished by placing boards around the plant, encasing it from the ground to above the bud and filling in with earth.

In the case of some of the climbers, which are used as standards, an attractive effect is produced by allowing the trailing shoots of such plants to grow downwards, more or less like the weeping willow tree, and these are called weeping standards, otherwise they are the same as the regular standard. In the case of some of the Teas, which are grown very close to the ground in this way, they can be moie thoroughly protected in cold winters than they could be if grown as the usual standard. It is believed that Teas are especially prolific when grown in this manner. One well known writer states that he has seen such a Tea with seventy-five blooms on it at one time.

Standards require very much more room than dwarfs, and this is another reason why they are not planted so extensively. If used we would strongly recommend for them the roses contained in our main list. Dwarfs are budded close to the root of the stock and the bud is planted below the ground level, hence they are hardier and much more easily 


\section{OUTDOOR ROSE GROWING}

handled in winter than standards. In our experiments with standards we have found them to be most uncertain, sometimes they last for several years and again fully fifty per cent. die. An average of ten per cent. would be a conservative estimate for winter loss, unless most thorough winter protection was given.

Every year the commercial rose growers in England and the Continent bring out their new varieties; before a satisfactory verdict can be given as to their adaptability to this country they must be tried for at least two years. In many cases new varieties are shipped as such small grafted plants that for the first year it is almost impossible to test them properly, and a year later larger plants must be tried again. Very probably these small plants would do well abroad, but here they run the risk of being passed upon as worthless when many may be first-class varieties.

Owing to the difference in our climate, even the color of imported roses may vary somewhat from the European catalogued description. The average rose is generally somewhat lighter in color, owing to our extreme heat in summer. Killarney is an exception which proves this rule. This rose is catalogued in the European lists as "Flesh-shaded white, suffused pale pink"; in this country it is a solid light 
pink, the shade depending on the sunlight, being deeper in bright, hot weatber. In the early spring and in the autumn the color of most roses with us is darker than in the summer, some varieties that usually have a slight yellow tint becoming almost pink under frosty nights and warm days. Mainly for the first reason given it is a lottery for the average rose grower to order new varieties; the greater part will prove utter disappointments, a waste of money, space, time and care, and the catalogued description must be more than discounted.

This book should guide the American purchaser to order those roses which will give him the best results. To secure a perfect list of such roses, we have carefully tested every variety found in the best of European catalogues, and in our list at the end of this chapter there has been included every variety which has come up to a certain standard. Those which we have excluded have not proved successful after a test in which all had the same chance.

\section{SIXTEEN BEST ALL-ROUND ROSES}

In order to be of the greatest practical aid to the home rose grower we have made a selection of the sixteen roses which have proved by our tests to be the best adapted in beauty and usefulness to outdoor 


\section{OUTDOOR ROSE GROWING}

growing. A color-plate with an accompanying full description is given of each of these roses.

This selection includes one white, one white with center shaded primrose or lightest blush, two fleshcolored-one shaded peach to lilac and the other shaded shell pink.

Four pinks: one light pink, one dark to imperial pink, one flesh to light salmon pink, and one silver pink to dark salmon-sometimes coral pink.

Four shades of red: crimson cerise, bright crimson, brilliant carmine and scarlet crimson.

Four shades of yellow: light yellow, yellow-orange, coppery rose and reddish bronze.

In this following selection of sixteen roses we have included the best rose of each main shade. Their qualities have been noted in the description which accompanies them; there is no doubt, from our experiments, that these are the best outdoor roses for our climate and will give absolute satisfaction. We have given this list and their descriptions before coming to the general list because we particularly wish to emphasize their value.

There are roses in the main list under No. 2 heading which are better than some in the above selection, but they are of different shades. The best rose of each main color is the one specified in this sixteen. 


\section{WHITE}

Frau Karl Druschki. Lambert; 1900. Hybrid Perpetual. (Merveille de lyon $\times$ Caroline Testott)

A very strong growing rose, foliage light solid green; long, erect stem; long, pointed bud, opening into a perfect flower of great substance and of great lasting quality (color, white-sometimes palest pink blush at center); in good quantity in June, shy in summer, moderately in autumn. Farther north it naturally comes into bloom later and, as the season of bloom is shorter, blooms longer for one period only. Farther south blooms earlier and later, with less summer bloom. Plant 30 inches center to center. Prune to 6 eyes (buds). 


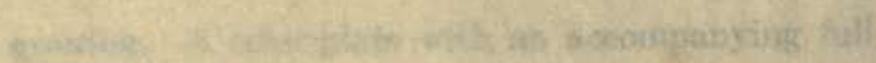

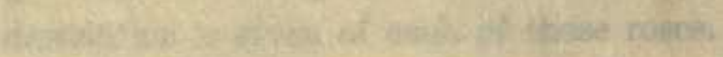

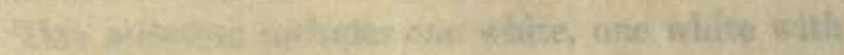

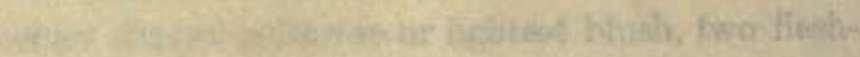

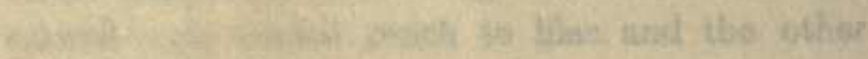

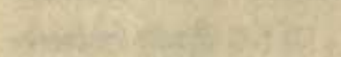

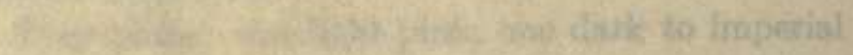

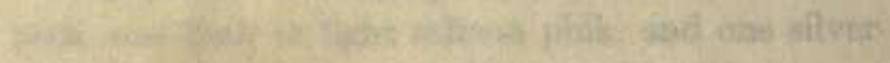

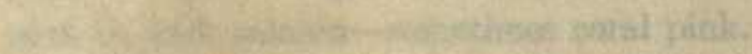

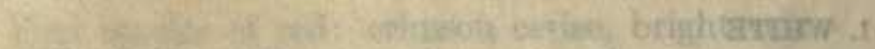

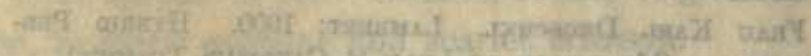

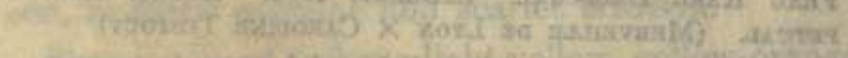

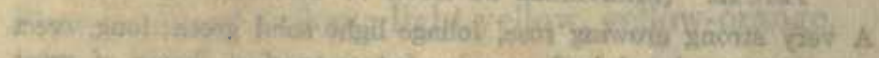

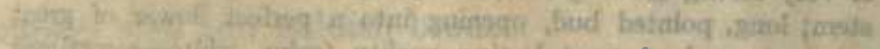

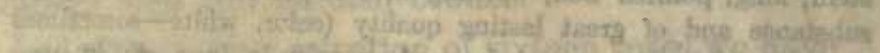

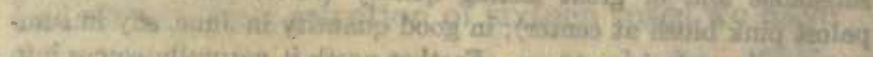

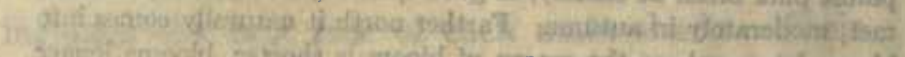

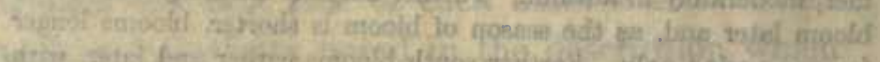

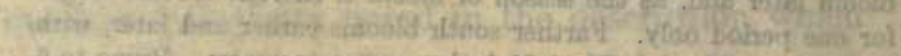

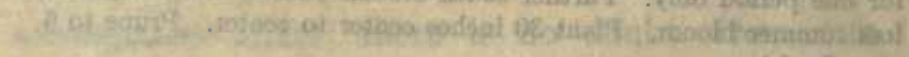

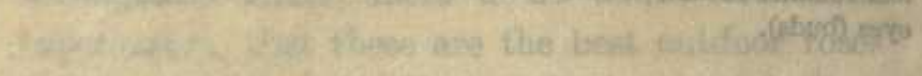

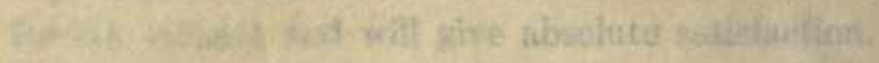

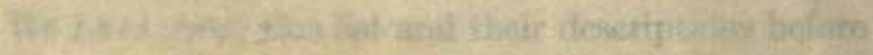

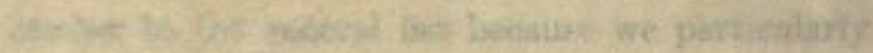

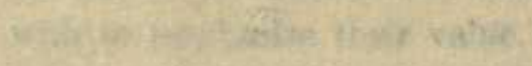

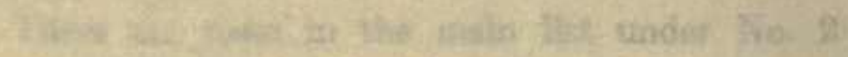

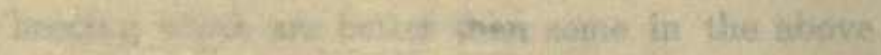

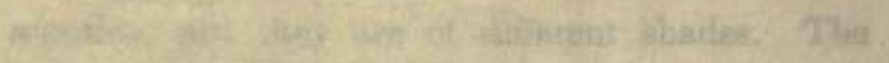

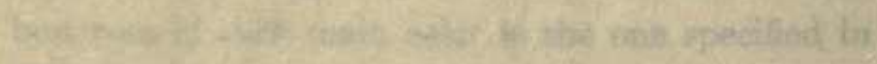
4hes in mata 


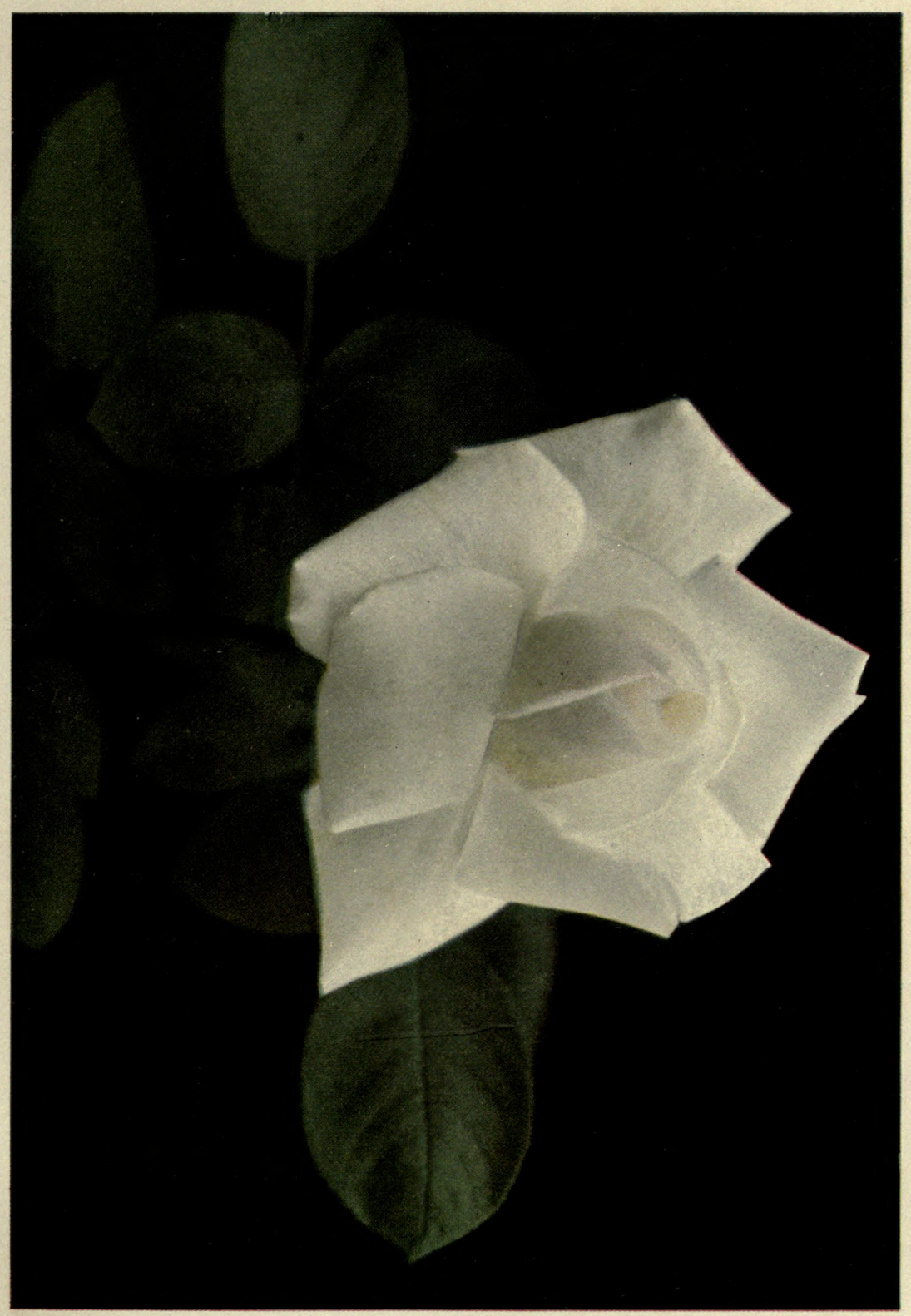



2. WHITE-CENTER SHADED PRIMROSE OR LIGHTEST BLUSH-VARIES

Madame Jules Bouche. Croibier \& Fils; 1911. Hybrid TEA

Of medium to large growth, very hardy; good to very good foliage, long, erect stem; long bud which develops into a medium-sized flower of wonderful substance and great lasting qualities. A splendid bloomer in spring, good in summer and remarkably good in fall. The best new rose since Duchess of Wellington and by all means the best white to blush rose. Plant 18 inches center to center. Prune to 5 eyes (buds). 



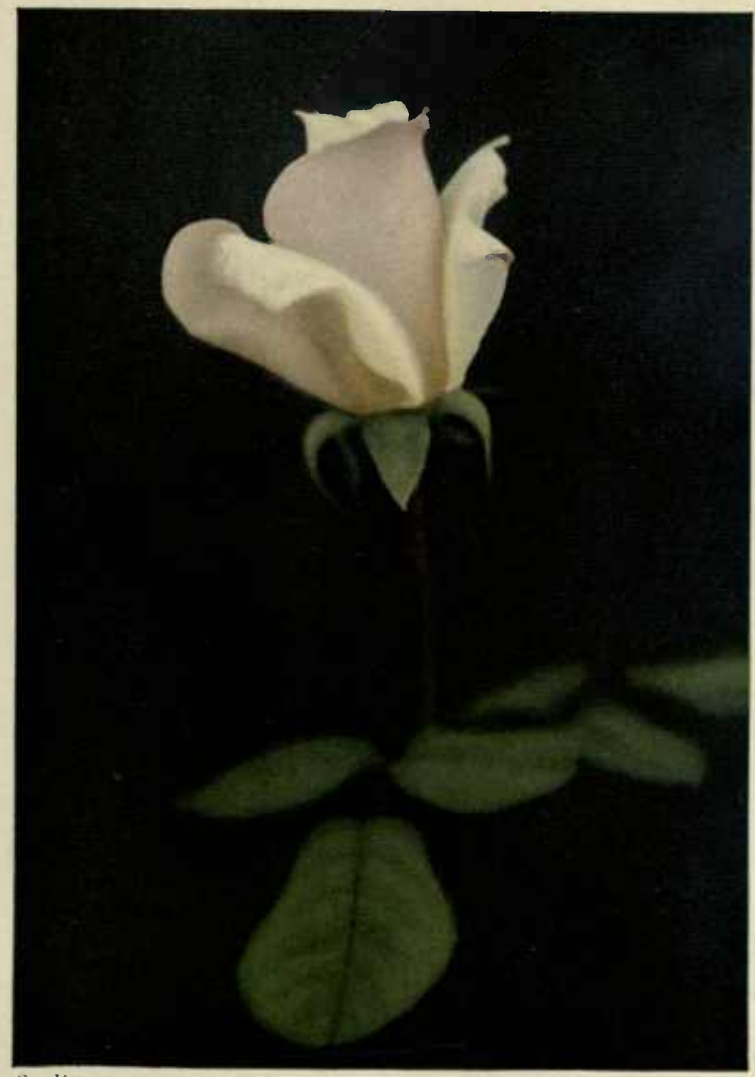

See list

MIDAME JULES BOCCHE IIybrid Tea

Crotbiek \& Fils 1911 

3. FLESH TO CREAM-YELLOW PEACH CENTER, SOMETIMES WITH LILAC SHADING

Antoine Revolre. Pernet-Ducher; 1896. Hybrid Tea. (Dr. Grill $\times$ Lady Fitzwilliam)

Of medium growth, very hardy; foliage blue-green leathery, long erect stem; beautiful bud, opening into medium to large bloom of gardenia form, fine substance, many petals, lasts very well after cutting. Blooms prolifically in June, quite well in summer, quite well in autumn. A rose which has stood as the best of this shade since its production. Plant 15 inches center to center. Prune to 4 eyes (buds). 


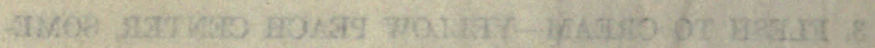

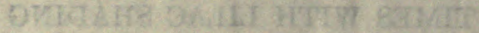

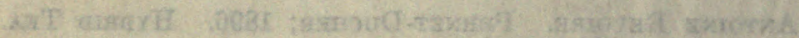

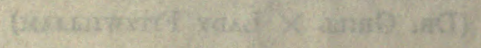

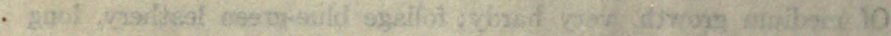

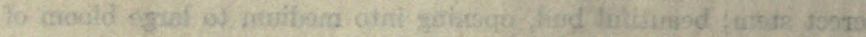

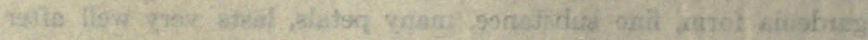

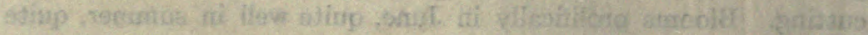

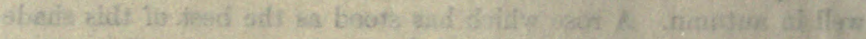

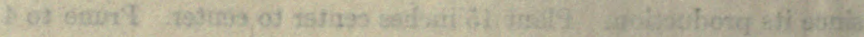




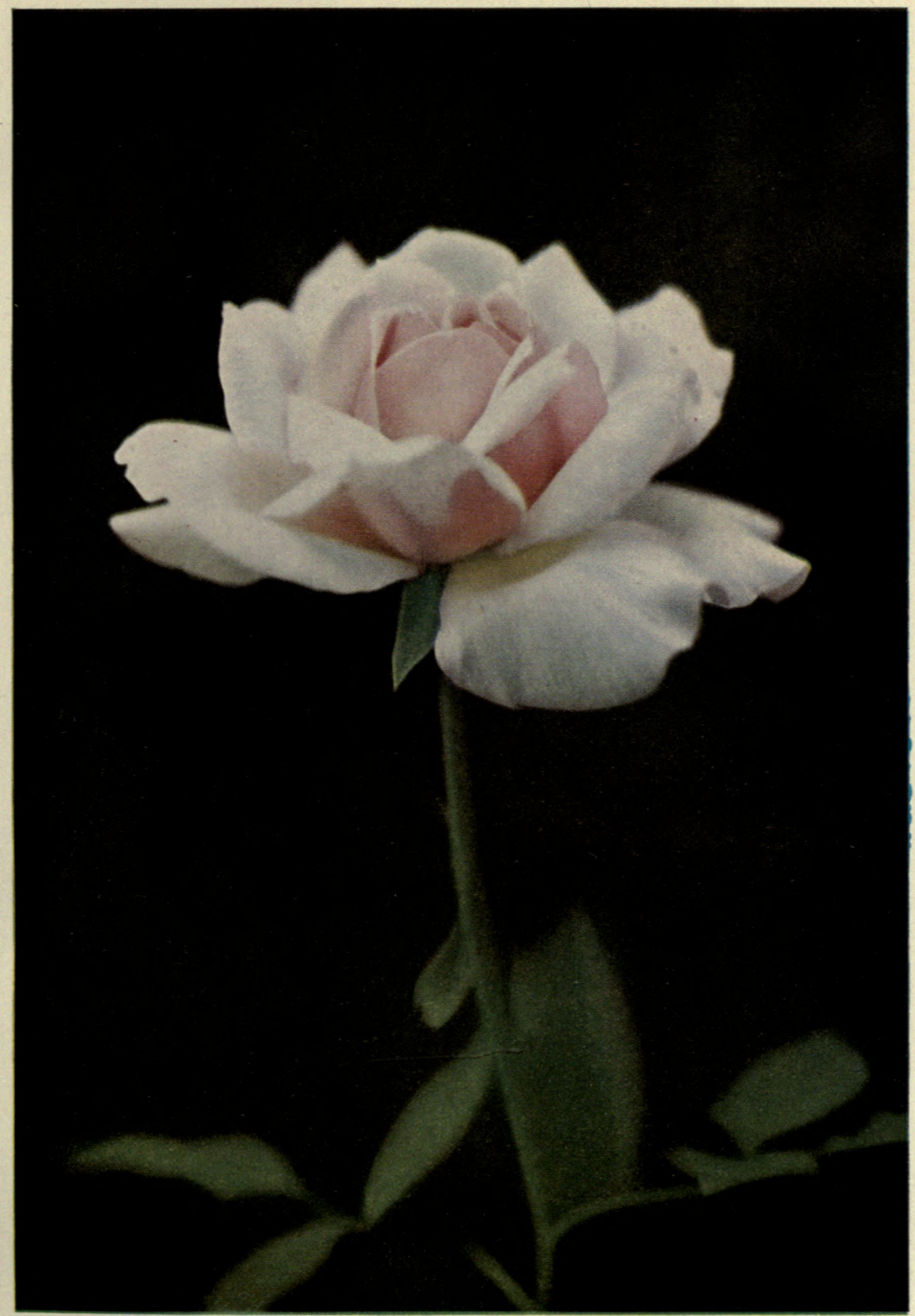





\section{SILVER FLESH TO SHELL PINK}

\section{Ellen Wilmot. Bernaix; 1898. Hybrid Tea}

Medium to strong growth, very hardy; splendid leathery green foliage; quite a good erect stem, opening into a bloom of medium size; very fine bloomer in spring, good to very good in summer and autumn; this rose is a stronger grower and has a better stem than Souv. du President Carnot although not quite as beautiful in bud form, but is placed first on account of its reliability as a summer and autumn bloomer and its better growth and foliage. Plant 18 inches center to center. Prune to 4 eyes (buds). 


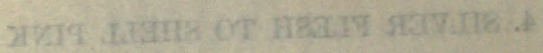

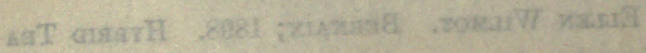

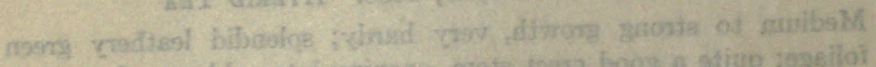

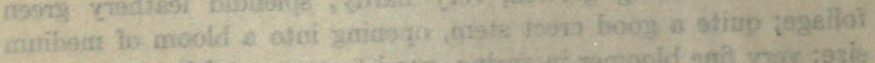

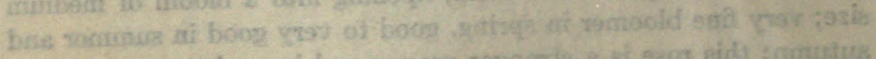

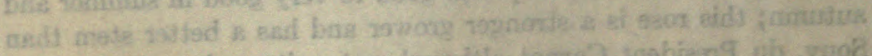

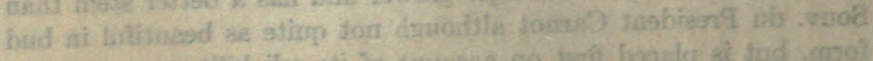

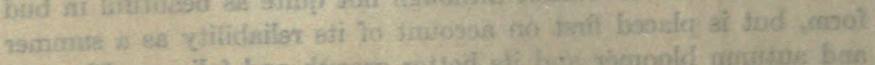

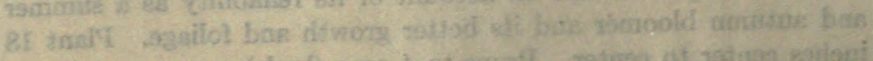

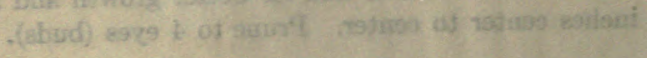




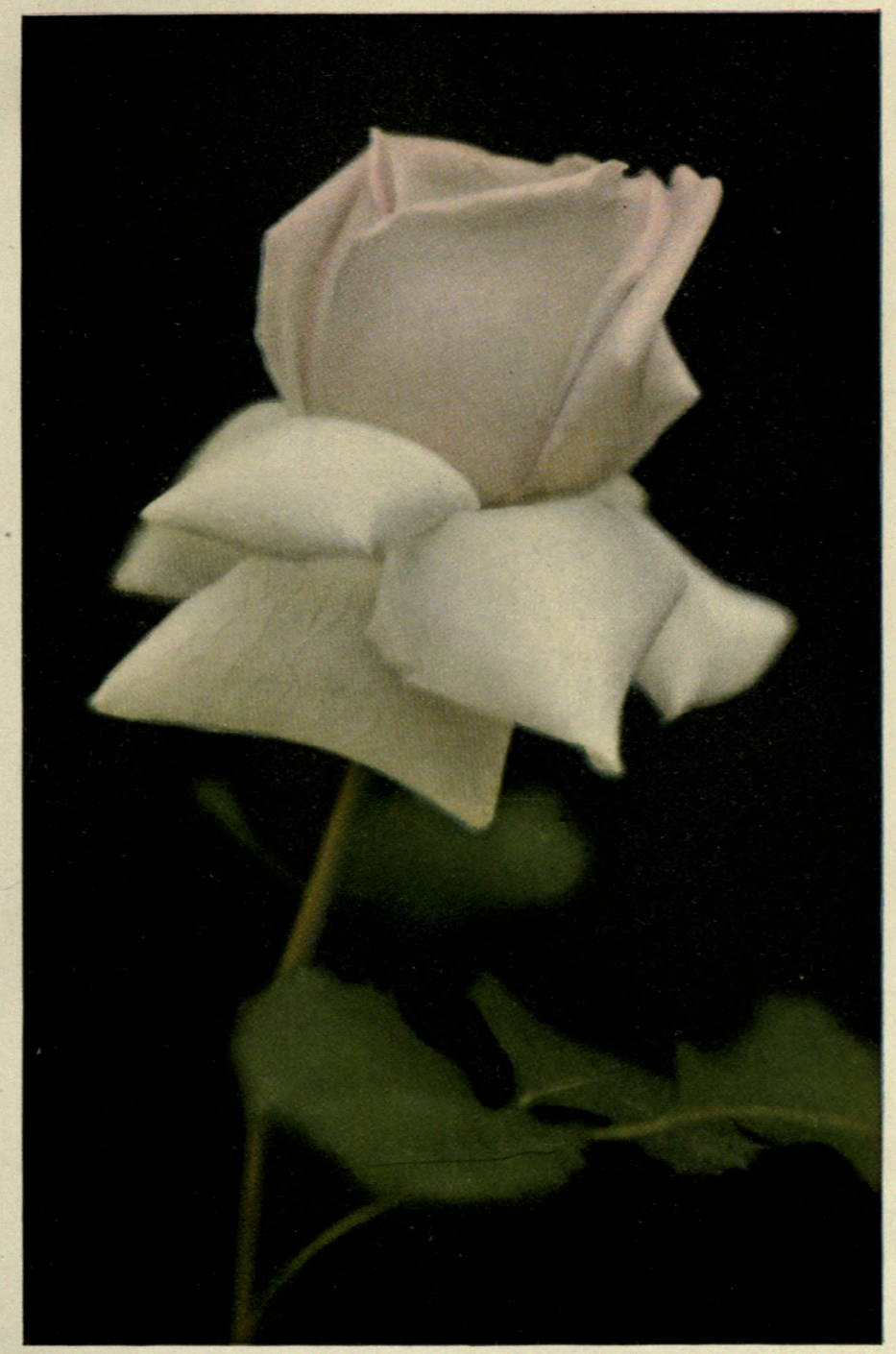





\section{LIGHT PINK}

Killarnex. Drckson \& Sons; 1898. Hybrid Tea

Medium to large growth, very hardy; foliage liable to mildew in wet seasons towards autumn, but Killarney has the red tea foliage, especially in young growth, which is so beautiful in many teas; long, fairly erect stem, beautiful pointed bud, not of great petallage but very beautiful, although not a very long keeper; a wonderful bloomer from frost to frost. Plant 18 inches center to center. Prune to 5 eyes (buds). 


\section{पทान THDH ล}

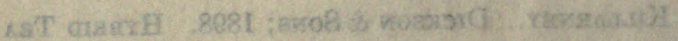

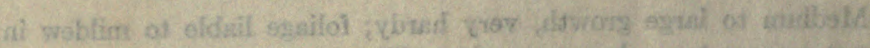

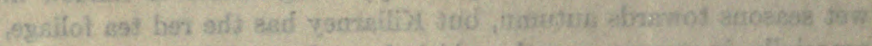

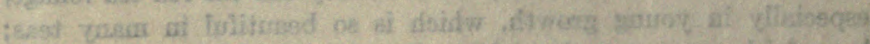

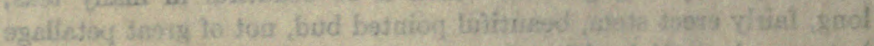

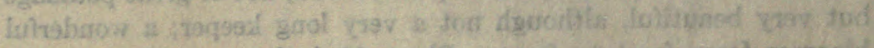

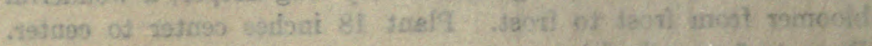

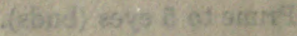




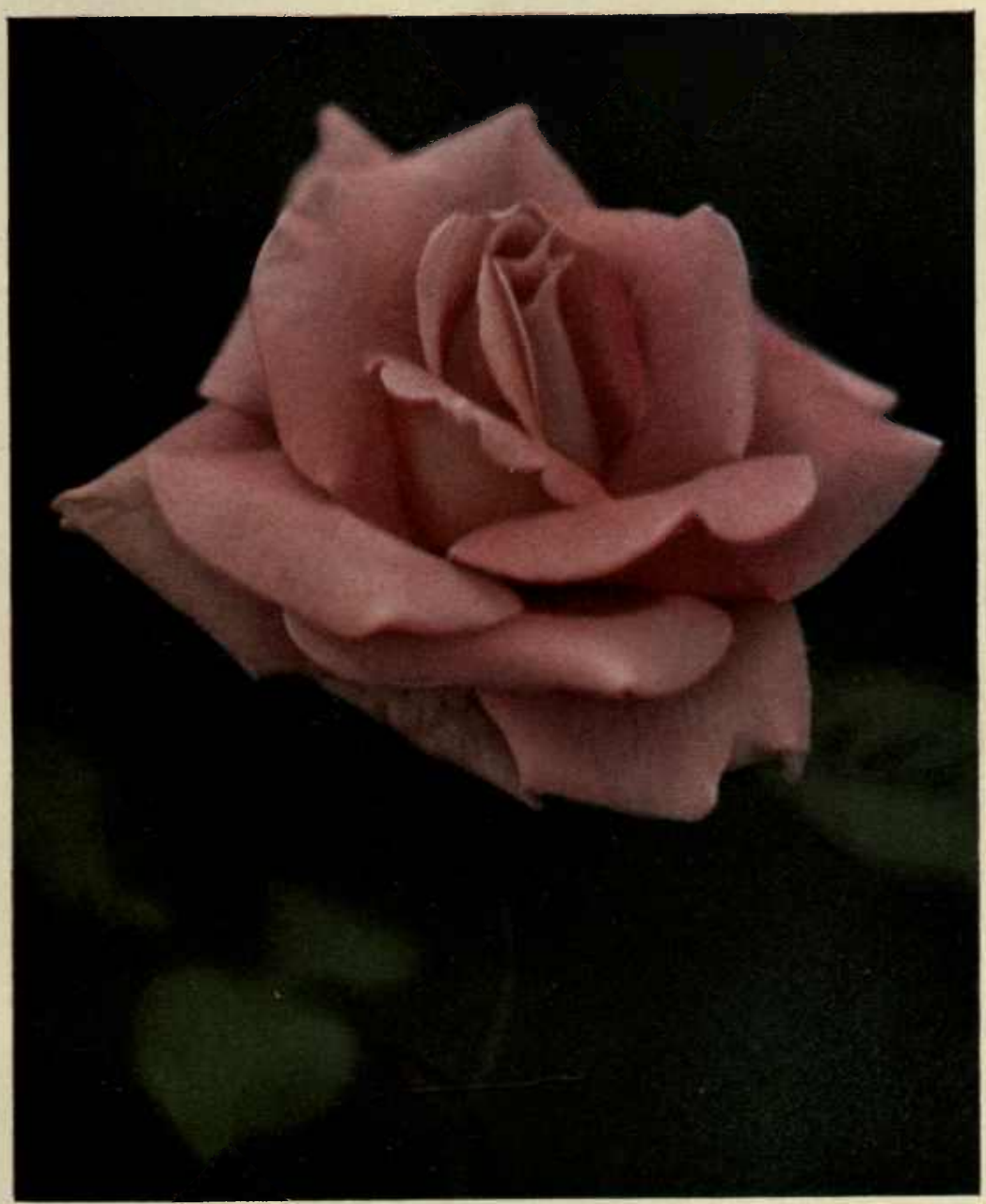





\section{IMPERIAL PINK}

Jonkheer J. L. Mock. Leenders; 1909. Hybrid Tea

Very large growth and very hardy; only fair foliage, extremely long stems; long bud and large bloom of great substance; not a prolific but, considering the length of stems, a fine bloomer from frost to frost and a long keeper. Absolutely necessary to secure in twoyear-old plants; yearlings do not appear to transplant with any success. Plant 20 inches center to center. Prune to 5 eyes (buds). 
आИाT . TAIझसQM 3

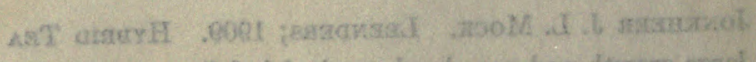

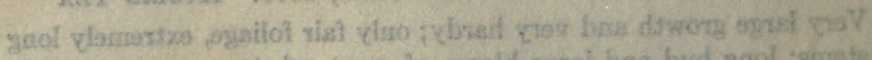

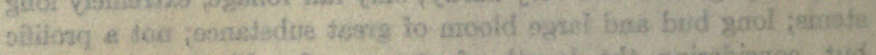

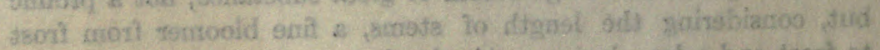

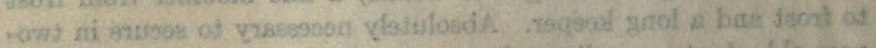

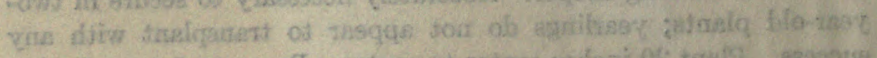

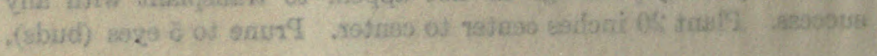




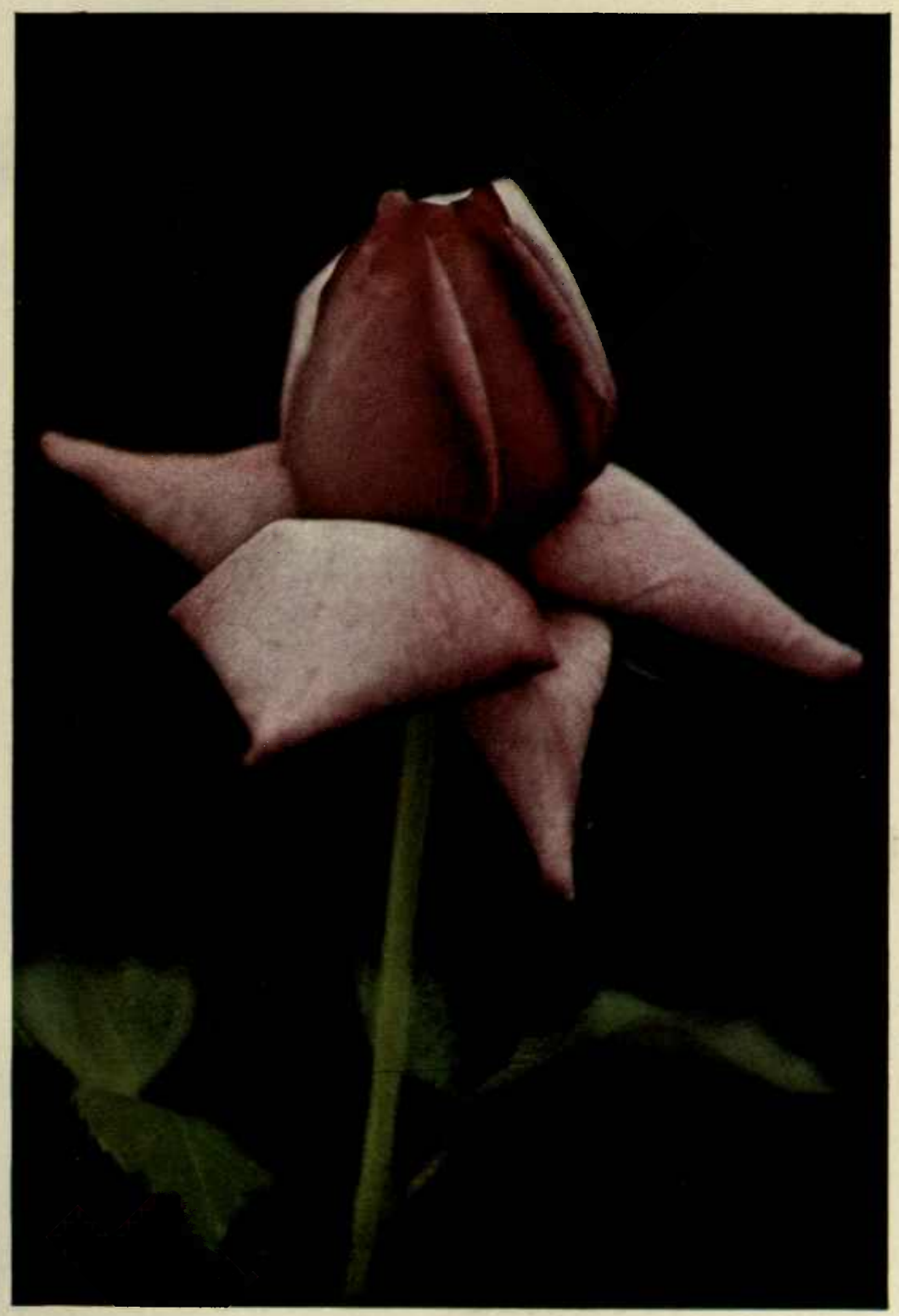





\section{SILVER FLESH TO PEARL SALMON PINK CENTER}

mime Leon Pain. Guillot; 1904. (Caroline Testout $\times$ Souv. de Catharine Guiliot)

Hybrid Tea. Of medium to large growth, very hardy; foliage perfect leathery green to reddish tea; long, erect stem; medium to large bud, opening into a bloom of substance, full, double, and of good lasting qualities; blooms very well in spring, summer and autumn. This is the best of the lightest salmon pinks and a fine, reliable, all-round rose. Mme. Segond Weber is a more brilliant salmon than Mme. Leon Pain and of more perfect form, but not as reliable a bloomer in the summer and autumn. Plant 18 inches center to center. Prune to 5 eyes (buds).

[The rose at the left is La Detroit, a fair rose but inferior to the newer pinks.] 


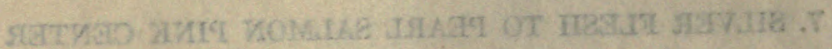

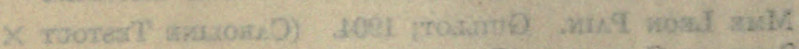

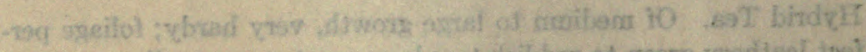

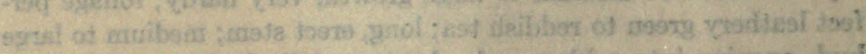

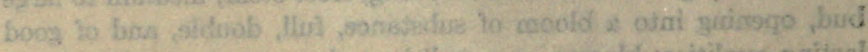

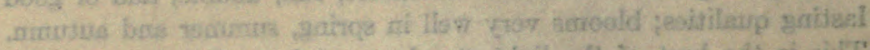

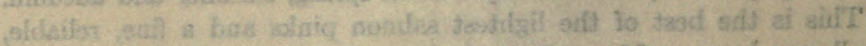

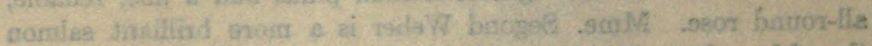

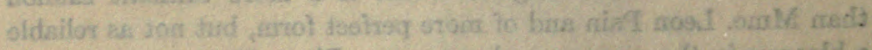

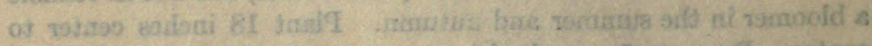

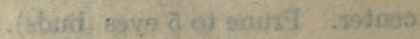

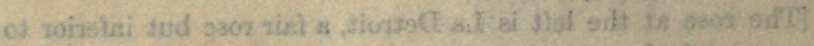

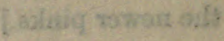




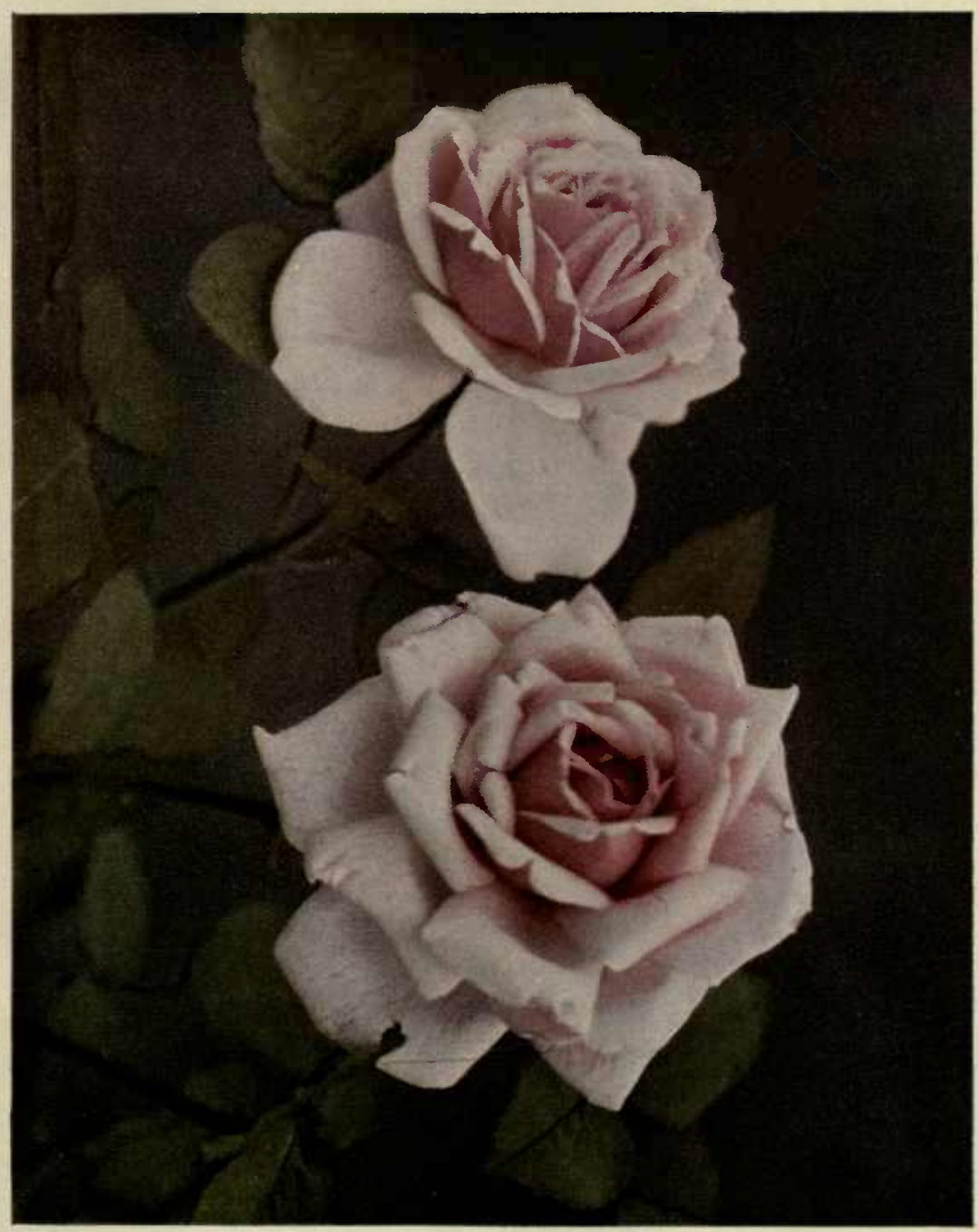





\section{TWO-SHADED PINK}

Silver Pink to Dark Salmon, Sometimes Approaching Coral Rose; Outside of Petals Dark Shade, Inside, Silver Pink

Ladt Alice Stanley. McGredy; 1909. Hybrid Tea

Medium to large growth; very hardy and very fair foliage; long, stiff stem; large bloom of great substance and petallage; a fine keeper; blooms most prolifically in spring, and quite well in summer and autumn. Undoubtedly a great rose and the best of the solid pinks of two shades, of which Lady Faire and Mrs. Hill were the forerunners. Plant 18 inches center to center. Prune to 5 eyes (buds). 


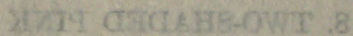

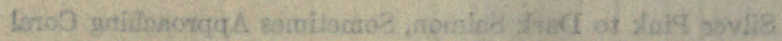

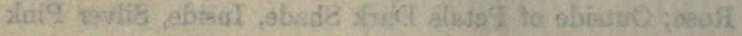

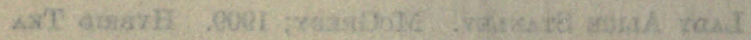

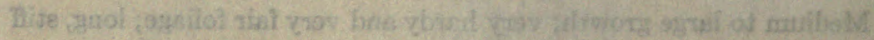

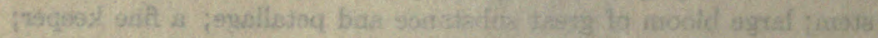

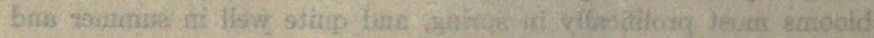

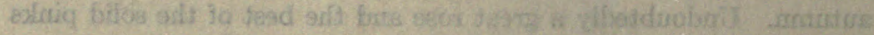

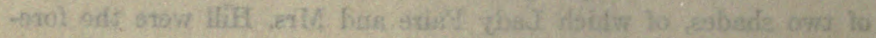

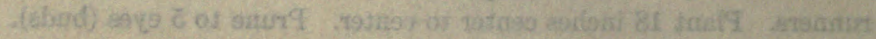




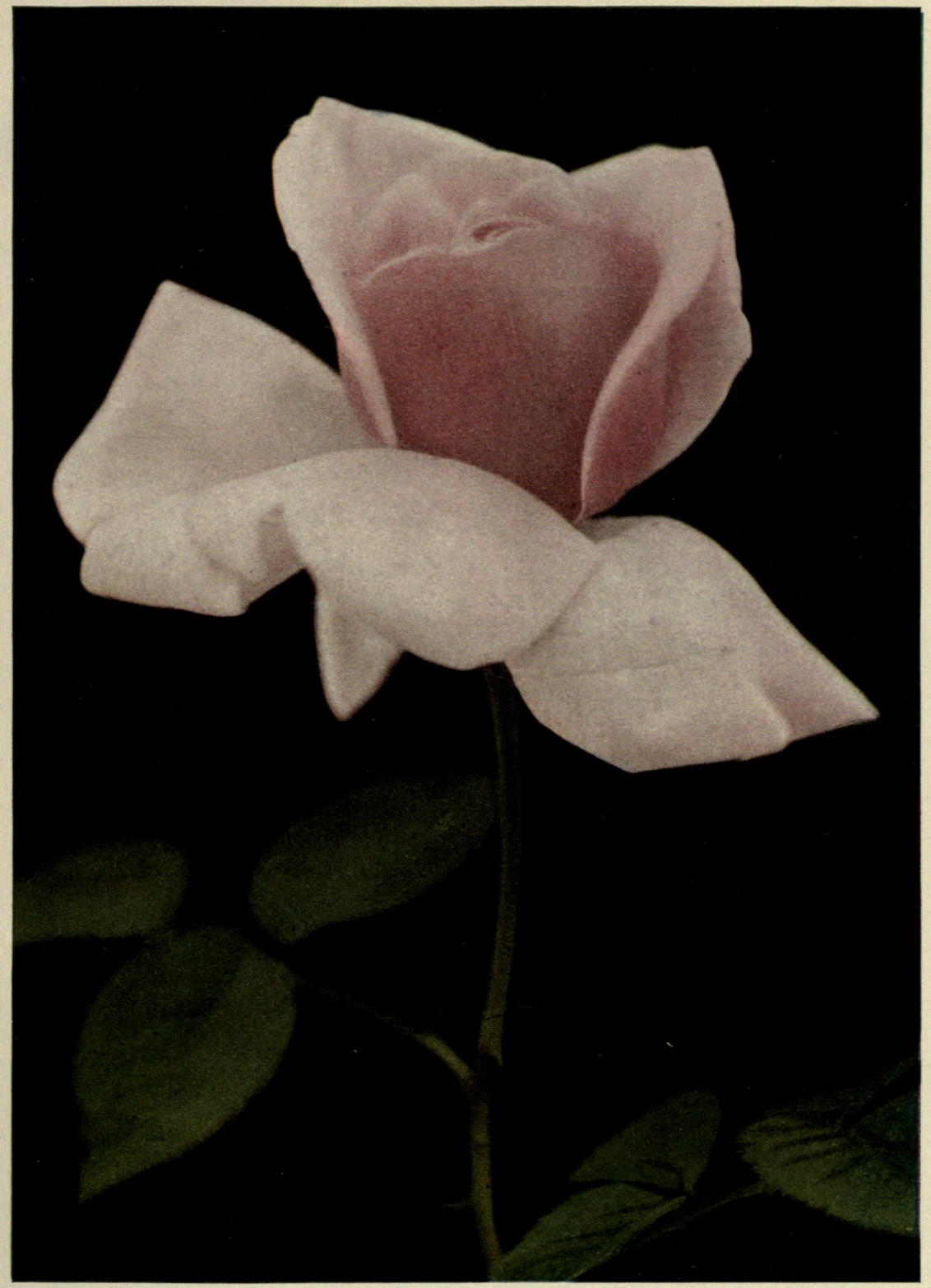





\section{WARM CRIMSON CERISE-EDGED PINK}

Robert Huex. Dickson \& Sons; 1911. Hybrid Tea Medium to large growth, very hardy; very good foliage, light green in color; fairly long, erect stems; beautiful long, pointed bud; a medium to large bloom of great substance and petallage; blooms well in the spring and does remarkably well in extremely hot summer weather; a good keeper but only a fair autumn bloomer. Plant 18 inches center to center. Prune to 5 eyes (buds). 


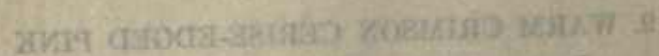

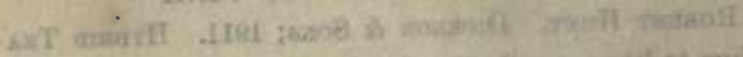

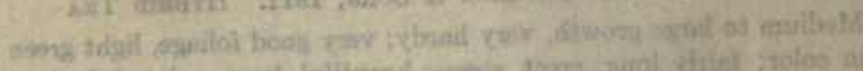

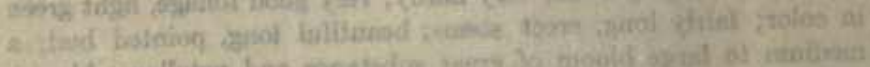

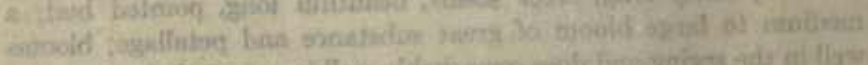

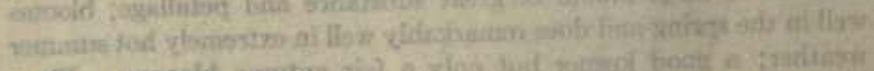

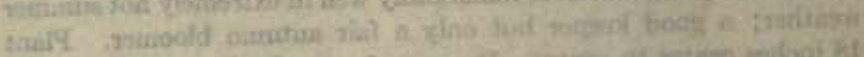

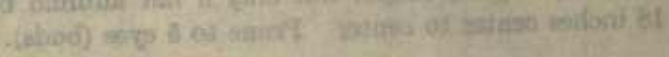




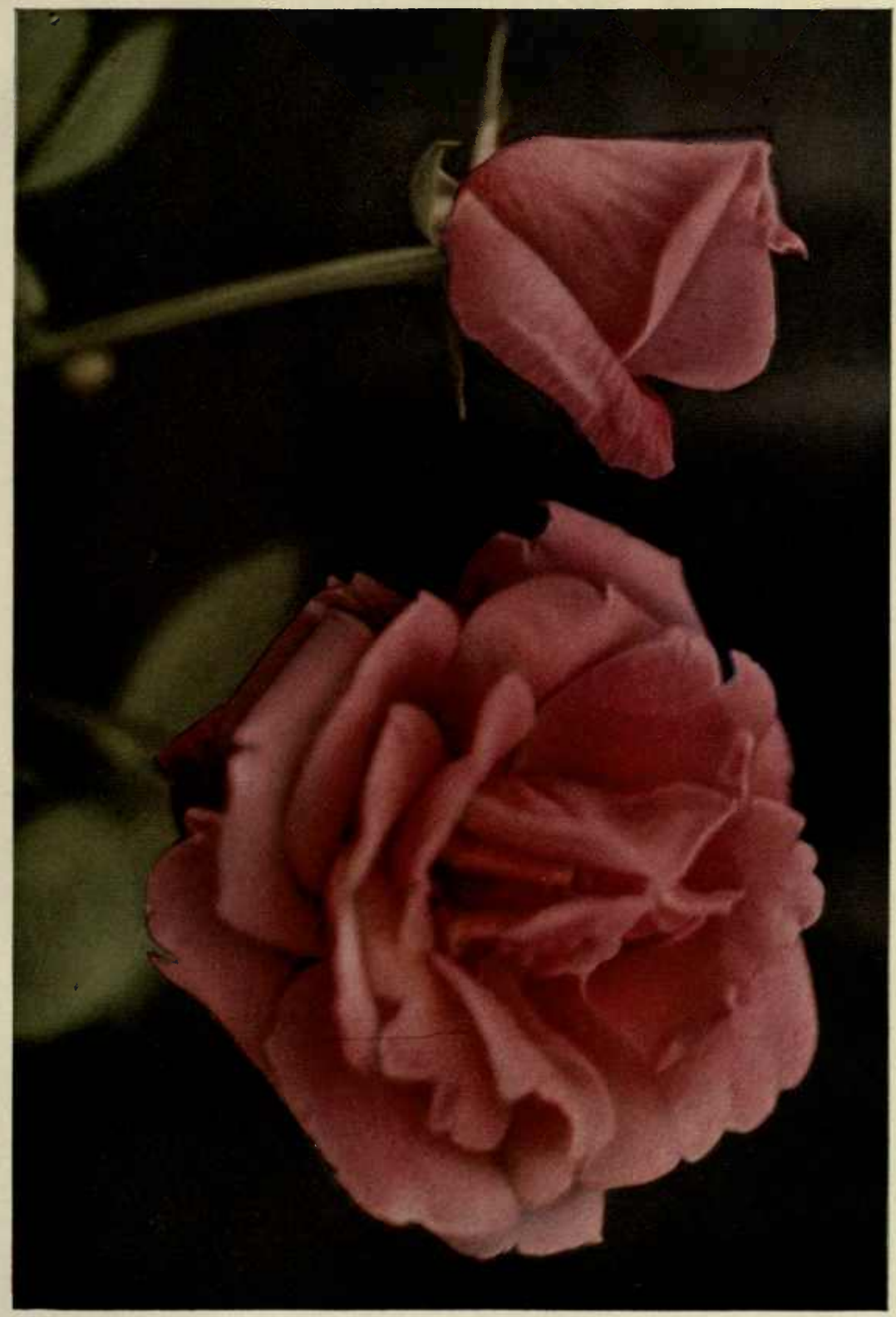





\section{BRIGHT CRIMSON}

General MacArthur. Hill; 1905. Hybrid Tea. (INTRODUCEd by aN AMERICan Grower)

Medium to large growth, very hardy; fine leathery foliage, good stems; fairly long bud, opening into medium-sized bloom of fair substance; a very fine keeper and good bloomer from frost to frost. Not as large as Huey or Carle. Plant 18 inches center to center. Prune to 5 eyes (buds). 



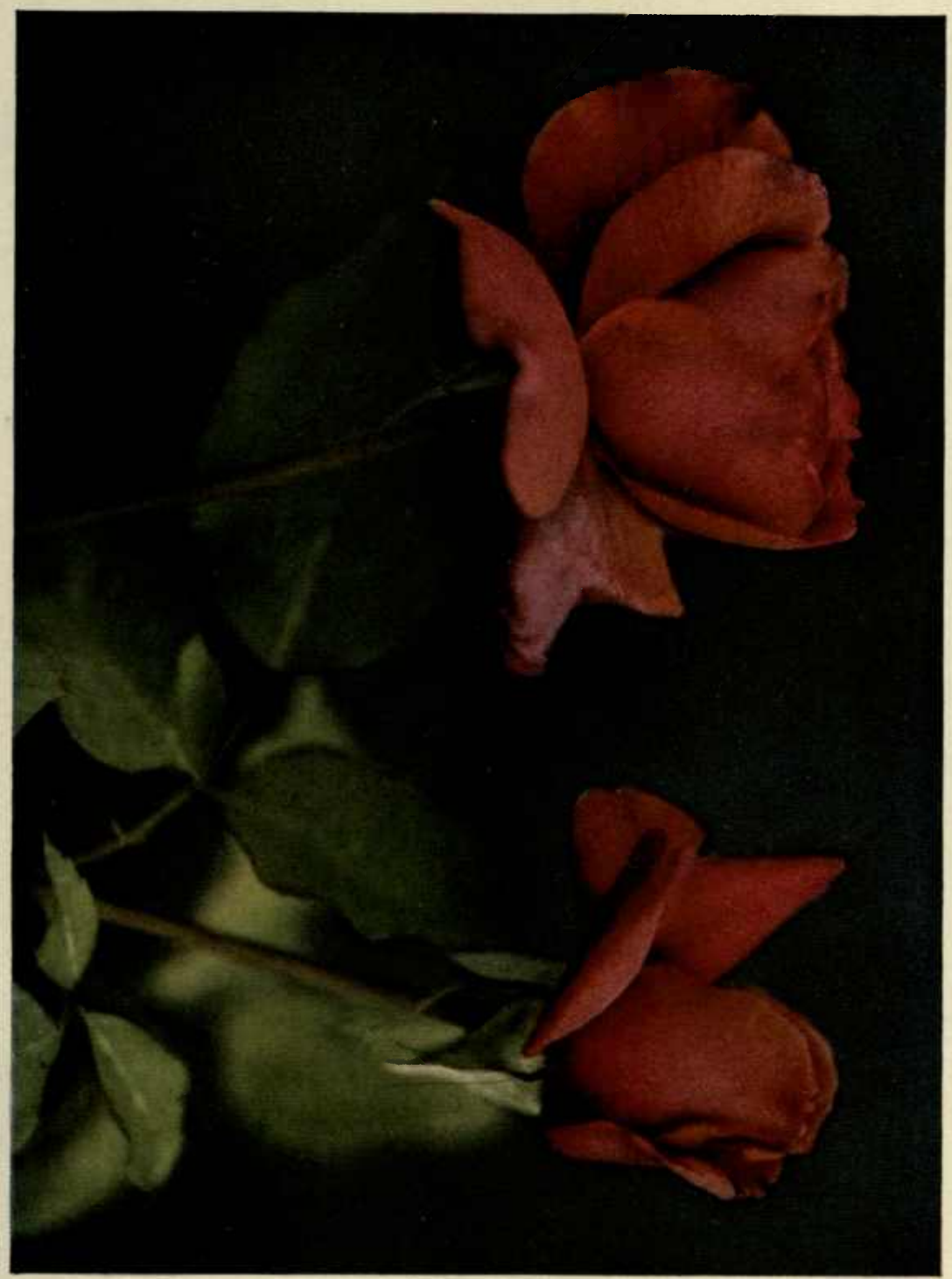





\section{BRILLIANT CARMINE}

\section{Laurent Carle. Pernet-Ducher; 1908. Hybrid Tea}

Medium growth, very hardy; fairly long, erect stem, good foliage, long, pointed bud; medium to large flower of good substance and beauty. Blooms well in the spring, fairly well in the summer, and quite well in the autumn. Plant 18 inches center to center. Prune to 4 eyes (buds). 


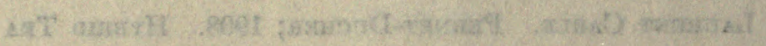

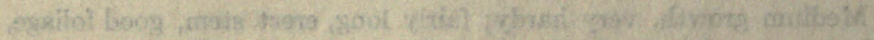

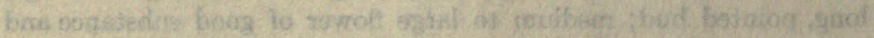

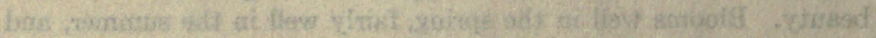

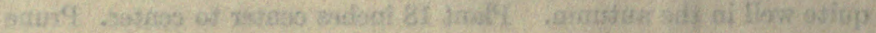




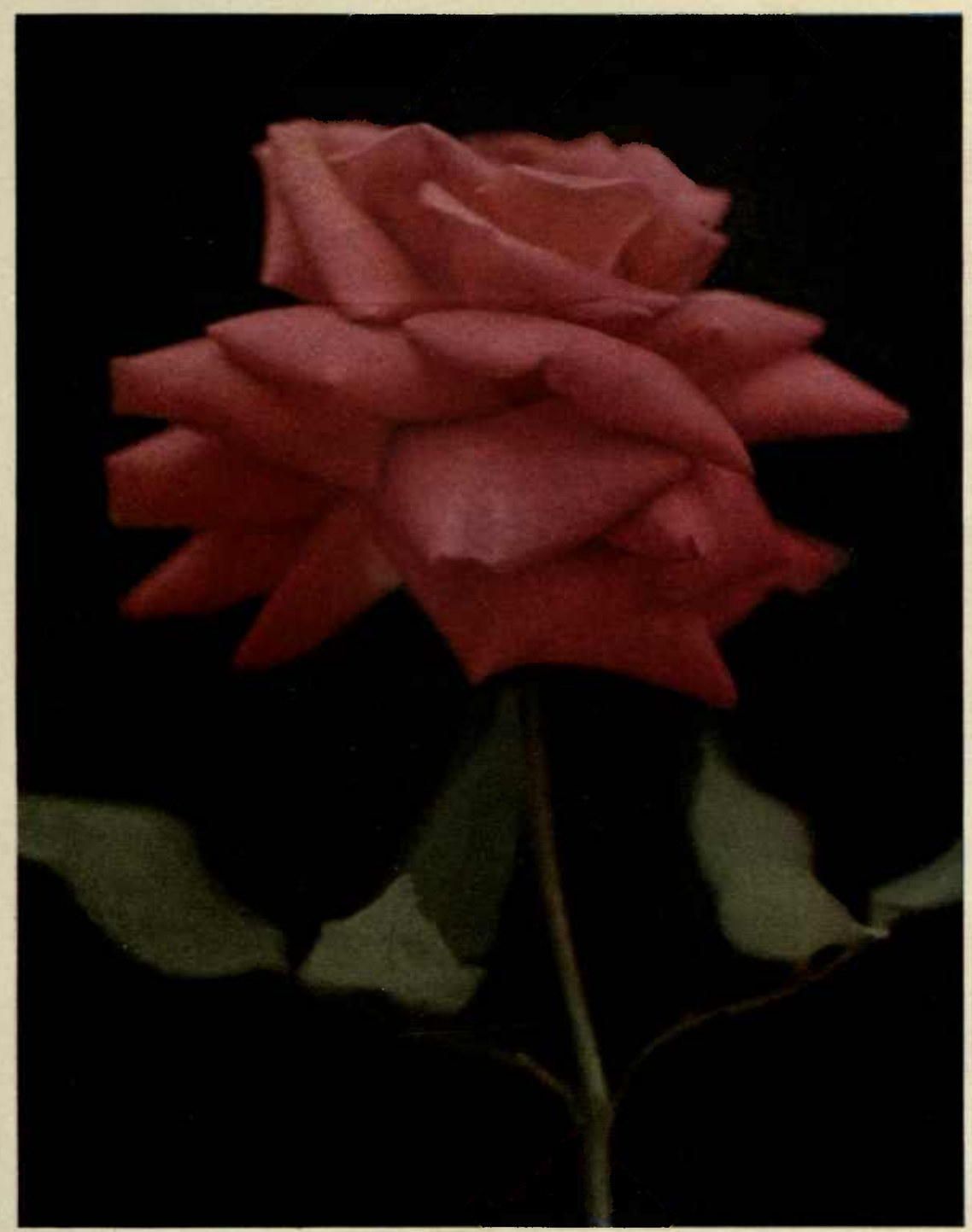





\section{SCARLET CRIMSON}

Gruss an Teplitz. Geschwind; 1897. Hybrid Tea. (Usually Classed with the Climbing Section). (Paxton $\times$ Fellemberg $) \times($ Papa Gontier $\times$ Gloire des Rosomanes $)$

Very large growth, extremely hardy; good foliage, short stems (often weak); bloom, which opens flat, nevertheless one of the best blooming roses existing today; a mass of color from spring till after frost; while not of perfect form for cutting still such a profuse and constant bloomer that it is included in this first list. Plant 27 inches center to center. Prune lightly. Cut out dead wood. 


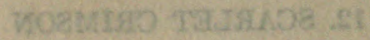

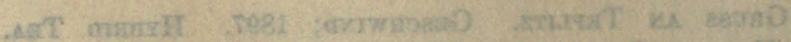

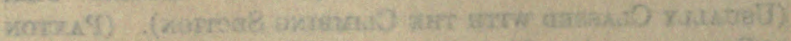

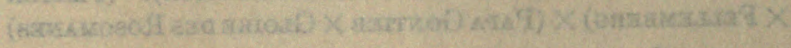

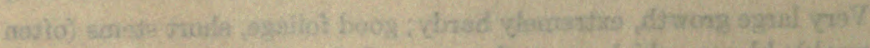

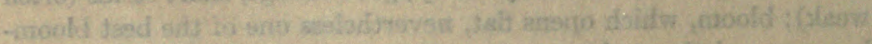

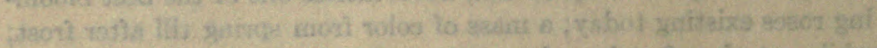

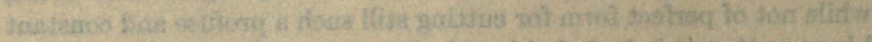

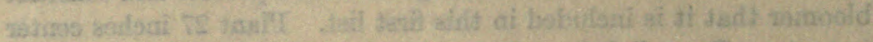

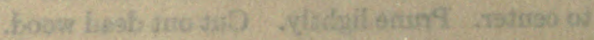




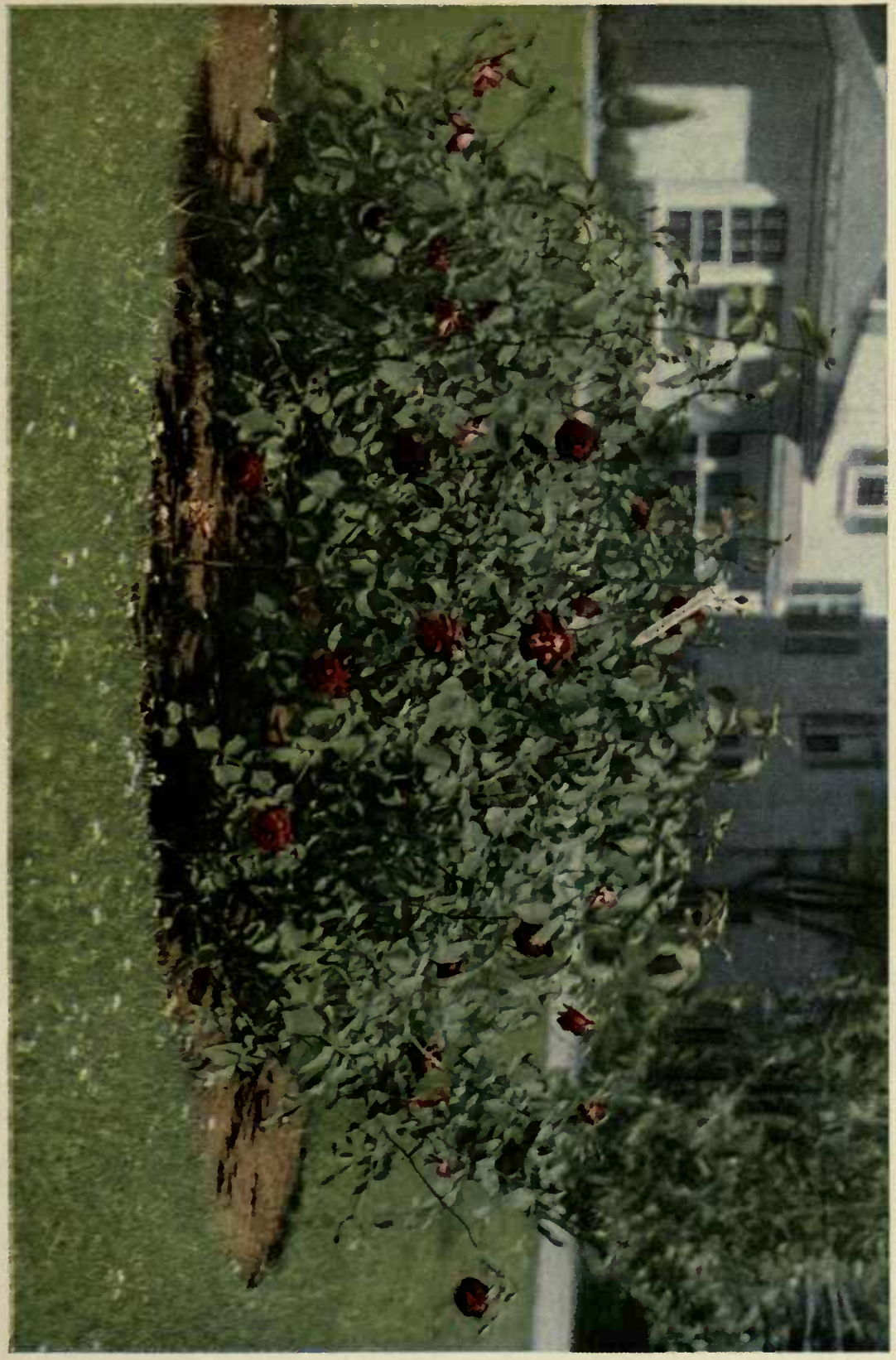




\section{LIGHT SULPHUR YELLOW}

\section{Harry Kirk. Dickson \& Sons; 1907. Tea}

Classed as a Tea but with the habits of the largest Hybrid Teas; large growth, very hardy; fine foliage, long stem; long, pointed bud, which opens into a bloom of medium to large size, but not double, and which does not last well; should be cut before the dew is off, or late in the afternoon before the bud is open. A great bloomer, splendid in spring, good in summer and in autumn. Plant 20 inches center to center. Prune to 5 eyes (buds). 


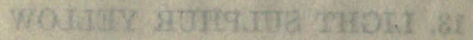

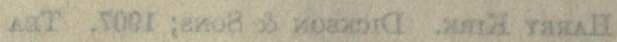

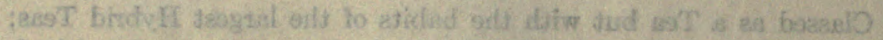

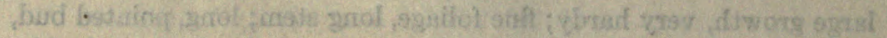

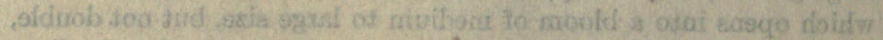

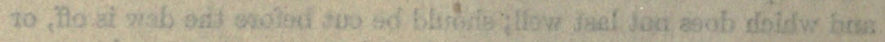

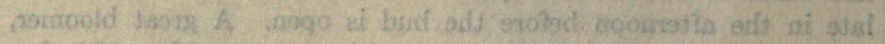

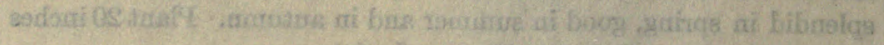

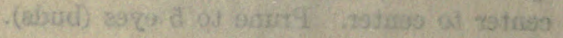




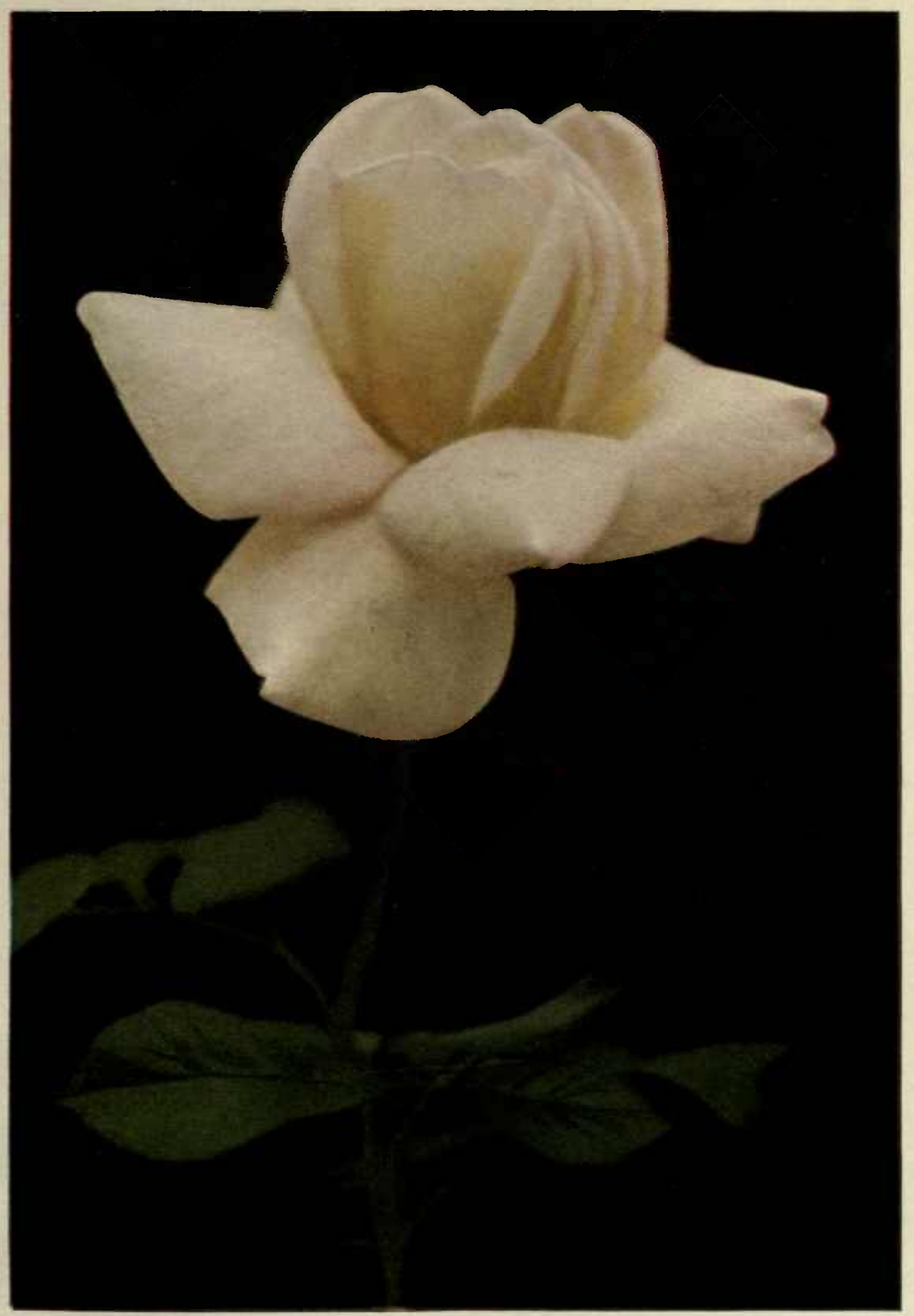



14. YELLOW TO ORANGE

Duchess of Wellington. Dickson \& Sons; 1909. Hybrid TEA

Medium to large growth, very hardy; fine foliage, fairly long erect stem; long, pointed bud, medium to large flower, but not of great petallage; only fair keeper but a wonderful bloomer from frost to frost; the best yellow rose beyond all question. Plant 18 inches center to center. Prune to 5 eyes (buds). 



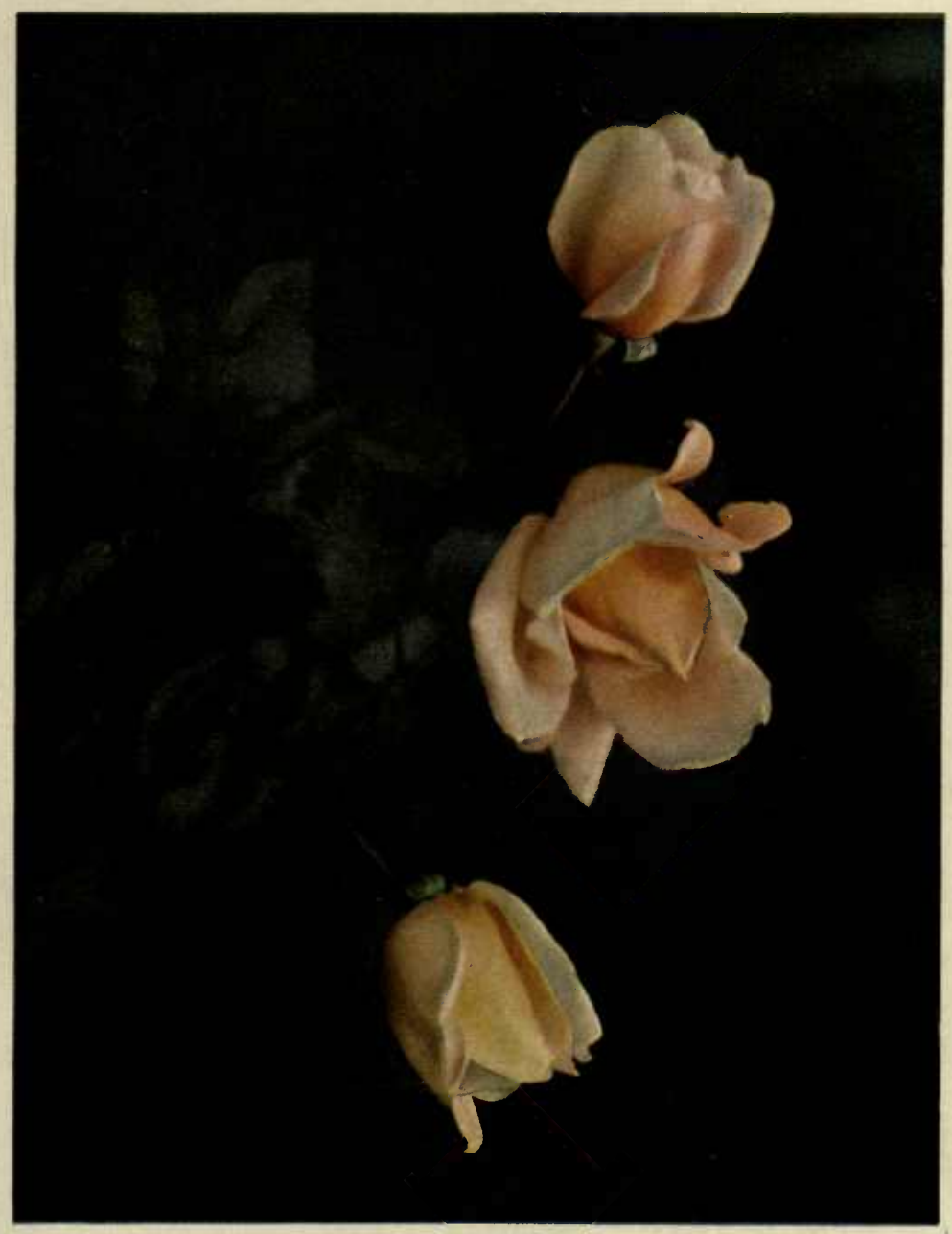





\section{COPPERY ROSE-OVERSPREAD WITH GOLDEN YELLOW}

This is Dicksons' description. With us, particularly in the late spring and summer, the rose verges more from cream to orange-salmon. In the autumn it more nearly approaches Dicksons' description.

Betry. Dickson \& Sons; 1905. Hybrid Tea

Large growth, good foliage; very hardy, long stem, but not always erect; long, pointed bud; a poor keeper; opens quickly and with no great petallage; its blooming qualities, wonderful in spring and autumn, good in summer, secure it a place in the first list. Plant 18 inches center to center. Prune to 5 eyes (buds). 


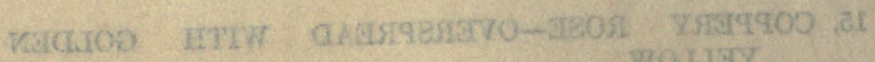
moxnय?

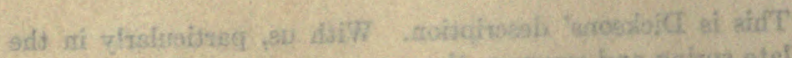

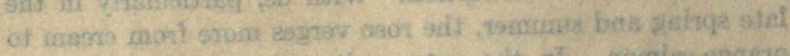

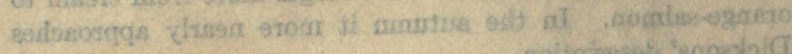

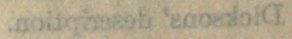

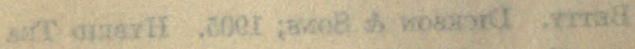

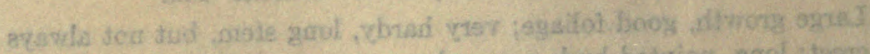

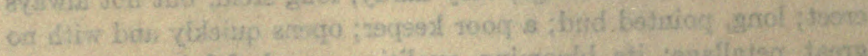

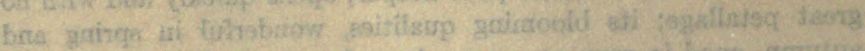

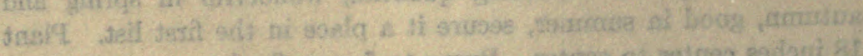

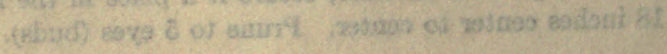




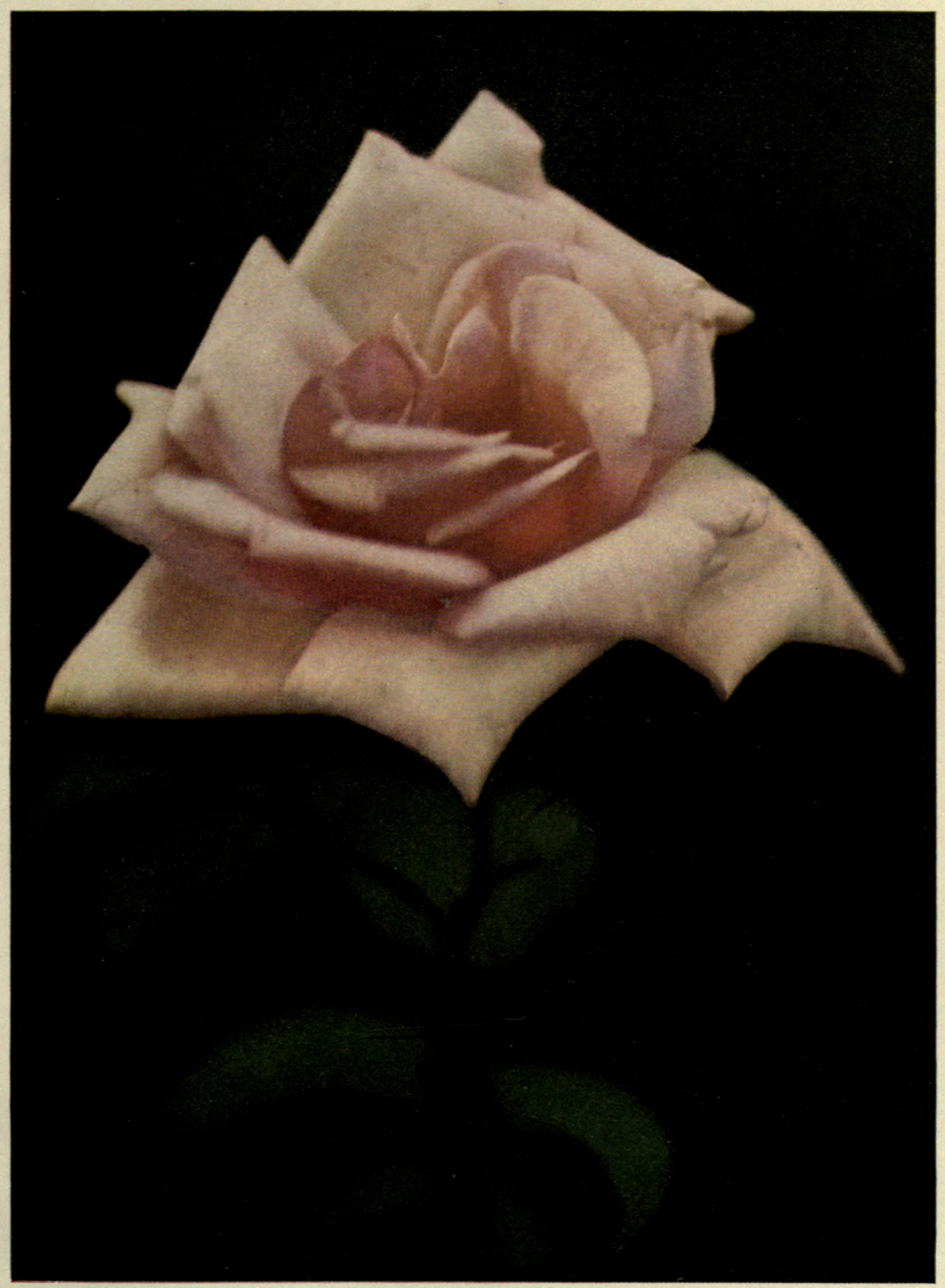



16. COPPERY SALMON-REDDISH BRONZE

Mrs. A. R. Waddell. Pernet-Ducher; 1908. Hrbrid TEA

Medium spreading growth, fine foliage; very hardy, fair stem; pretty bud, but opens somewhat single; in summer not a good keeper. Undoubtedly the best of its color, and a wonderful bloomer in spring, moderate in summer and very good in autumn. Plant 18 inches center to center. Prune to 4 eyes (buds). 


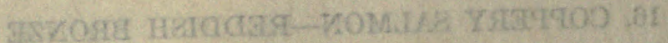

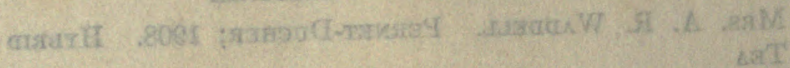

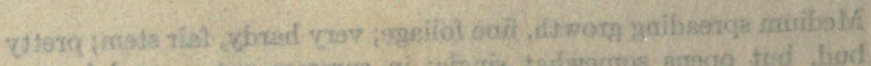

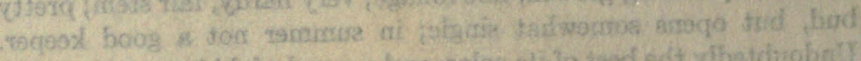

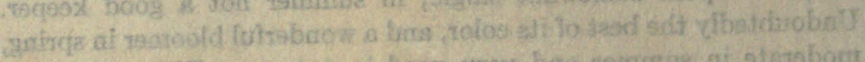

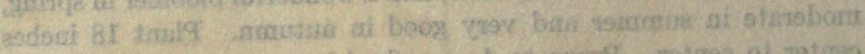

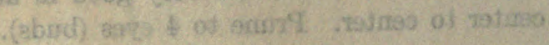




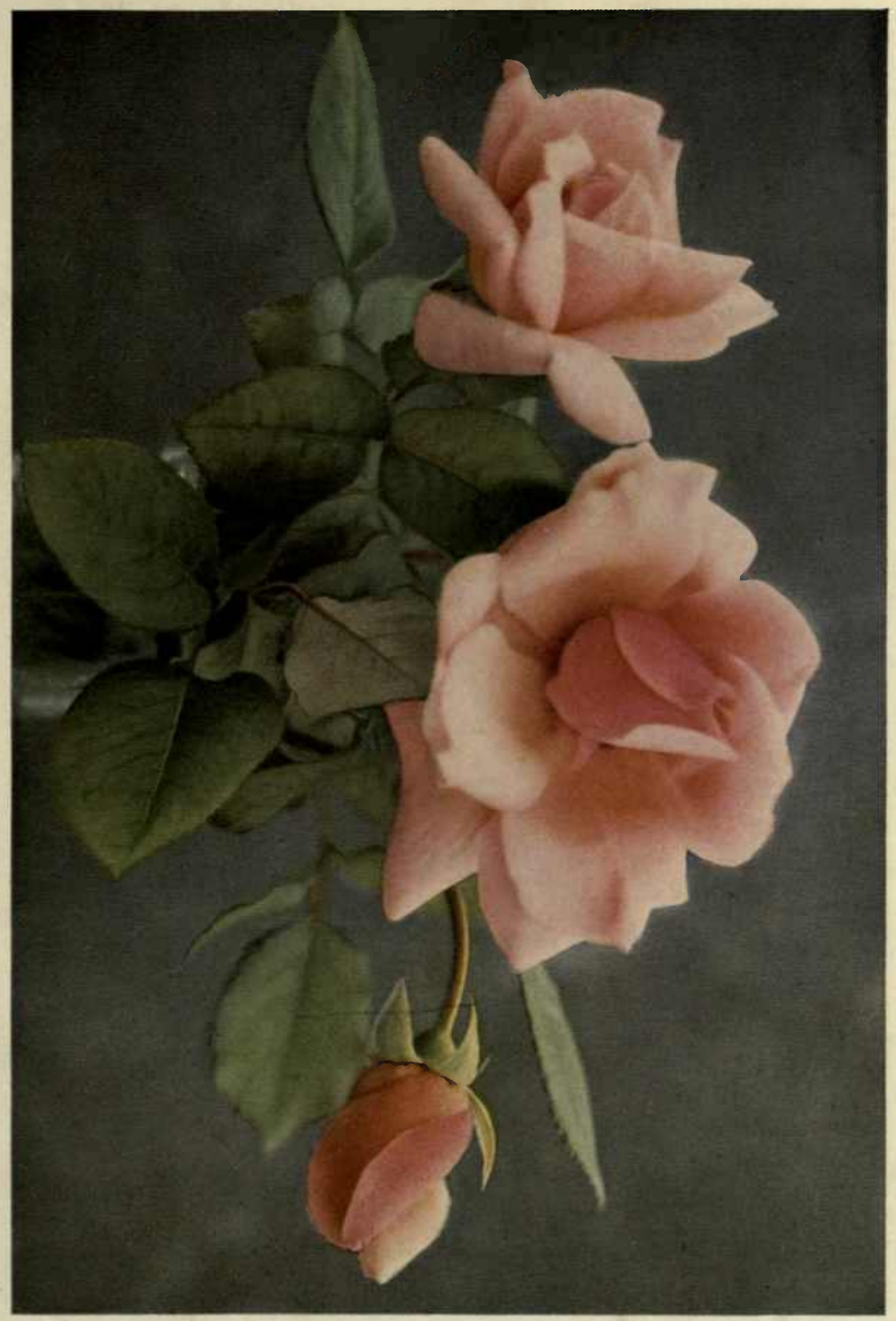





\section{BEST VARIETIES WITH CHARACTERISTICS}

\section{A Main List of Roses}

In the main list the numbers 1,2 and 3 appear in column marked "List."

No. 1 is for the sixteen roses which have just been described, and they should be sufficient for any one desiring from twelve to fifty roses.

The roses listed No. 2 are those which have stood the tests very well; they have surpassed the great main body of varieties which have been discarded as not coming up to the requisite standard. No. 2 is a list of honor and is for good, all-round roses, with the faults plainly noted under the various headings. Before putting these roses in this No. 2 list hundreds of roses have been carefully tested, and these are the ones which have been found most suitable for our climate and conditions as all-round varieties.

For a person wishing a greater variety of allround roses than is included in the No. 1 list, No. 2 is recommended. If one prefers more pink roses, for instance, than the four named in the first list, other pink roses under No. 2 will supply the want.

The roses listed No. 3 are special roses and should be mainly ordered either for large gardens or collections, or by persons thoroughly understanding their failings, all of which are noted under the various headings. 


\section{OUTDOOR ROSE GROWING}

It would be easy to make list No. 3 very much larger; for instance, in the case of the single Irish roses, we have included in this list only the best of this type. If one of these roses is tried, and the person so experimenting wishes more, it is very easy for him to order others. Originally our list was very much larger, but we have cut it down on the theory that we wish every rose contained therein to be the very best of its kind, or to have some special merit. For this reason there may be some few roses which it will be thought we should have included, and, no doubt, we could have included more which might do well under certain conditions; but for average conditions, and particularly for the amateur rose grower, who does not wish a very large number of roses, this list will be found more than sufficient, and this book is especially written for such persons.

All the best Hybrid Perpetuals are included in the list No. 3, the only Hybrid Perpetual being put in Nos. 1 or 2 being Frau Karl Druschki. No other Hybrid Perpetual will compare with Druschki as a bloomer, for, as a rule, the Hybrid Perpetuals bloom only in June for a short season. It is true that occasionally a flower or two will make its appearance in the autumn, but these blooms cannot be counted upon. 


\section{BEST VARIETIES WITH CHARACTERISTICS}

In list No. 3 we have also included some weakgrowing roses which have beautiful blooms; they are not perfectly hardy and, in addition, are weak growers, but are so distinct in the beauty of their bloom that they should be included in any large collection, particularly by a person understanding their failings. As an example of these roses Joseph Hill is perhaps the best known. It is a wonderful flower, of distinct and beautiful coloring, with nothing of its shade to compare with it, but it is such a weak grower that it would be hardly right to include it in list No. 2; to place it in list No. 1 would be doing an injustice to those who wish a good all-round rose, such as list No. 1 is designed to contain. Also in list No. 3 are placed some single roses which, while good bloomers and of robust habit, are so much below the average in the form of their blooms that they should not be included in any list but No. 3 .

It has been aimed to cover, under the columns of the main list, the principal points of each rose. Under the greater number of headings the letters " $A$ "-very good, " $C$ "-fair, " $\mathrm{X}$ "-failure,

$$
\text { "B"-good, "D"-poor, }
$$

are used to describe each variety.

Under the heading "Form of Rose" the abbreviation " $\mathrm{Si}$ " indicates that the rose is single. 


\section{OUTDOOR ROSE GROWING}

Under the heading "Size of Bloom" "L"-large, "M"-medium, "S"-small.

It will be readily understood that under "Growth," for example, all the roses marked "A" are not absolutely the same in growth, but for all practical purposes they form an approximate class under "A," all of which would come up to a certain standard. This principle applies to all headings. It would be impossible, without using very many more classes, to define the small differences existing between the roses marked " $A$," " $B$," " $C$ " or " $D$," but for all approximate purposes, and for general information, each letter or letters will divide the varieties into a class of nearly the same merit under each particular heading. In order to secure the data for so classifying each rose, under the various headings, careful notes have been taken for years, and the average of each rose so tested has been noted. As an example, Killarney, in list No. 1, is marked "C" as to foliage. The reason for this is that in very damp weather of long duration the foliage of Killarney is more liable to mildew than that of many varieties, or if Killarney is watered late in the day mildew occurs. In ordinary seasons, and with proper watering and other care, the foliage of Killarney will do well, but mildew is a failing of this very good, all-round rose and should be noted. 


\section{BEST VARIETIES WITH CHARACTERISTICS}

Under size of bloom all the roses under " $M$ " (which stands for medium) could not be expected to be of a uniform size, but approximately they are the same. Concerning the blooming, as designated by the letters, it will be appreciated that, under certain conditions, roses will exceed or fall below the averages which we have decided upon. It would be impossible to give a list all the subdivisions of which would be absolutely correct under any and all conditions; but for all average working conditions our list will be found to be accurate, and by going over the same carefully, the reader should be able to decide just exactly what he may expect from any given rose.

The roses marked "A" for hardiness indicate that as a rule the wood does not winter kill enough to prevent their being pruned as recommended. Among the Hybrid Perpetuals, the canes in the spring will be less winter killed than the Hybrid Teas; but as you are pruning to at most six or seven eyes in the very strongest of the Hybrid Teas, and as low down as two or three eyes, you will find that in the varieties marked "A," as to hardiness, the wood will be living beyond this point; and, therefore, while in reality the Hybrid Teas marked "A" are not as hardy in the amount of wood left as the Perpetuals, nevertheless we mark them 


\section{OUTDOOR ROSE GROWING}

"A" because the plants do not die, and, in addition, because there is enough wood for us to cut to the proper number of buds.

Those marked " $\mathrm{B}$ " are roses which are likely to kill back below the proper pruning mark, and sometimes show a death here and there, while those marked " $C$ " are roses among which you may expect to find a few deaths and more winter killing.

We did not put any roses in the list which were down as low as "D" for hardiness. We consider hardiness of the first moment and do not wish to include any roses which are not fairly hardy. Roughly speaking, under " $A$ " you should not lose more than one per cent. from winter killing; under " $B$ " from two to three per cent., and under " $C$ " from five to ten per cent.

During the past winter with a new shipment of nearly one thousand roses, chiefly new varieties, in addition to our old plants, we have lost in our entire rose garden not more than twenty plants, or about one per cent., and some of the plants were very small and weak when set out. We consider this immunity from deaths due largely to the fact that we hill up our roses every autumn after the heavy frosts have set in, as described in the chapter "Cultivation."

The color descriptions of the blooms as given in 


\section{BEST VARIETIES WITH CHARACTERISTICS}

our main list are taken from the catalogue of Alexander Dickson \& Sons, Ltd., which we consider particularly clear. We believe that the variations in color which may occur in this country will differ less from the English standard as quoted than from color descriptions taken from our own flowers, although where there is a very marked difference we have noted the same.

Regarding the column for color: we have marked this only in relation to the clearness and -beauty of the color of each rose; where the letters " $B$ " or "C" occur the color of the rose is either somewhat muddy or verges on a solferino shade, which is not considered of the first beauty in roses.

Where two letters are used it will be understood that the description in question will range, for instance: from "B"-good to "A"-very good; or from "C"-fair to "B"-good, etc.

The last two right-hand columns are a handy reference for planting and pruning, and the distances for planting may be followed implicitly.

The pruning column will be understood after the chapter "Pruning" is read; "D. W." in this column stands for dead wood.

The Main List referred to will be found on the following pages. 


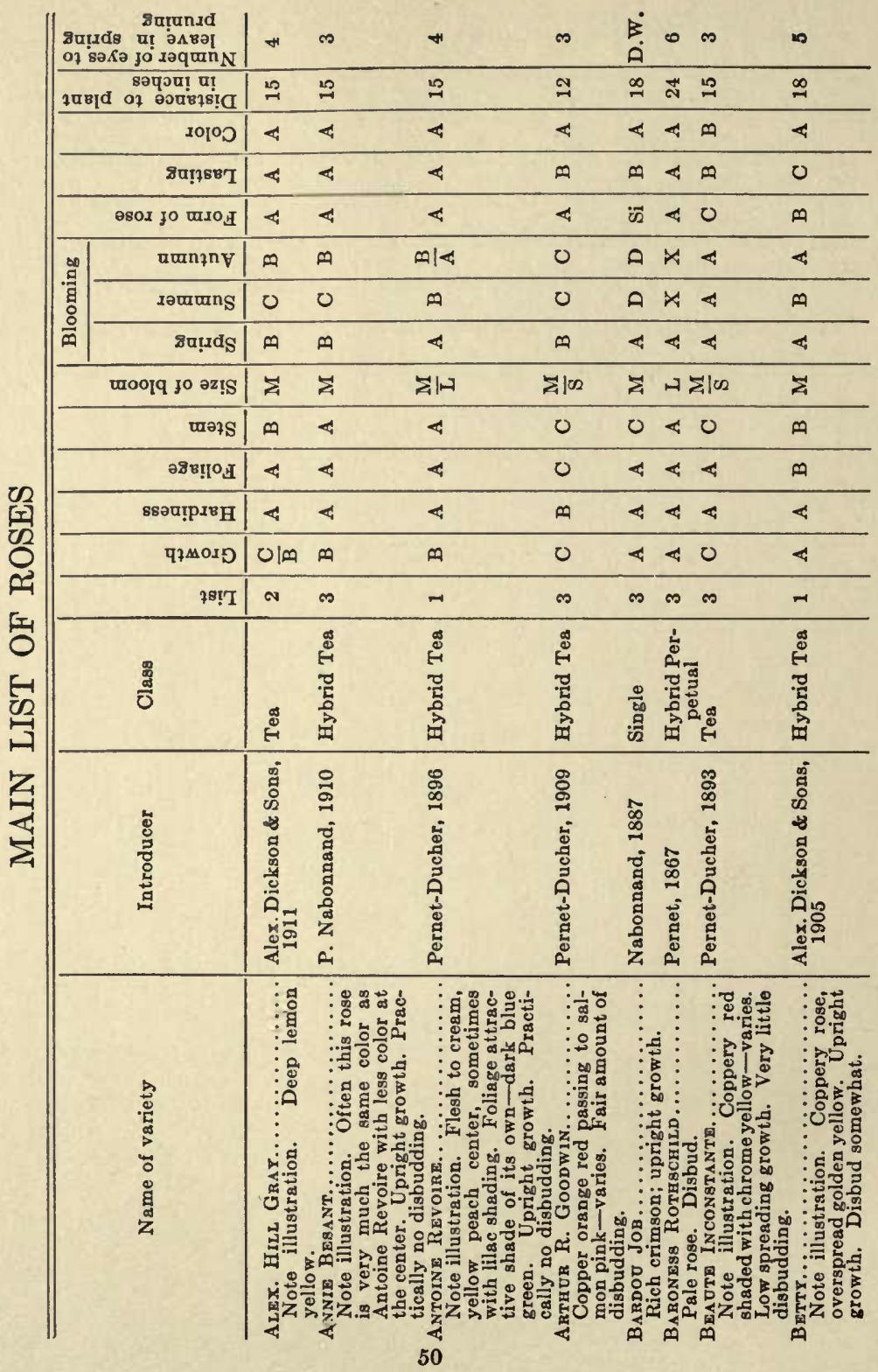




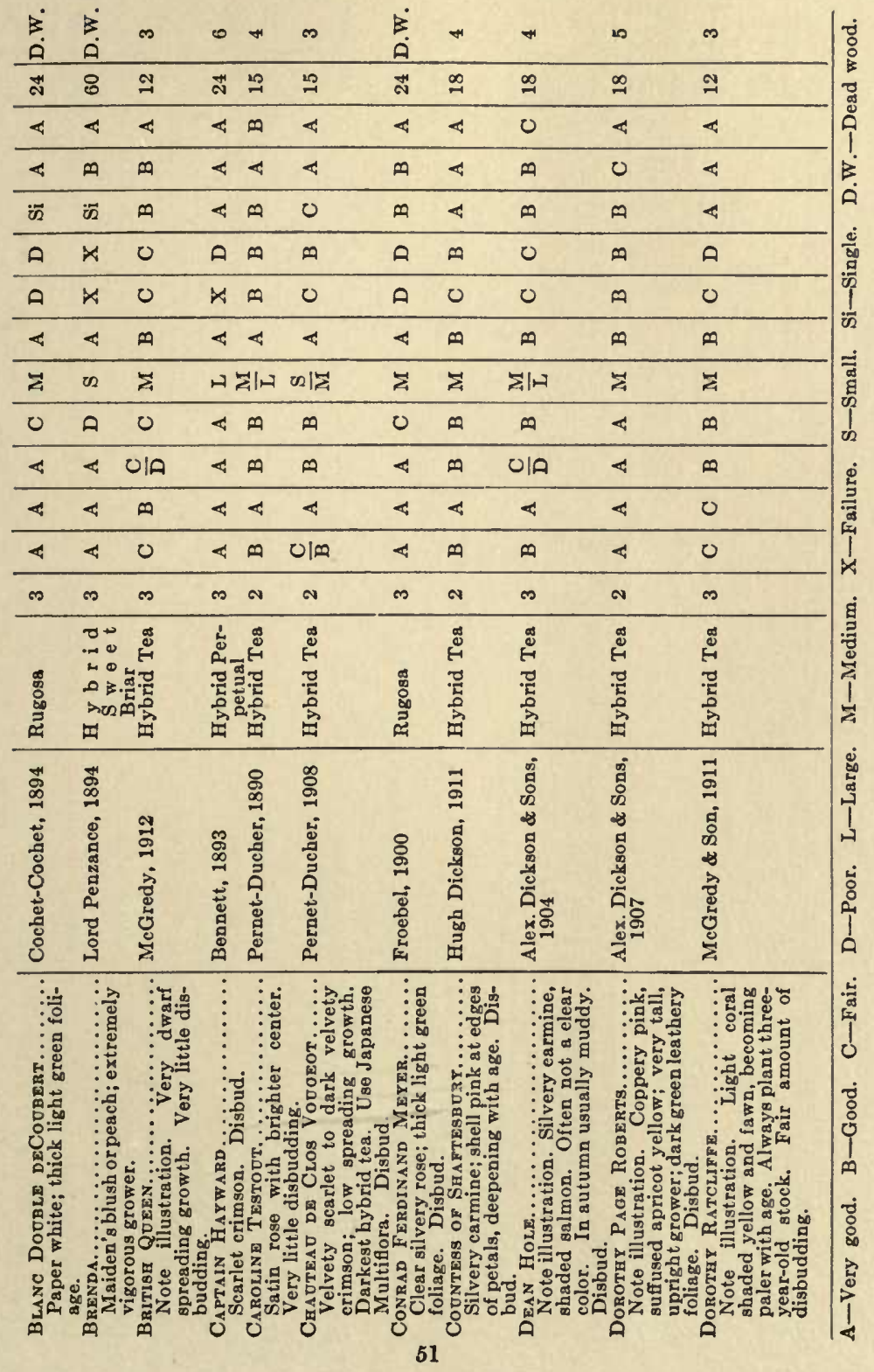




\begin{tabular}{|c|c|c|c|c|c|c|c|c|}
\hline $\begin{array}{l}\text { gur } \\
\text { of } 5\end{array}$ & 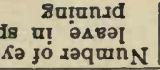 & $\infty$ & $\infty$ & $*$ & $*$ & $\infty \pi$ & $\infty$ & m \\
\hline \multicolumn{2}{|c|}{ 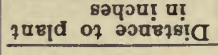 } & \&ิ & $\stackrel{\infty}{=}$ & $\stackrel{\infty}{\sim}$ & $\stackrel{\infty}{\rightarrow}$ & $\stackrel{\infty}{\sim}$ & $\stackrel{\infty}{=}$ & $\stackrel{\infty}{=}$ \\
\hline \multicolumn{2}{|r|}{ มоำ } & $<$ & $<$ & 4 & $\varangle$ & $<<$ & A & $\varangle$ \\
\hline \multicolumn{2}{|r|}{$80 ! 788 T$} & $<$ & $\infty$ & 4 & 0 & $0<$ & Q & A \\
\hline \multicolumn{2}{|r|}{ esos jo wros } & $<$ & 4 & 4 & 0 & $\ddot{\varpi} \oplus$ & 0 & 0 \\
\hline \multirow{3}{*}{ 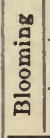 } & ธưาวกท & $x$ & 4 & $U$ & 4 & $A \oplus \mid<$ & 0 & $\oplus$ \\
\hline & satumins & $x$ & $\oplus \mid<$ & U1m & $<$ & OAl< & 0 & 0 \\
\hline & 8utuds & 4 & 4 & $\oplus$ & 4 & $\oplus<$ & $m$ & 4 \\
\hline \multicolumn{2}{|r|}{ щxoо१q jo әz!s } & H & 完川 & Е્દlબ & 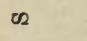 & $\infty 2$ & $\sum \mid 00$ & $\Sigma$ \\
\hline \multicolumn{2}{|r|}{ ᄄᄄวาS } & $<$ & $\oplus$ & $\varangle$ & 0 & $0<$ & $\oplus$ & $\infty$ \\
\hline \multicolumn{2}{|r|}{ วมีเกิด } & 4 & $\varangle$ & $\oplus$ & $<$ & $\infty<$ & 0 & $\infty$ \\
\hline \multicolumn{2}{|r|}{ вsәu!preH } & 4 & $<$ & $<$ & $<$ & $\infty<$ & $<$ & $<$ \\
\hline \multicolumn{2}{|r|}{ पҰMODD } & 4 & $\oplus \mid<$ & $\infty$ & $m$ & $0 \oplus 1<$ & 0 & A \\
\hline & $78 ! 1$ & $\infty$ & -1 & $\infty$ & N & en -1 & $\infty$ & $N$ \\
\hline \multicolumn{2}{|r|}{ 总 } & 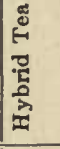 & 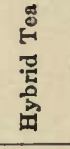 & 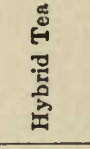 & 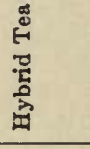 & 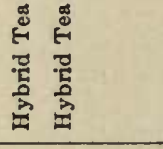 & 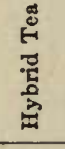 & 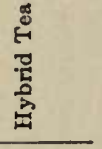 \\
\hline \multicolumn{2}{|r|}{ 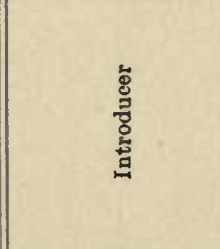 } & 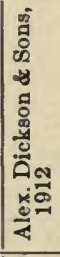 & 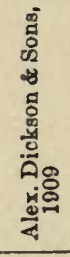 & 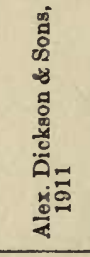 & 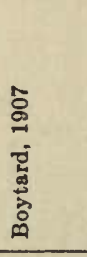 & 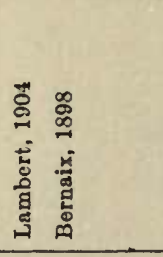 & 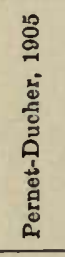 & 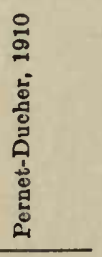 \\
\hline \multicolumn{2}{|r|}{ 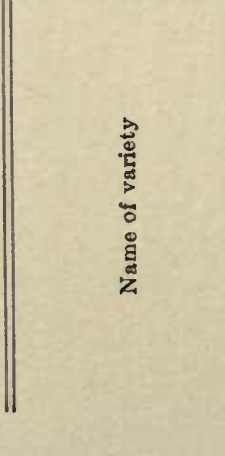 } & 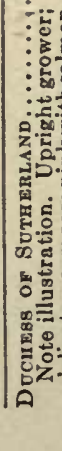 & 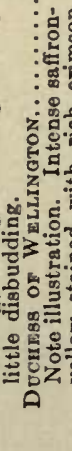 & 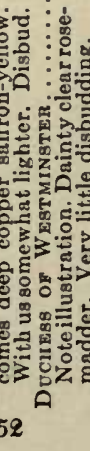 & 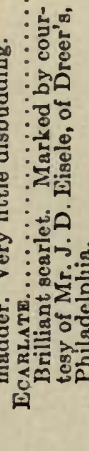 & 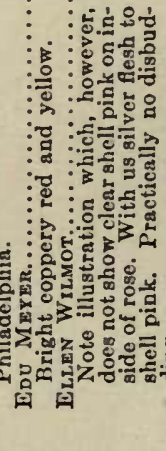 & 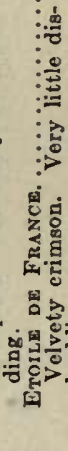 & 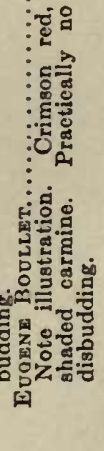 \\
\hline
\end{tabular}




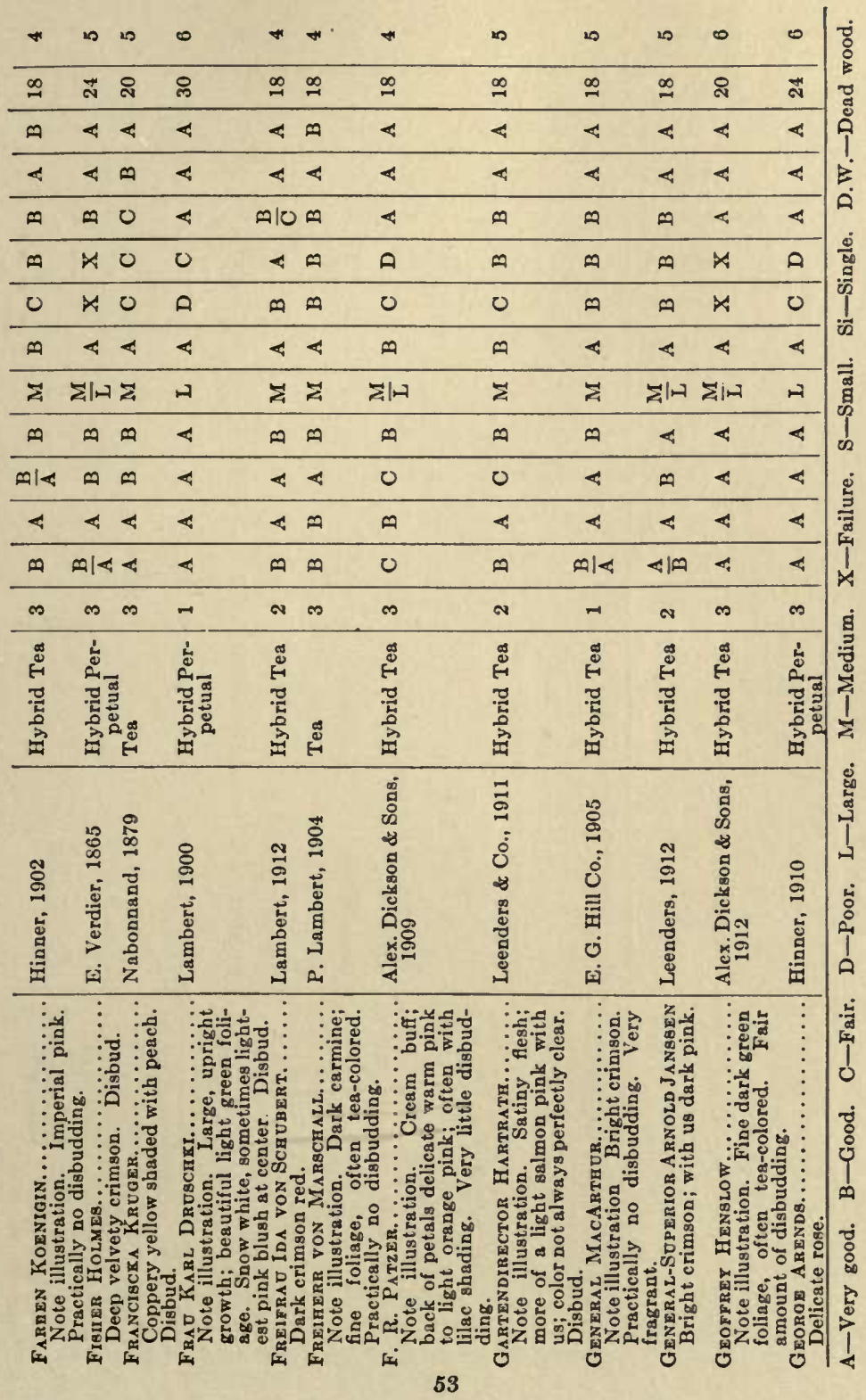




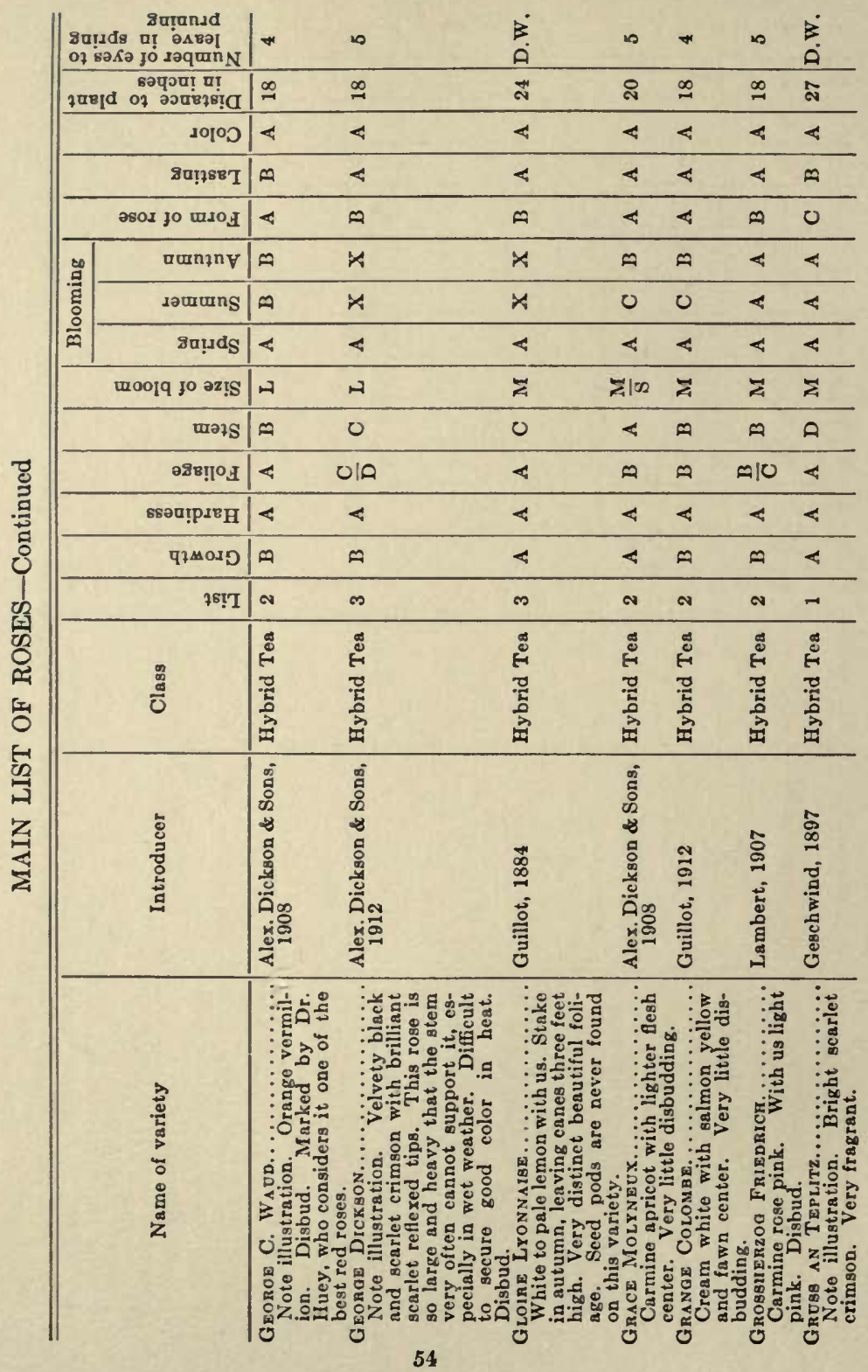




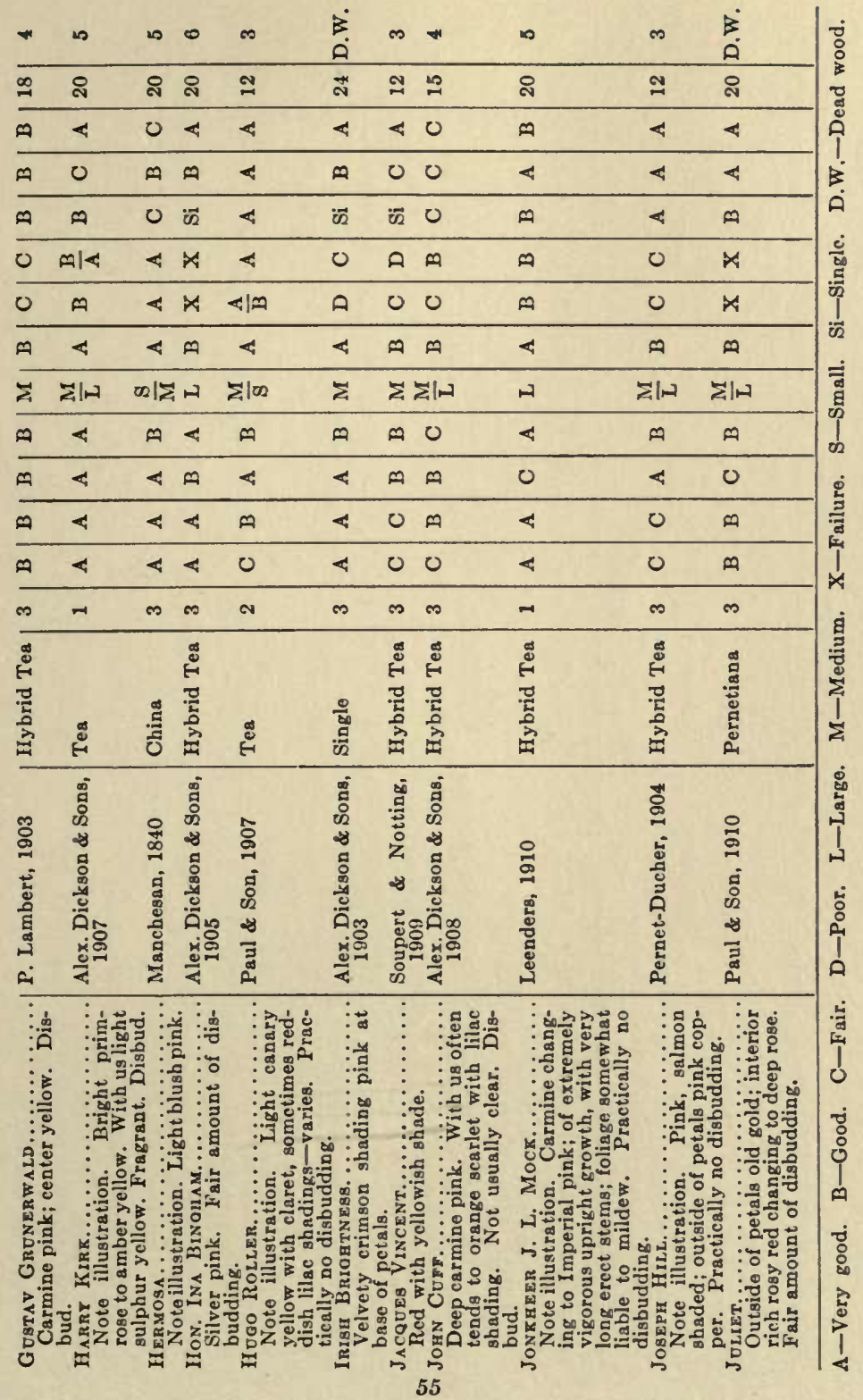




\begin{tabular}{|c|c|c|c|c|c|c|c|c|c|}
\hline \multicolumn{2}{|c|}{ 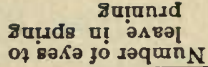 } & $*$ & 10 & & + & $\infty$ & $H$ & $\infty$ & $\infty$ \\
\hline \multicolumn{2}{|c|}{ 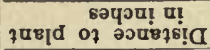 } & $\stackrel{\infty}{\rightarrow}$ & $\stackrel{\infty}{-1}$ & & $\stackrel{\infty}{\sim}$ & $\stackrel{\infty}{-1}$ & $\underset{\sim}{\infty}$ & 2 & $\stackrel{0}{\sim}$ \\
\hline & มำ & $\varangle$ & 4 & & 4 & $<$ & $\varangle$ & $<$ & $\infty$ \\
\hline & $84 ! 758 \mathrm{~T}$ & 4 & $\infty$ & $\overrightarrow{0}$ & 4 & 4 & 4 & 4 & $\varangle$ \\
\hline & อsas fo tuso & 4 & 4 & 돈 & 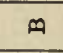 & $<$ & $<$ & $\theta$ & 4 \\
\hline \multirow{3}{*}{ 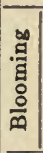 } & uxanวny & $\infty$ & 4 & $\bar{z}$ & 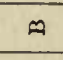 & $4 \mid m$ & $\infty$ & 0 & 0 \\
\hline & səurutus & 0 & 4 & $\stackrel{m}{\infty}$ & 0 & $\infty$ & 0 & A & $\infty$ \\
\hline & 8n!IdS & $\infty$ & 4 & हूँ & $\oplus$ & 4 & $\infty$ & A & 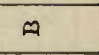 \\
\hline \multicolumn{2}{|r|}{ 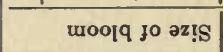 } & 究 & El川 & $\begin{array}{l}\infty \\
\vec{y}\end{array}$ & 氛川 & આ & $\Sigma$ & ¿्राम & $\sum 102$ \\
\hline & шә7S & $<$ & $<$ & : & 4 & $<$ & $\infty$ & $\infty$ & $\oplus$ \\
\hline & әระหกุ०ด & $<$ & 0 & 8̊ & $\varangle$ & $\oplus$ & $\theta$ & $\infty$ & 0 \\
\hline & вะอนเุрม & 4 & 4 & $\frac{0}{3}$ & 4 & $\varangle$ & 4 & 4 & $\varangle$ \\
\hline & प7МОID & $\theta /<$ & mा< & $\frac{8}{62}$ & 4 & বाळ & $\infty$ & 0 & $\oplus$ \\
\hline & $79 ! 1$ & N & - & o & $\infty$ & - & N & $\infty$ & $\infty$ \\
\hline \multicolumn{2}{|r|}{ ర్ } & 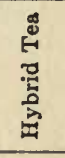 & 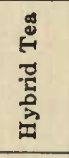 & 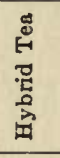 & 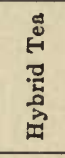 & 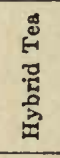 & 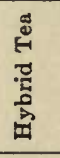 & 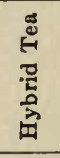 & 造 \\
\hline \multicolumn{2}{|r|}{ 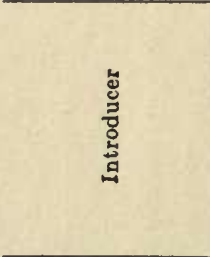 } & 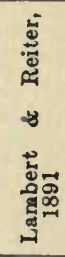 & 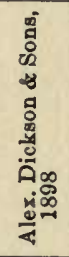 & 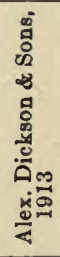 & 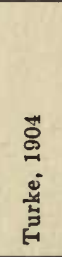 & 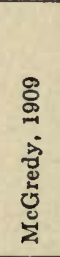 & 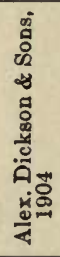 & 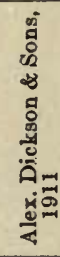 & 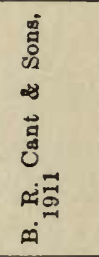 \\
\hline \multicolumn{2}{|r|}{ 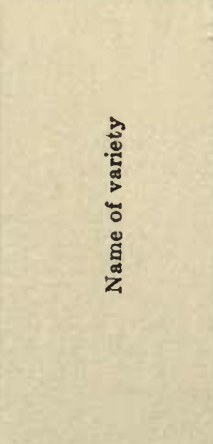 } & 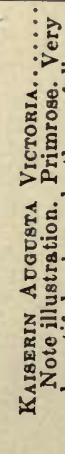 & 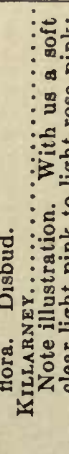 & 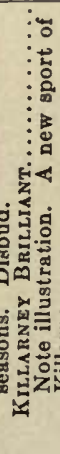 & 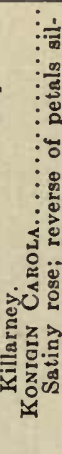 & 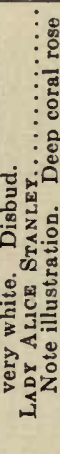 & 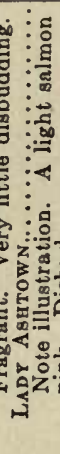 & $\begin{array}{c}\vdots \\
\vdots \\
\vdots \\
\vdots \\
\vdots \\
\vdots \\
\vdots \\
\vdots \\
\vdots\end{array}$ & 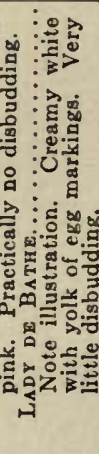 \\
\hline
\end{tabular}




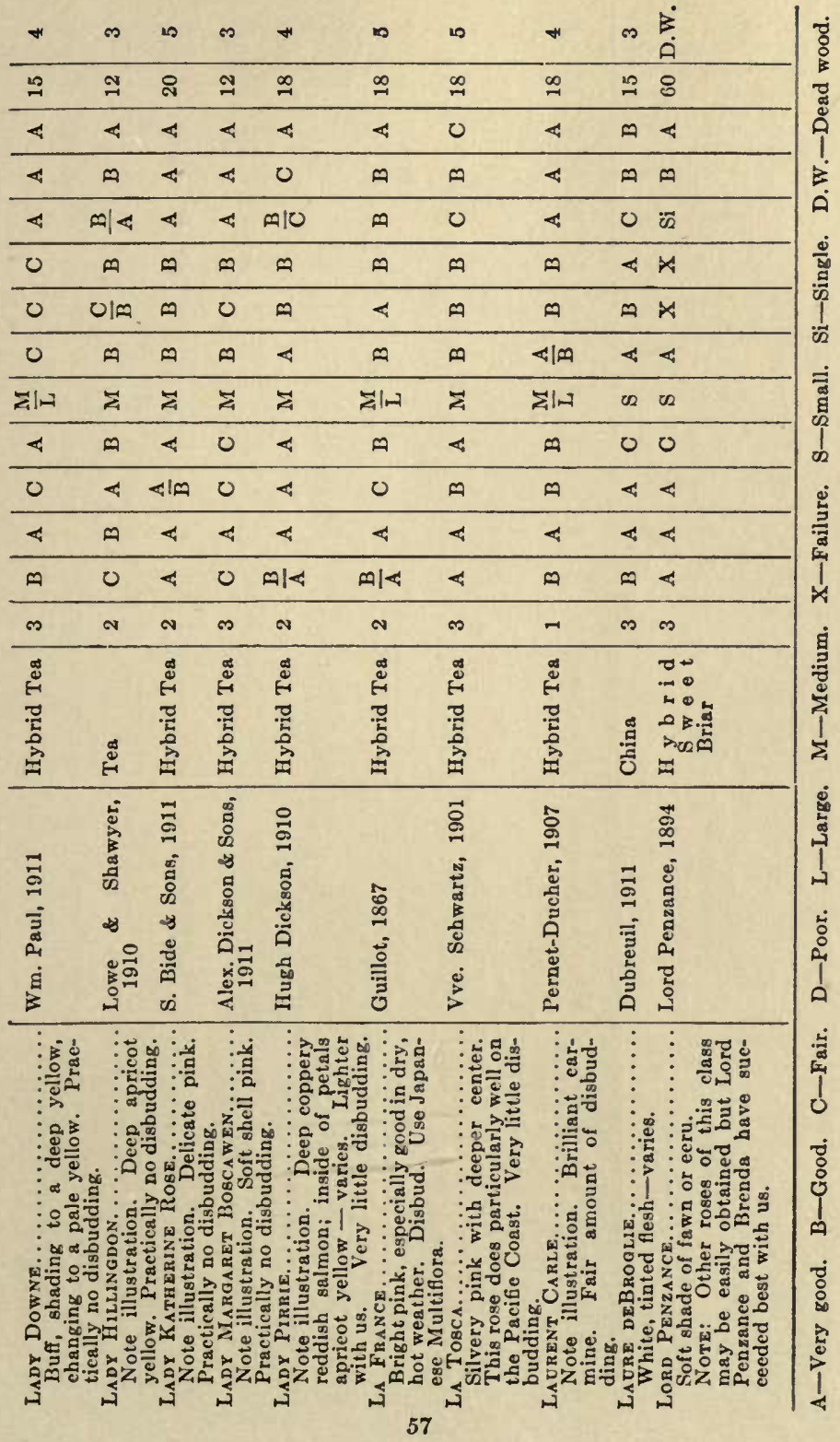




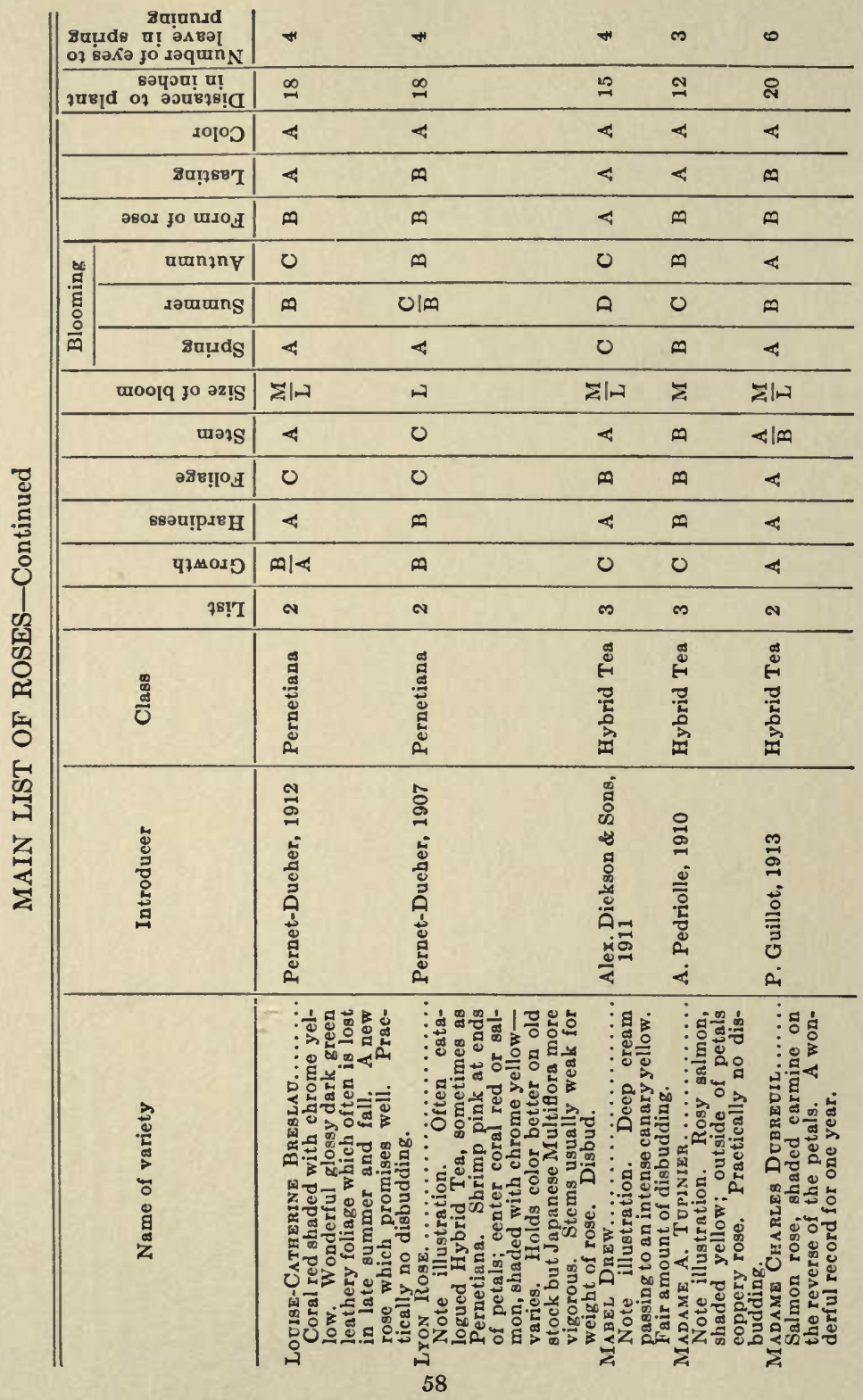




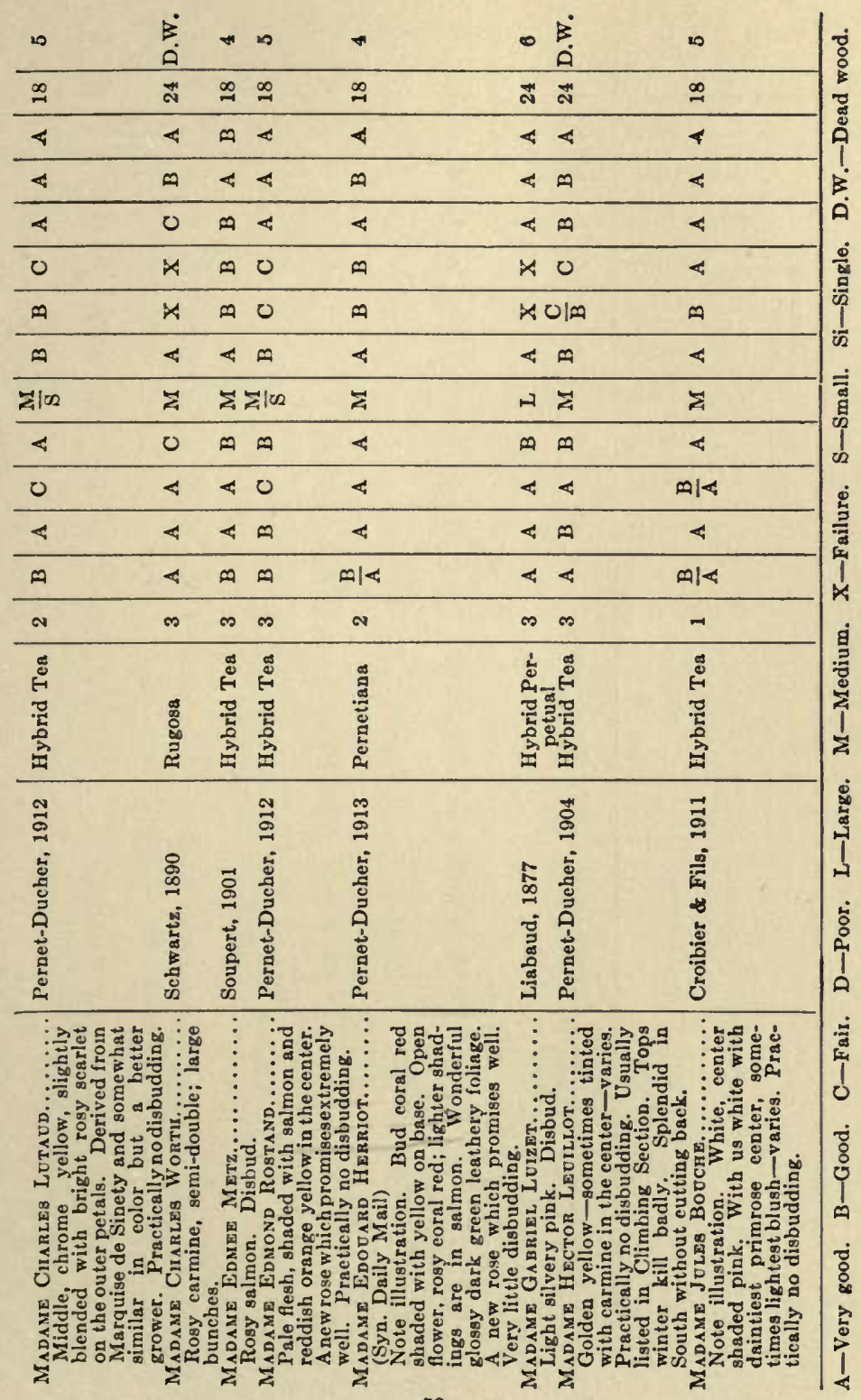




\begin{tabular}{|c|c|c|c|c|c|c|c|c|c|}
\hline \multicolumn{2}{|c|}{ 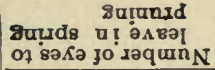 } & $\$ 10$ & $\pi$ & (x) & 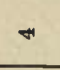 & ח & m & & $\infty$ \\
\hline \multicolumn{2}{|c|}{ 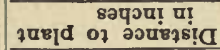 } & $\stackrel{\infty}{=}$ & $\stackrel{\infty}{=}$ & $\stackrel{9}{-1}$ & $\stackrel{\infty}{\sim}$ & 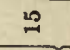 & 22 & $\vec{a}$ & $\stackrel{\sim}{\sim}$ \\
\hline \multicolumn{2}{|r|}{ มоО) } & $\infty<$ & $<$ & 4 & 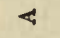 & 4 & 4 & $\oplus$ & 4 \\
\hline \multicolumn{2}{|r|}{ 8นเุะ8า } & $<<$ & 4 & $\infty$ & $\varangle$ & 4 & $\oplus$ & $<1$ & $\oplus$ \\
\hline \multicolumn{2}{|r|}{ esox fo wiol } & $\infty<$ & 4 & 4 & 4 & 4 & 4 & $\infty$ & $\infty$ \\
\hline \multirow{3}{*}{ 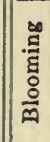 } & uuxn?nV & $\varangle<$ & 0 & A & A & 0 & $\infty$ & A & A \\
\hline & səưưns & $m<$ & 0 & 0 & 0 & 0 & 0 & $x$ & 0 \\
\hline & sutuds & $<4$ & $\infty$ & D & 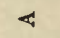 & $\oplus$ & 4 & 4 & $\infty$ \\
\hline \multicolumn{2}{|r|}{ moolq yo әz!S } & $\sum \Sigma \omega$ & $\Sigma$ & $\Sigma$ & 비령 & 穵 & 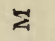 & 凹 : & $s$ \\
\hline & trots & $\oplus \ll$ & 4 & $\infty$ & 4 & 4 & $\infty$ & 4 & 0 \\
\hline & әอยกัด & $4<$ & 0 & $\oplus$ & $\oplus$ & $\varangle$ & $\infty$ & 4 & $m$ \\
\hline & ssoutpren & $<4$ & $<$ & 0 & $\varangle$ & $<$ & 0 & 4 & 0 \\
\hline & पวМอมด & $A \infty \mid<$ & 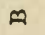 & 0 & $\infty$ & $m \mid 0$ & ๓ & 4 & $\mho$ \\
\hline & $26 ! T$ & N $\rightarrow$ & ผ & "s & N & $\omega$ & N & $\infty$ & $\infty$ \\
\hline \multicolumn{2}{|r|}{ 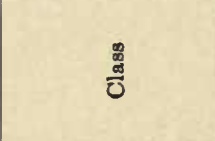 } & 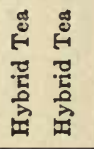 & 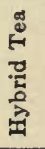 & 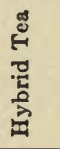 & 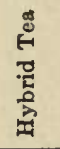 & 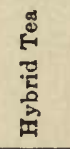 & 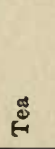 & 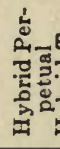 & 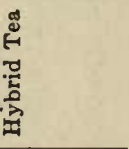 \\
\hline \multicolumn{2}{|r|}{ 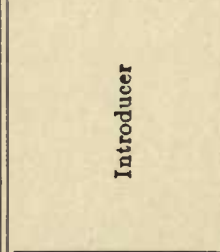 } & 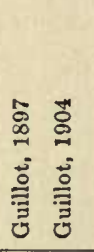 & 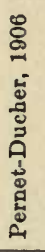 & 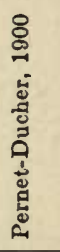 & 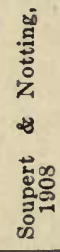 & 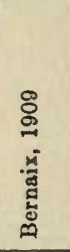 & 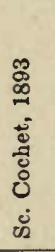 & 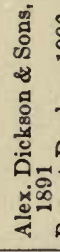 & 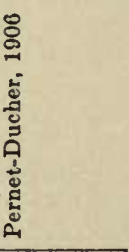 \\
\hline \multicolumn{2}{|r|}{ 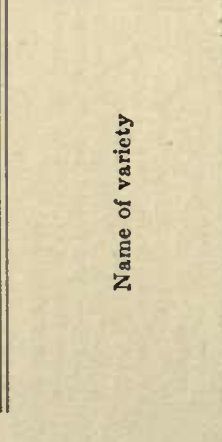 } & \multicolumn{8}{|c|}{ 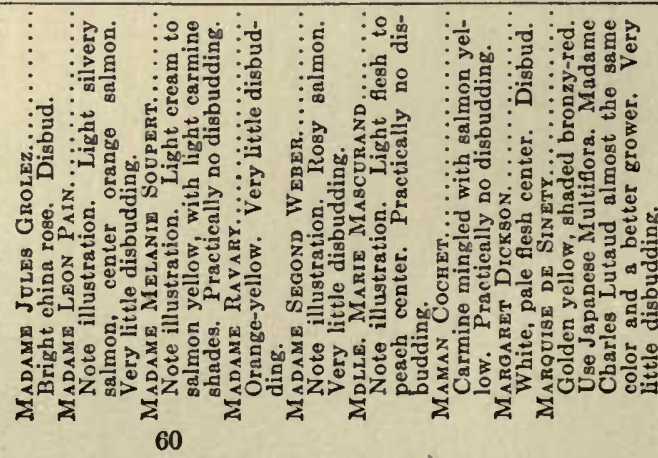 } \\
\hline
\end{tabular}




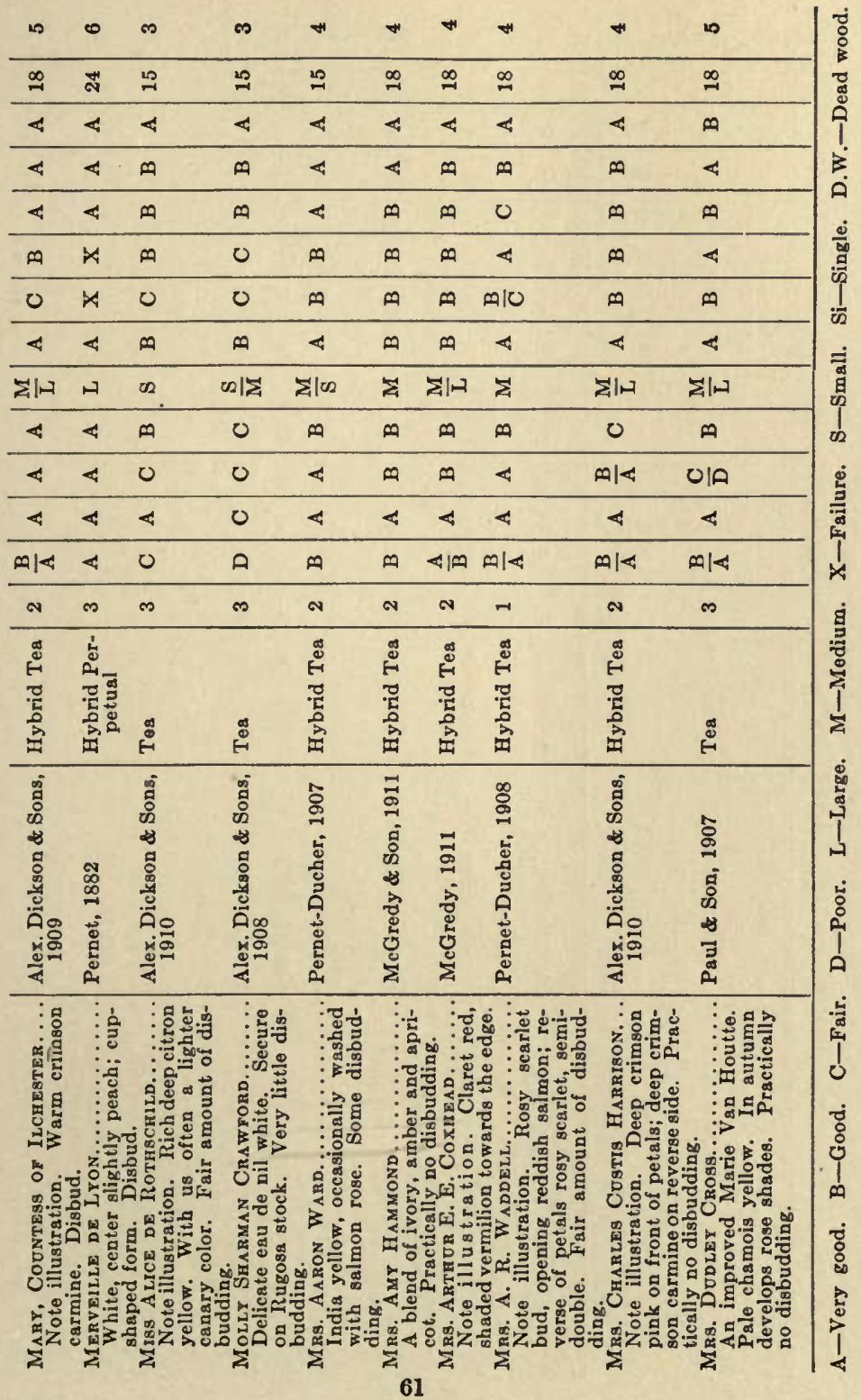




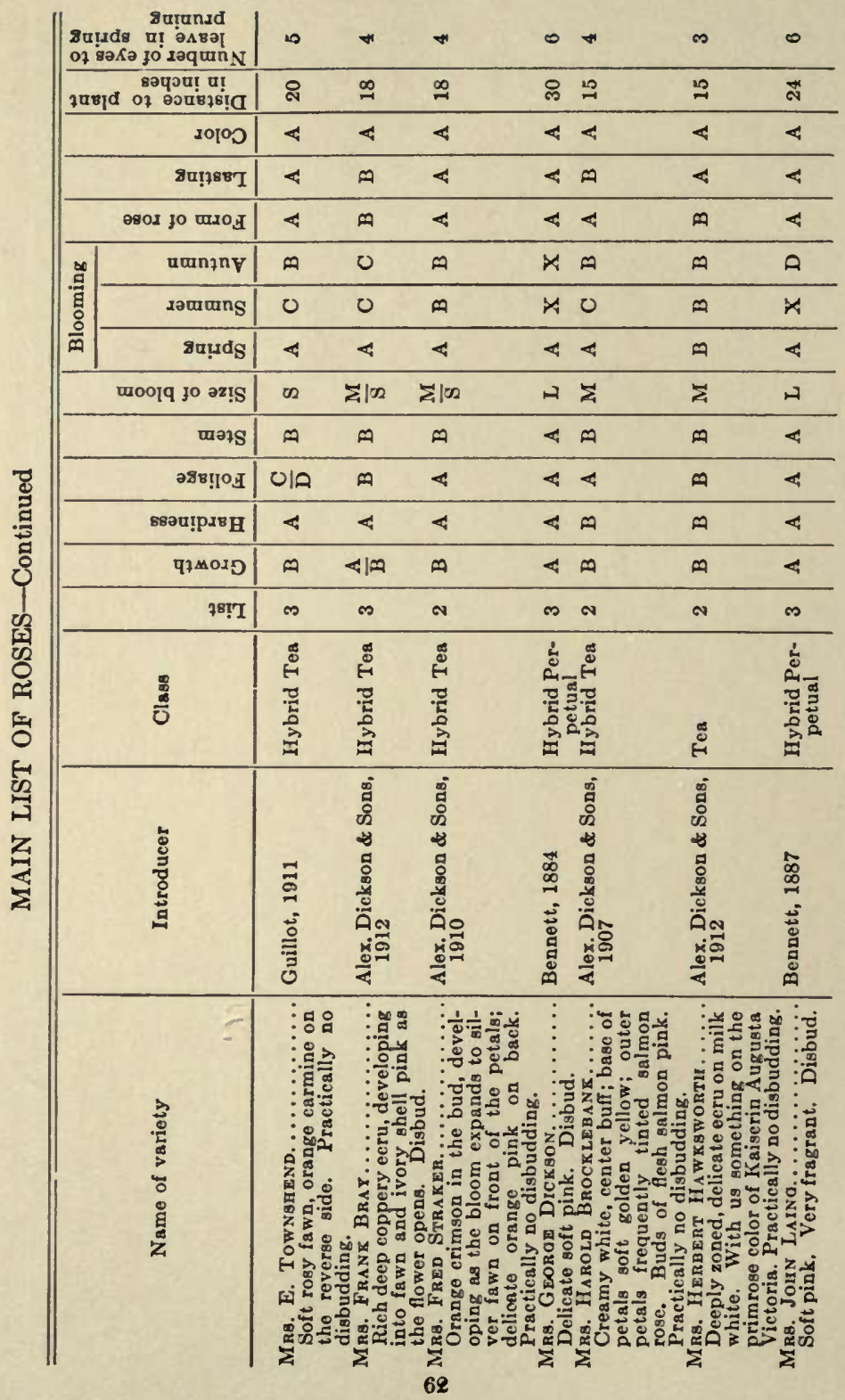




\begin{tabular}{|c|c|c|c|c|c|c|c|c|c|}
\hline מo & $*$ & 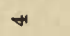 & + & + & $*$ & $*$ & $m$ & $H$ & $\bullet$ \\
\hline ฉ & $\stackrel{\infty}{\sim}$ & $\stackrel{\infty}{\sim}$ & $\stackrel{\infty}{\sim}$ & $\stackrel{\infty}{\sim}$ & $\stackrel{\infty}{\sim}$ & $\stackrel{20}{2}$ & $\stackrel{\sim}{\sim}$ & $\stackrel{2}{-1}$ & ลิ \\
\hline 4 & 4 & 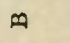 & $\oplus$ & 4 & $\varangle$ & 4 & 4 & 4 & 4 \\
\hline 0 & $\oplus$ & $A$ & $\oplus$ & $\oplus$ & 4 & 4 & $\varangle$ & $<$ & $\oplus$ \\
\hline 脑 & $\oplus$ & 0 & 0 & D & $\oplus$ & 4 & 4 & 4 & 4 \\
\hline$\infty$ & 0 & D & $\infty$ & $\oplus$ & $\oplus$ & 0 & 0 & $\oplus$ & OIA \\
\hline 0 & 0 & 0 & 0 & 0 & $\infty$ & 0 & 0 & 0 & $x$ \\
\hline$\infty$ & $\theta$ & $\infty$ & 4 & $\varangle$ & 4 & $m$ & $m$ & $\oplus$ & $\triangleleft$ \\
\hline म & 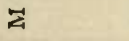 & $\Sigma$ & $\vec{z}$ & $\Sigma$ & $\Sigma$ & $\Sigma$ & $\sum \mid 00$ & $\Sigma$ & $\mu$ \\
\hline 4 & $\oplus$ & $\oplus$ & $\oplus$ & $\infty$ & $\mathscr{A}$ & $\infty$ & 0 & $m \mid<$ & $\oplus$ \\
\hline$<$ & $\oplus$ & $\infty$ & 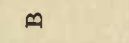 & 0 & 4 & $\infty \mid<$ & 0 & $\infty \mid<$ & 4 \\
\hline 4 & $\oplus$ & 4 & 4 & $<$ & 4 & $<$ & 4 & $\varangle$ & 4 \\
\hline$<$ & 0 & A & $<\mid \infty$ & $\oplus$ & 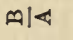 & $\oplus$ & 0 & $\infty$ & 4 \\
\hline n & $m$ & $m$ & $m$ & $n$ & N & $\infty$ & $\infty$ & N & $m$ \\
\hline 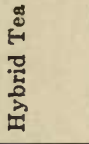 & 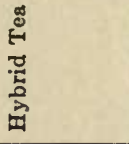 & 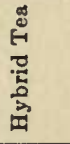 & 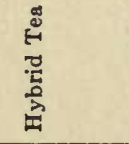 & 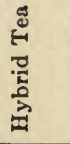 & 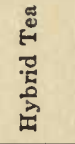 & 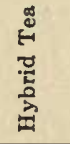 & 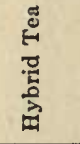 & 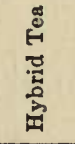 & 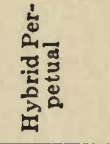 \\
\hline 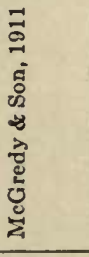 & 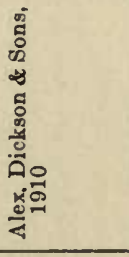 & 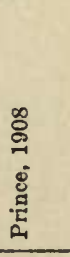 & 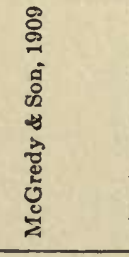 & 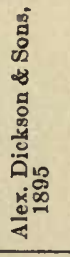 & 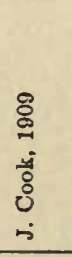 & 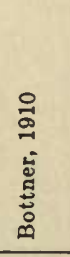 & 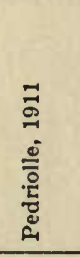 & 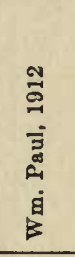 & 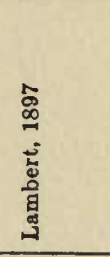 \\
\hline 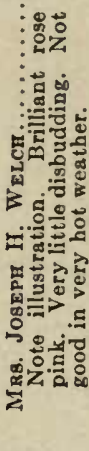 & $\begin{array}{l}\vdots \\
\vdots \\
\vdots \\
0 \\
\vdots \\
\vdots \\
\vdots \\
\vdots\end{array}$ & 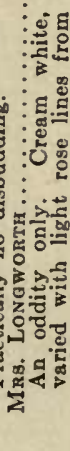 & 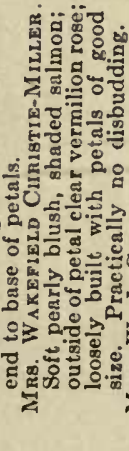 & 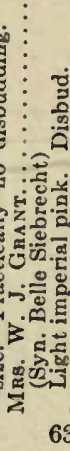 & 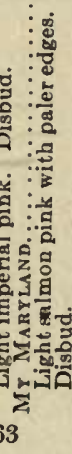 & 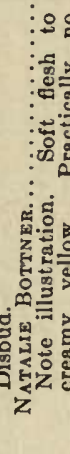 & 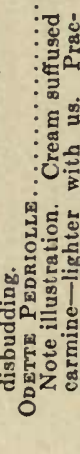 & 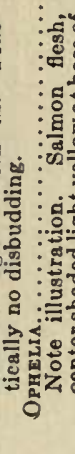 & 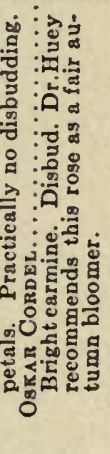 \\
\hline
\end{tabular}




\begin{tabular}{|c|c|c|c|c|c|c|c|c|c|}
\hline \multicolumn{2}{|c|}{ 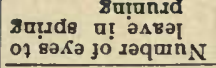 } & 0 & is & $H$ & $m$ & $\mapsto$ & $\infty$ & 10 & $H$ \\
\hline \multicolumn{2}{|c|}{ 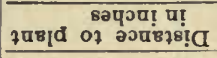 } & లి & $\stackrel{\infty}{-1}$ & $\stackrel{\infty}{\sim}$ & $\stackrel{\infty}{\sim}$ & $\stackrel{\infty}{-}$ & $\stackrel{2}{-1}$ & สิ & $\stackrel{\infty}{-\infty}$ \\
\hline \multicolumn{2}{|c|}{ รоำ } & 0 & $\varangle$ & $<$ & 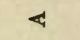 & $<$ & 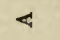 & $\oplus$ & $\varangle$ \\
\hline \multicolumn{2}{|r|}{8 8นกะระ } & A & $<$ & $<$ & 4 & $\varangle$ & 0 & $\oplus$ & A \\
\hline \multicolumn{2}{|r|}{ 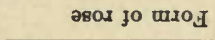 } & 0 & 4 & $\oplus$ & $\infty$ & $\infty$ & $\infty$ & $\approx 10$ & $\oplus$ \\
\hline \multirow{3}{*}{ 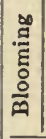 } & uampny & UIR & $\oplus$ & $\infty \mid<$ & $\oplus$ & $\infty$ & 0 & a & 0 \\
\hline & sourung & $x$ & $\oplus$ & $\infty$ & $\infty$ & 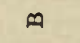 & 0 & $\oplus$ & $\oplus$ \\
\hline & 8uṭds & 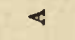 & 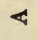 & $A \mid<$ & $\varangle$ & 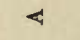 & m & $<$ & 4 \\
\hline \multicolumn{2}{|r|}{ щоoІq эо әz!S } & $\mapsto$ & $\Sigma$ & $\Sigma$ & $\sum \mid 02$ & $\vec{z}$ & 02 & 空 & $\vec{\Sigma} \mid \leadsto$ \\
\hline \multicolumn{2}{|r|}{ mets } & $<$ & 4 & $\oplus$ & $<$ & $\oplus$ & 0 & $\oplus$ & $\varangle$ \\
\hline \multicolumn{2}{|r|}{ อ8हाก प } & 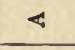 & 0 & $\infty i<$ & $\oplus \mid<$ & $\oplus$ & $\oplus$ & $n_{1<}$ & $\infty$ \\
\hline \multicolumn{2}{|r|}{ вsəu!p ${ }^{8} \mathrm{H}$} & $<$ & $<$ & $<$ & $\varangle$ & 4 & $\infty$ & $<$ & 0 \\
\hline \multicolumn{2}{|r|}{ प1M015 } & 4 & $\oplus$ & $A$ & $\infty$ & $91<$ & 0 & Al< & $\infty$ \\
\hline \multicolumn{2}{|r|}{$78 \div 7$} & $\infty$ & $N$ & $N$ & $N$ & $\infty$ & $m$ & N & $\infty$ \\
\hline \multicolumn{2}{|r|}{$\frac{\mathscr{m}}{0}$} & 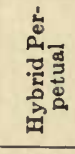 & 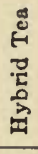 & 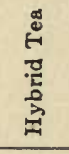 & 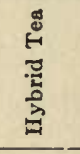 & 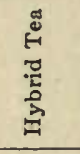 & 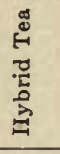 & 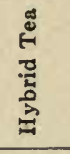 & 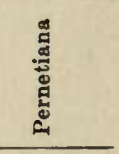 \\
\hline \multicolumn{2}{|r|}{ 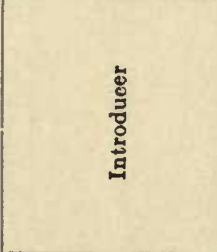 } & 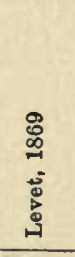 & 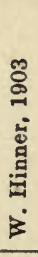 & 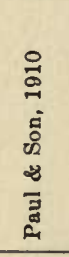 & 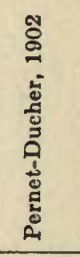 & 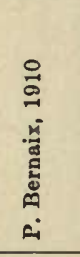 & 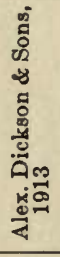 & 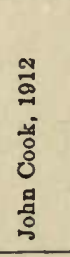 & 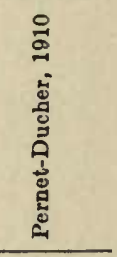 \\
\hline \multicolumn{2}{|r|}{ 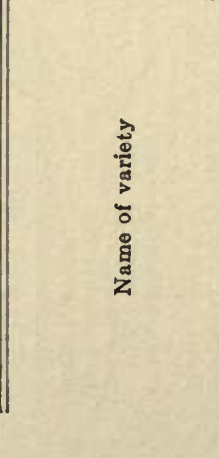 } & 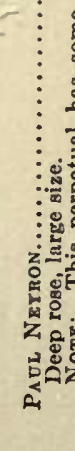 & 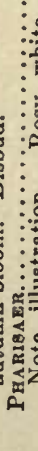 & 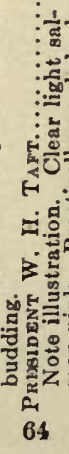 & 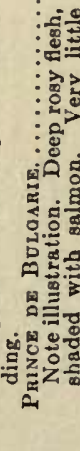 & 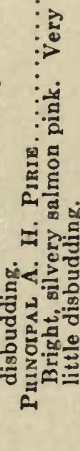 & 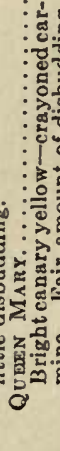 & 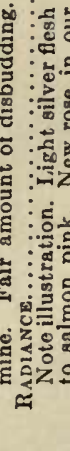 & 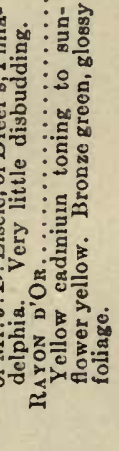 \\
\hline
\end{tabular}




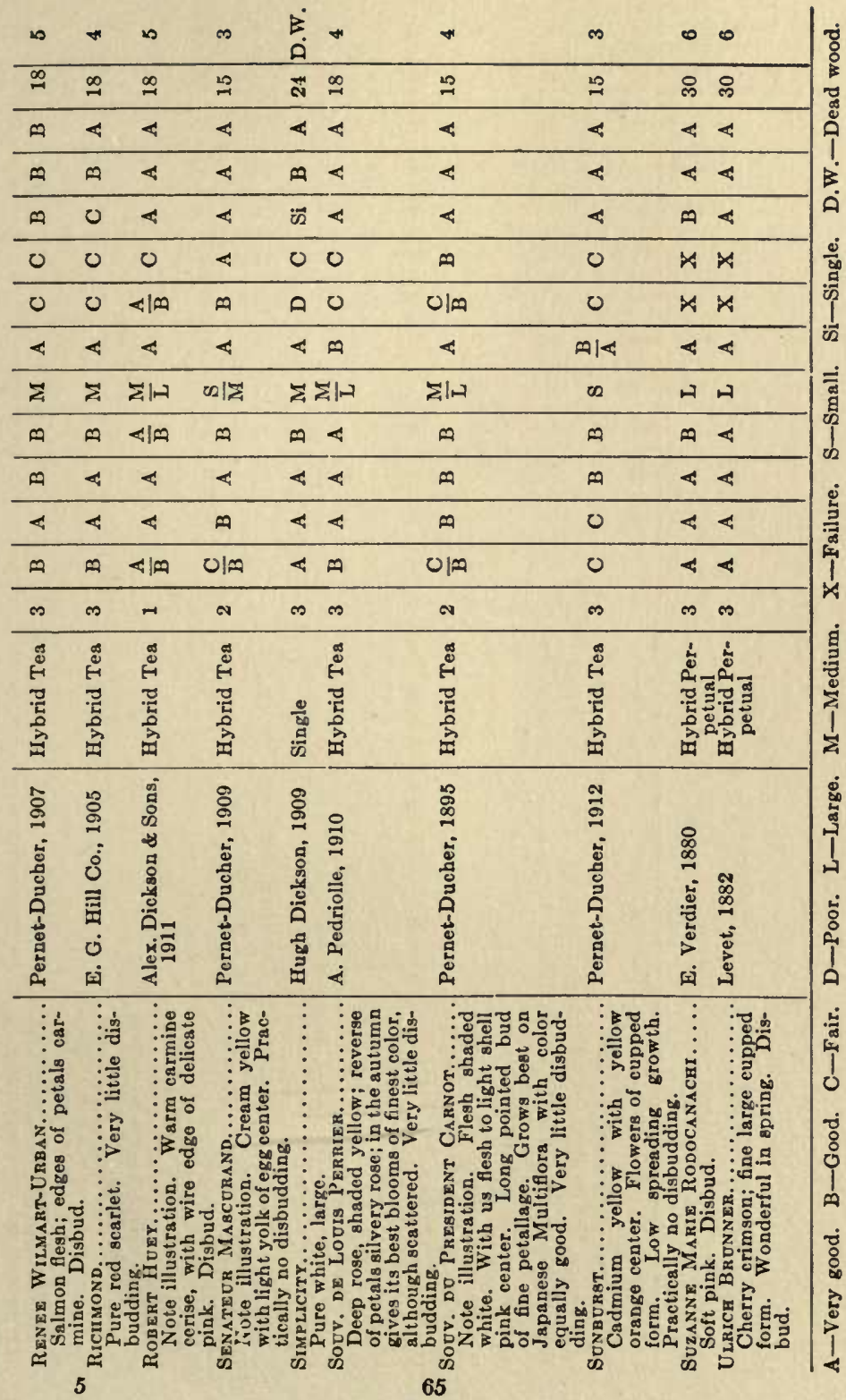




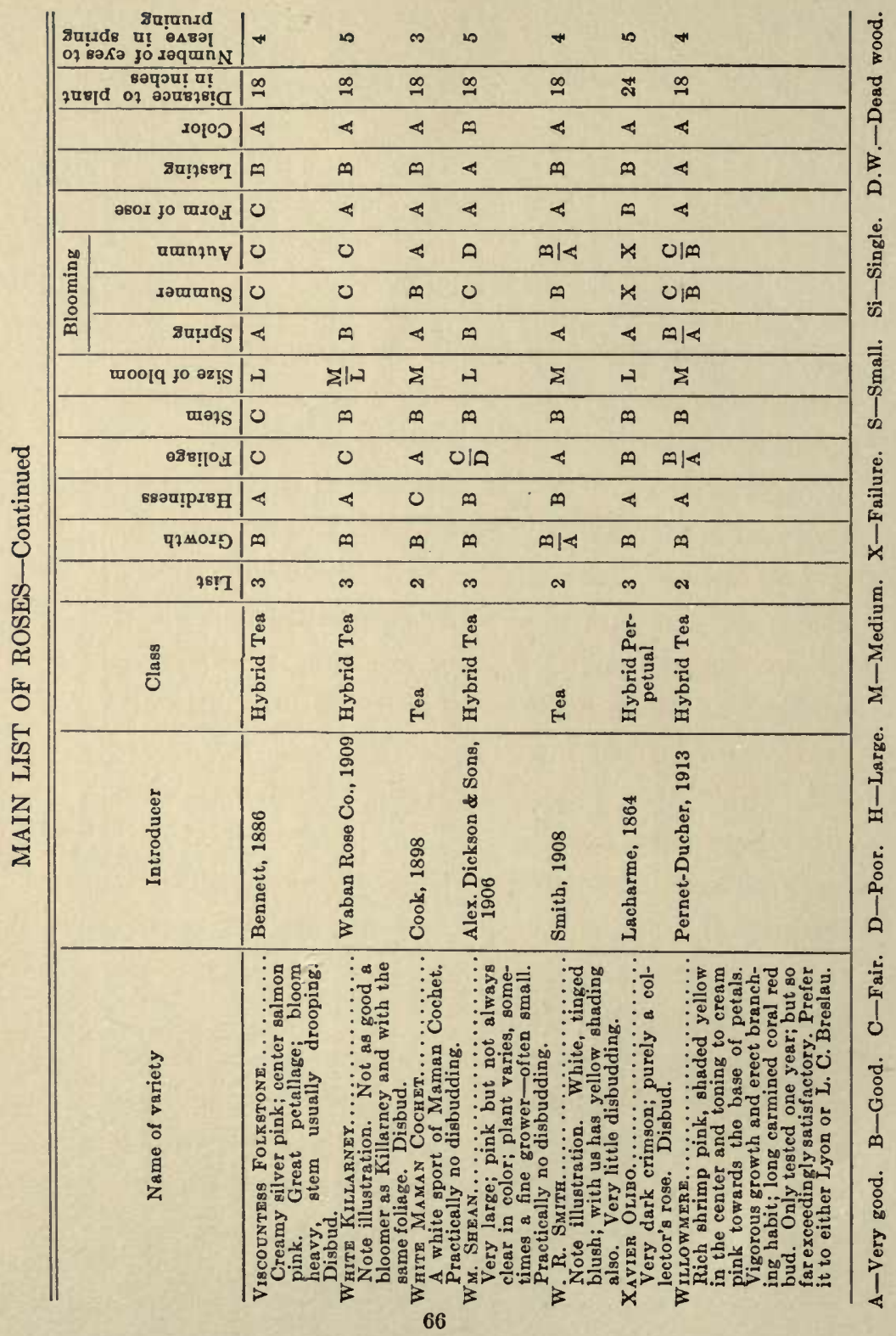




\section{III}

\section{CLIMBERS}

IN the list which we have just given in the preceding chapter we have not included any climbing roses, as we desire to take these up separately.

Unfortunately there is not at this time any good, all-round climbing rose which blooms through spring, summer and autumn with great reliability. There are climbing roses which are advertised so to bloom, but although we have tried out all of these, we cannot recommend any for the Middle Atlantic States and farther north as having this very desirable habit to a marked degree, combined with other necessary merits.

There are dwarf climbers which bloom quite well through the summer, but they are so very small that they are only useful as borders to large beds and we do not include them.

For the same reason that we have cut down our main list to the most dependable varieties, we have also cut this climbing list down to those roses which we know will succeed. It would be very easy to include a great many more which we have tried 


\section{OUTDOOR ROSE GROWING}

and found fairly successful, but we shall confine the list to those climbers which we know will prove most reliable for the person desiring a few of this class only.

In order to make the subject as clear as possible, we shall divide all the various climbers into two classes; this is an absolutely arbitrary division and not at all in accordance with the ordinary manner of classification.

In our first division we shall include Climbing Hybrid Teas and some other climbers whose blooms have the general shape and size of the Hybrid Tea rose. Hybrid Tea climbers are mostly, as has been explained heretofore, sports from very well-known Hybrid Tea roses. They do not bloom as profusely as the Hybrid Teas nor as constantly. They may be depended upon to give good blooms in the spring, and a few other blooms mainly in the autumn, although these are so scattered that they cannot be called continually-blooming roses. In addition to these we have included one or two other roses which, as stated before, have the Hybrid Tea form of bloom; unfortunately they bloom only in the spring and have practically no bloom thereafter, but we have included them because of their great beauty.

Ards Rover. Hybrid Perpetual Climber; Alex. Dickson and Sons; 1898. Color is crimson shaded 68 
1

CLIMBING ROSE CHRISTINE WRIGHT ON DR. HUEY'S

PLACE 


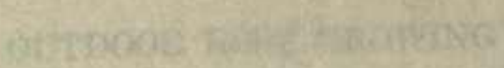

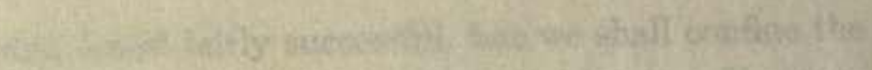

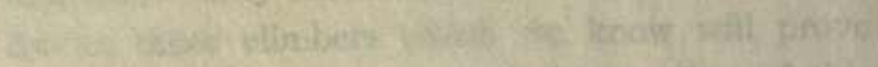

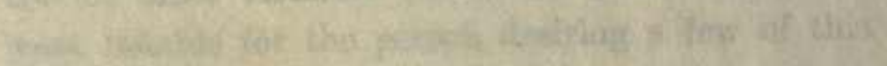

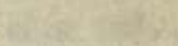

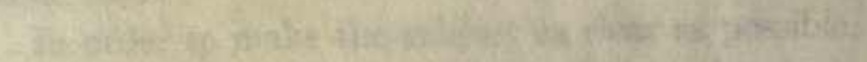

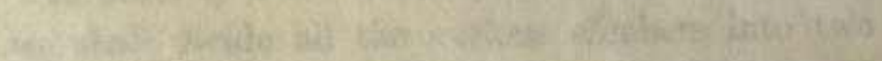

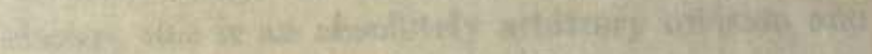

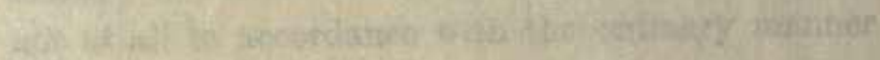

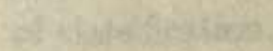

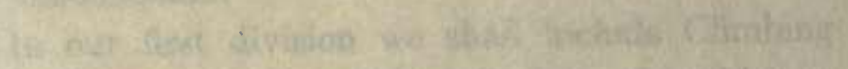

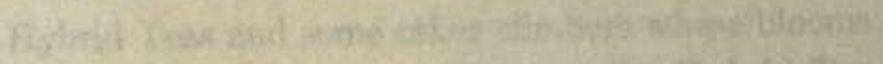

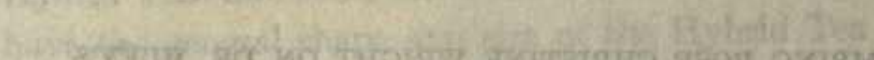

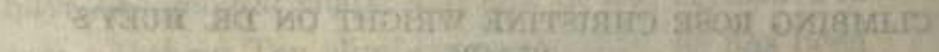

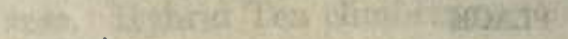

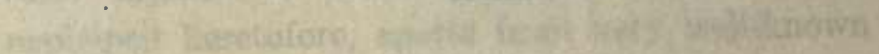

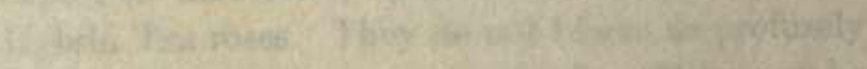

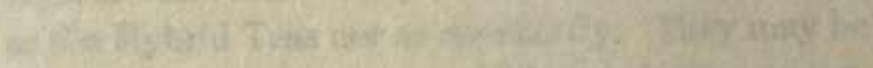

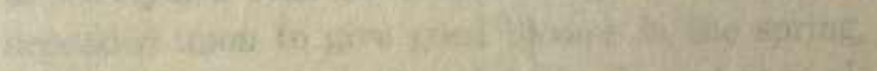

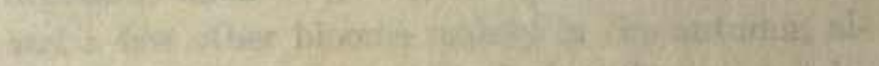

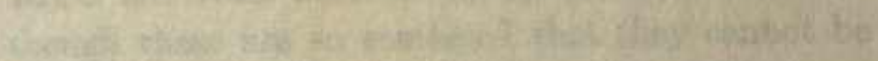

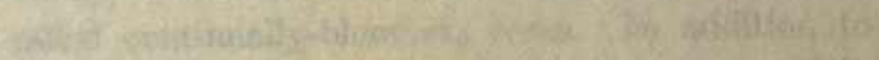

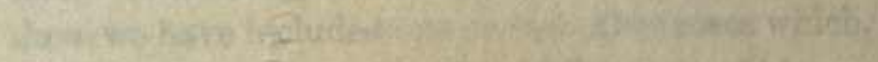

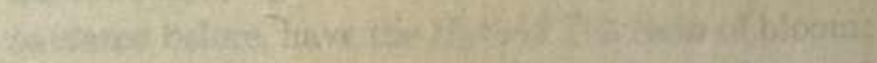

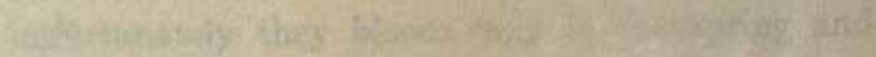

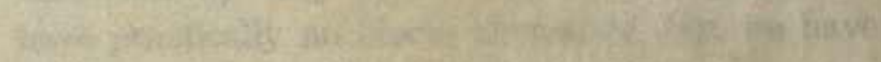

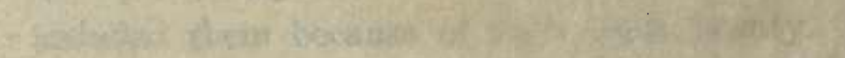

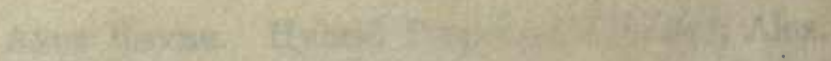

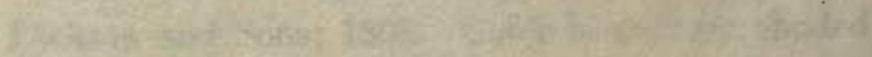




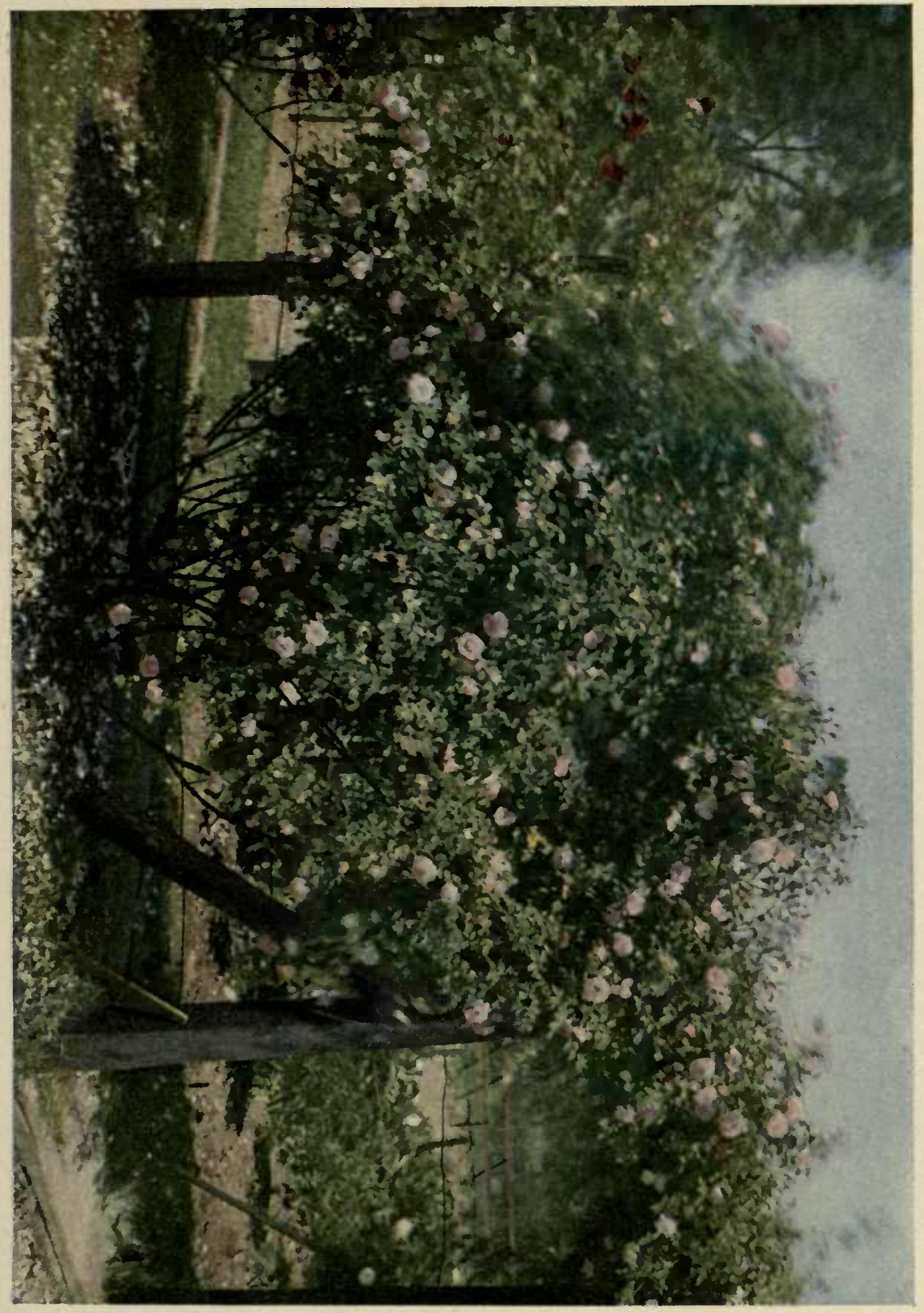





\section{CLIMBERS}

maroon; medium size, good form; blooms in the spring only; flowers come on short stems; has a fair petallage and is very fragrant. A hardy rose but in the North it is advocated that the canes should be given winter protection.

Christine Wright. Hoopes Bros. and Thomas; 1903. Cross between Caroline Testout and a Wichuraiana seedling. Placed with Hybrid Tea climbers on account of the fact that its flowers are large and fairly double though borne in clusters; good form, with a perfect bud and good petallage; color is wild rose pink; requires no protection; blooms best in spring. A few scattering flowers in autumn.

Climbing Kaiserin Augusta Victoria. Hybrid Tea; Alexander Dickson and Sons; 1897. Primrose of same form and color as the dwarf rose of the same name; very beautiful, but only gives scattering blooms throughout the season. Requires heavy winter protection.

Climbing Lady Ashtown. Hybrid Tea; Bradley; 1910. Salmon pink, not quite as good form as the dwarf rose of the same name; gives fair amount of bloom in spring and an occasional bloom during summer and early autumn. Requires heavy winter protection. 


\section{OUTDOOR ROSE GROWING}

Climbing Mrs. W. J. Grant. Hybrid Tea; William Paul and Son; 1899. Imperial pink; medium to large size and of good form; blooms fairly well in the spring and gives scattering blooms in the summer and autumn. Requires heavy winter protection.

Climbing Richmond. Hybrid Tea; Alex. Dickson and Sons; 1912. Pure red scarlet; bloom similar to the ordinary dwarf Richmond; of fair form only and blooming less freely in the autumn and summer than in the spring but a few blooms may be expected throughout the entire season. Requires heavy winter protection.

Dr. Van Fleet. Peter Henderson \& Co.; 1910. This is reported to be a cross between a Wichuraiana and Souv. du President Carnot, although we have no absolute data on the subject. It is a Hybrid Wichuraiana, but on account of the form of the bloom we put it with the Hybrid Tea climbers. This rose is more hardy than the Hybrid Tea climbers and is a rose of a soft flesh tint shading to a delicate peach pink; gives a bloom on somewhat longer stem than the average climber; blooms well in the spring and scattering blooms thereafter. Foliage very good.

Reine Marie Henriette. Hybrid Tea; Levet; 1878. Madame Bérard (of Gloire de Dijon) $\times$ 
CLIMBING KAISERIN AUGUSTA VICTORIA 



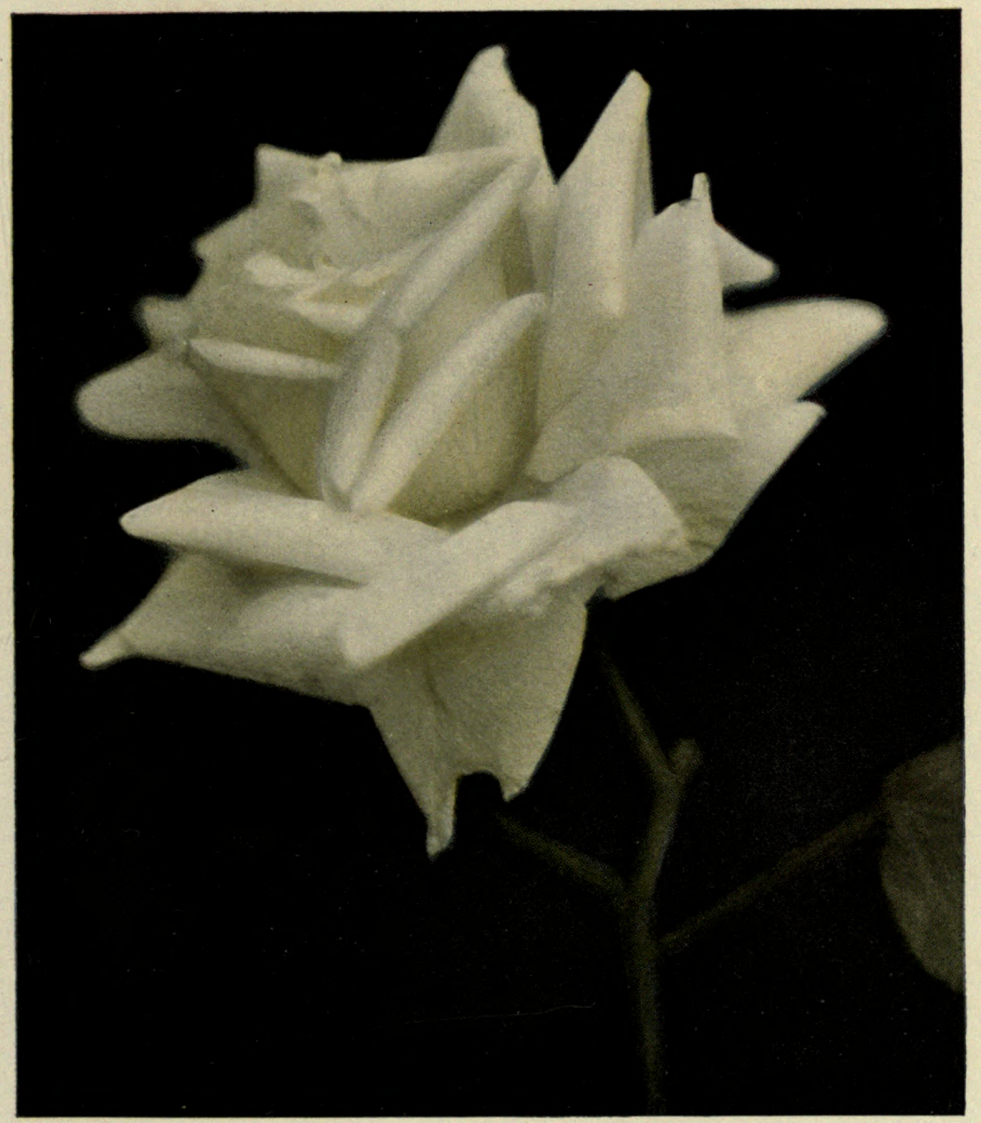





\section{CLIMBERS}

General Jacqueminot. Deep cherry red; blooms prolifically in the spring, the flowers being of good form and petallage and fragrant; later in the season it occasionally gives blooms in summer and autumn. Requires winter protection in the North only.

There are quite a number of the Hybrid Tea climbing sports, but those given above represent the main shades. There is very little to choose between any of them. They are all of approximately the same habit, growth, and blooming qualities.

Unfortunately there are no yellow climbing $\mathrm{Hy}$ brid Teas which we can recommend. Madame Hector Leuillot is a yellow climbing Hybrid Tea but its canes winter kill, and although the plant lives we consider it a collector's rose and have so placed it in the main list.

In our second division we have placed all the other climbing or rambling roses which have given us the best results, most of them being Hybrid Wichuraiana. Except where noted they are absolutely hardy and of much more vigorous growth than the Hybrid Tea climbers, though as a rule they only bloom for a short season in the early summer and a few have some autumn or summer flowers. With these we have also included the best of the many other varieties of climbers 


\section{OUTDOOR ROSE GROWING}

which have given us very good results, and one of these-climbing Cecile Brunner-we have found to to be the most constant bloomer we have tried.

Cecile Brunner. Polyantha Hybrid; sprays; beautifully formed, small. This rose, if secured in three-year-old plants and given heavy winter protection, has proved in our experience the best bloomer among climbing roses. It is not as vigorous a climber as the Wichuraianas, but makes good growth of eight- to ten-foot canes, on which its miniature, perfectly-formed flowers appear in sprays. The color is flesh cream with a shell pink center. It must not be confounded with the ordinary Cecile Brunner, which is a dwarf Polyantha. We have never seen this rose catalogued excepting by The Conrad \& Jones Company, West Grove, Pa. On account of its blooming qualities it is our own favorite climbing variety, as it may be expected to bloom splendidly in the spring, quite well in summer, and also in autumn. There are a few other climbing Polyanthas already catalogued, and several new roses of this class have been introduced during the present year.

Dorothy Dennison. Hybrid Wichuraiana; Dennison; 1909. Trusses, very light pink; sport of Dorothy Perkins. 


\section{CLIMBERS}

Dorothy Perkins. Hybrid Wichuraiana; Perkins; 1902. Trusses, single, light pink.

Eliza Robichon. Hybrid Wichuraiana; Barbier; 1901. Trusses, single; rose, shaded old gold.

Evangeline. Hybrid Wichuraiana. Walsh; 1907. Single, white, tips of petals carmine pink.

Excelsa. Hybrid Wichuraiana. Walsh; 1909. Trusses, double, brilliant scarlet. Crimson Rambler with good foliage.

Gardenia. Hybrid Wichuraiana. Manda; 1899. Clusters, bright yellow, paler as flowers expand; very pretty in bud form. Foliage very good. This rose can be secured from Henry A. Dreer, Philadelphia, Pa. Do not confound it with Gardenia of Soupert \& Notting, which is inferior with us.

Hiawatha. Hybrid Wichuraiana. Walsh; 1905. Single, crimson, center pure white to cream.

Whiте Dorothy. Hybrid Wichuraiana. Paul \& Son, and B. R. Cant \& Sons; 1908. White; sport of Dorothy Perkins.

In addition to the above well-tried climbers there are three listed in the catalogue of M. H. Walsh, Woods Hole, Mass., which appeal to us. We have not tried them as yet, but from the descriptions they are unique or late bloomers. They are all seedling 


\section{OUTDOOR ROSE GROWING}

Hybrid Wichuraianas introduced by Walsh and the descriptions are his.

Coquina. "Shell pink; base of petals creamy white; produces blooms in September."

Debutante. "Soft pink. Blooms freely in July and in September and October."

\section{La Framma. "Flame-colored."}

It must be remembered that in Massachusetts the season is shorter and starts later than with us and that a rose may bloom there in September which farther south ends its season in August.

For climates in which there is little or no frost we are glad to recommend the following climbers. With the exception of Shower of Gold, which is a Hybrid Wichuraiana, they may be expected to give blooms quite well through the season.

Céline Forestier (Noisette). Trouillard; 1842. Fairly free flowering; old gold.

Clotн of Gold (Noisette). Coquereau; 1843. Sulphur yellow, deeper center; large double.

Glotre de DiJon (Tea). Jacotot; 1853. Buff, orange center; large and double. Perhaps the hardiest of the Tea climbers.

Marechal Nrel (Noisette). Pradel; 1864. Bright rich golden yellow; large, full, fine form. 


\section{CLIMBERS}

Madame Alfred Carriere (Hybrid Noisette). Schwartz; 1879. Pure white, very free; a good pillar rose.

W. A. Richardson (Noisette). Ducher; 1878. Very deep orange-yellow; small, very showy and distinct.

Shower of GoLd. Hybrid Wichuraiana. Paul and Son; 1910. Light cream to pale yellow; spring only; foliage fair.

In addition to these there are quite a number of Climbing Teas and Noisettes.

\section{PLANTING CLIMBERS}

In planting climbers the bed should be prepared in exactly the same way as for an ordinary bed, excepting that it should be much smaller, but the roots of the climbers will naturally take up more space underground than the roots of the dwarf bushes, and climbers should have a bed of some extent. This is particularly necessary for the Hybrid Tea Climbers; Wichuraianas are so hardy that they will do very well if given even a fair start. The bed should be made of the same depth and drained as the average rose bed noted under "Preparation." For each plant the bed should be about two feet wide and not less than four feet in length.

In planting climbers, especially the Hybrid Teas, 


\section{OUTDOOR ROSE GROWING}

it is hardly necessary to say that they will not do well on the north side of any arbor or wall. Roses must have the sun in order to flourish and, besides, many climbers on a north wall would be winter killed to a very great degree. It would be easy in the case of all rustic benches, with rustic tops and arbors running east and west, to plant roses on their southern, eastern and western sides and secure plants which would entirely cover the structures. For an ordinary six-foot bench with a rustic top the same length, one good climbing rose planted on the southern side would be sufficient to cover the entire structure. The very hardiest of the Wichuraianas would make a brave effort to do well on a north wall, but unless this is the only available space we would not advise its use. There is one exception to north wall planting, as explained later.

\section{PRUNING CLIMBERS}

Wichuraiana Climbers. About the last of July or the first of August, when the blooming season is over, it is well to cut out some of the oldest canes; this gives new wood a better opportunity to develop and it becomes the flowering wood of the following season. The older wood on Wichuraiana blooms to some extent but not as well as the growth of the previous year. After this August pruning it 
AVIATEUR BLERIOT 


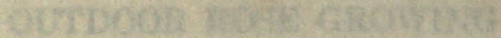

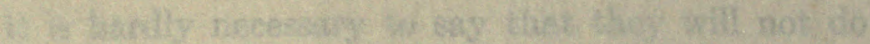

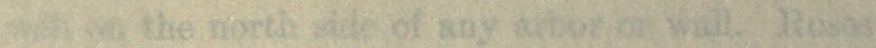

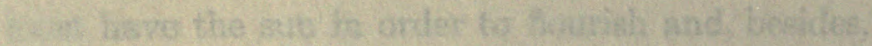

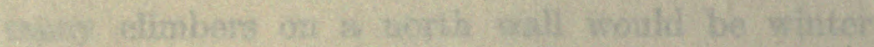

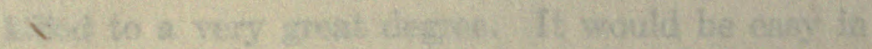

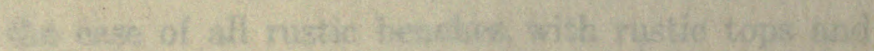

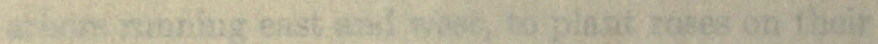

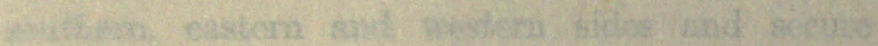

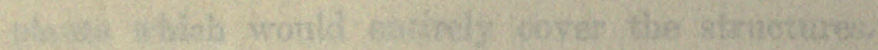

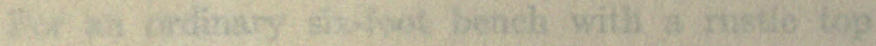

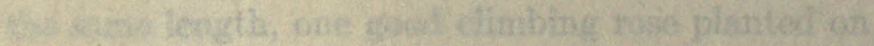

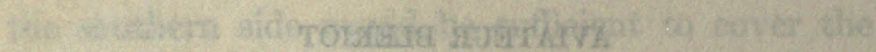

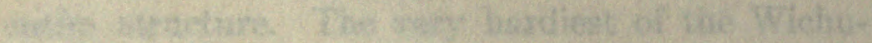

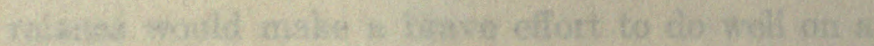

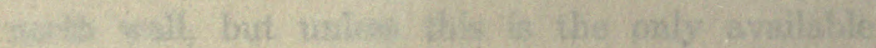

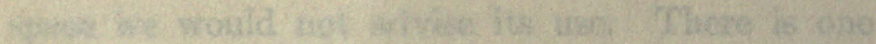

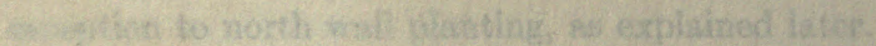

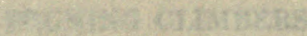

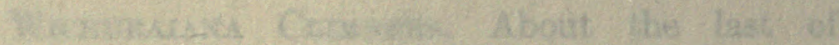

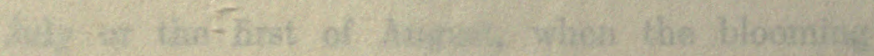

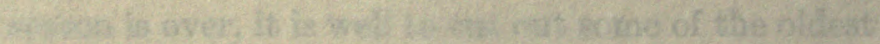

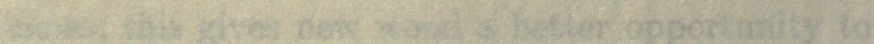

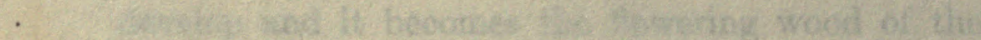

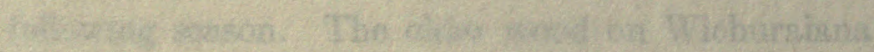

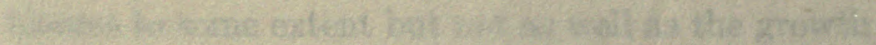

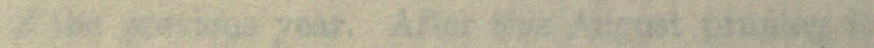




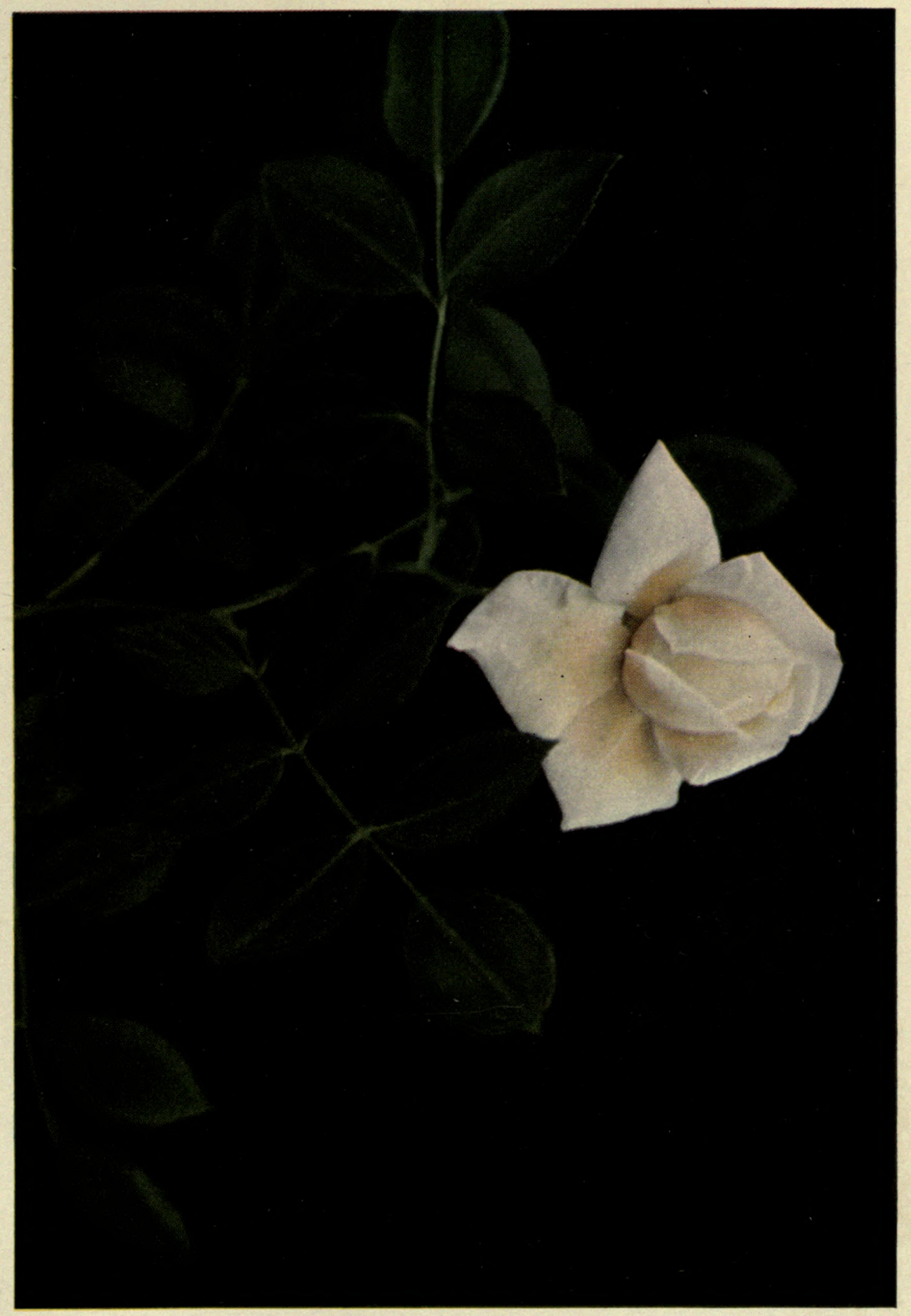





\section{CLIMBERS}

will hardly be necessary in the following spring to do more than cut out the dead wood and keep the plant within the prescribed bounds, which may be determined by the arbor or trellis on which it is grown. The new canes springing from the base which have grown during the previous season should remain untouched, excepting that the ends or tops of the longest canes should be somewhat shortened. The same process used in pruning recently planted Hybrid Teas applies in the case of newly-planted Wichuraiana, and especially weakergrowing climbers planted the previous autumn, viz., pruning back "wickedly" in the spring to a few eyes. This gives the roots less work to do and insures good growth for the following year. It gives no chance for flowers during the first summer, but at best the blooms on a newly-planted climber would be poor; the great point is that such cutting back gives the plant a better chance to become established and secures good flowering wood the second year and thereafter. But, if you insist upon trying for some flowers the first summer on newly-planted stock, be sure that such climbers as you do not cut back have well-established root systems with fibrous feeding roots and that they were planted the previous autumn, their root systems having been noted at that time.

Under no circumstances should we advise allow- 


\section{OUTDOOR ROSE GROWING}

ing the canes to remain uncut on any imported climbers of winter or early spring planting, and we cannot recommend the course above suggested, though if it succeed with any variety it should do so with the Wichuraiana. With two- and three-yearold dormant American field-grown plants of Wichuraiana or its strong growing hybrids there is an even chance of success. Most certainly it would be well to give such plants special care, for example, the use of liquid manure as suggested in "Cultivation."

It is not necessary except in the extreme North to give winter protection to the canes of Wichuraiana; however, if you find that they die back, bend them down to the ground in the future and cover with earth before the severe frosts set in.

In "Roses and Rose Growing,"* Miss Kingsley suggests for special effect cutting out all the old wood on Wichuraiana and training the pliant, new canes over wire frames in the shape of arches. Undoubtedly very pretty effects could be obtained by this method. She also states that the Banksias, some of the Multifloras such as Crimson Rambler, and one Noisette, Fortune's Yellow, "only flower on the sub-laterals, i.e., on wood three years old." We knew that Crimson Rambler needed practically

\footnotetext{
* "Roses and Rose Growing," by Rose G. Kingsley (The Macmillan Co.).
} 


\section{CLIMBERS}

only thinning, but were ignorant of the interesting fact regarding the sub-laterals. It will be readily understood how easily the above-named climbers could be spoiled by unintelligent pruning.

Hybrid Tea and Hybrid Perpetual Climbers (other than sports) and Polyantha Climbers should be treated on somewhat the same principle as the Wichuraiana Climbers. The difference is that their wood winter kills more easily, and therefore no thinning out of old canes should be done before spring, and then only when such canes crowd the new growths. The laterals on the main canes should be cut back to from two to four eyes.

Climbing Sports of dwarf roses, Tea Climbers and Noisettes should be pruned more sparingly. Old canes should only be removed as they become profitless, laterals but slightly shortened unless they are crowded. In the case of all climbers better results will be obtained if they are carefully and systematically trained and fastened in place. Most Hybrid Tea Climbers, Noisettes, and all the Teas need winter protection, as above described.

For all climbers, on account of the greater evaporation due to their larger growth, much more water is necessary than for dwarfs.

We strongly recommend for them the peat moss mulch, noted later. 


\section{IV}

\section{LOCATION AND PREPARATION}

Every one cannot have an ideal location for roses, yet given enough sunlight it is astonishing what fine results may be obtained in a small bed bordering on a path or road should no lawn space be available. Too much shade will not give good results and the roots of trees are very detrimental to rose growth. Unless the trees overhang the beds, if you believe your plants will get direct sunlight at least half the day - there being no other place available-the chances are that your bed will succeed, but you must protect the rose roots from the roots of the trees. As a general rule a tree sends out roots in a circumference the radius of which equals its height, but the roots near the outer edge of the circumference are small and can be cut without injury to the tree; nevertheless where tree roots once grew they will come back again, and it is imperative that the roses be protected from them. The simplest and cheapest way is to line the outside of your rose bed with boards, but as these rot it is only a question of time before the tree roots will again 


\section{LOCATION AND PREPARATION}

force their way into the space reserved for the roses, so the boards must be renewed. The best way is to put in a small wall of concrete four inches in thickness, which will protect your bed for all time from this interference of tree roots.

Providing your roses get at least half a day's sunlight and the tree roots do not interfere, the bed can be successfully made as above proposed. The ideal location is a south to southeast exposure, especially with a windbreak on the north and northwest sides from which the coldest winter winds come. Windbreaks may be in the form of trees, houses, or anything which will stop the direct force of the cold, bleak winds. Roses will do well even on a north slope if they get the sun and are properly cared for. Worse than a north slope is low land, which is not and cannot be easily drained, and where roses will get more late frost than they will on the exposed hillside.

Having looked over your ground and selected, in accordance with the general working directions given above, the most suitable place for your roses, consider next the shape of the bed, the extent of space to be given to it and the number of plants it will accommodate. Unless formal or landscape gardening is desired the most practical form of bed for roses is one three feet wide (the proper width 


\section{OUTDOOR ROSE GROWING}

for two rows of plants), and long enough to accommodate the number of plants desired when they are spaced at an average distance of eighteen inches, center to center. Some of the weaker growing roses will do better if set only twelve inches apart, while the stronger growing varieties should be placed as far apart as three feet; but for a working rule, unless you expect to order only the very largest roses, an allowance of eighteen inches each will be found to give roughly the number of plants which your bed will hold.*

Having decided on the number of plants which you want before proceeding with the actual ordering of the varieties, instructions for which will be found in the following chapter, consider what steps are necessary to make the beds properly and have them in absolute readiness for the arrival of the plants. They should be made some weeks before planting to allow for settling and if they should have settled too much below the ground level additional soil may be added, although to conserve moisture the actual finished level of the bed should be from one-half to one inch below the surface of the adjacent ground.

* "Pictorial Practical Rose Growing," by Wright, gives four very clever sketches for formal rose gardens. "Gardens for Small Country Houses," by Gertrude Jekyll and Lawrence Weaver, would be a great help to any one desiring to do more than lay out a few beds. 
ROSES ON DR. HUEY'S PLACE 


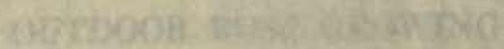

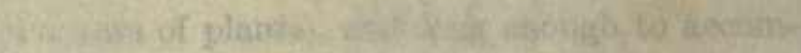

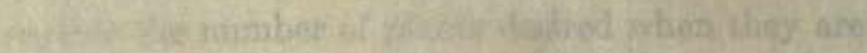

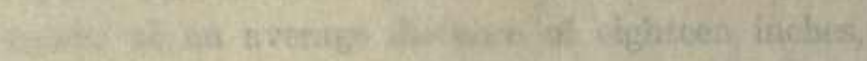

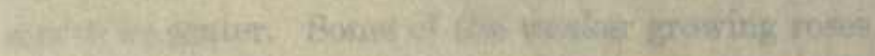

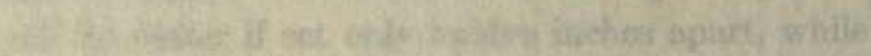

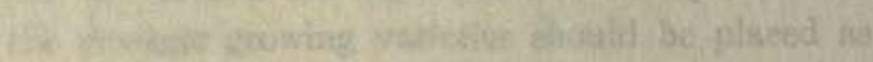

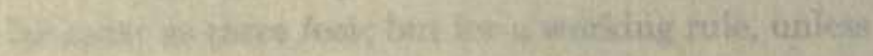

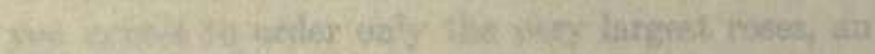

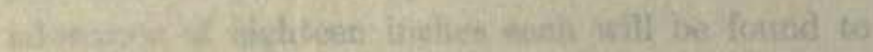

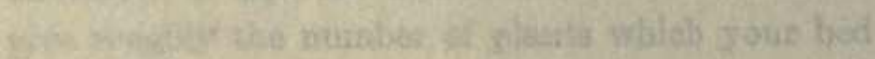

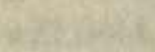

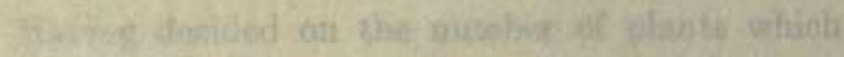

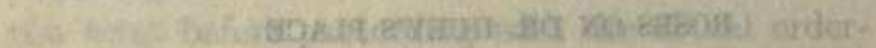

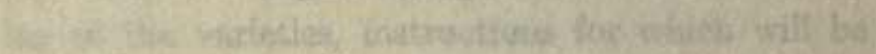

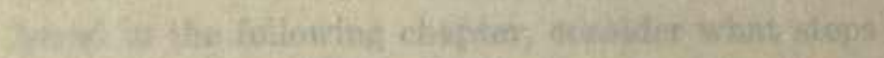

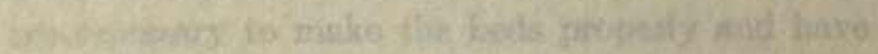

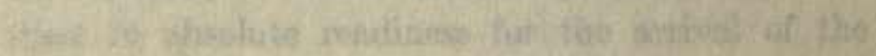

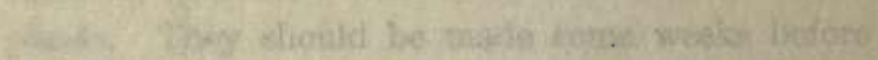

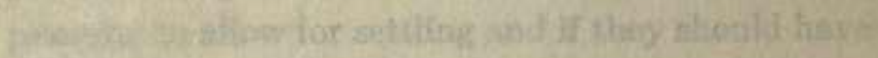

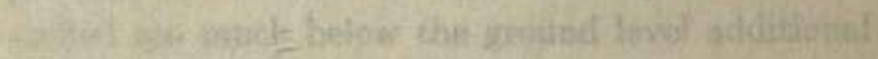

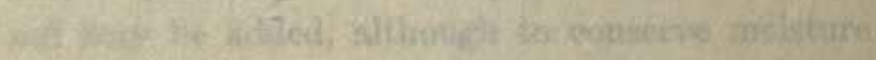

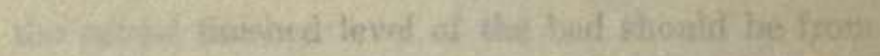

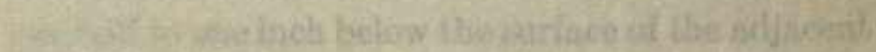
$y^{2} x^{2}+x^{3}$

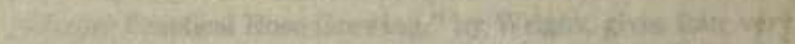

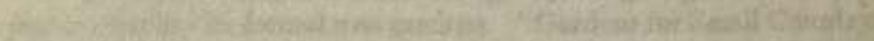

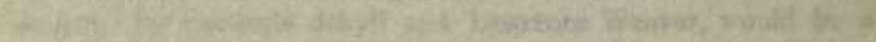

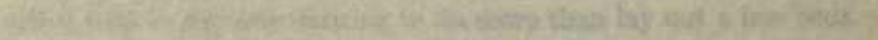




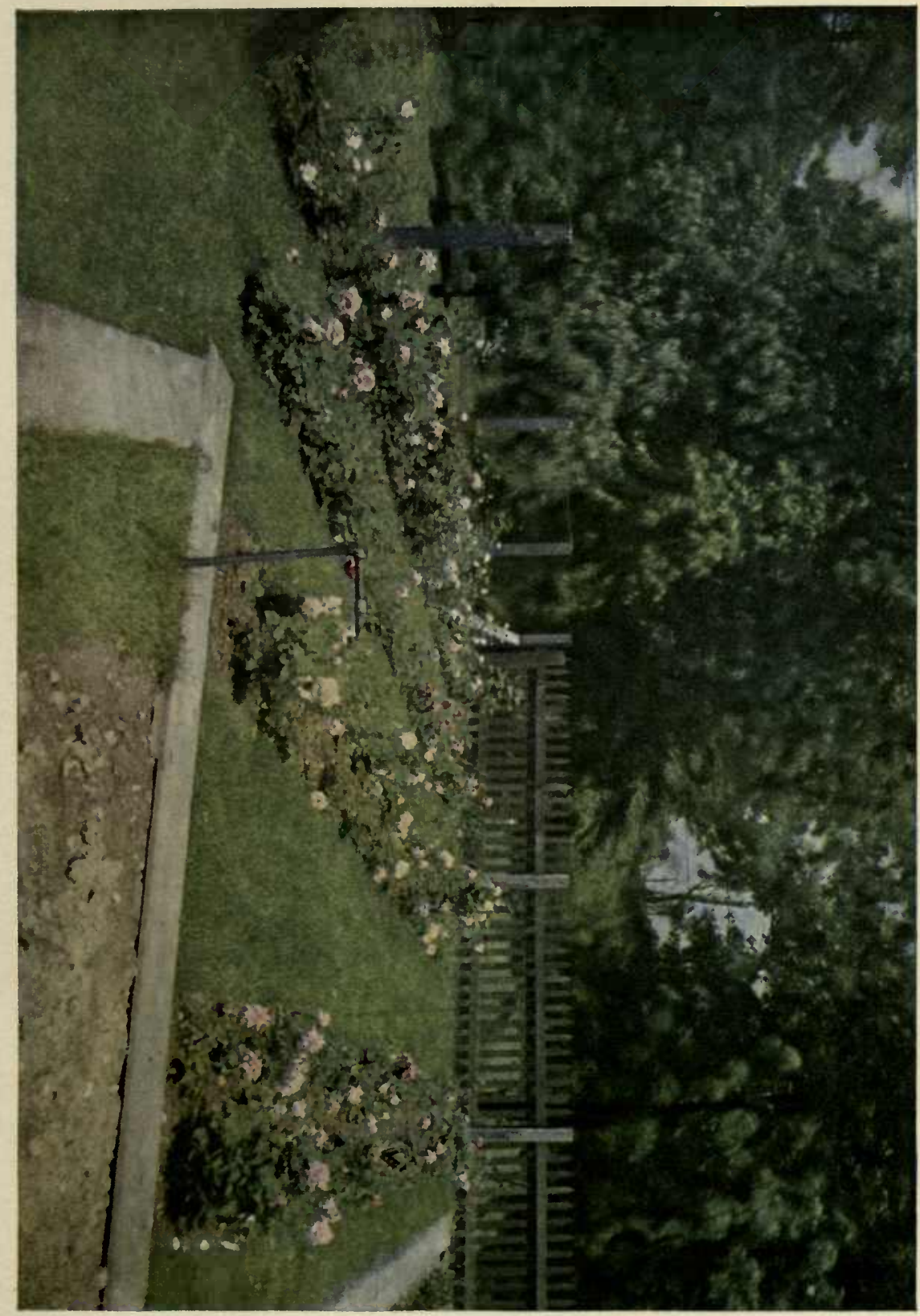





\section{LOCATION AND PREPARATION}

The matter of soil, or of the best composition of soil, for the rose bed is a very interesting one, and when a person wishes to go into rose growing on a large scale beds should be constructed for each particular kind of rose.

Pemberton goes most thoroughly into this subject of soils; any one contemplating the planting of several hundred roses will do well to study his chapter on soils. He advocates for roses, where autumn blooms are desired, from forty to seventy per cent. of clay in the bed, and this statement of his has been borne out by our experiments with different soils.

The most complete and technical book on this subject which we have found is: "Soils," Lyon and Fippin; L. H. Bailey, editor.

A rule which seems to be endorsed by all rosarians is that Hybrid Perpetuals and the stronger Hybrid Teas do better in clay, and the weaker Hybrid Teas and Teas are more certain to thrive in soil containing some sand.

At the present time, Mr. Frederick W. Taylor, of Philadelphia, is conducting a great many interesting and exhaustive experiments with different kinds of soils, particularly in relation to the growing of grass but to some extent in testing roses. Some of his beds have been made up in most complicated and expensive ways, and while good results have been 


\section{OUTDOOR ROSE GROWING}

secured, nevertheless, from careful comparison between his roses and those in our ordinary beds, we cannot see enough advantage gained to warrant our recommending his beds for general use, primarily on account of the expense and trouble involved in their construction. No doubt Mr. Taylor will eventually discover the best beds for each given type of rose, changes in the beds being made in accordance with the different habits of growth of the plants. If these new beds are to be brought before the rosegrowing public, most certainly they should have the advantage of being explained by their originator and not by us. It is our opinion that for the average rose lover who wants to grow his few dozen plants, such experiments, while interesting, would not as yet be practical and would certainly be very expensive. It is far better to order the best roses as carefully tested in the regular beds, and to construct beds from which good all-round and practical results may be obtained at a moderate cost. There is, however, one new feature of Mr. Taylor's experiments which seems very practical and useful and is so simple that we take great pleasure (with his permission) in recommending it for rose beds, i.e., the covering of the bed in the spring with a blanket of peat moss. This is a non-conductor of heat and cold, and will not only keep the moisture in the ground by pro- 


\section{LOCATION AND PREPARATION}

tecting it from the sun's absorbing rays but also greatly reduce the actual temperature of the bed.

In July and August the ground temperature of beds covered with this mulch is from five to six degrees lower than adjacent beds. Later, when the average ground temperature is below seventy, there is little if any difference. In addition to this it prevents some seeds of weeds from germinating, so that this cover practically eliminates constant weeding. It also gives the beds a neat and most attractive appearance. The best time to put on this peat moss is as yet an undecided point, but we are inclined to recommend placing the moss on the beds after the frost is well out of the ground and before the days become very warm. Undoubtedly after this year, in which we shall try covering different beds at different times, this new operation will be better understood.

This peat moss may be secured from any nursery, and it should be ground fine by a machine, then sprinkled with water before it is placed on the beds, to keep it from blowing about. By putting on a sixinch blanket you will secure the depth required of from three to four inches.

In order to avoid breaking the rose canes the safest way to pack the moss properly into place is to trample on it carefully. It will be found that the 


\section{OUTDOOR ROSE GROWING}

roses so covered will give bloom about as early as plants left unprotected by moss, and during the hottest weather the covered plants will thrive to a greater degree while the moss renders watering less necessary, and thereby somewhat prevents the likelihood of mildew.

The beds we have tested with and without moss show that the covered plants bloom only one day later, but hold the bloom much longer.

In some of our beds we are putting a four-inch layer of peat moss at each side of the bed and at the ends, which should still further act in keeping the temperature low. We do not think this necessary, but in districts where dry, hot weather of long duration occurs, and in seashore planting, where soil must be imported, and where the existing, extremely sandy soil surrounding the rose bed becomes very hot, such side protection should be of great benefit. The moss should go from the surface to the bottom of the bed and make a four-inch wall between the bed and the hotter ground around it. Where cement or boards have been used to keep out tree roots, this side protection is, of course, unnecessary.

Peat moss is worth about fourteen dollars a ton by the carload and one ton will cover over one hundred yards of rose beds, averaging three and one- 


\section{LOCATION AND PREPARATION}

half feet in width, the finished level of the moss being over three inches; in other words, two hundred pounds, at a cost of less than two dollars, would protect ten yards of rose bed, or about forty plants. The hundred-pound price is a little more expensive than the carload rate.

To return to the composition of the bed itself. We have found that there are two most important things necessary to insure success: first, the bed must underdrain, to get rid of any great surplus of water, so that in very damp seasons the rose roots will not be too wet; second, the bed must, on the other hand, retain moisture to a certain extent so that in very dry seasons the roots will not be too dry. To obtain the drainage it is necessary in soil which is greatly composed of clay to underdrain the beds by a layer of crushed stone; where the soil is more open, gravelly or sandy, this is not needed. The bed should be made two and one-half feet in depth if underdrainage is necessary, with about six inches of crushed or broken stone put in the bottom; small crushed stone lies evenly, and the earth does not sift through it enough to clog the drainage. Large or uneven stone should be covered by something to keep the earth from sifting through. If the bed is made in a lawn the turf cut from the surface and turned upside down is a good expedient, 


\section{OUTDOOR ROSE GROWING}

or a couple of inches of fine cinders will be found all that is required. Fine stone is really the best. Of course, for a location which is gravelly or sandy, this stone will not be needed and a depth of two feet will be sufficient.

We will now consider that we have dug a trench, the bottom either covered or not covered with stone to the depth of six inches, as the case may be, but which is now two feet deep from the ground level. It should be noted that in digging this trench for the bed the top soil should be placed in one pile and the subsoil in another. The top soil is the soil on the surface, which runs to different depths, usually about six inches, and which is composed for the most part of decayed vegetation from the roots of many generations of grasses, etc. It contains a percentage of humus and is, therefore, very valuable as food to the rose roots. Usually it is darker in color than the subsoil and can easily be noted. In soils where there is a large percentage of clay or loam it will not be necessary to use subsoil other than that taken from the trench, as far as one-third of the mixture to be put back into the bed is concerned; but where soil is very gravelly or sandy it would be best to secure some heavy loam or clay to make the proper kind of bed. The finished bed should be one-third top soil, one-third heavy clay subsoil, and 


\section{LOCATION AND PREPARATION}

one-third cow manure. There will not be enough top soil taken from the trench to supply the onethird necessary for the bed, and more must be provided.

In localities where there is no heavy clay or loam there will often be found heavy, dark soil which contains decayed leaves, roots, etc., which is a very good substitute. Subsoil containing sand in any quantity should have loam and clay added and top soil containing much sand should have other top soil added. Reverting to what we have said before, and so as to make our objects perfectly clear, it will be remembered that the soil should be heavy enough to hold moisture, be rich enough for sustenance, and yet must drain at the bottom, as otherwise in wet seasons the plants will be too damp.

The ideal way to mix the top soil, clay and manure in three equal parts would be by machine, but for all practical purposes we have found the following procedure to be all that is necessary: Cover the bottom of the trench with a given number of wheelbarrow loads of the rich, darker top soil, then add the same number of loads of the lighter, clayey subsoil, and then an equal number of loads of manure, after which the whole bed should be forked together thoroughly to mix the ingredients. After this first layer is thoroughly mixed, proceed as above with the 


\section{OUTDOOR ROSE GROWING}

wheelbarrow loads of each ingredient and mix again. After each mixing the bed should be thoroughly rammed, otherwise it will settle too much after it is finished.

When making beds for autumn planting it would be well to realize that very often roses imported from the other side. are delayed. The season may be very late with the European growers, and the leaves not fall from the plants until after our heavy frosts (which may be early ones) have frozen the ground. For this reason, when the beds are made the ground conditions must be carefully watched, and if frost appears they should be covered with a heavy litter. This will usually protect the ground so that if the roses do not arrive until well into the autumn they may still be planted. We have successfully planted roses after hard freezing and six inches of snow in December, our beds having been covered with a heavy litter before the snow fell. When planting we removed snow and litter and the following year our roses did well. 


\section{V \\ ORDERING}

Having gone carefully over the chapter on "Varieties" and considered the lists of roses, the reader will be ready to order his plants. It is believed that the suggestions hereinafter given will aid in avoiding many of the errors and disappointments usually connected with this necessary work.

Ordering is indeed one of the most important features to be considered; when properly done it insures success, and when improperly done it is sure to bring disappointment and to secure what is not desired. An understanding of the conditions which beset all nurserymen would do much to help towards success. The main trouble is that the average man does not properly specify just what he wants and when he wants it, nor what he desires done if the order cannot be filled exactly with each variety ordered. He does not consider substitution.

The nurseryman receives his greatest number of orders in the spring and autumn when he and his clerks, his packers and his entire force are overworked. He has only so many varieties and only 


\section{OUTDOOR ROSE GROWING}

so many plants of each, and his roses are in a certain condition, which may or may not be good. Therefore the man who sends his order early, specifying exactly what he wants, stands the best chance of securing what he desires. Later orders, unless very specific, naturally are filled from what stock is left, not always with what was desired, and the fault does not rest with the nurseryman. If the order is properly made out and request is made for its immediate filling, and the nurseryman who receives the order advises that he is unable to ship, then the purchaser has an opportunity to place his request elsewhere; but if the order is not properly made out and does not specify regarding substitutions the shipment may not be satisfactory.

At the end of this chapter we supply a form of order blank which thoroughly covers the matter and which will greatly aid the reader.

In ordering roses the following requisites should be specified: field-grown, two-year-old stock or if possible three-year-old stock; budded stock, not grafted or own-root roses, except perhaps in case of some climbing varieties; dormant stock. In addition instructions should be given for substitutions.

Ordinarily dormant roses are much better for either spring or autumn delivery; but if roses are ordered after the growing season has started it is 


\section{ORDERING}

impossible to get dormant plants. In our opinion plants which have started growth are uncertain but with care will often do well.

If the ordering is done in the fall and the roses are so late in coming that although the beds have been covered with litter the ground is frozen hard to some depth and it is impossible to plant them, do not, under any circumstances, have them kept indoors during the winter; for they will then generally sprout and, if planted early, will be set back by the late frosts, or if kept until later will be set back on account of their change after growth has started. It would be wiser to heel the plants in the open ground; that is, dig a trench deep enough to cover the roses half-way up the canes and place the plants therein, filling in with dry earth.

As we believe that the greater number of budded roses can be properly secured from almost any large nurseryman, the nearest one would perhaps be the best from whom to order. The roses budded by Alex. Dickson \& Sons, of Ireland, whom every nurseryman knows, are as good as any foreign roses and will include most varieties. We feel, after having planted many of Dicksons' budded roses, that we can safely recommend them, though by so doing we do not wish to condemn the budded foreign roses of any other grower; we simply have not tried 


\section{OUTDOOR ROSE GROWING}

them to any great extent because we have always been satisfied with Dicksons' stock, Dr. Robert Huey having used it for over thirty years and we also having tested it for nearly fifteen.

Recently, as we have mentioned in "Propagation," there have been some American firms who have tried budding on Japanese Multiflora. We have grown some of these plants for a number of years past and have had very good success with them.

In ordering from such growers the planter has the advantage of securing stock more or less acclimated, and does not run the risk of having the heat of the steamers sprout plants directly imported; he is dealing with firms close at hand and is also aiding an American enterprise.

We, therefore, suggest that when the desired varieties may be secured, the same can be obtained from the following growers, who are budding on the Japanese Multiflora. There may be other firms unknown to us who are using this stock, but at the present time these budded plants may be secured from George H. Peterson, Fairlawn, N. J.; Henry A. Dreer, Inc., Riverton, N. J.; Bobbink \& Atkins, Rutherford, N. J. Peterson was the first to our knowledge to grow it to any extent, and while it is not mentioned in his catalogue as "Japanese Multiflora," we understand this is the stock used. 


\section{ORDERING}

The budding of roses by American firms is certainly a great advance in rose culture and of inestimable value to our rose growers. Where it is possible to secure the varieties desired, we recommend American field-grown plants, budded and grown outof-doors by any well-known firm of nurserymen.

For all large collections when American fieldgrown stock cannot be obtained, we would suggest that budded stock as grown by Alex. Dickson \& Sons, of Ireland, be ordered from the nearest nurseryman. When making inquiry or ordering we advise the use of blanks similar to those suggested by us.

Out-of-doors a few roses budded on the Multiflora do not give as perfect color as those budded on other stocks, and we believe an example of this to be the Lyon Rose. In our greenhouse the Lyon Rose on Japanese Multiflora gave splendid results, but outside the color was not always perfect; the Lyon Rose on other stocks does not succeed well in outdoor culture. This bears out the statement in . the chapter on "Propagation" that different stocks should be used for different varieties, and that the best stocks for all roses have not yet been definitely decided.

We particularly wish the reader to understand that the care which we have used in going into the 


\section{OUTDOOR ROSE GROWING}

matter of ordering and our remarks pertaining thereto are not meant in any way to reflect upon nurserymen, through many of whom we have received orders properly filled, and with whom our relations have been most pleasant. On the contrary, we show the purchaser the conditions under which the nurserymen labor and point out a practical way in which ordering may be done, so that there will be no disappointments to the purchaser, and that pleasant relations will be maintained between him and the grower or importer. We believe this explanation of conditions will help the nurseryman as well as the purchaser, for we are of the opinion that the errors which occur are generally the fault of the man who orders.

In closing, we wish to add a few words regarding the different times of the year in which planting may be done. The temperature of the ground is as important as the time of year, and the condition in which the plant is received has more to do with future success than either. Unless the growing season has begun and is well under way plants must be received in a dormant condition. We ourselves have planted roses at all times of the year and have found that if the plants were in proper condition and properly handled they have nearly always done well; if plants were not in proper condition, no 


\section{ORDERING}

matter how much care was used, failure practically always resulted unless plants received greenhouse care.

The advantage of planting roses in the autumn is that if they are dormant, i.e., if growth has stopped for the year prior to their shipment, and if they have not been subjected to heat during shipment causing growth to recommence, they will when planted become more or less fixed in their position, and little fibrous roots will have in most instances commenced growth before spring. Roses so planted and which have become so established will start off well in the spring, much better than a rose which has only been in the ground a short time.

Our advice to all planters with whom the expense of replacing dead plants is not of much moment is this: From October to May plant your roses as soon as you have decided that you want them. Undoubtedly, you will lose some if you plant after the growing season has begun; perhaps if you plant the last of the winter you will not secure as good roses as if you set out perfectly dormant plants in the late autumn, but no doubt a great many of them will come through and be better plants the following year than if you had waited, say from the early spring to the following autumn. In addition to this there is the pleasure of having the roses. 


\section{OUTDOOR ROSE GROWING}

\section{SUGGESTED FORMS FOR INQUIRY AND ORDER BLANKS}

Can you supply in two- or three-year-old dormant field-grown, budded plants the following roses:

(LIST OF ROSES)

In the event of not having all the above varieties, what plants can you substitute which comply with the above requirements?

On what date can you ship?......... Kindly answer at once, using enclosed addressed and stamped envelope....... If answer is to hand by............... I will, if satisfactory, at once place order; otherwise I will not consider same.

This is an inquiry-NOT an order

Note: In ordering climbing varieties other than Hybrid Teas leave out the word "budded." 


\section{ORDERING}

When a satisfactory reply is received the order should be placed and the following form is suggested:

Please place my order for the following roses, as per my inquiry of .......... (date) and your reply of ............. (date)

\section{(LIST OF ROSES)}

I understand that the above-named roses are two- or three-year-old dormant fieldgrown, budded plants; that there are to be no substitutions; that they are to be shipped me on.... (date)

(LIST OF CLIMBERS)

I understand that the climbers are ownroot plants, otherwise they are as above specified. 


\section{VI \\ PLANTING}

LET us suppose that your beds are ready, your shipment has been ordered, and on one eventful morning it has arrived. You naturally take great pains to unpack carefully and to see that the varieties received check off properly with the order given. Sometimes one or more mistakes may be made in a large shipment, but as a usual thing great eare has been exercised both in the selection and packing of your order, and it should arrive in good shape and the varieties should be as ordered. Very often the nurseryman will add a plant or two for good measure. The plants should be unpacked inside some building, unless perfect weather conditions prevail, viz., a damp, moist day-neither cold nor hot. After having been checked off, the plants should be carefully covered so that the roots will neither be frozen nor dried out by too much wind or heat. Usually the roses come packed in moss which should be left on them. If there is no moss, cover the roots with damp earth, and when taken outside keep them protected with any kind of wrapping, such as burlap or gunny sacks; or, better still, keep them in buckets or tubs of water, 


\section{PLANTTNG}

except in freezing weather, when you should not plant. This is most important so that the roots may be placed in the ground in proper condition. Before taking the roses to their beds you should have made a small plan of just how you propose to plant them; if for a formal or landscape effect this has no doubt been all arranged beforehand to suit your taste. If, however, you are merely planting them in the ordinary form of bed it is a very simple matter to have your bed arranged for their reception.

You know what roses are coming, you have the distance apart in which they should be planted (covered in our main list), and you should decide on the order in which you wish to place them. Personally we prefer planting roses in alphabetical order, as we find that nature's colors never conflict and that it is the easiest way of telling where any particular rose is located.

Your bed should be three feet wide for Hybrid Teas and Teas. For Hybrid Perpetuals and very strong growers four feet is better. You plant your roses ten inches from the edge of the bed and eighteen inches apart, and you do not plant them exactly opposite to one another; in other words, you "stagger" them. You have two rows of plants, each row ten inches from the side of the bed. With one row you plant the first rose nine inches from the 101 


\section{OUTDOOR ROSE GROWING}

end of the bed; with the other row you plant the first rose eighteen inches from the same end of the bed. This does not bring the plants opposite one another and gives them a trifle more room in which to grow, making them eighteen inches apart each way. For our own beds we make a drawing, as indicated by sketch below, which we find very easy to correct from time to time if a rose dies or is taken out for any reason and another substituted. Suppose, for example, you have decided to put in four roses each of the following: Antoine Revoire, Duchess of Wellington, General MacArthur, Killarney, and two each of Souv. du President Carnot and Joseph Hill.

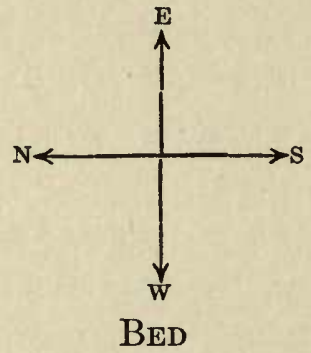

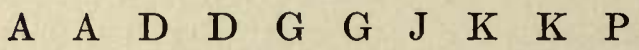

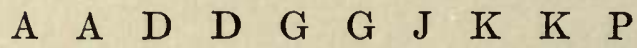

Name Introducer Date Color Notes

A-Antoine Revoire..........................

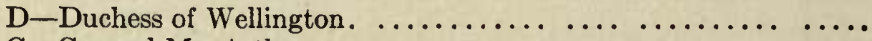

G-General MacArthur.... $\ldots \ldots \ldots \ldots \ldots \ldots \ldots$

J-Joseph Hill.......... $\ldots \ldots \ldots \ldots \ldots \ldots$

$\mathrm{K}$-Killarney $\ldots \ldots \ldots \ldots \ldots \ldots \ldots \ldots \ldots \ldots \ldots \ldots \ldots \ldots$

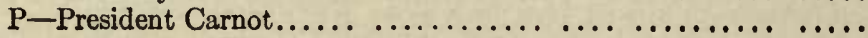




\section{PLANTING}

It is well to make a compass drawing as outlined so that there may be no question as to which end of the bed you refer.

This plan of procedure is suggested because labels are a delusion and a snare, do not last, and also become misplaced through various causes, so that while we keep labels in our beds we depend absolutely upon our written plan for positive information as to what each rose is, its location, etc. It is but the matter of a few moments to make this record and the time so occupied will well repay you.

Having run two lines ten inches from each side of the bed, and from one end to the other, you can then space off the proper point at which each rose is to be planted by a stake, which can be measured with ordinary rule or line. In the case of the roses which we have given you will note that they are to be placed eighteen inches apart, with the exception of Joseph Hill, President Carnot, and Antoine Revoire, which are to be placed twelve and fifteen inches apart. Before starting work put on an old pair of gloves; you will need them to protect your hands from the thorns. Bring out but a few roses at a time, and, in order to avoid any possible mixing of the plants, we would suggest that each variety be kept absolutely separate and be planted at one time before the next kind is placed in the bed. 


\section{OUTDOOR ROSE GROWING}

Sometimes rose roots are injured in the shipment, in which case it will be necessary to cut off the broken ends. A good pair of pruning shears and a sharp knife are the two best implements for this work. Cuts should be sharp and clean and the roots should be cut off above the break. It will only take a minute to examine each plant before it is actually set and to cut off broken roots and any suckers in which growth may have started.

The thing to be most carefully considered, and most important in planting roses, is to dig a hole about eighteen inches deep, the center of which is approximately the center of the mark for the rose. The earth should be taken out with a spade from this hole and, before finally placing the earth in it, two things should be carefully noted: that the roots spread out at the bottom and do not cross one another. The more you spread out your roots the more sustenance the plant will get, and the more room there will be for the little fibrous roots. It is particularly difficult to spread out the roots of potgrown plants, as they become curled in the pots; and this is one reason why pot-grown plants are not recommended. The other important point is that the bud, i.e., the point at which the variety has been budded to the stock, which you will easily note, should be at a certain given distance below 


\section{PLANTING}

the ground level. On these two factors depend the size of your excavation. The bud should be not less than two inches and not more than three inches below the finished level of the bed. This seems like getting down to very exact planting, but if the bud is higher it is not sufficiently protected in winter, and the rose does not do as well if it is planted lower.

The hole being properly dug, place your rose in it, carefully spreading out the roots so that they do not cross or touch one another at any point. This will take some time and care, but it is of the greatest importance to the future growth of the rose that it be properly done. Two persons can do the work much better than one. In our own planting we always have a small bucket containing top soil and bone meal finely powdered in equal parts which we lightly sprinkle at the bottom of the hole and also on the roots; we have found this to be very helpful to their growth, because it precludes the possibility of any manure touching the roots (manure which is too fresh and not well rotted will burn them) and promotes the growth of the very much to be desired fibrous feeding roots. After this preparation is put in, we have our helper shovel in the soil carefully, a little at a time, to fill up the hole. As he puts it in, we tamp it firmly with a stick, and, 


\section{OUTDOOR ROSE GROWING}

as the hole gradually fills, we take particular care that there is no space left just underneath the main root of the plant, for air space is most detrimental to the growth of the rose. Having filled up the hole to the ground level of the bed, we consider the rose to be planted, and proceed to the next. When the first hole is dug, remove the earth and put it beyond the stake for the last hole, then use the earth from the second hole to fill around the first plant and so on; this saves much work and insures keeping the entire bed the same level.

An easy way to get your approximate two and one-half inches below the ground for your bud is to have a lath or other straight piece of wood, in the center of which a two and one-half inch measure is nailed. This will enable you to secure an exact and proper depth for your bud. It seems as if this operation should be very simple, and it is, if the main points, as enumerated above, are carefully and absolutely carried out.

These rules are so important for the future success of your plants that we again enumerate them:

First, unpack indoors unless weather conditions are absolutely perfect.

Second, keep the roots well covered, preferably with moss if they have been packed in it, otherwise with damp earth, or coverings, or water. 


\section{PLANTING}

Third, have your bucket containing a mixture of equal parts of top soil and bone meal to place around the roots.

Fourth, take plenty of time in digging the hole to get it large enough and wide enough at the bottom to spread the roots properly.

Fifth, do not let the roots cross one another.

Sixth, plant carefully and slowly, tamping down the earth with a stick, making sure by gently raising and lowering as the earth is filled in that no air space remains below the main part of the root.

Seventh, do not place the bud more than three inches or less than two inches from the finished surface of the bed.

If it is impossible to finish your planting in any one day take particular care of the remaining roses. Keep them heeled in damp earth, or if the season is so late that you are unable to do this, keep them well covered indoors with soil. It is very easy to cover the finished beds with a heavy litter of manure and straw to keep the frost from them. If a quantity of soil is mixed and kept indoors ready for use, holes can be dug and the plants set in this soil as has been suggested in "Location and Preparation." We have used this method successfully in the very late autumn and at the end of the winter. If planting in the late autumn, it is well to protect the plants 


\section{OUTDOOR ROSE GROWING}

as much as you can. The best way to do this is to add a few wheelbarrow loads of soil to the beds after planting and make little mounds around each plant, hilling them up as it were, and then covering these with litter. If this is done the coarse litter should be removed in the early spring and the fine manure remaining should be forked carefully into the bed, as this will be a good fertilizer during the summer. In autumn planting you will generally find that rose plants have been cut back to about a foot from the ground, and if this is the case leave them as they are. If, however, they have the long, full growth they had when taken up or a large part of it, cut back to a foot and a half. 


\section{VII}

\section{PRUNING}

Pruning is one of the most important parts of rose culture; just as it is most necessary to prepare the ground properly and to plant intelligently, so also should one be certain to prune systematically. The whole growth of the plant is changed by the manner of its pruning.

Under climbing varieties we have given rules for their proper care and in this chapter we will take up that pruning which applies to all the roses contained in our main list. It is an easy matter when the theory of it is understood. Perhaps the simplest and clearest illustration which could be given would be to suppose a rose cane has fifteen buds or eyes on it; from these buds or eyes spring the shoots which afterward become the flower stalks of the plant. Now, if you did not prune at all but left the entire cane, the sustenance received from the roots would be divided into fifteen parts. As a matter of fact the greatest amount would go to the end or top of the cane and to those buds nearest the top, for in all plant life it is more difficult to get the sap to break the buds nearest the base, especially 


\section{OUTDOOR ROSE GROWING}

if there is too great a distance from that base to the top of the lateral, limb, or cane.

Roses will differ in growth and the strongest growers will naturally throw out more buds on any given length of cane than the weaker. In addition to this, plants of low spreading growth, whose canes grow more or less parallel to the ground, do not send their sap as quickly to the ends of the growth as do plants whose canes are more upright. For this reason different varieties require somewhat different pruning, and in our list we have given the number of eyes or buds to which each variety should be cut back, provided, of course, the wood has not been winter killed below the point indicated. Returning to the theory of the sap and the illustration of the cane with fifteen buds: we cut off, say, ten of these buds from the cane and the five remaining will receive just so much more sap and there will be that much more chance of the lowest buds breaking and sending out their shoots. If the cane were not cut the greater part of the sap would go to the few top buds and the lower buds would be late in growing, some possibly not breaking at all. Nature prunes the weaker varieties by killing back a portion of their wood, thus causing them to throw up strong, new canes.

It will readily be understood that the larger the 110 


\section{PRUNING}

cane and the hardier and more vigorous the plant, the more buds could be left with still a chance for their breaking; conversely, the weaker the variety and the smaller the cane the less sap would be contained therein and the fewer buds would break and grow shoots in any given length of cane. This is the main theory of pruning roses, provided that it is reasonable quality, and not quantity without much quality, that one wants.

The average rose plant in its second year should give from fifteen to fifty blooms, according to the variety, if it is cut back on this principle. Shy bloomers will not give fifteen flowers and the greater number of these will be borne in the spring.

Usually a good bloomer will have three or four flowering periods, the most profuse being in the spring and early fall. Some of our records for 1914 are as follows:

Duchess of Wellington: June, thirteen flowers; July, eight flowers; August, ten flowers; September, sixteen flowers; total forty-seven.

Madame Leon Pain: June, eleven flowers; July, six flowers; August, eight flowers; September, eight flowers; total thirty-three.

Lady Alice Stanley will give twenty-five flowers; Killarney a few more; Mock not over twenty; General MacArthur twenty-five. 


\section{OUTDOOR ROSE GROWING}

These figures are made from average plants, not selected specimens, and the late bloom is not included.

In counting blooms only those with fair stems are considered and the usual amount of disbudding done.

If you desire more blooms of poorer quality you should not prune your roses as far back as suggested below. They will also require a certain amount of thinning out after the growing season starts so that the various shoots do not crowd each other too much. Except for the strongest varieties of roses which are so pruned they should be staked, i.e., fastened to a stake driven firmly into the ground. If you so prune and stake do not use wire but tie the bushes to the stakes with soft woolen string. This latter course of pruning is usually carried out with roses of the bedding type, on which the blooms are seldom fine enough for cutting; but so treated the plants form a mass of color and are used for this reason for garden decoration.

The best and usually accepted way of pruning roses for cutting is to prune for the finest blooms. As a general working rule prune the strongest varieties to five buds or eyes, about six to ten inches, on the main strong canes, the small weaker canes being cut to three or four eyes, about six inches. You can always make your plant grow in whatever direction you wish by cutting to a bud which leads 


\section{PRUNING}

in the desired direction; e.g., in order to spread your plant, if the fifth eye is on the inside of plant, cut to the eye above it if is a large cane, for the eye above is on the outside of the plant; or if the wood is somewhat smaller and weaker than the other canes on the plant cut to the outside eye below. In this way your plant will be spread out and the shoots will not all crowd together on the inside, as would be the case if you cut to inside eyes. It is always better to cut to an outside bud; although in special cases where you wish to throw a shoot in some other desired direction cut to the bud nearest the space you wish to fill with the new growth. With weaker varieties cut to three and four eyes on the stronger-growing canes, and to two and three eyes on the very weak ones. Each of these buds left on the cane should throw up flower stalks.

In addition to this main theory, there are one or two other points which it is necessary to consider in pruning plants. They should not be too much crowded and the best way to prevent this is by cutting out the weakest growths. At first it may be somewhat difficult for one to be sure which cane should be removed, but by watching the plants after growth is started this will soon be readily understood. An absolute rule cannot be given for the number of canes to be left, but there must 


\section{OUTDOOR ROSE GROWING}

not be too much crowding, particularly in the center of the plant. All dead wood should also be removed. This can be easily detected and it should be cut back to its junction with the bud, care being taken not to injure the bark of the bud and to make a clean, sharp amputation.

Quite a number of varieties have the unfortunate habit of throwing out one or perhaps two very large growths on one side of the plant, the opposite side being correspondingly immature and weak. In such cases, in order to balance the plant, particularly for succeeding years, cut back the one or two large growths very "wickedly," one or two eyes being the proper distance. Cut out all but the best of the remaining weaker stems, and after growth has commenced do not allow the stalks on the strong canes to get beyond control. This treatment will serve to equalize the growths on such plants. In England, where the cold does not kill back the canes so far, the Hybrid Teas are pruned to a greater number of eyes. Pemberton, for example, advises leaving Caroline Testout from two to three feet, but in our climate this rose would be killed back to from four to eight inches and in the north to an even greater degree.

Pruning is usually done after the main body of frost has left the ground. Where frost does not occur the pruning should be done at the season of 


\section{PRUNING}

the year when the buds commence to break; even in climates where there is no frost roses will have a dormant season, and the time the buds begin to break will be the proper time to prune in such localities. Usually in such climates the dormant season of the rose is the time during which it does not get any water, that is, during the dry season. With the return of the rains the dormant plant commences further growth. This refers, of course, to climates in which there is practically no winter, i.e., no frost.

When the buds begin to push out on all the living wood, the operator can more readily see exactly how much wood is dead and which needs to be thinned out, and just how much wood is living on each cane; therefore this is the best time in which to prune roses in all climates.

In the spring pruning it will sometimes be found that canes of the weaker varieties have died back after a very severe winter to a smaller number of buds than above noted or given in our list, though these exceptions should be rare. If the wood has died back to any extent you will, of necessity, be forced to prune to the first good bud or eye below the winter killed portion without reference to the number of buds, even if the cane is shorter than that left by the usual system. This information is a 


\section{OUTDOOR ROSE GROWING}

general working rule. There are some few varieties which, on account of their peculiar growth, should be pruned differently, and to cover this point thoroughly we have noted in our main list the number of eyes to which each variety should be pruned, the number so given referring to the strongest canes; on the weaker ones you will, of course, cut to a less number of eyes.

In order that the rules which we have given for pruning may be more thoroughly understood the system is illustrated in Figs. 4 and 5 herewith given. The first is a Hybrid Tea rose which was not pruned in the spring but was allowed to develop. The second is the same plant properly pruned.

Fig. 4 shows the plant photographed after it was taken from the ground. On stem "A," in particular, it will be noted that none of the lower buds have pushed but that the top buds are well developed. This carries out exactly our theory that on a long, weak stem the sap will go to the top buds only. To properly prune this weakest stem it should be cut off to two buds as is shown in Fig. 5. On stem " $B$," which is somewhat stronger, it will be noted that the lower buds have pushed, owing to some extent to the fact that this stem is not so long. Fig. 5 shows that we have pruned stem "B" to the third bud, which is on the outside. The first bud 


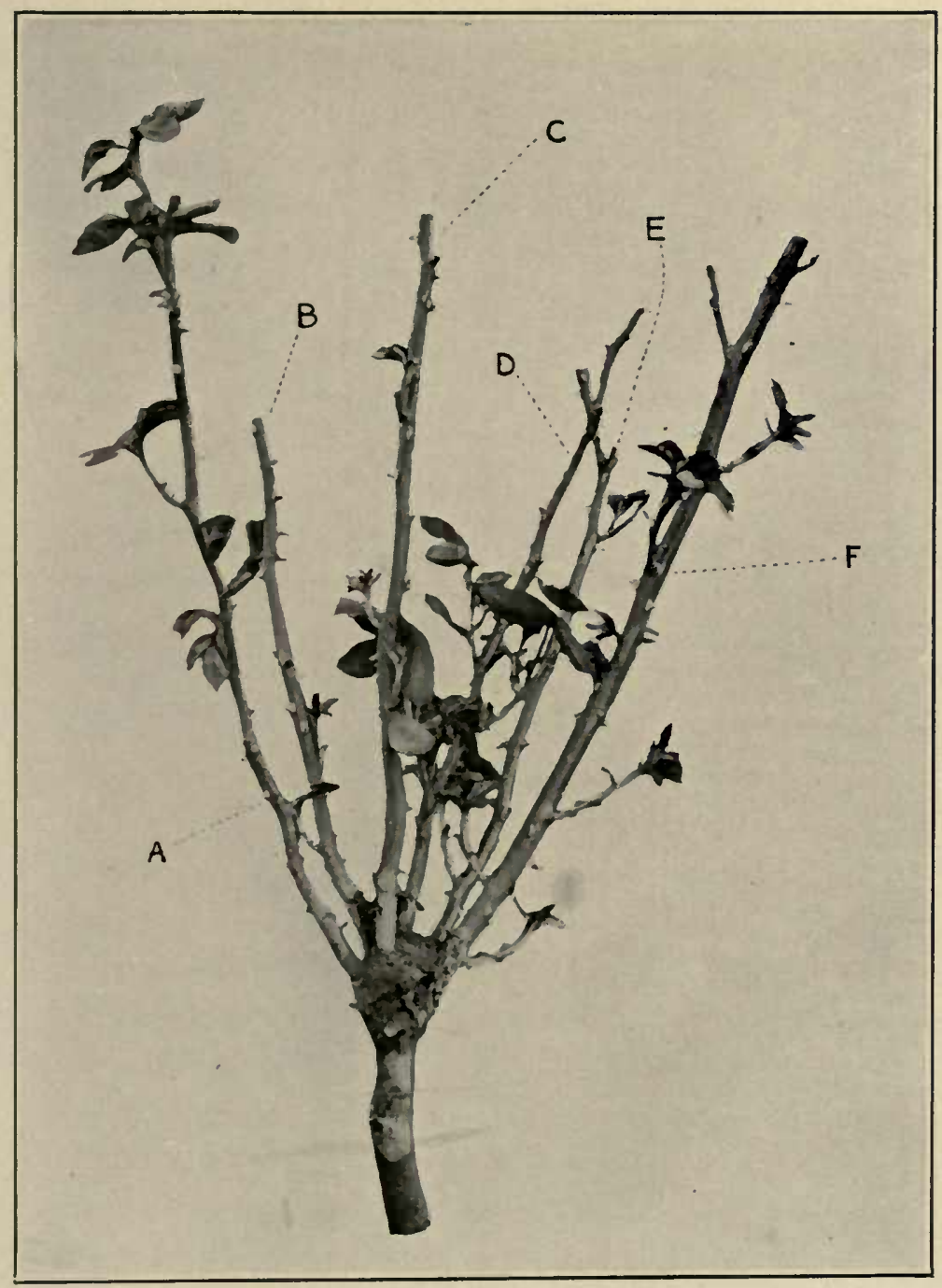

FIG. 4

HYBRID TEA ROSE, NOT PRUNED BUT ALLOWED TO DEVELOP 



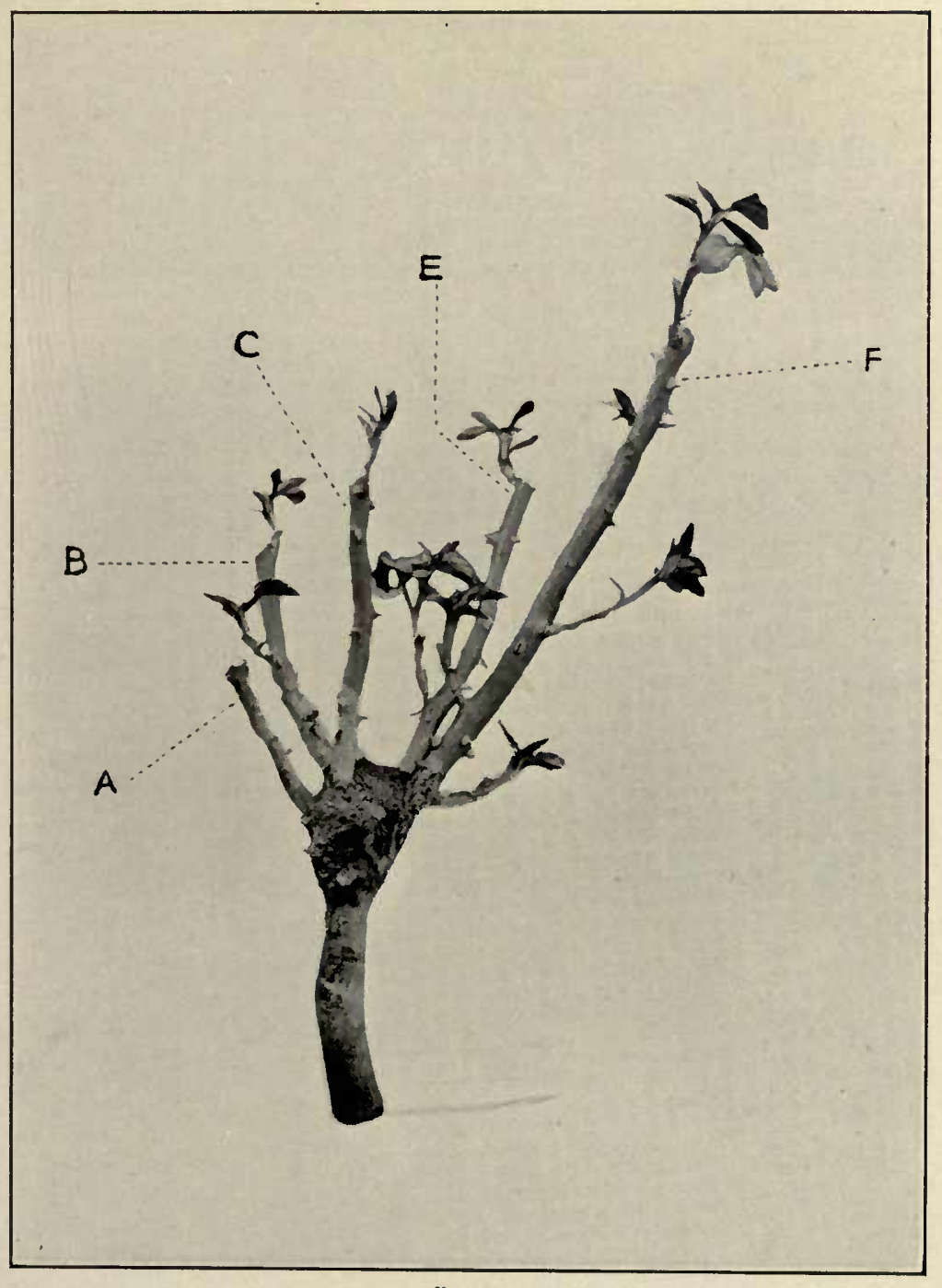

Fia. 5

SAME ROSE AS FIG. 4 PROPERI.Y PRUNED 



\section{PRUNING}

is dormant and does not show clearly in the illustration. Cane " $\mathrm{C}$ " on Fig. 4 should be pruned in exactly the same way, cut to the third bud on the outside, and this is done in Fig. 5. Cane " $D$ " in Fig. 4 is undoubtedly the one which should be removed, as it crowds the center of the plant, and in Fig. 5 this stem has been cut out. You will note how much more space is left for the balance of the growth, particularly for the strong lowest shoot of "E." "E" in Fig. 4 should be cut to the fourth bud on the outside, and this is shown in Fig. 5. "F" is undoubtedly the strongest cane and on its whole length the young shoots have started vigorous spring growth. You cut " $F$ " to five eyes as in Fig. 5. Had this plant (Fig. 4) been pruned in the early spring the dormant buds on " $\mathrm{A}$ " and the lower buds on " $\mathrm{B}$ " and " $\mathrm{C}$ " would have been forced into growth, but as the stems were left long, the sap went to the top of these weaker growing canes. If cane " $F$ " had been somewhat larger, and "B," " $\mathrm{C}$," and "E" had been as small or smaller canes than "A," the plant would have been too one-sided and it would have been necessary to have cut" " $F$ " back certainly to the third bud, which is on the outside, possibly to its lower bud to equalize the growth; but in this instance the three remaining canes in the center, "B," " $\mathrm{C}$," and " $\mathrm{E}$," are nearly 


\section{OUTDOOR ROSE GROWING}

as large as " $F$," and the cane " $A$ " by being cut back to its second eye should throw out strong growths, as the two buds remaining will secure all of the sap of this stalk.

These instructions are given for general work to secure the greatest number of fine blooms. Naturally, if a person wishes exhibition blooms, such roses as he could exhibit with a chance of taking a prize at a rose show, and he is willing to be satisfied with only a few of these, we would suggest after growth has started and the shoots have broken, that he again go carefully over his plants and cut out all weak growths, keeping only the most promising shoots of the most vigorous canes. It will generally be necessary, in order to secure this result, to cut back to two shoots, but with a particularly vigorous and promising growth you may leave more, in which case, however, you must cut off the weaker growths below-in other words, following out our first theory, the fewer buds the more sap to each.

The English custom for exhibition varieties, as a general rule, is to wait until the flowers have been formed and then to cut out such growths as are not required, mainly because they are not promising, and to allow all the vitality contained in the sap to go to the blooms which are left. Such blooms, receiving all the nourishment, tend to be larger and 


\section{PRUNING}

more perfect than the average flowers. However, they do not surpass the average bloom recommended to any marked degree, and they cut down the number of flowers so greatly that they are not worth the sacrifice they entail except for exhibition purposes.

The bush should be carefully and thoroughly pruned according to the rules given above, an additional and very necessary point being that the cut ought to be made not less than one-quarter of an inch above the bud and not more than one-half of an inch from it. The cut should not be straight across, that is, parallel with the ground, but should be slanting. This will keep the water from rotting out the wood too quickly before the bud starts and the shoots are established. In other words, one might say that the cut would drain off water like a roof on a miniature house. The cut should be clean. An ordinary pair of gardening pruning shears is the best implement for this work. These shears must be kept sharp, otherwise they leave rough edges and bruise the bark, which then will not heal.

The most comfortable way in which to prune is to have a heavy square of carpet placed on the ground on which one may either sit or kneel. It is impossible to do any great amount of pruning unless some such method is used; to keep the dampness from coming through the carpet should be doubled 


\section{OUTDOOR ROSE GROWING}

over at least once. Persons having trouble with their eyes should be very careful to use their glasses in this work, as more minute attention is required than one would think. The foregoing suggestions apply mainly to a large amount of pruning, but even where the plants are few it would perhaps be best to employ this method, as the operation would certainly be much more comfortable. In all pruning a pair of heavy gloves will be found a necessary protection.

In the autumn the only pruning necessary is to cut down the bushes so that the fibrous feeding roots will not be broken by the thrashing about of the tops in the heavy winter winds. It is quite easy to cut down to an approximate height until the early spring pruning, and when the plants have done blooming and the frost has set in severely we would suggest that they be cut to an approximate height of one foot and a half, except in strongest growing kinds and climbers. Do not cut to less. The buds liable to break are upper buds, and if forced in a warm, late autumn or early spring, after breaking they will certainly winter kill. If left short there are not enough buds remaining below to carry out the scheme of pruning; if left longer, no harm is done.

Under pruning it is well to include the cutting of the bloom. This is a part of rose culture which is usually neither considered nor understood. It is 


\section{PRUNING}

not easy to regulate by actual rule but if the principle is understood the proper cutting of roses is a very easy matter. In this, as in spring pruning, the method to be employed depends entirely upon what is desired. Cutting off the blooms insures more. If they are not cut new growth will not start so quickly. For this reason it is advisable to pinch off any blooms which may have been left on the plants. This should be particularly noted with all bedding varieties which are kept for garden decoration and are not usually cut. If a stem is left and the seed pod forms it takes the greater part of the nourishment on any shoot, the sap going to the top as has been previously noted. Nature thus provides for the greatest amount of sustenance going to the seed pod. By autumn, if blooms are not cut but pinched, you will have a very much larger plant than if the blooms had been cut, and the plant has perhaps somewhat better foliage. But with us the cutting of flowers is a great pleasure and we like to have them in the house as well as to see them on the bushes, so that the great majority of our blooms are cut and, after the method of pruning which we have advocated, mostly with long stems. If this is what you want you must be a little careful in the cutting of your stems to leave enough buds below the cut on the shoot from which you are 


\section{OUTDOOR ROSE GROWING}

taking your flower to provide other shoots, which will later in the season give you more blooms. On the stronger varieties in the June blooming season, on a Hybrid Tea rose or a rose which you expect to bloom further, you should leave enough buds to give shoots for summer and for autumn bloom. Therefore in such cuttings we would suggest leaving never less than two buds at the base of the shoot, and with very strong varieties three buds, always seeing that the bud you cut back to is a strong one. If you cut leaving a long stem you may, perhaps, get more flowers but they will not be on such stalwart stems, nor will they produce as fine blooms. If you are cutting from a Hybrid Perpetual, or from a rose from which you do not expect to secure more bloom, to cut to one bud will be sufficient. In this cutting of blooms, the same as in pruning, you can follow the well-known theory that on a weak growth you can cut farther back than on a strong growth. Approximately on an average growth we would leave, as above stated, two buds on the constantlyblooming varieties. In late fall cutting it will be unnecessary to leave any buds below the cut as there will be no more bloom after frost. In the weak kinds, with the frail, drooping stems, perhaps you do not wish all of the stem cut to remain on your bloom, but you certainly do not wish it to 


\section{PRUNING}

remain on the plant; therefore cut harder on the weak growths and afterwards reduce the length of the stem to suit your fancy. Unless you have hybridized, or wish to try raising seed from chance fertilization, you do not need the seed pods or heps to develop, and if twice a week during the blooming season you pick all old blooms from your plants you will not only keep the beds in better order but secure more flowers thereafter.

Spring pruning as given here applies to roses after the first year. For the first year they should all be cut back to three eyes on good wood and one eye in weak wood. This gives the young, unestablished roots less work to do and provides more time for them to prepare for the following year.

In pruning other varieties not mentioned in our list, and neither Hybrid Teas, Hybrid Perpetuals, nor Teas, the main work to be done is always to cut out all the dead wood. This, of course, also applies to the list. Moderate pruning only is necessary and the same theories which we have advanced for our list will be found to give good results for other roses, with the exception of the climbers and those specially mentioned.

To go over the main points, the theories which we have tried to bring out in this chapter are: prune when the new growth can be plainly noted; 


\section{OUTDOOR ROSE GROWING}

for medium fine blooms prune the strong varieties on the strongest canes to five and six eyes; weaker canes to a smaller number. On the weaker varieties prune to three and four eyes on the strong canes; two and three eyes on the weaker ones. If you wish more blooms and do not care so much for quality, desiring the bushes to be more of a garden decoration, do not prune quite so far down the canes. If you want only a few exhibition blooms, cut harder, and, later in the season, thin out unnecessary and unpromising growths. For all plarts cut out dead wood. In cutting roses during the spring and summer never leave less than two eyes on any stem which you cut. This gives you summer and autumn blooms. On the very strongest varieties cut to three eyes-always cut to a strong eye. Be sure that your cut is a clean one and slanting, and from one-quarter to one-half an inch above the bud. Always cut to outside buds, unless for some particular reason you wish to have the plant grow in some other direction.

In all pruning remember the working rule and so accomplish your purpose; the fewer buds you leave to break the more sap they will receive, and the more buds you leave the smaller amount of sap each one will get, and also that the buds near the base may not break. 


\section{VIII}

\section{CULTIVATION}

IF you have followed the directions given in this book for location, preparation of bed, ordering, planting and pruning, your really hard work is over and the most pleasant part is before you. The actual culture of the rose is very easy and agreeable. Beyond a little spring and autumn care, some spraying and the weeding of the beds, there is not much work to be done. In the spring, after the frost is out of the ground, you should have taken off the covering of your bed, whether it be litter or only leaves. The little mounds should now be raked down so that the bed is level, and if your roses were covered with litter the greater part of it, especially the straw, should be removed, and the manure that is left should be well forked into the bed. After the roses are pruned, the next thing which should occupy your attention is the feeding of the plants in order to give a particularly fine growth.

In the bed itself, of course, you have enough manure to furmish the roots with food for many years, but to secure the best results you should 


\section{OUTDOOR ROSE GROWING}

also feed the roots from the surface. Wood ashes and bone meal may be alternately forked into the bed after growth has begun. Another good food is liquid manure water in the proportion of half a bushel of manure to a barrel of water-"weak and often" is the old gardener's recipe.

Blood diluted with water is sometimes used. Mr. Frederick W. Taylor uses this alternately with manure water; his recipe is five pounds of blood to a barrel of water. After mixing, permit the blood to settle, then draw off the greater part of the water; use the same blood in the same manner twice again, five pounds making three mixtures.

In April or May the shoots should begin to grow, and very shortly the buds themselves will appear and gradually turn into blooms. On certain varieties, too few unfortunately, there is only one terminal bud on each growth; on a great many you will find small buds appearing close to the larger ones; these should be gone over and carefully removed if you wish the finest blooms, as naturally they take a certain amount of sustenance, and the main bloom will develop better and will be of finer quality if it receives all the nourishment. It does not take very long to go over your plants and disbud all these smaller flower buds, and unless you wish nothing but a mass of color in your beds our advice is to 


\section{CULTIVATION}

remove them. The easiest way is to pull them off carefully with the thumb and forefinger, and in doing so see that you do not take hold of anything but the bud to be removed. This can be easily and quickly done.

You will now find to your consternation, if you are a novice in rose growing, that all your young buds and leaves are covered with little, light green insects-Green Flies or Aphides, which are common pests in rose gardens. There is, however, a very effective remedy for them which, if properly applied, will greatly check their future development; this is to spray, with an ordinary spraying outfit (secured at any seed store), a solution of tobacco stems and whale oil soap. The proportions of this mixture which we have found to be best on our place are as follows: One pound of tobacco stems to a bucket of water, to which add an ounce of whale oil soap, first dissolved in a small quantity of hot water. It will take about three hours for this to dissolve. It should then be added to the tobacco mixture. This is an easy preparation to remember: one bucket of water, one pound of tobacco stems and one ounce of the whale oil soap; the two latter-named articles can be readily secured at any seed store. The Aphides are quickly destroyed with this spray and a gallon of the mixture by careful application is 


\section{OUTDOOR ROSE GROWING}

enough for from fifteen to twenty-five rose plants; by applying with an ordinary whisk broom it will take care of fifty plants and can be done as well, but it requires more time in applying than with the sprayer.

By this time the ground will naturally need weeding. It seems hardly necessary to go into details regarding the proper method. An ordinary scratch hoe, as the gardener terms it, will quickly take out the weeds and also destroy some of those not yet up. Care must be taken not to hurt the rose roots. This is really a very simple operation, and any gardener can do this if you do not care to do it yourself. Your roses are now in bloom and you are cutting them carefully and no doubt having much pleasure in seeing them about the house and giving them to visitors.

As the days become warmer and the ground drier you must take more care of the plants. You should keep the earth broken up in the beds and not permit it to form a hard cake or crust, as it will do if left alone. This breaking up should be done twice a week. In addition to this you must consider feeding your roses further if you want the very best blooms. For this purpose ordinary manure water, as described above, is the best possible food and perhaps easiest to secure in most places. When 


\section{CULTIVATION}

the roses are fully formed, withhold manure water until after the first crop, apply again as each succeeding crop of buds commences to develop. Roses need a slight rest between crops. If you have placed the blanket of peat moss on your beds, which was recommended in a former chapter, there will be very little weeding and no breaking up of dried earth necessary and the moisture should be well conserved in your beds. We recommend that this covering be put on and believe that it will save labor and greatly aid the growth of the plant by keeping the ground at a much more even temperature than it would be otherwise. The first of May would seem about the proper time for the peat moss.

Watering is necessary in very dry weather if your ground becomes thoroughly baked, but you should never water your plants late in the day. The plants should go to sleep with dry foliage, otherwise mildew will develop. Roses should always be watered early in the morning before the temperature rises-it is unnatural to water them during heatthey are accustomed to cool temperature with rain. Mildew is a disease of the leaves which appears when there is too much moisture. The use of peat moss will render watering to some extent unnecessary.

One other plague for which you must watch is 


\section{OUTDOOR ROSE GROWING}

the rose slug, which chews the leaves. This pest must be destroyed by a stronger preparation than tobacco leaves, as it is very hardy and not as quickly disposed of as the little green bug. Lemon oil is considered a good remedy and we have proved its efficiency. It also can be taken care of by mixing whale oil soap, already referred to, and water, in the proportion of about an ounce to a gallon of water. The very best remedy, however, is powdered white hellebore. Make a solution of two tablespoonfuls in a bucket of boiling water, and after it has cooled apply it with a whisk broom under the leaves.

These directions are really all that are necessary to raise roses successfully, except that you must watch carefully for any sprouts of the Manetti or other stock, on which the roses themselves are budded or grafted. As explained in the chapter on propagation, these shoots are a lighter-colored green than the average foliage of roses, and have seven leaves instead of three or five, in addition to which the wood itself is covered with little prickles. You will not find many of these, though after looking for a time and not seeing any you will believe that they probably will not appear at all, when suddenly some morning you will be surprised to find a tall, light green shoot on the outside of one of your rose bushes which you have heretofore not noticed. The 


\section{CULTIVATION}

cutting off of this shoot from the root itself is the proper remedy for this enemy to the growth of your plant.

Rose bugs or beetles are really the worst pests which you have to endure. They are quite large and it is most annoying to find these destructive insects on your beautiful blooms. The best way is to pick them off by hand. This, if done thoroughly when they commence to appear, is really the only sure method of ridding one's rose gardens of these miserable pests. We have tried a number of sprays which have undoubtedly helped to some extent, but it is much more thorough to go around and actually remove and destroy the bugs yourself-pick them off, drop them into a can of kerosene and they are gone.

At the end of this chapter will be found a list of recipes for the diseases of roses.

So your plants work on through the hotter part of the summer and now towards its close the nights commence to become cooler and the days are still quite warm; the air itself is very moist and humid. This occurs usually in the latter part of August, and this change from eighty degrees or more in the daytime to sixty degrees or less in the night is one which the rose foliage does not like. When there is also great humidity mildew is liable to occur. A 


\section{OUTDOOR ROSE GROWING}

good remedy is grape dust, which can be obtained in any seed store or from any nurseryman with directions for use. Another remedy is a solution of sulphide of potassium, one-quarter of an ounce to a gallon of water, to which add one and one-half ounces of common soft soap. The soap should be boiled before being added to the solution. This is the cure we prefer.

Black spot is another disease which sometimes comes towards the end of the summer. We have experienced it mostly in potted greenhouse plants and we advise against planting roses from pots, as each time we have done so black spot has resulted. If we plant only dormant field-grown stock we do not have this disease. Dr. Huey concurs in this opinion and, as a cure, advocates picking off such leaves as are affected as soon as they appear. Last year we used a formaldehyde solution with fair success, but black spot is most difficult to eradicate.

The "American Florist," in its issue of June 14, 1914, has a very interesting article on black spot treatment, taken from publications of the National Rose Society of England. The main point in the article is that black spot is a fungous disease which invades the living tissues of the plant and there reproduces itself by means of spores on the leaves. 


\section{CULTIVATION}

To combat the disease formaldehyde is suggested and is supposed to be absorbed by the tissues of the plant and to kill the spores on the leaves. This article further states that it is considered advisable to use the formaldehyde as a spray not only on the leaves and stems, but also to have the solution reach the plant through the soil. To accomplish this result it is advised that "the cool of a calm evening in summer when the soil had been previously loosened, and moistened if necessary, would be ideal." In the treatment referred to above it is necessary, in order to secure the proper results, to spray as soon as the buds begin to open early in the spring, and for this early spraying two tablespoonfuls of commercial formaldehyde are diluted in a gallon of water; for later spraying when the plant is in full growth one-half strength is used, i.e., one tablespoonful to a gallon of water, and the weaker spray used at intervals of a week or ten days through the growing season. Where black spot has gained a firm hold on the plants, it is also advocated that a solution of double strength be used in February.

As the nights become still colder your blooms will, of course, take longer to develop and you cannot expect as much from your bushes; nevertheless the roses still make a fight to give you flowers and 


\section{OUTDOOR ROSE GROWING}

you will nearly always be able to pick them from the late bloomers until about the middle of November. We have picked roses until Thanksgiving, and during the past year even later. From the middle to the last of November is the time roses should be given proper winter protection.

The first thing to do with all ordinary bushes is to cut them down to an approximate height of a foot and a half. They will nearly all die down to this height or below in any event, and by cutting off the bushy tops damage by high wind is prevented. The peat moss should at this time be removed and saved for the following spring.

The matter of hilling up has been noted, but is so important that we will give the description again. It consists of heaping the ground up around the bush. It is well to add some top soil to the bed and hoe this up in a little mound around each plant to a height not less than six inches above the bed level.

With the Hybrid Perpetuals and the very hardiest of the Hybrid Teas this hilling up is not really necessary, but there are very many beautiful varieties which can be brought through the winter by this method only.

After the roses are hilled up, wait until the ground freezes before placing the litter on the beds. No 


\section{CULTIVATION}

insects or mice will then inhabit it during the winter and injure the green wood of the canes. Another good way is to fill the spaces between the little mounds with autumn leaves or meadow hay, with enough earth spread over the top to keep them from blowing away. This is an easy method and undoubtedly adds warmth to the beds.

After the winter is over it is better to remove the litter or leaves too early rather than too late, because they will rapidly heat up under the influence of the warm spring sun and the buds of the rose canes will be forced into breaking too early, when any later heavy frost will severely kill back the young shoots so started by the heat. It is therefore advisable to take this covering from the roses when the frost is out of the ground and before the heat of the sun becomes great and lasting.

Standard roses should be most carefully protected. We have lost during the winter about twenty per cent. of our plants; at best from ten to twenty per cent. lost has been our average of these in the strongest varieties, even when winter protection was given.

We believe that you will not have ten per cent. of deaths if you give these very attractive standards proper winter protection. Try placing around them a rough box made of boards and filling it with earth, covering well above the junction of the strong 


\section{OUTDOOR ROSE GROWING}

growing stalk with the rose itself. Mr. Frederick W. Taylor recommends making this box at least two feet square, and filling it with tightly packed earth from the ground level to the top of the plant above the bud. Another good method often used is to bend down the entire plant after carefully loosening the roots and to place it in a trench and cover it heavily with earth. We have tried protecting standards with old pieces of carpet, carefully wrapped around the upper part of the plants only, but find that the method of actually encasing the entire plant with earth is the best.

Most Wichuraiana and other climbers will come through the winter well by themselves. Others, however, winter kill more or less, not enough to kill the plant itself but to destroy parts of the main stems. The Wichuraiana climbers bloom upon the wood of the preceding year, and if such wood is lacking and the rose has to throw up new shoots there will be no bloom. If the main shoots are killed back the few existing blooms will be low down, so that in the far north it would be well to bend down the canes and protect them with the usual blanket of earth. Ordinarily where climbers are protected from the north and particularly the northwest winds, it really is not necessary to give them any other protection; but it does not take very long to bend 


\section{CULTIVATION}

down the long trailing branches carefully and cover them with earth. This should especially be done in the case of climbing Hybrid Teas, as these kill back very much more than the other climbers.

\section{RECIPES FOR THE DISEASES OF ROSES}

Below we quote extracts from the best known authorities, giving their recipes for mildew, black spot, rust, etc.

"The Rose Book" (Page 211). H. H. Thomas suggests using a mixture for mildew of equal parts of fine quicklime and sulphur dusted on the affected areas.

"Roses, Their History, Development, and Culture". (Page 303). Pemberton advocates the same dusting and also gives the following: $1 \mathrm{lb}$. flowers of sulphur, $1 \mathrm{lb}$. powdered quicklime. Add sufficient water to form a paste. Add one gallon of cold water. Boil for twenty minutes and when cool pour off the liquid and spray at the rate of balf a pint of the above mixture to six gallons of water.

(Page 303). PEMBERTON recommends 11/2lb. of Calvert's carbolic soft soap in $71 / 2$ quarts of water-a pailful; spray with one part of mixture to three parts of soft water, and he adds, "this is the remedy we apply."

"Roses and Rose Growing" (The Macmillan Co.), (Pages 137138). Miss KingsLey advocates flowers of sulphur for mildew, distributed by a pair of powder bellows, and suggests applying before mildew appears. She uses Quassia Chips for Aphis, and recommends picking by hand for caterpillars.

"The Rose" (Page 89). Ellwanger's recipe for mildew is sulphur and soot, applied while the dew is on the plants so that it will adhere.

"Roses" (Page 52). The Garden Library of Doubleday, Page \& Company suggests for black spot carbonate of copper compound, using five ounces of copper compound to three quarts of ammonia and sixty gallons of water. The spraying should be done once a week, using a hose with a nozzle that gives a fine spray.

"Pictorial Practical Rose Growing" (Pages 80-84). Wright does not mention black spot, but our understanding of the reference made to orange fungus or red rust is that it develops into black rust, possibly the same as the well-known black spot. This article is so clear and appeals to us so strongly that we quote it verbatim, and will try the recipes given if troubled in the future. 


\section{OUTDOOR ROSE GROWING}

"When the experienced rose grower observes orange-yellow spots on the leaves of his plants in early summer, he knows that he sees the advance guard of the fungoid disease known variously as orange fungus and red rust.

"Some suppose these to be separate diseases; on the contrary they are separate stages in the triune life-cycle of disease, Phragmidium subcorticatum. The first, or EEcidium, stage gives the orange fungus; the second, or Uredo, stage gives the red rust; the third, or Teleuto, stage gives a black rust.

"Where the orange fungus has obtained a strong hold, and has caused trouble for several successive years, it cannot be exterminated at a single attempt. Repeated attacks on it must be made. Measures may begin by spraying the bushes thoroughly in the spring, before growth starts, with Bordeaux mixture.

"Bordeaux Mixture.-To prepare Bordeaux mixture take $21 / 2 \mathrm{lb}$. of sulphate of copper (bluestone), dissolve in a little hot water; $21 / 2 \mathrm{lb}$. of freshly burned lime, dissolve in cold water; $1 \mathrm{lb}$. of agricultural treacle, $1 \mathrm{lb}$. of soft soap. Pour together when cool; stir the treacle or soft soap well in and make up to twenty-five gallons with water.

"When the first signs of the disease appear in summer, spray with carbam, repeating if necessary. The solution should reach the under as well as the upper side of the leaves.

"To prepare carbam, take 1 ounce of carbonate of copper, $1 / 2$ pint of liquid ammonia. Dissolve the carbonate of copper in the ammonia and mix with ten gallons of water."

One point that all authorities seem to agree upon is the picking and burning of all dead and fallen leaves affected by black spot. 


\section{IX}

\section{SOME GENERAL INFORMATION AND HINTS ON HYBRIDIZATION}

$\mathrm{By}$ this time the reader should have gained a practical idea of how to make a small rose garden and care for it. If he wishes to go into the various features of rose culture more thoroughly, the books we have suggested will give him the necessary information. We have treated more especially of the small rose garden for the average American ' home; we have not considered formal gardens, nor how to cultivate the various weaker varieties of roses to any extent.

In the roses marked numbers 1 and 2 under heading "List" we have been careful to give only those varieties which we know will succeed well without any great care or special protection. In the American climate of which we write, the latitude of the Middle Atlantic States, it is not possible to grow some of the roses which succeed so wonderfully in the south of England and in France. However, there is a vast area in the United States in which all of those more delicate roses may be successfully grown, more particularly in the southeast and south- 


\section{OUTDOOR ROSE GROWING}

west; in fact in every part of our great country where there is little frost all of these wonderful Teas and Climbing Teas and Noisettes may be successfully cultivated. Therefore, if your home is in that section of the country we strongly advise you to try all roses marked " $\mathrm{B}$ " and " $\mathrm{C}$ " in our main list under the heading "Hardiness," but we do not believe it would pay you to grow Hybrid Perpetuals to any extent except in a large garden or collection. Although we can recommend these more delicate roses for the southern climate referred to above, we do not wish to intimate that they are better than the Hybrid Teas of our well-tried list. These should succeed as well as in our own climate.

The point that we desire to bring out is that the more delicate roses can be successfully cultivated below the frost belt. In the northern part of our country, where the winter is very cold and severe and the temperature remains considerably below zero for long periods, roses must be given every protection to succeed; in that part north of Boston, for instance, only the very hardiest of the Hybrid Teas, Hybrid Perpetuals and Wichuraianas will stand the winter out-of-doors, and they must be given even more thorough winter protection than is advised for our Middle Atlantic climate. In all except the very coldest parts of our climate it would 


\section{GENERAL INFORMATION}

be feasible to grow the hardiest roses by covering them with a deep layer of soil, or by transplanting in the winter to boxes placed indoors. If one really loves roses it would seem that this extra trouble would be well worth while.

In this colder climate the best method which we have seen is that roses be grown in good-sized pots or boxes, and in the autumn when frost comes the plants be moved in their flower pots or boxes to a cellar or building where extreme cold will not reach them. In the case of a cellar with an earthen floor the pots can be placed beneath the surface. The only thing necessary during the winter is to give the plants several waterings. In the spring the rose pots or boxes should be carried out and again placed beneath the surface of the soil in their old bed. While we have never tried this plan ourselves we feel confident that even in an extreme climate it is prefectly feasible and could be carried out in any part of the United States. We know of roses being grown on the Gulf of St. Lawrence where the temperature reaches forty degrees below zero; they were protected during winter by the device of covering each bush with a small keg, filled with earth. The Hybrid Perpetuals did best in this locality; even the strongest of the Hybrid Teas tried gave poor results. In our own more moderate climate of the Middle 


\section{OUTDOOR ROSE GROWING}

Atlantic States and in approximate temperatures it would be possible to grow many of the more delicate roses with the heaviest winter protection, and we propose to try this experiment next year.

One of the best means of protecting roses from the cold and the wind is a good brick or stone wall. It is expensive, but even a low wall will make it possible to grow the smaller Teas, and a four-foot wall would be of great use in protecting low bushes from the heavy winds, while with a six or eight-foot wall it would be possible to care for the wonderfully blooming Climbing Teas. The tender Cherokee rose is being successfully grown near Philadelphia on the south side of a wall. The ideal exposure would be a wall facing the south or southeast and, as the winter approaches, the climbers could be taken down from their fastenings on the wall and covered over with earth and the smaller roses cut back and heavily covered. In an ideal rose garden, with such a wall completely surrounding it, there would be a great opportunity not only for the proper growing of many of these very beautiful varieties which otherwise one cannot hope to raise, but by utilizing both sides of the wall it also would be possible to bring roses into bloom at different times. On the north side only the very hardiest of the climbing roses would do at all well. Crimson Rambler and 


\section{GENERAL INFORMATION}

Wichuraianas would be roses to try on such an exposure, and if four such roses of the same variety were planted on four different exposures they would come into bloom at various times, thus lengthening the period of bloom.

A difference in soil and situation affects the time of bloom to some extent. A north slope will come in slightly later than a southern exposure; but in colder sections, and particularly in sections where late frost is liable to occur after growth is started, a north slope is a safe exposure. In such a situation the early spring sun will not reach the roses as it would on a southern slope, and they will not be forced into growth only to be killed back afterwards by the late frosts. It has been well proven that high ground will not have as much frost as low, wellsheltered ground, for in the latter the frost will settle in the late spring and cause damage, whereas on the high ground the air will have free access and will not allow the frost to remain, as it seems to do in low-lying ground.

Proximity to the ocean or any large body of water gives a more even temperature than is found in inland sections. On Buzzard's Bay, Massachusetts, where we lived for a number of years, we were very successful with our Hybrid Teas, and even with some of the Teas. The winters were much colder 


\section{OUTDOOR ROSE GROWING}

there than farther south in Philadelphia where we now reside, but with proper and heavy hilling up there was a very small percentage of deaths, and owing to the cool, moist climate, the blooms were particularly fine. We remember especially that the Pierre Notting of the Buzzard Bay district was a much superior rose to the one grown near Philadelphia. However, since that time, after experimenting with various roses of about the same growth and bloom as Pierre Notting, we have discovered that Alex. Hill Gray is much superior to it, being the same type but a better grower, with more perfect foliage and bloom. For these reasons we have replaced Pierre Notting with Alex. Hill Gray.

There is a very interesting list of roses for the locality of Chicago published in "How to Make a Flower Garden," in which Mr. W. C. Egan gives his experience with roses near Jackson Park, Chicago. From the list which he selects it would seem that the hardiest Hybrid Teas would do well there, as his article included with the Hybrid Perpetuals several Hybrid Teas and Teas which are not among our hardiest varieties.

On the Pacific Coast roses do wonderfully well. In Santa Barbara, California, they come into bloom before Christmas, and the growing season there be- 
FIRST BLOOM ON HYBRID TEA SEEDLING-AT SIX WEEKS 


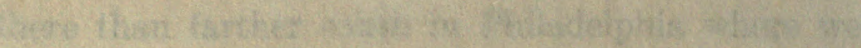

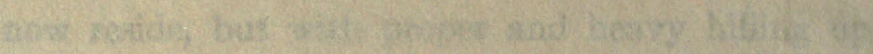

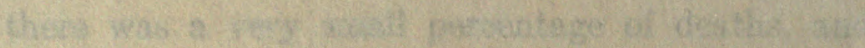

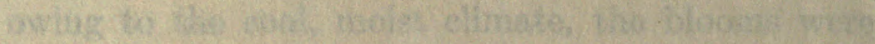

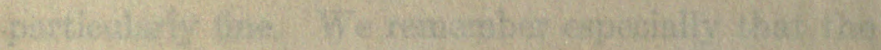

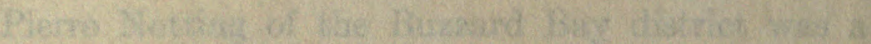

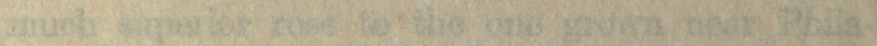

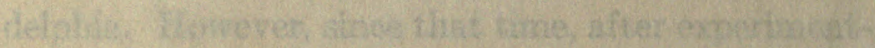

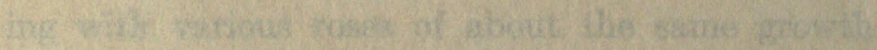

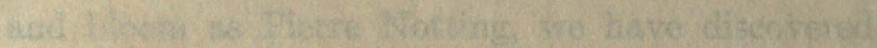

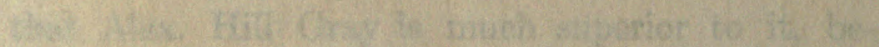

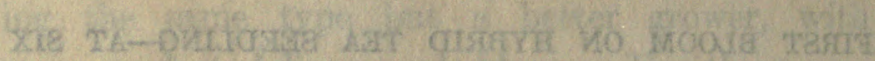
Wha

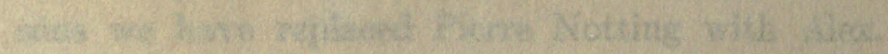
ifing

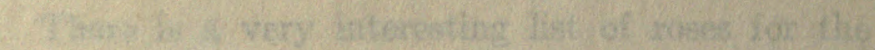

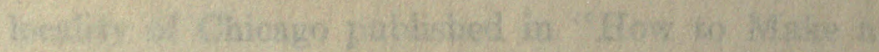

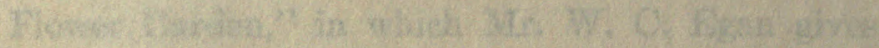

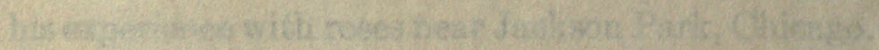

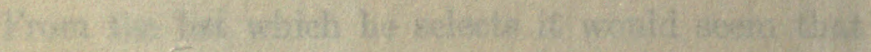

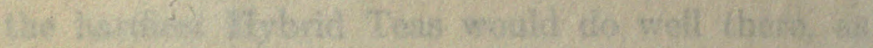

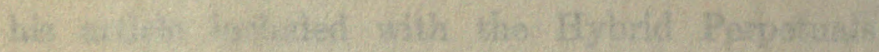

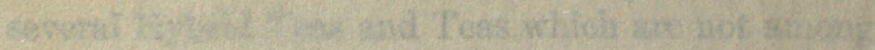

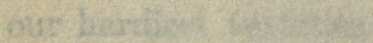

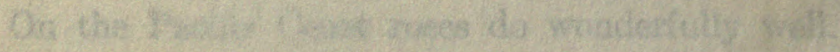

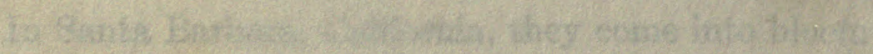

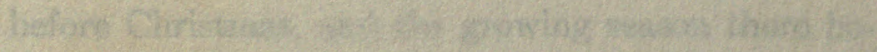




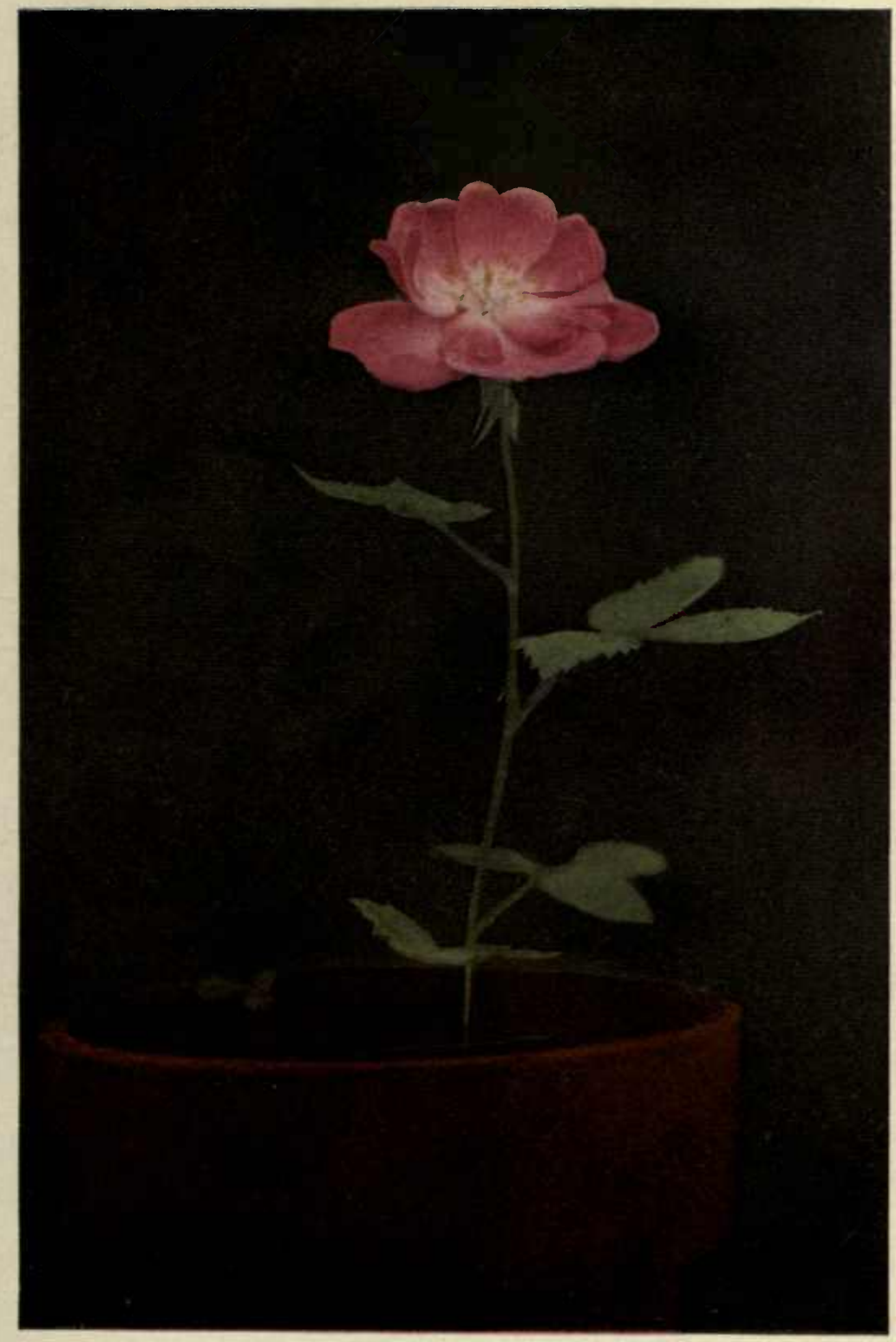





\section{GENERAL INFORMATION}

gins after the priod of summer drought; what we in the East would call early autumn is, in reality, spring in southern California. Farther north on the Pacific Coast we have friends who advise that roses are most successful with them, and no doubt roses in our list which are marked " $\mathrm{B}$ " and " $\mathrm{C}$ " as to hardiness would probably not winter kill to any extent, although we, naturally, more strongly recommend the roses in our set of sixteen chosen varieties.

HINTS ON HYBRIDIZATION

It would hardly seem that this chapter will be complete without further information on the most interesting part of rose growing, that is, hybridization to secure new varieties. The books which we have noted in the chapter on propagation will take the reader very thoroughly through this most fascinating subject, and they should be secured by any one who proposes to attempt such work.

We have been making experiments with seedlings and with hybridizing for some time past. It will be found by the person who wishes to have some interesting work for the winter and who can give up part of his greenhouse, that a great deal may be accomplished even in a limited space. A conservatory would also give one an opportunity to make interesting experiments. 


\section{OUTDOOR ROSE GROWING}

The Hybrid Tea list, with the addition of PernetDucher's Pernetiana, makes this section of outdoor roses very complete, but there is still a large field to work upon and particularly in the climbing section. Any one who can breed a hardy seedling climber which will bloom reliably from frost to frost will be giving the rose world a most important addition. By securing a few potted plants in the early autumn quite a number of crosses could be made, although the chances of securing what is desired would not be as great as if one had more plants with which to experiment.

During the past season we have been most successful with all our hybridizing and therefore one or two hints may be of use to any one deciding to undertake such a task.

As most of the books state, a rose will become fertilized with its own pollen more quickly than by the pollen of any other rose. The main point for success is to watch most carefully the rose which is to be bred so that before the pollen becomes ripe the anthers and stamens may be removed. It is very easy to tell when the pollen is ripe because it will then drop in small yellow particles upon the petals of the rose, and if one's finger is rubbed across the anthers the yellow dust will at once be noticed. Our procedure has been to pluck off the petals of 


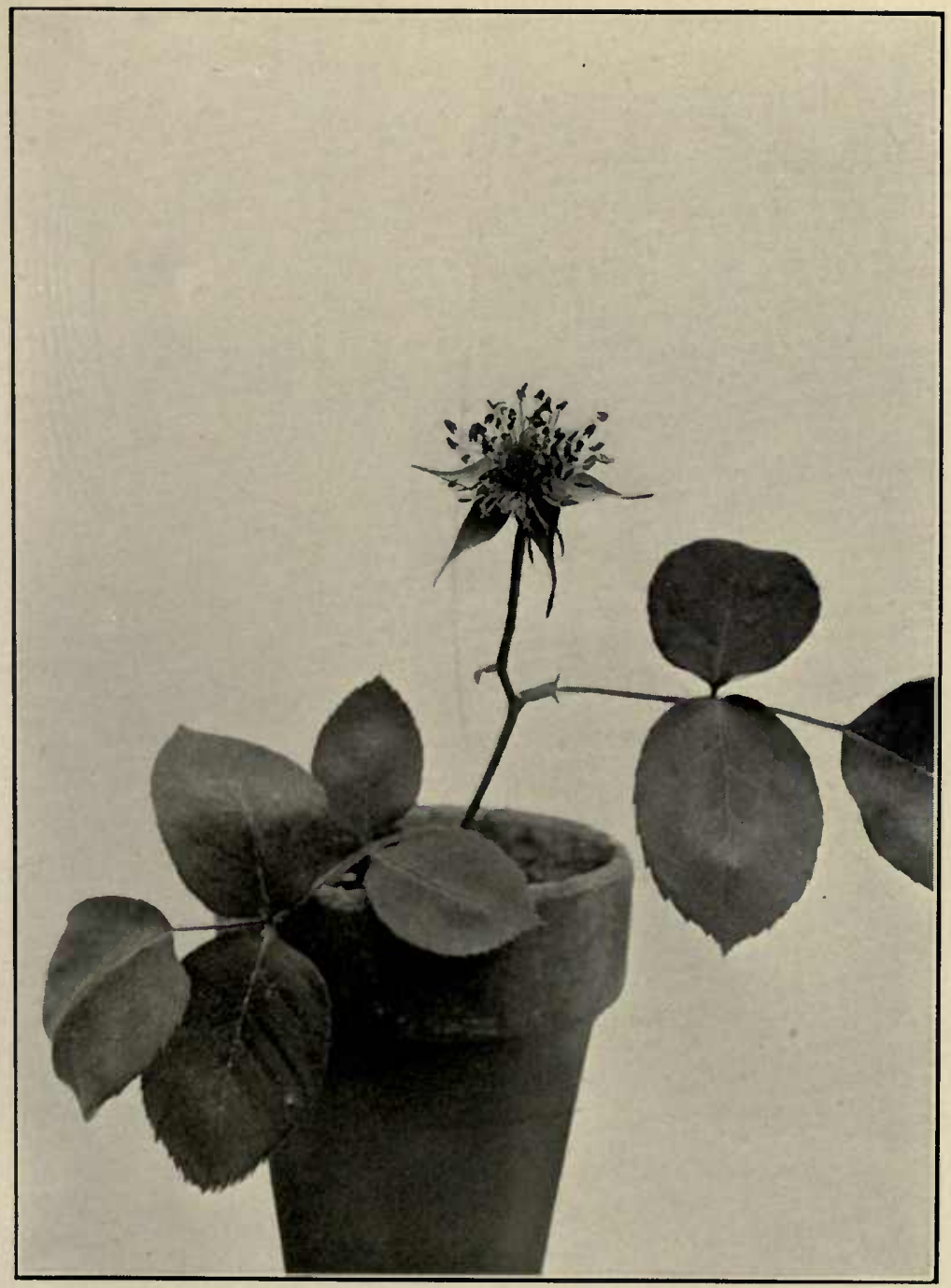

Fig. 6

ROSE WITH PETALS REMOVED, SHOWING THE STAMENS AND ANTHERS WHICH BEAR THE POLLEN 



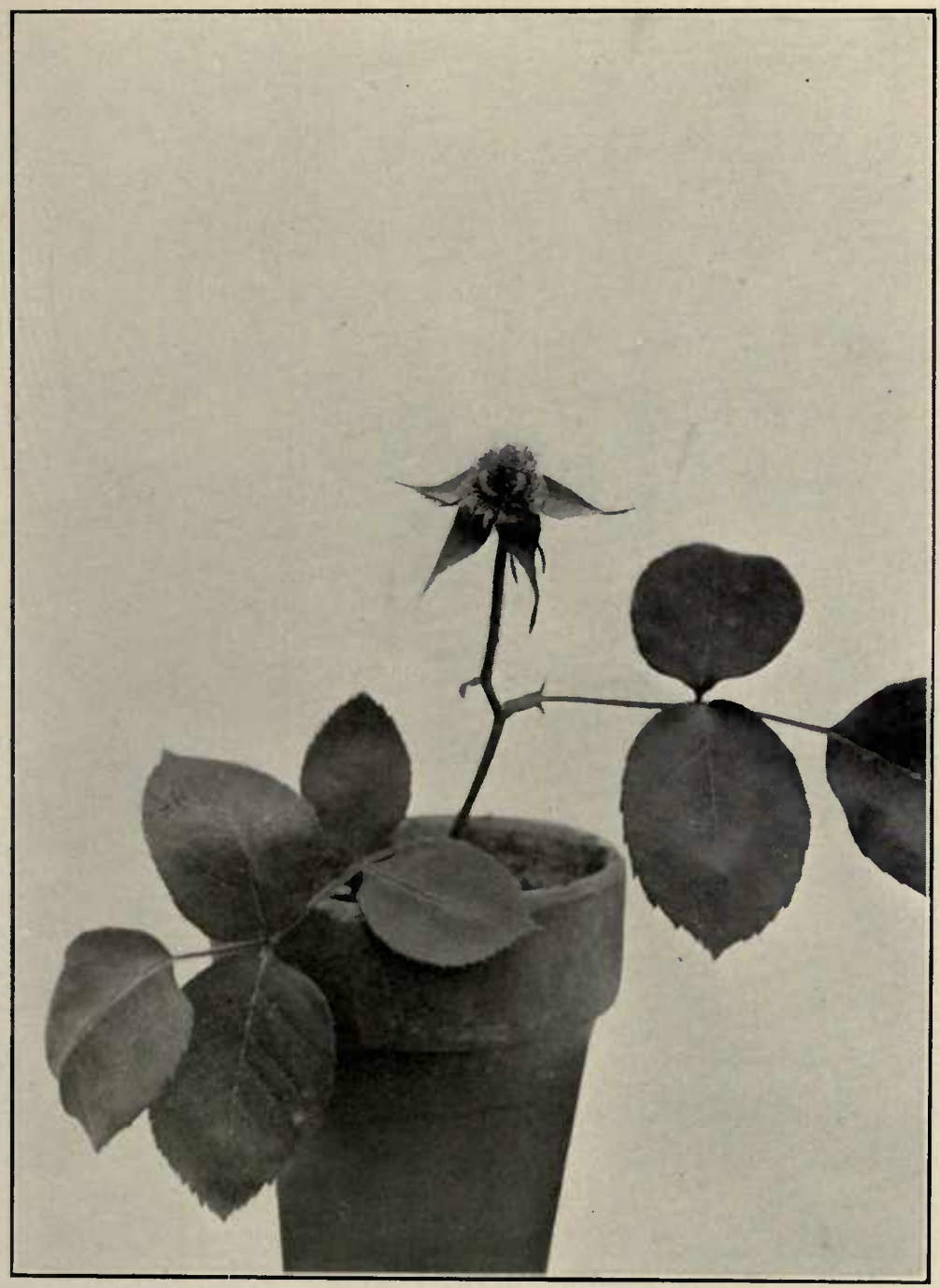

Fig. 7

SAME ROSE AS FIG. 6 WITII MOST OF STAMENS AND ANTHERS REMOVED, SHOWING THE STYLES AND PISTILS-THE FEMALE ORGANS 



\section{GENERAL INFORMATION}

the selected rose before the pollen reaches this stage. After the petals have been removed a small pair of scissors should be used to cut off the anthers. Our method has been to have a helper hold a piece of paper on which most of the stamens and the anthers and their pollen will be caught, and as we cut them off we turn the rose and only cut the stamens from the under side, thus precluding any possibility of the immature pollen reaching the pistils. As the stamens are cut off we generally find that some few of them will be bent over and not yet fully developed, and these should be carefully severed from the plant because later on they will be dangerous to the experiment. The pollen contained on the anthers which you have cut off if kept in the sun will be developed and can be used on any other flower which you care to hybridize. Having prepared the seed parent or female flower, you must now secure the pollen from the other parent selected. If you do not desire to use the other plant from which you purpose taking the pollen for a seed parent, it will be unnecessary to secure the pollen as above suggested, but the whole flower may be cut and the pollen should be active to have the experiment a success.

All authorities seem to agree with our experience that a bright, warm day is the best on which to breed roses, as in damp, cloudy weather the pollen does not 


\section{OUTDOOR ROSE GROWING}

seem active. When the pollen is falling from the anthers in the small, yellow dust, just mentioned, there is little doubt that your rose will be properly fertilized, it being only necessary to shake the pollen on to the pistils of the rose selected as a seed parent for the hybridizing to be complete. If you desire to use the rose you have selected as pollen bearer also as a seed parent, you must remove the pollen from it as suggested above, otherwise it will become fertilized by its own pollen. Perhaps it is safer to be sure of each experiment as one progresses; therefore it is well to cut off the anthers before the pollen becomes ripe and then, cutting the rose selected for the other parent, dust its pollen on the seed parent selected.

We have found that practically all of the roses we have hybridized have become good, healthy seed pods and have contained seeds; this success we attribute to the fact that we have always used great care and have never tried to.hybridize except with active pollen.

After roses have been hybridized you have nothing to do but allow the seed pods to develop, and when the weather becomes warm in late spring or early summer take the plants from the greenhouse or conservatory and plant the pots in soil out-of-doors to enable the heps to mature properly. In order to 


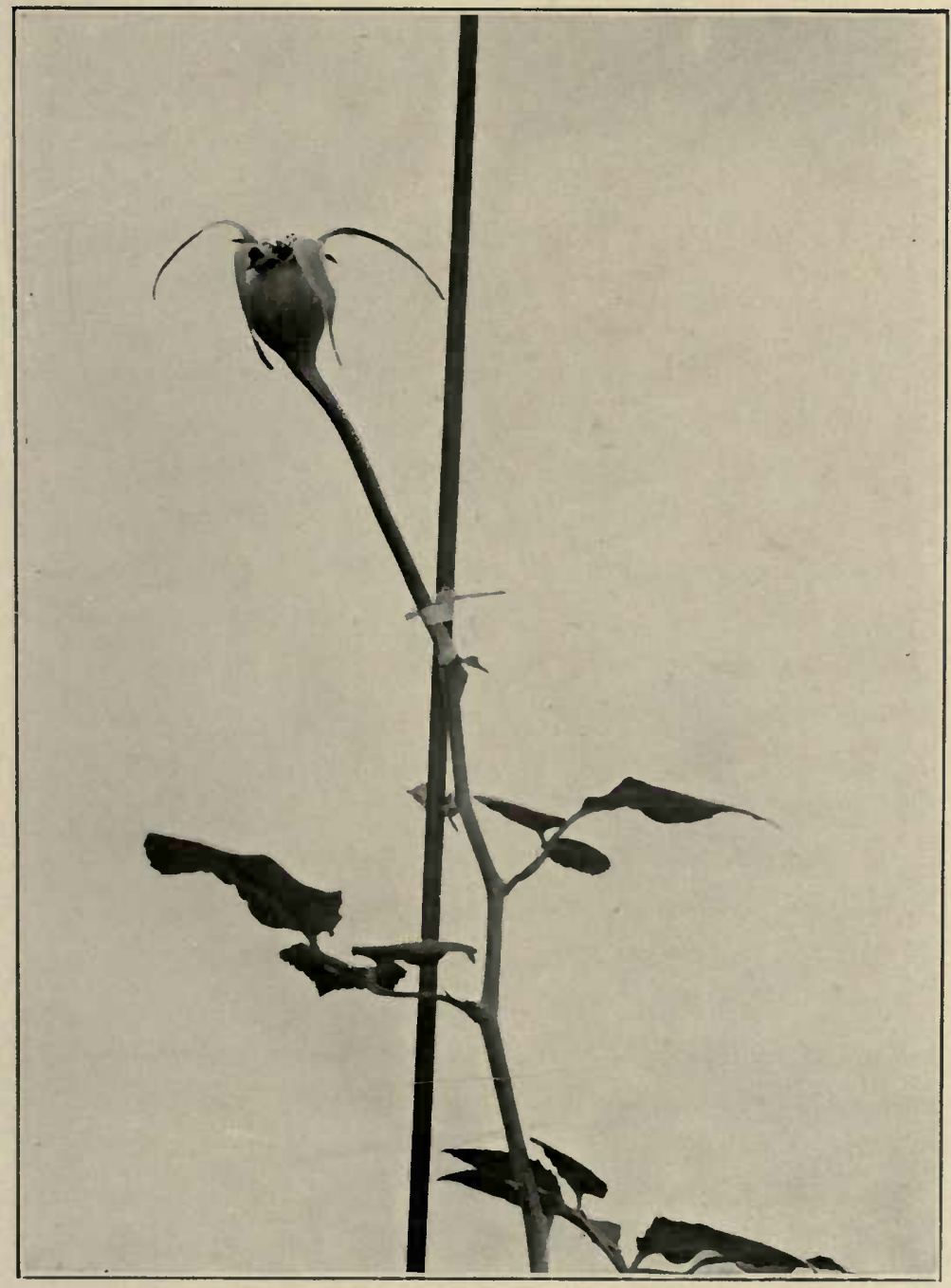

FIG. 8

SEED POI ON A HYBRID TEA ROSE WHICH IIAS BEEN IIYBRIDIZED 



\section{GENERAL INFORMATION}

protect seed pods from birds or other interference it is advisable to cover them both on the sides and tops with wire netting. Towards early autumn the seeds should be taken carefully from the heps and planted, each lot being kept separate from the others.

Our experience has been that probably in mature seeds a little rose plant will sprout in a month or thereabouts. Sometimes it will take two months or even longer, but with greenhouse care, bottom heat, and carefully-selected soil for germination of the seed a month and a half will witness the appearance certainly of some plants; in the course of another six weeks very small blooms will appear on some few of them, though not with the climbers.

It is our understanding that the commercial firms who grow new varieties at once bud on Manetti or Briar stocks to propagate the wood, but where a person had only a few seedlings, the method of inarching would seem to us the most practical way to secure quick results.

"Commercial Rose Culture," by Eber Holmes, contains a very interesting article, with illustrations, of this method. It mentions that the Department of Agriculture, Washington, D.C., Bulletin No. 202, Bureau of Plant Industry, Mr. George W. Oliver, is the source from which the information is taken. 


\section{OUTDOOR ROSE GROWING}

This operation would be very much quicker, and is supposed to be even more rapid than securing average blooms from cuttings. This is a plan we hope to try in our own seedlings.

To learn the method of inarching, the "Nursery Book," by Mr. L. H. Bailey, previously referred to, will give all the information required and should be used in conjunction with the book by Holmes just mentioned. 


\section{INDEX}

\section{A}

Admiral Dewey rose, 36

Aimeé Cochet rose, 36

Alex. Hill Gray rose, 50, 144

All-round best roses, $41,50,52$, $53,54,55,56,57,59,60,61,65$

Alphides, or green flies, 127

Alpina roses, propagation of, by suckers, 17

American growers, advantages of buying from, 94

Annie Besant rose, 50

Antoine Revoire rose, 36,50 102,103

Best 16, No. 3

Ards Rover rose, 68

Arthur R. Goodwin rose, 50

Ashes as a fertilizer, 126

Autumn planting, advantage, 97

\section{B}

Bardou Job rose, 50

Baroness Rothschild rose, 50

Beaute Inconstante rose, 50

Beds, care of, 107

composition, 87

design - suggestions, 100,102

drainage, 87

finished, 88

for autumn planting, 90

location and preparation, 80 soil, soils, 83,88

Belle Siebrecht rose, 37

Best all-round roses, 41 sq.
Betty rose, 50

Best 16, No. 15

Black spot, cure for, 132,138

Blanc Double de Coubert rose, 51

Blanks, forms for, 98

Blood as a fertilizer, 126

Bone meal, 105, 126

Bourbon Perpetual rose, 31

Breeding new varieties, 30

methods kept secret, 35

table of main varieties, 31

Brenda rose, 51

Briar stocks for budding, 19, 149 for grafting, 24

Bridesmaid rose, 36

British Queen rose, 51

Budded roses, 20, 22, 23, 93 advantages of, 21,22 objections to, 20

Budding, 18, 19

Buds, small, removal of, 126

Bugs or beetles, 131

\section{C}

Camoens rose, sport from (Ecarlate), 26

Captain Hayward rose, 51

Caroline Testout rose, 36, 51, 69

Cecile Brunner, climbing, 72

Céline Forestier rose, 74

Characteristics of prominent roses, 33

Chauteau de Clos Vougeot, 51 


\section{INDEX}

Cherokee rose, 142

China roses, 31

Christine Wright rose, 69

Classification-main varieties, 50-66

Climate, American, influence of, on European roses, 38, 40, 139

Climbers, 67 planting, 75 pruning, 76

Wichuraiana, 76

Climbing Hybrid Tea roses, 68

Climbing Kaiserin Augusta Victoria, 69

Climbing Mrs. W. T. Grant rose, 70

Climbing Richmond rose, 70

Cloth of Gold rose, 74

Colors and shades, 40, 42

Conrad Ferdinand Meyer rose, 51

Coquette de Lyon rose, 37

Coquina rose, 74

Countess of Shaftesbury rose, 51

Crimson Rambler, 78, 142

Crushed stone for underdrainage, 87

Cultivation, 125

Cutting of flowers, 121

Cutting off bushy tops in late autumn, 134

Cuttings, 15, 17, 21

\section{D}

Daily Mail rose, 59

Damask Hybrids, 31

$$
\begin{aligned}
& \text { propagation of, } 17 \\
& \text { Perpetual, } 31
\end{aligned}
$$

Dean Hole rose, 51

Debutante rose, 74
Diagram showing location of each rose should be kept, 102, 103

Disbudding, 126

Diseases, 125 remedies, 126,137

Dr. Gill rose, 36

Dr. Van Fleet rose, 70

Dorothy Dennison rose, 72

Dorothy Page Roberts rose, 51

Dorothy Perkins rose, 72, 73

Dorothy Ratcliffe rose, 51

Drainage, 87

Duchess of Albany rose, 26

Duchess of Sutherland rose, 52

Duchess of Wellington rose, 52 , 102,111

Best 16, No. 14

Duchess of Westminster rose, 52

Dwarfs (bushes) and standards, $38-40$

\section{E}

Ecarlate rose, a sport from Camoens, 26, 52

Edmée Metz rose, 36

Edu Meyer rose, 52

Eliza Robichon rose, 73

Ellen Wilmot rose, 52

Best 16, No. 4

Etoile de France rose, 52

Eugene Boullet rose, 52

Evangeline rose, 30, 73

Excelsa rose, 29, 73

\section{F}

Farben Koenigin rose, 53

Ferdinand Jamin rose, 36

Fisher Holmes rose, 36, 53

Flies, green, 127 


\section{INDEX}

Flowers, number of, in a season, 111

Foreword, 7

Formaldehyde for spraying, 133

Forms for inquiry and order blanks, 98, 99

Fortune's Yellow rose, 78

Franciscka Kruger rose, 53

Frau Karl Druschki rose, 36, 44, 53

Best 16, No. 1

Freifrau Ida von Schubert rose, 53

Freiherr von Marschall rose, 53 Frost, protection of soil from, for late autumn planting, 90

F. R. Patzer rose, 53

\section{G}

Gardenia rose, 73

Gartendirector Hartrath rose, 53

General Jacqueminot rose, 35, 70

General MacArthur rose, 29, 53, 102, 111

Best 16, No. 10

General-Superior Arnold Janssen rose, 53

Geoffrey Henslow rose, 53

George Arends rose, 53

George C. Waud rose, 54

George Dickson rose, 54

George Laing Paul rose, 3

Gloire de Dijon rose, 74

Gloire Lyonnaise rose, 54

Grace Molyneux rose, 54

Grafting, 24

Grange Colombe rose, 54

Green flies, destruction of, 127

Greenhouse for hybridization, 32

Grossherzog Freidrich rose, 54
Ground, cultivation, 128

Gruss an Teplitz rose, 54

Best 16, No. 12

Gustav Grunerwald rose, 55

\section{H}

Harry Kirk rose, 55

Best 16, No. 13

Heinrich Schultheis rose, sporte from, 27

Hermosa rose, 55

Hiawatha rose, 29, 73

Hilling up late in autumn, 134, 144

Hoeing, 128

Hon. Ina Bingham rose, 55

Hugo Roller rose, 55

Hybrid China roses, 31,34

Perpetual roses, 22, 27, 29$31,34,38,44,47,68$, 122,139

ancestors of, 30,31

Tea roses, 22, 27, 30, 31, 34, $38,47,68$ sq., 122,139 , 143,144

Wichuraiana roses, 29,69

Hybridization, 30, 32, 33, 145

Hybrids, seeds from, useless, 16

\section{I}

Indica, Odorata, 31

Information, general, 139

Irish Brightness rose, 55

Irish roses, single, 44

\section{J}

Jacqueminot rose (see General Jacqueminot)

Jacques Vincent, 55 


\section{INDEX}

Japanese Multiflora stocks for budding, 19, 20, 94, 95

John Cuff rose, 55

Jonkheer J. L. Mock rose, 55, 111

Best 16, No. 6

Joseph Hill rose, 45, 55, 102, 103

Juliet rose, 55

\section{K}

Kaiserin Augusta Victoria rose, 37,56

Key to classification, 51

Killarney rose, 40, 46, 56,102,111 new varieties of (sports), 26

Best 16, No. 5

Killarney Brilliant rose, 56

Konigin Carola rose, 36, 56

L

La Detroit rose, 36

La Fiamma rose, 74

La France rose, 34, 37, 57 dark, 26

La Tosca rose, 57

Lady Alice Stanley rose, 56, 111

Best 16, No. 8

Lady Ashtown rose, 56

Lady Barham rose, 56

Lady de Bathe rose, 56

Lady Downe rose, 57

Lady Hillingdon rose, 57

Lady Katherine Rose, 57

Lady Margaret Boscawen rose, 57

Lady Mary Fitzwilliam rose, 37

Lady Pirrie rose, 57

Late autumn planting, 90

Laure de Broglie rose, 57

Laurent Carle rose, 57

Best 16, No, 11
Layering, 16

Liquid manure, 126

Litter for winter protection, 134 , 135

Location and preparation of beds, 80

Lord Penzance rose, 57

Louise-Catherine Breslau rose, 58

Lucida roses, propagation of, from suckers, 17

Lyon rose, 58, 95

\section{M}

Mabel Drew rose, 58

Madame Alfred Carriere rose, 75

Madame A. Tupinier rose, 58

Madame Bérard rose, 35, 70

Madame Bravy rose, 34, 35

Madame Charles Dubreuil rose, 58

Madame Charles Lutaud rose, 59

Madame Charles Worth rose, 59

Madame Edmée Metz rose, 36 , 59

Madame Edmond Rostand rose, 59

Madame Edouard Herriot rose, 59

Madame Gabriel Luizet rose, 59

Madame Hector Leuillot rose, 59,71

Madame Jules Bouche rose, 59 Best 16, No. 2

Madame Jules Grolez rose, 60

Madame Leon Pain rose, 60, 111 Best 16, No. 7

Madame MelanieSoupertrose, 60

Madame Ravary rose, 60

Madame Segond Weber rose, 60

Madame Victor Verdier rose, 34 


\section{INDEX}

Mdlle. Marie Mascurand rose, 60 Main list of roses, 43, 50-66

Maman Cochet rose, 60

Manetti stocks for budding, 19, 149 for grafting, 24

Manure, 105, 125, 126

Marechal Niel rose, 74

Margaret Dickson rose, 60

Marquise de Sinety rose, 60

Mary, Countess of Ilchester, rose, 61

Merveille de Lyon rose, 36, 61

Mildew, 129, 131, 132

Miss Alice de Rothschild rose, 61

Mrs. Aaron Ward rose, 61

Mrs. Amy Hammond rose, 61

Mrs. Arthur E. E. Coxhead rose, 61

Mrs. A. R. Waddell rose, 6 Best 16, No. 16

Mrs. Charles Custis Harrison rose, 61

Mrs. Dudley Cross rose, 61

Mrs. E. Townshend rose, 62

Mrs. Frank Bray rose, 62

Mrs. Fred Straker rose, 62

Mrs. Greorge Dickson rose, 62

Mrs. Harkness rose, 27

Mrs. Harold Brocklebank rose, 62

Mrs. Herbert Hawksworth rose, 62

Mrs. John Laing rose, 62

Mrs. Joseph H. Welch rose, 63

Mrs. Leonard Petrie rose, 63

Mrs. Longworth rose, 36, 63

Mrs. Wakefield Christie-Miller rose, 63

Mrs. W. J. Grant rose, 37, 63 climbing, 70
Mock rose (see Jonkheer J. L. Mock), 55, 111

Molly Sharman Crawford rose, 20,61

Moss, 84, 100, 129

Mulching with peat moss, 84-87, 129

Multiflora (see Japanese Multiflora)

Musk rose, 31

My Maryland rose, 29, 63

\section{$\mathrm{N}$}

Natalie Bottner rose, 63

New varieties, development, 25

Noisette roses, $31,74,75$

\section{0}

Odette Pedriolle rose, 63

Ophelia rose, 63

Ordering, importance of care in, 91

Oskar Cordel rose, 63

Own-root roses, 21, 22, 92

\section{P}

Paul Neyron rose, 64

Paul's Early Blush rose, 27

Peat moss for rose beds, 84-87,

129

Periods of blooming, 111

Pernetiana rose, 31,146

Perpetual Hybrids, 22, 27, 29, 30, 31, 38

Persian Yellow rose, 16

Pests, 125

$$
\text { Briar (Luteae), } 31
$$

remedies, 127, 137

Pharisaer rose, 64

Pierre Notting rose, 144 


\section{INDEX}

Pinching off superfluous blooms, 121

Planting, bedsand preparation, 80 general instructions, 100 late autumn, advantage, 97 of climbers, 75 rules for, 106

Plants, acclimated, 94 autumn, 90

budded-field-growndormant, 92 grafted-small, 38 ordering of, 91 own-root, 21, 22, 92

Polyanthas, climbing, 72

President Carnot rose, 102, 103 President W. H. Taft rose, 64 Prince de Bulgarie rose, 64 Principal A. H. Pirie rose, 64 Propagation by suckers, 17 established varieties, 15 new varieties, 23

Protection fromautumn frosts, 90 general, 133

of standards, 135

wall一wind-winter, 136

Provence hybrids, propagation of, from suckers, 17

Pruning, general, 109 in late autumn, 134 of climbers, 76

\section{Q}

Queen Mary rose, 64

R

Radiance rose, 29, 64 Rayon d'Or rose, 64 Red Four Seasons, 31
Reine Marie Henriette rose, 35, 70

Remedies, pests and diseases, 125,137

Renee Wilmart-Urban rose, 65

Richmond rose, 65

climbing, 70

Robert Huey rose, 65

Roots of roses, care of, 100 , 106

feeding of, 125

spreading out, 104, 107

Roots of trees, protection from, 80

Rosa Moschata, 31

Roses, best of each main color, 42,43 sq.

breeding - main varieties, 31

budded, 19, 22, 95

budding, 19

classification of, 50-66

climbers, 67

cultivation, 125

dwarfs, 39

foreign-color varying, 40 pedigree, 35,36

sixteen best all-round, 41, $50,52,53,54,55,56,57$, $59,60,61,65$

standards, 38, 135

Rugosa roses propagated by suckers, 17

stock for budding, 20

Rules for planting, 106

$\mathrm{S}$

Seedlings, 25, 28

Seeds, established varieties, 16 hybrids, 16 


\section{INDEX}

Senateur Mascurand rose, 65

Shoots from below the bud, 20

Shower of Gold rose, 74, 75

Simplicity rose, 65

Sixteen best roses, 41 sq.

Slugs, destruction of, 130

Soil, most suitable, 83

Souv. de Louis Perrier rose, 65

Souv. de M. Verdier rose, 36

Souv. du President Carnot rose, 65,70

Spinosissima roses, propagation of, by suckers, 17

Sports, 25 rarity of, 28

Spraying to kill aphides, 127

Standards and dwarfs (or bushes), 38

protection of, in winter, 39 , 40

weeping, 39

Stock of plants kept on sale, 92

Stocks, Briar, 19, 24

budded - dormant - fieldgrown, acclimated, 92, 94

Japanese Multiflora, 19, 94, 95

Manetti, 19, 24

Rugosa, 17

shoots from, below the bud, 20

Suckers, 17, 130

Sunburst rose, 65

Suzanne Marie Rodocanachi rose, 65

Sweetheart rose, 29
T

Tea roses, $22,37,38,39,140,144$

climbing, 68 sq., 140, 142

Tongueing (see Layering), 17

ర

Ulrich Brunner rose, 65

Underdrainage, 87

V

Varieties, best, 33, 41, 50 sq.

established, 15

introducers of new, 27

main list, 50-66

new, 40

propagation of new, 23,25

Viscountess Folkstonerose, 36,66

W

W. A. Richardson rose, 75

Watering, 129

White Dorothy rose, 73

White Killarney rose, 66

White Maman Cochet rose, 66

Wichuraianas, 69, 70, 72 sq., 140

Wm. Shean rose, 66

Willowmere rose, 66

Windbreaks, 81,142

Wintering roses, $139 \mathrm{sq}$. received late in autumn, 93

Wood ashes as a fertilizer, 126

W. R. Smith rose, 66

\section{$\mathrm{X}$}

$\mathrm{X}$ avier Olibo rose, 66 



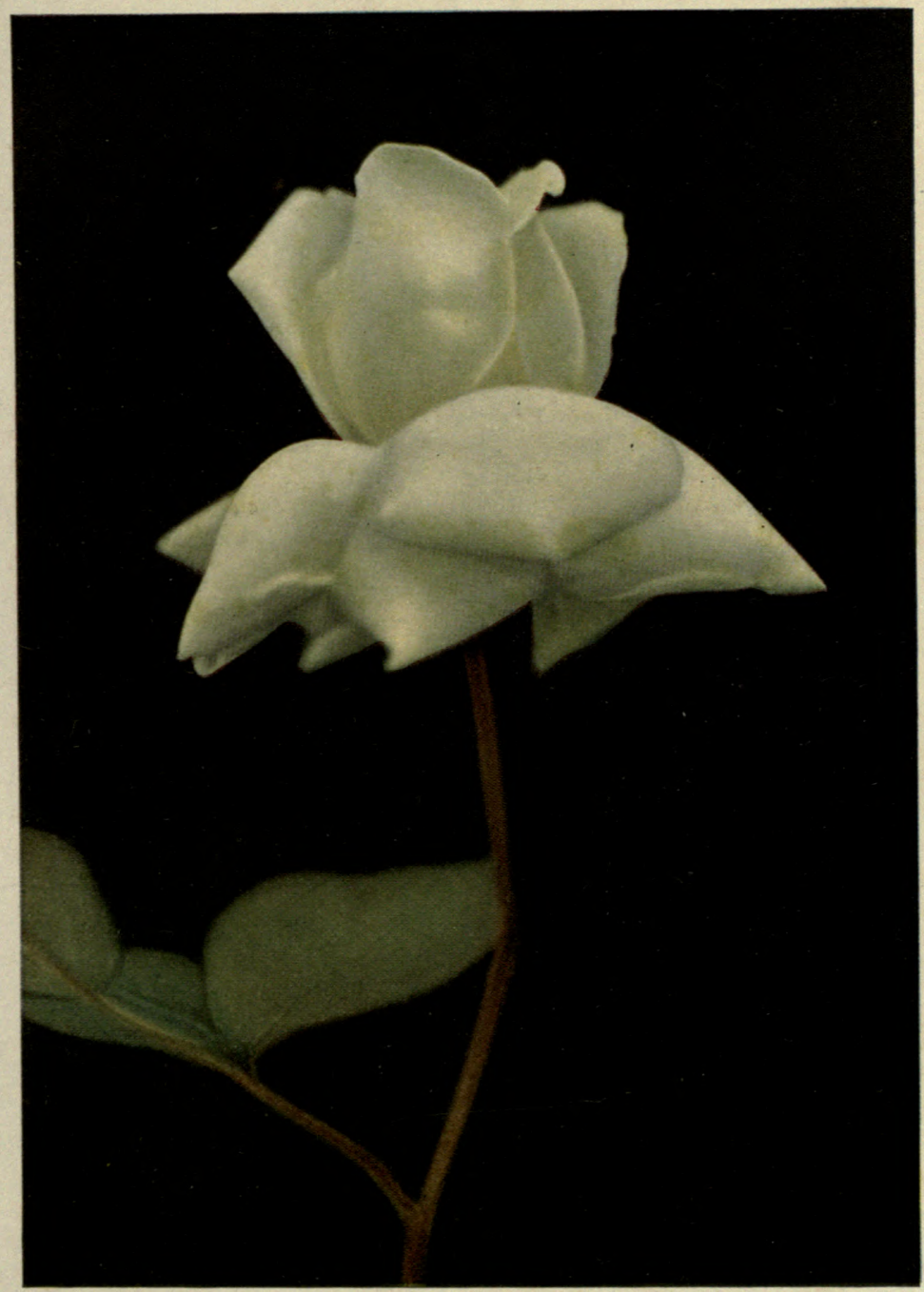

ALEX. HILL GRAY Tea

Alex. Dickson \& Sons 1911

With us lighter than description. Fair growth, some autumn bloom 



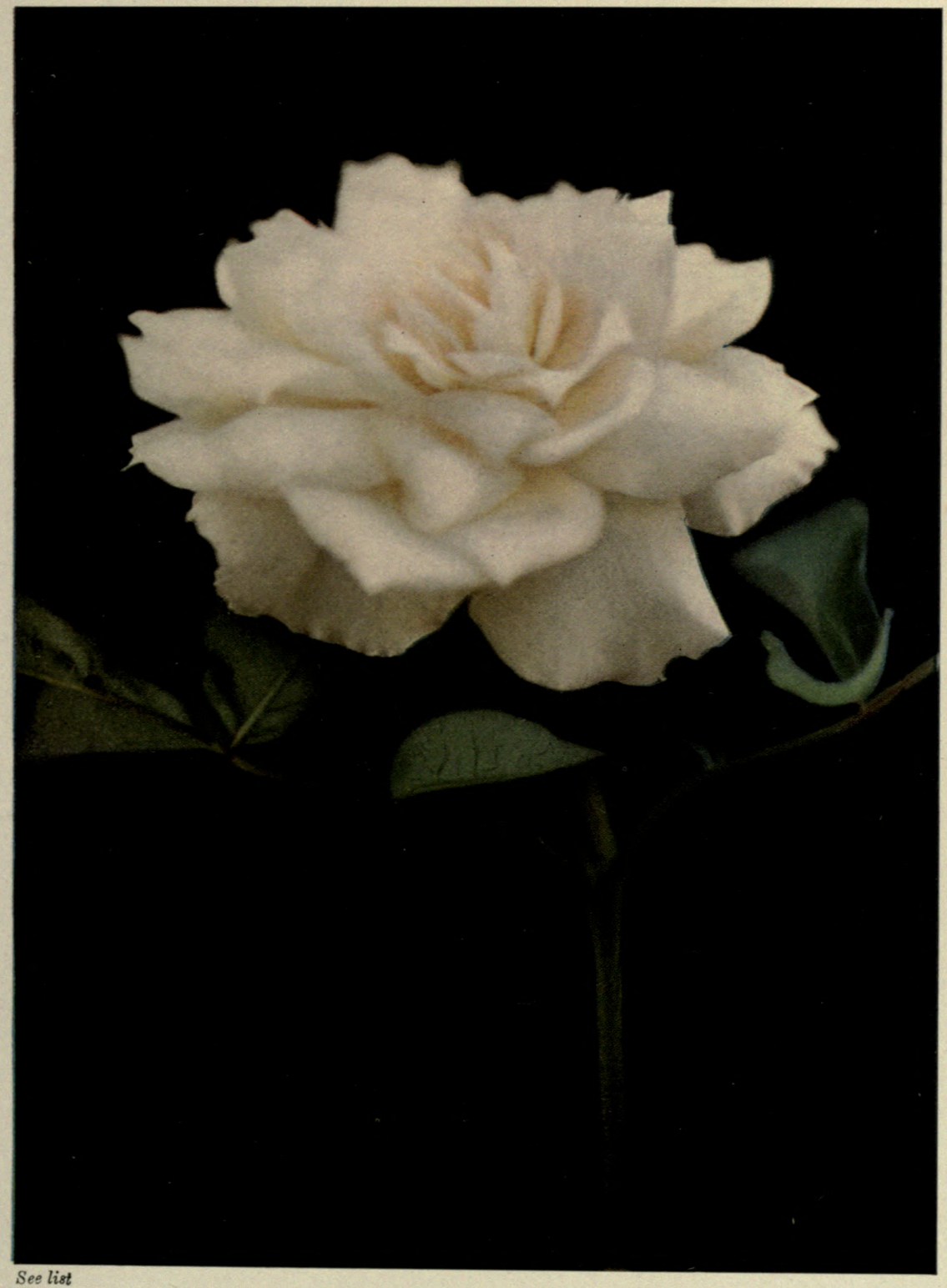

ANNIE BESANT Hybrid Tea

P. NABONNAND 1910 



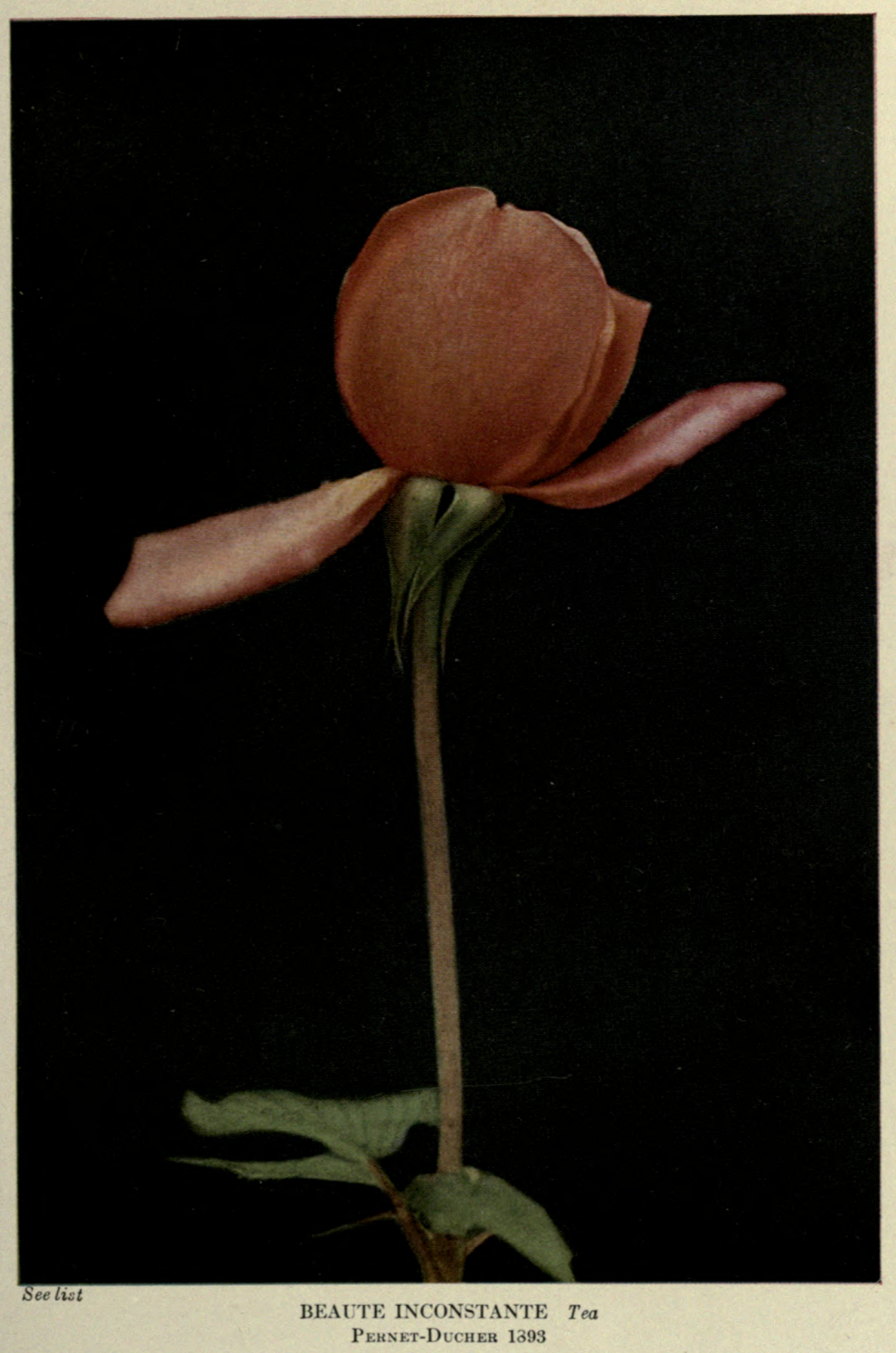





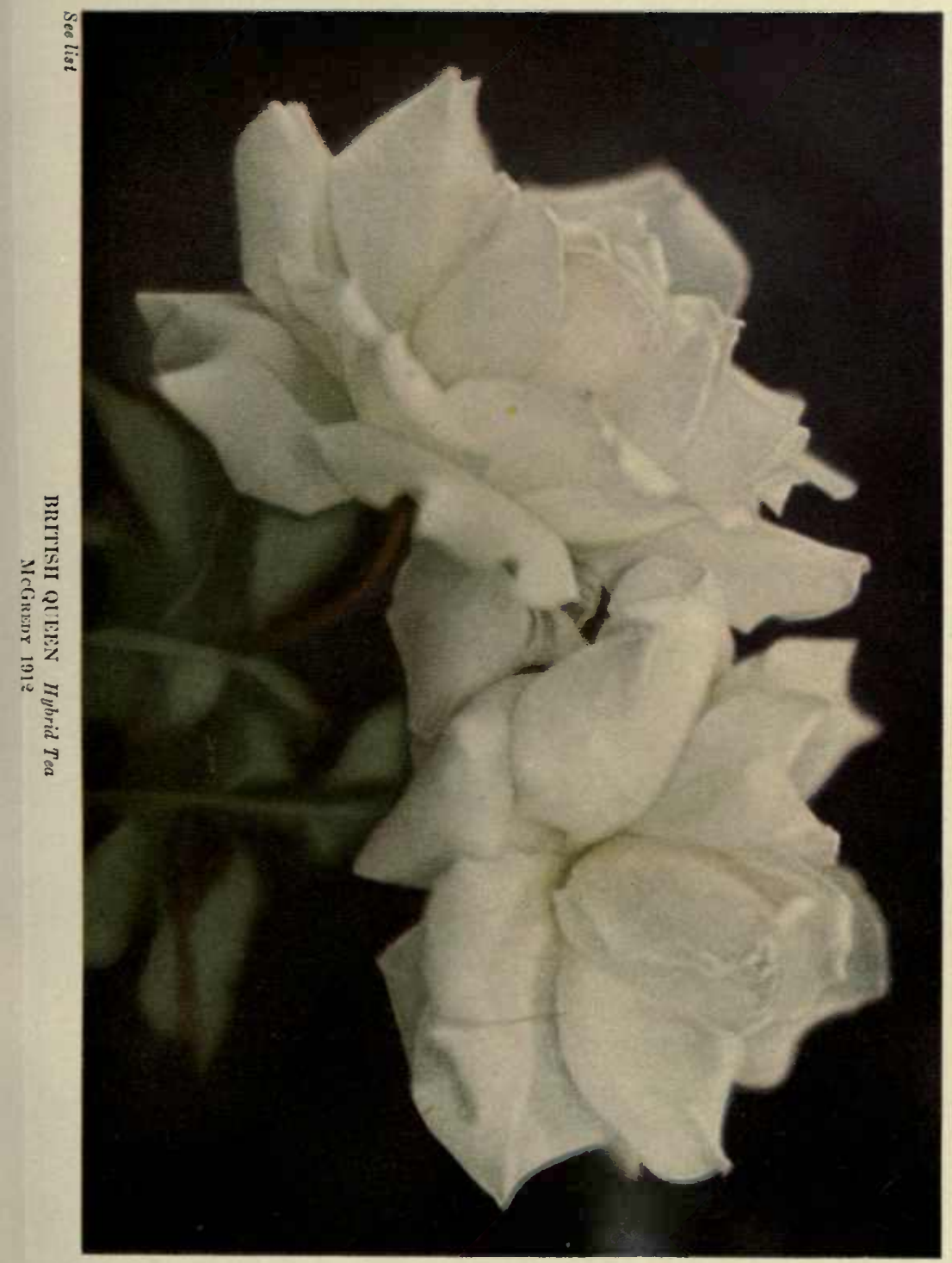





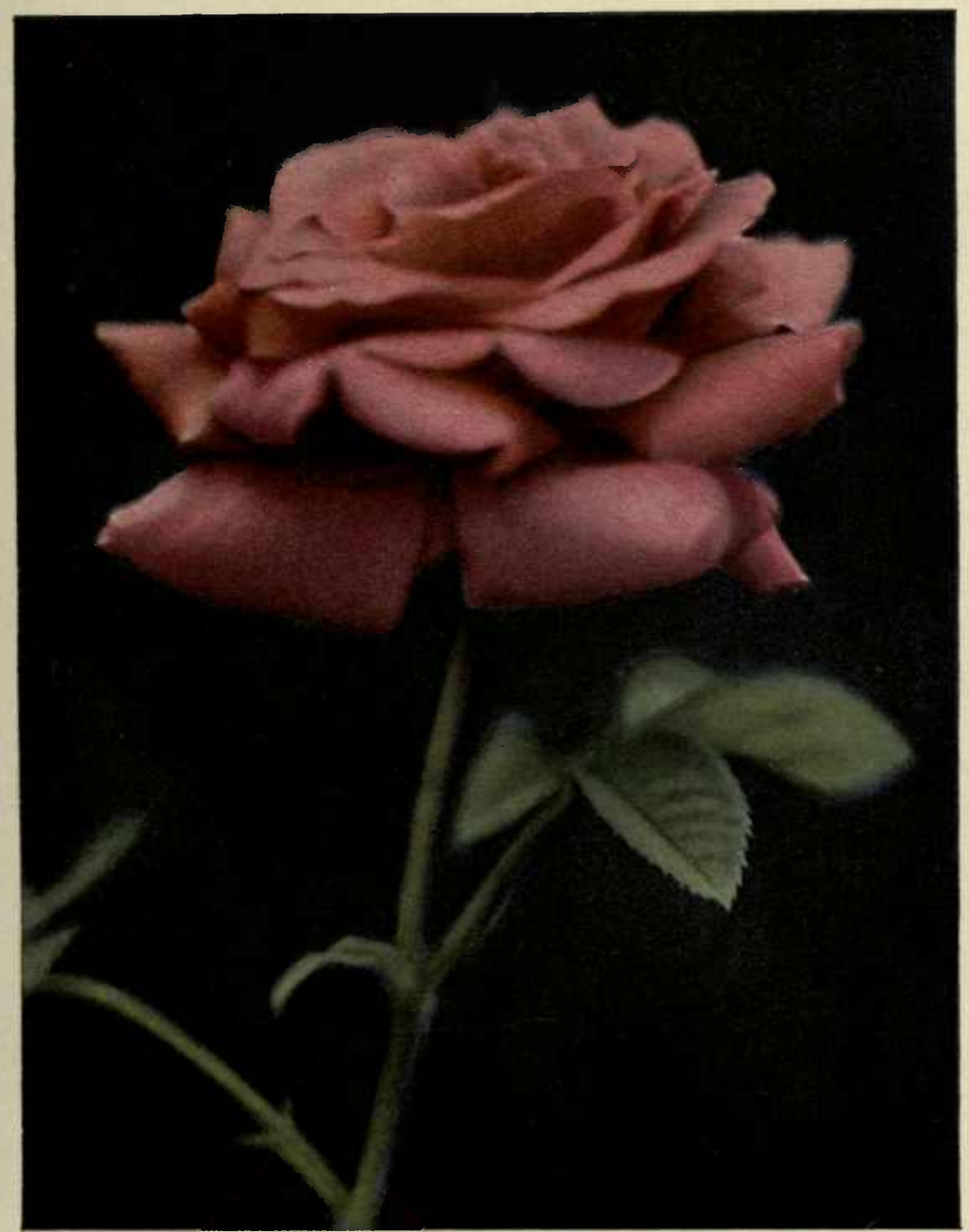

\section{CARDINAL IIybrid Tea}

Cook \& SoN 190

Fair growth, some late aut _mn bloom

A Collector's rose 



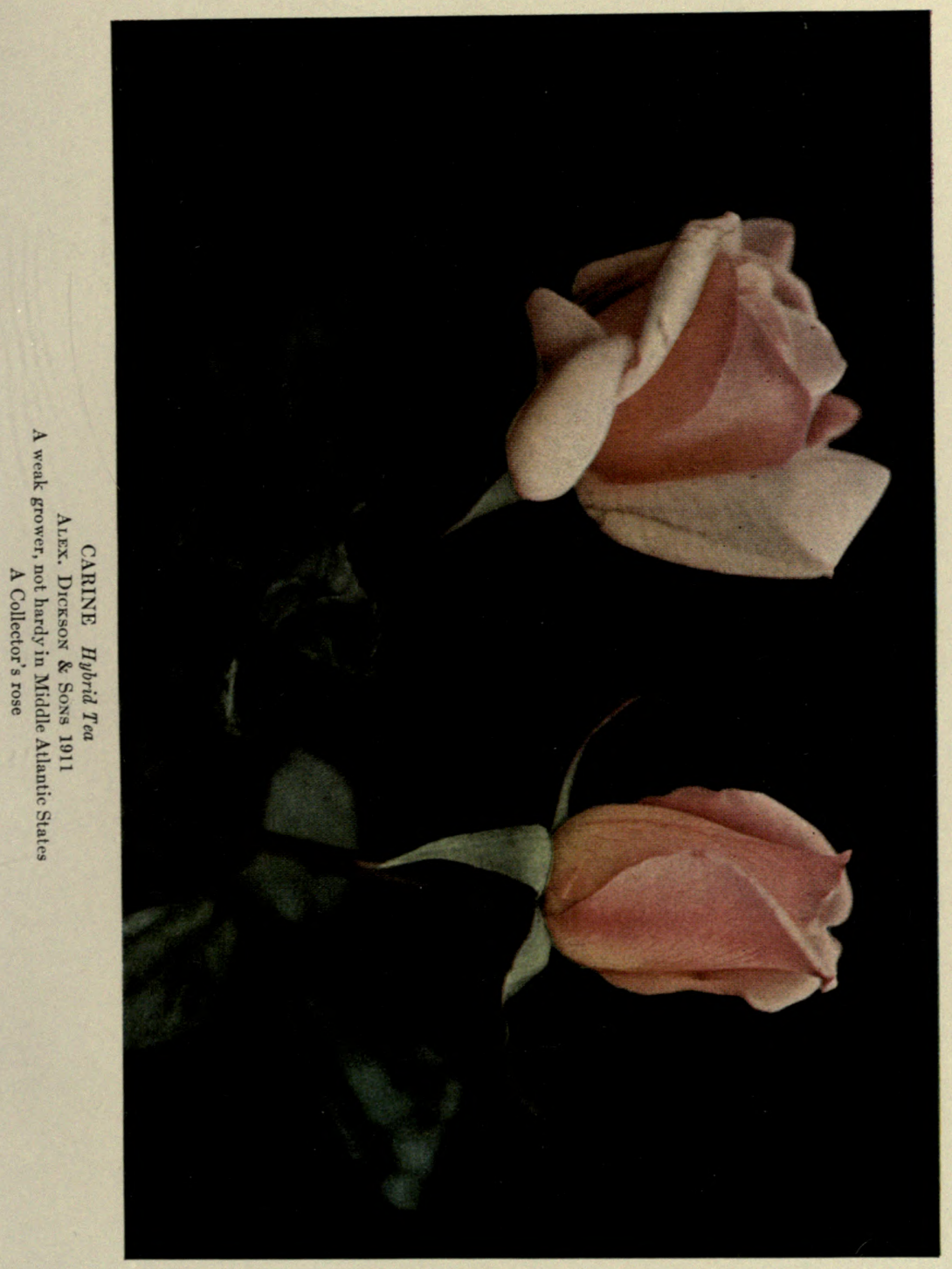





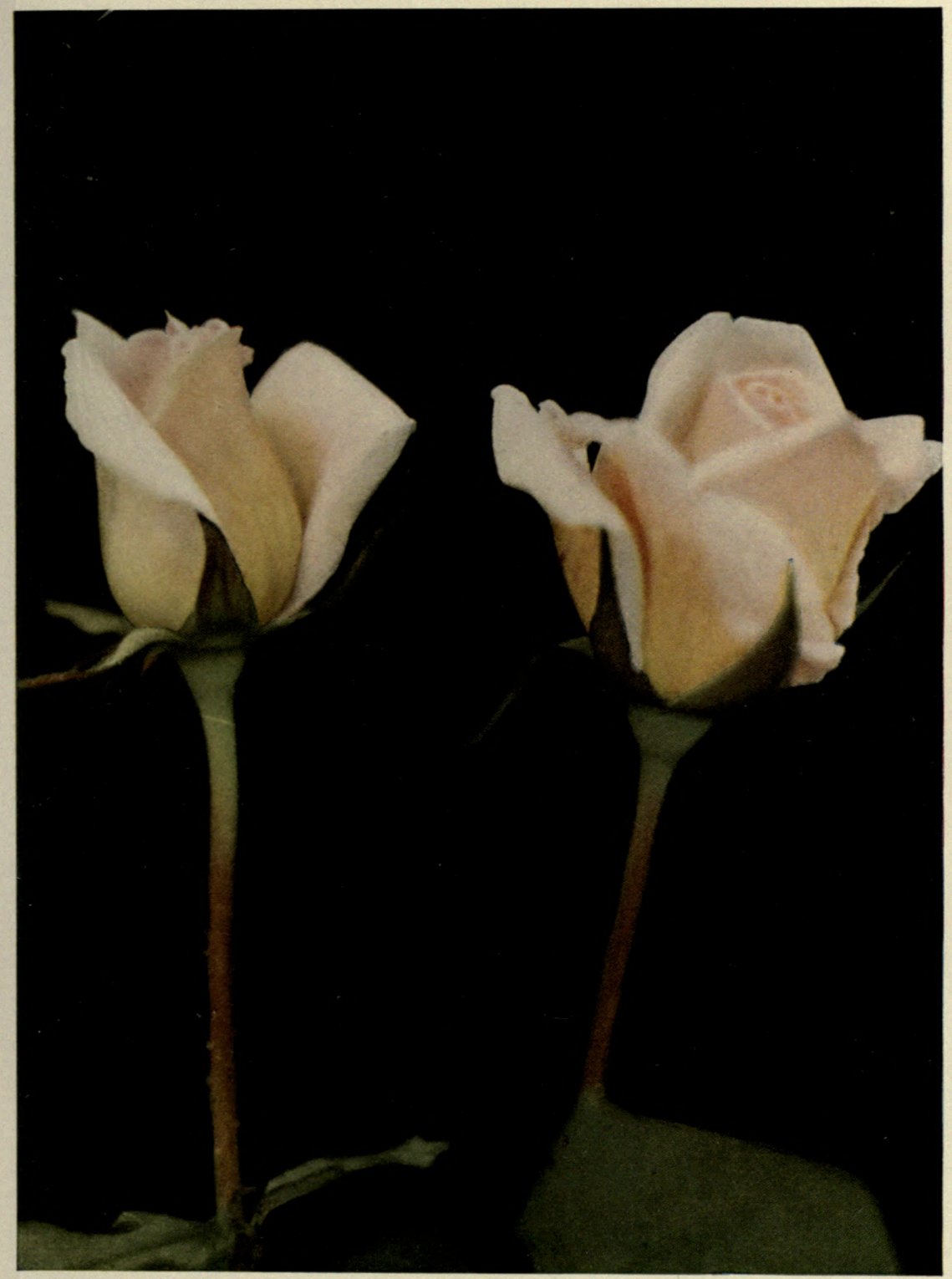

COMTESSE FELICIE HOYOS Hybrid Tea

SOUPERT \& NotTING 1912
LADY GREENALL Hybrid Tea

Alex. Dickson \& Sons 1911 



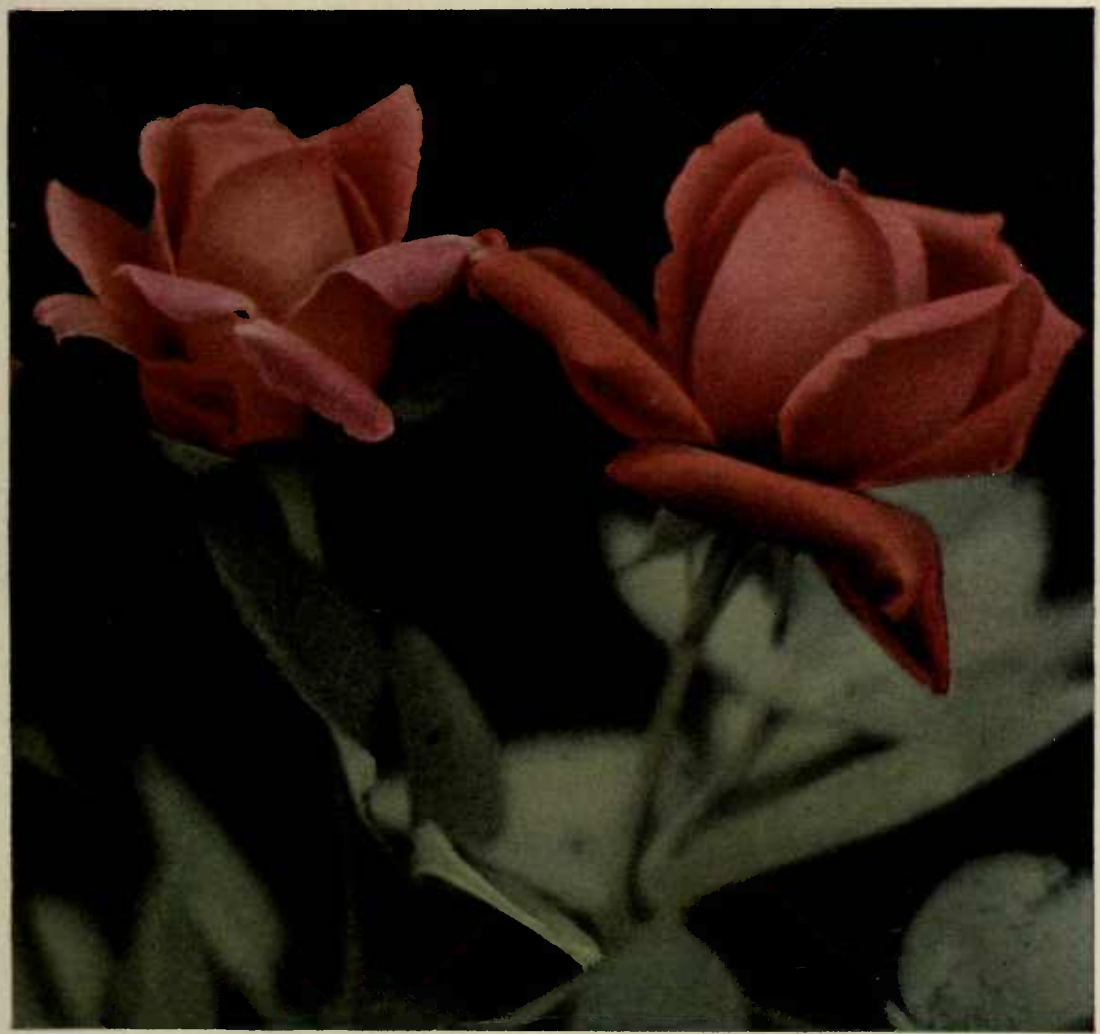

CHARLES J. GRAHAME II $y$ brid Tea

ALEX. Dickson \& Sons 1905

KAISER WILIIELMI II. IIybrid Tea

Both weak growers in Nliddle Atlantic States 



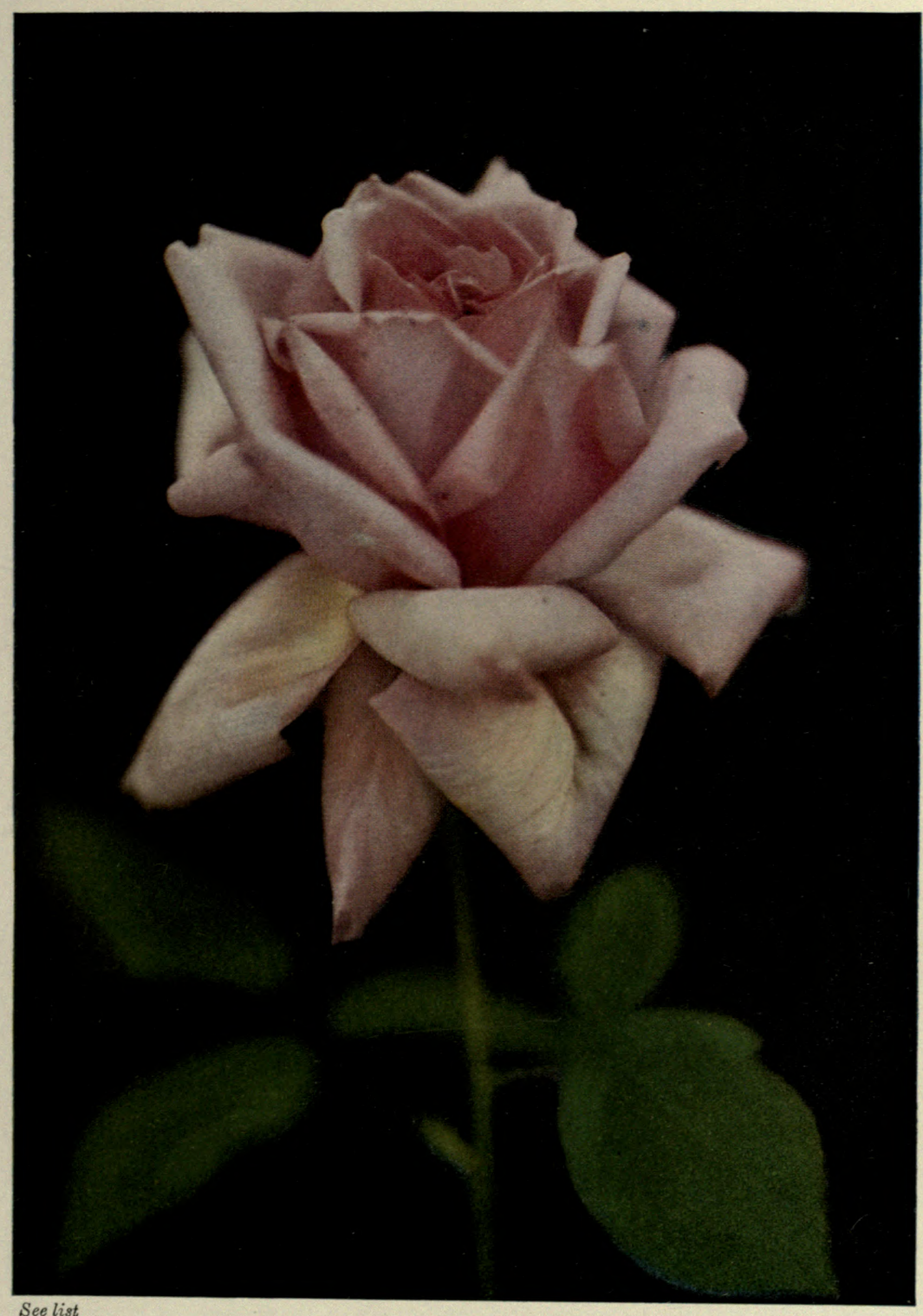

DEAN HOLE Hybrid Tea

Alfx. Dickson \& Sons 1904 



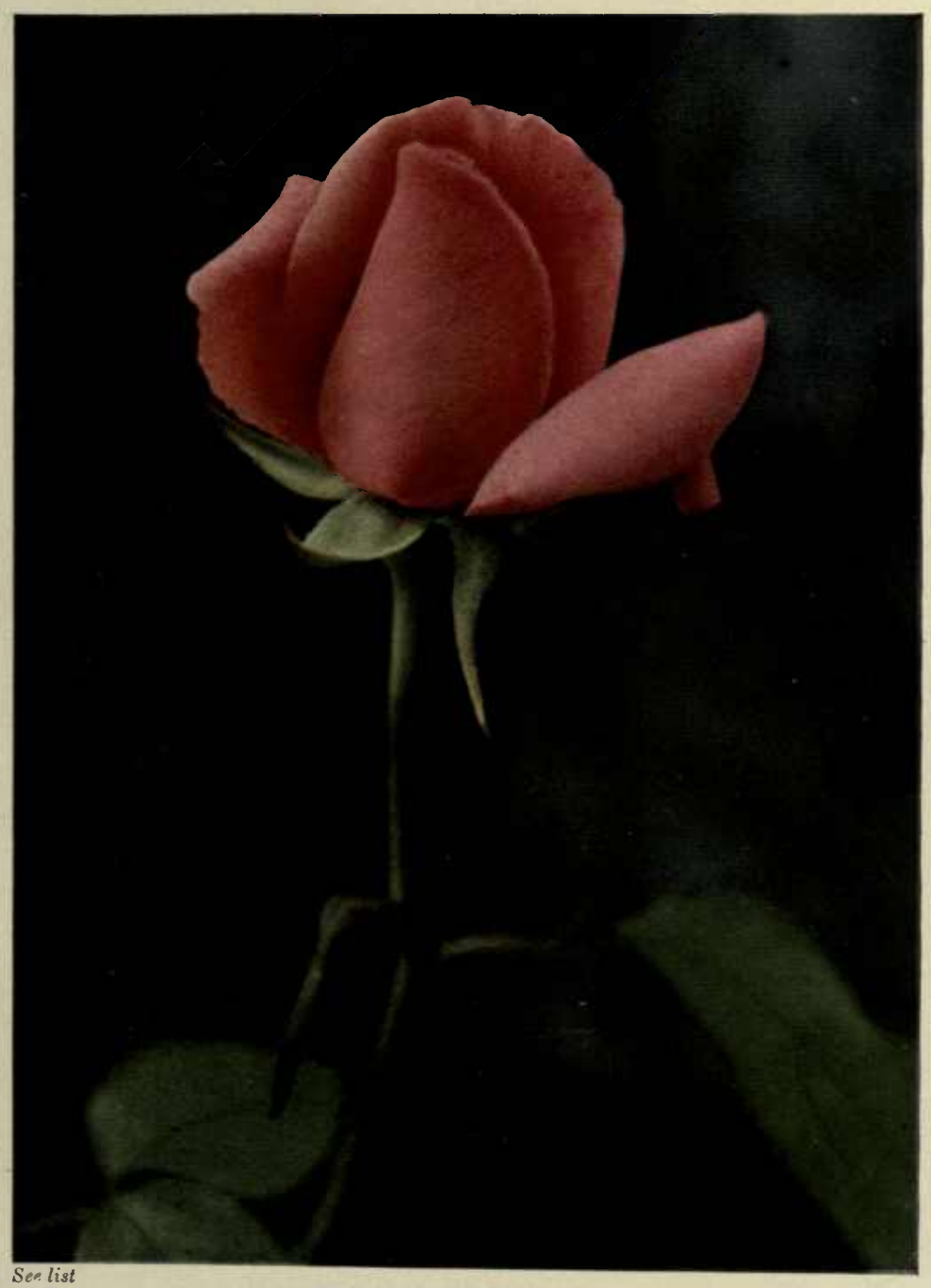

DOROTHY PAGE ROBERTS Mybrid $T_{e a}$

Alex. Dicksox \& Soss 1907 



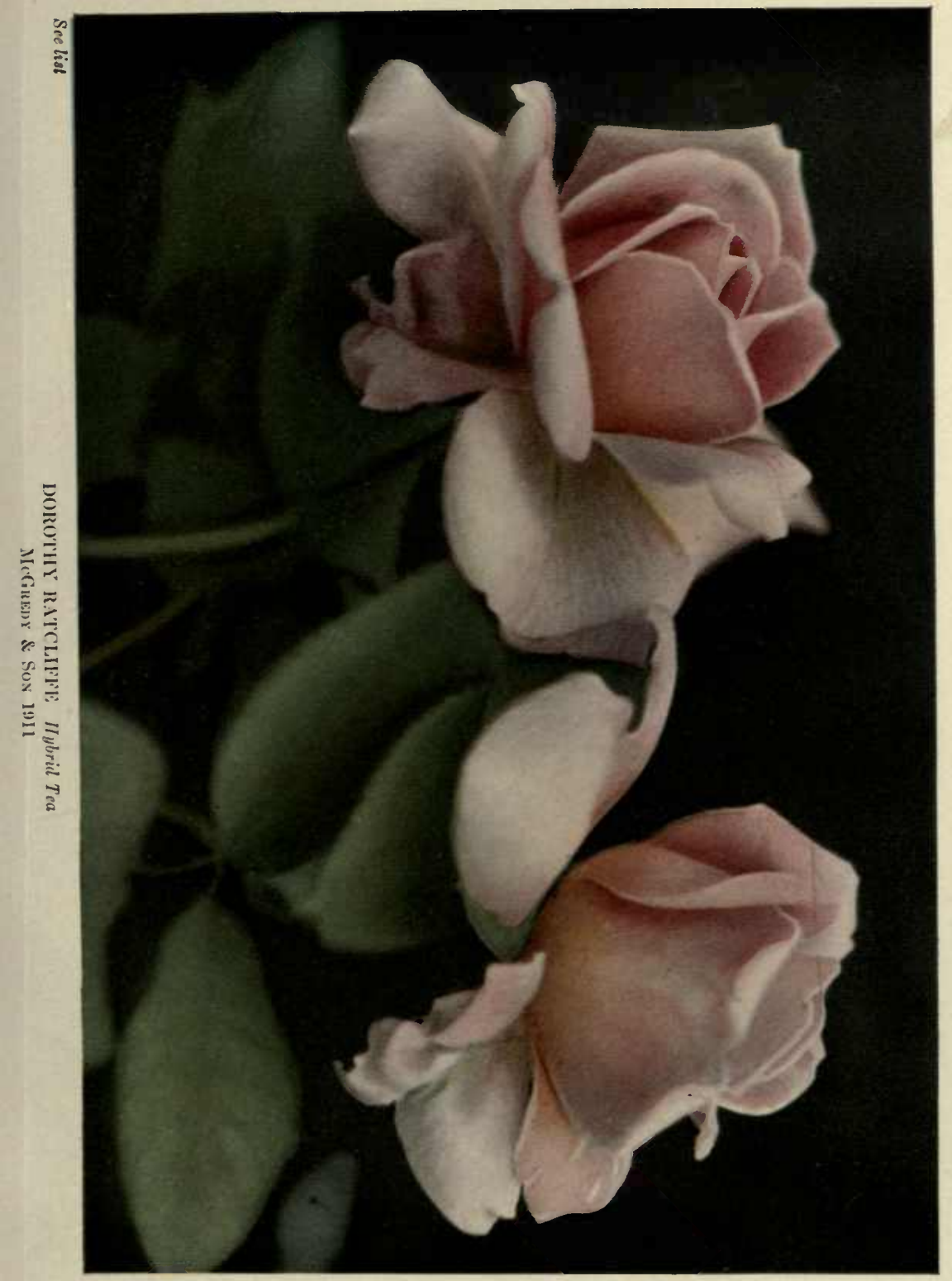





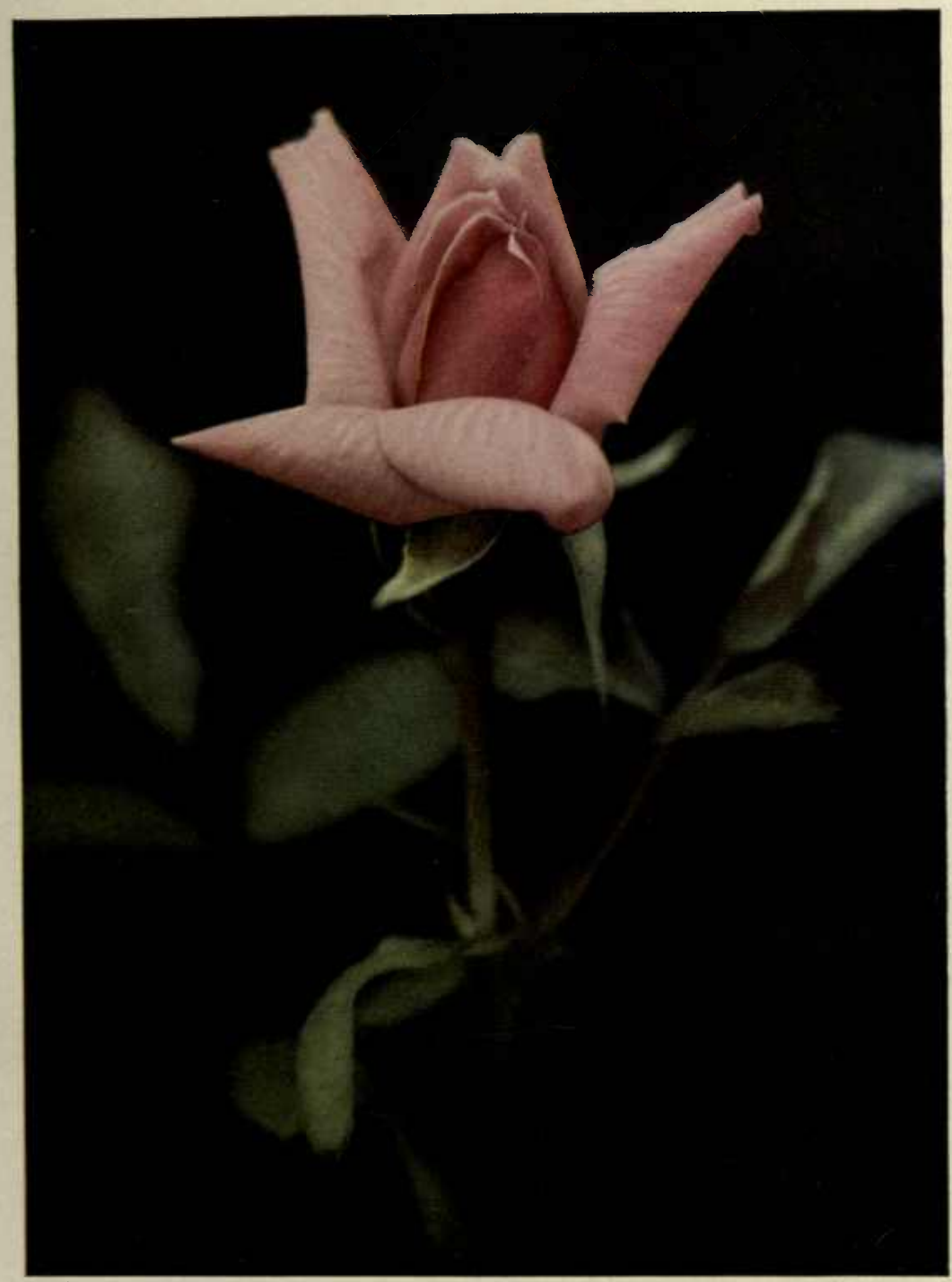





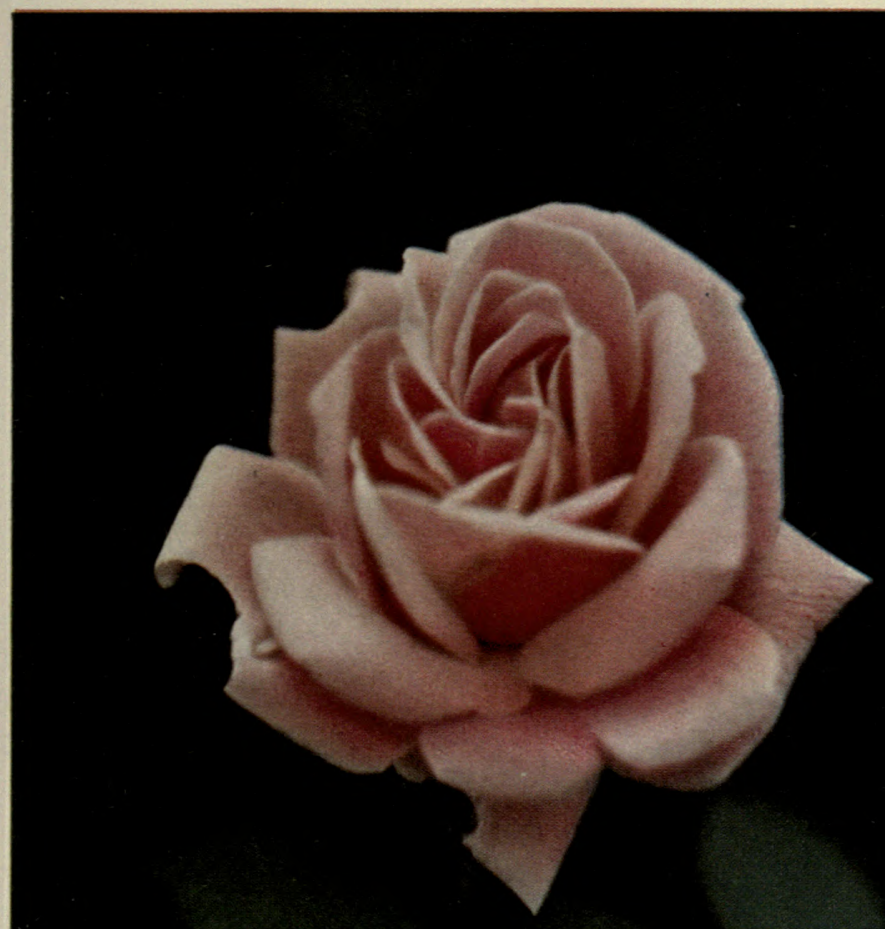





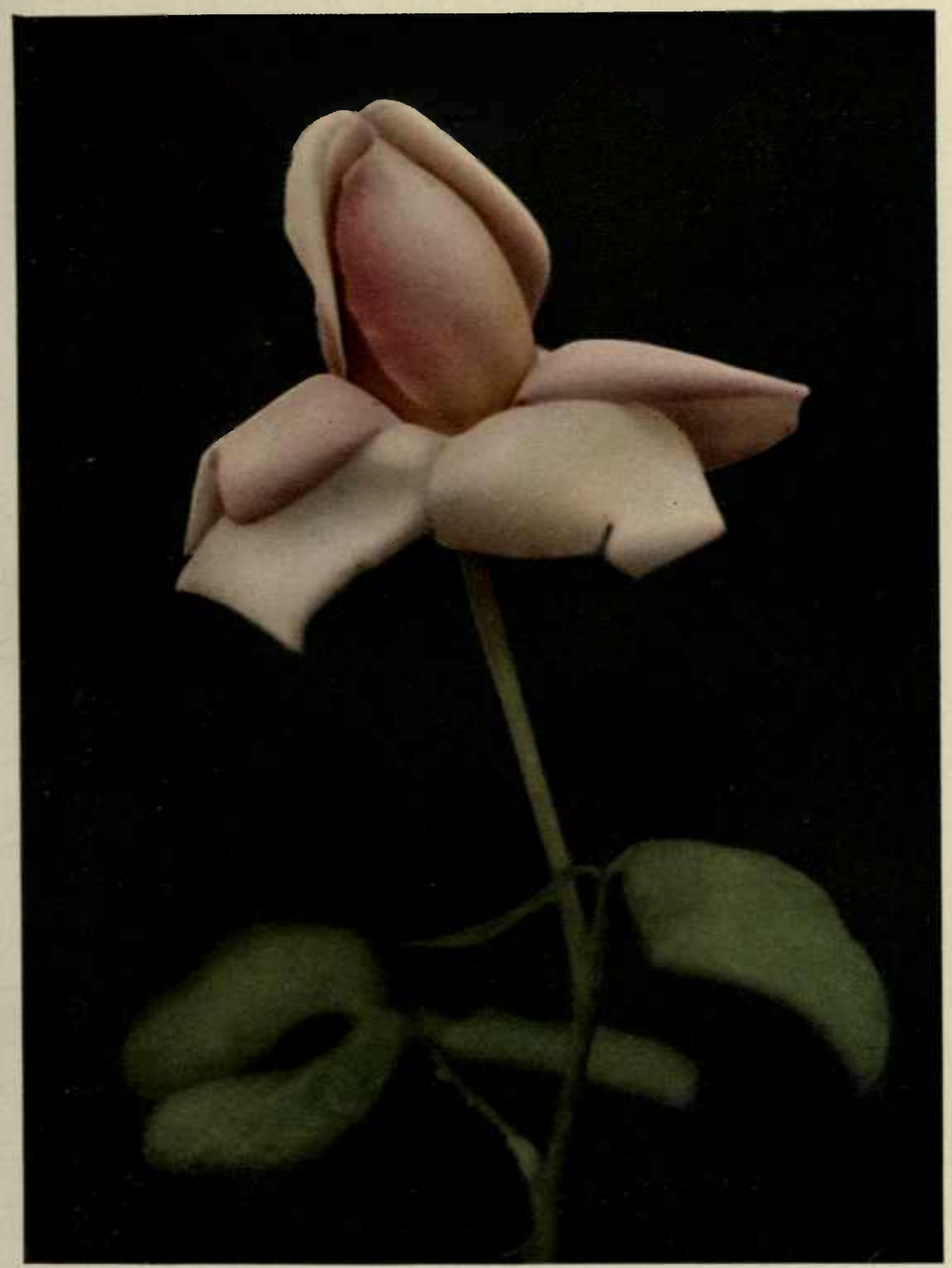

EARL OF WARWICK IIybrid Tea

PACL \& Son 190

Fair grower, some autumn bloom 



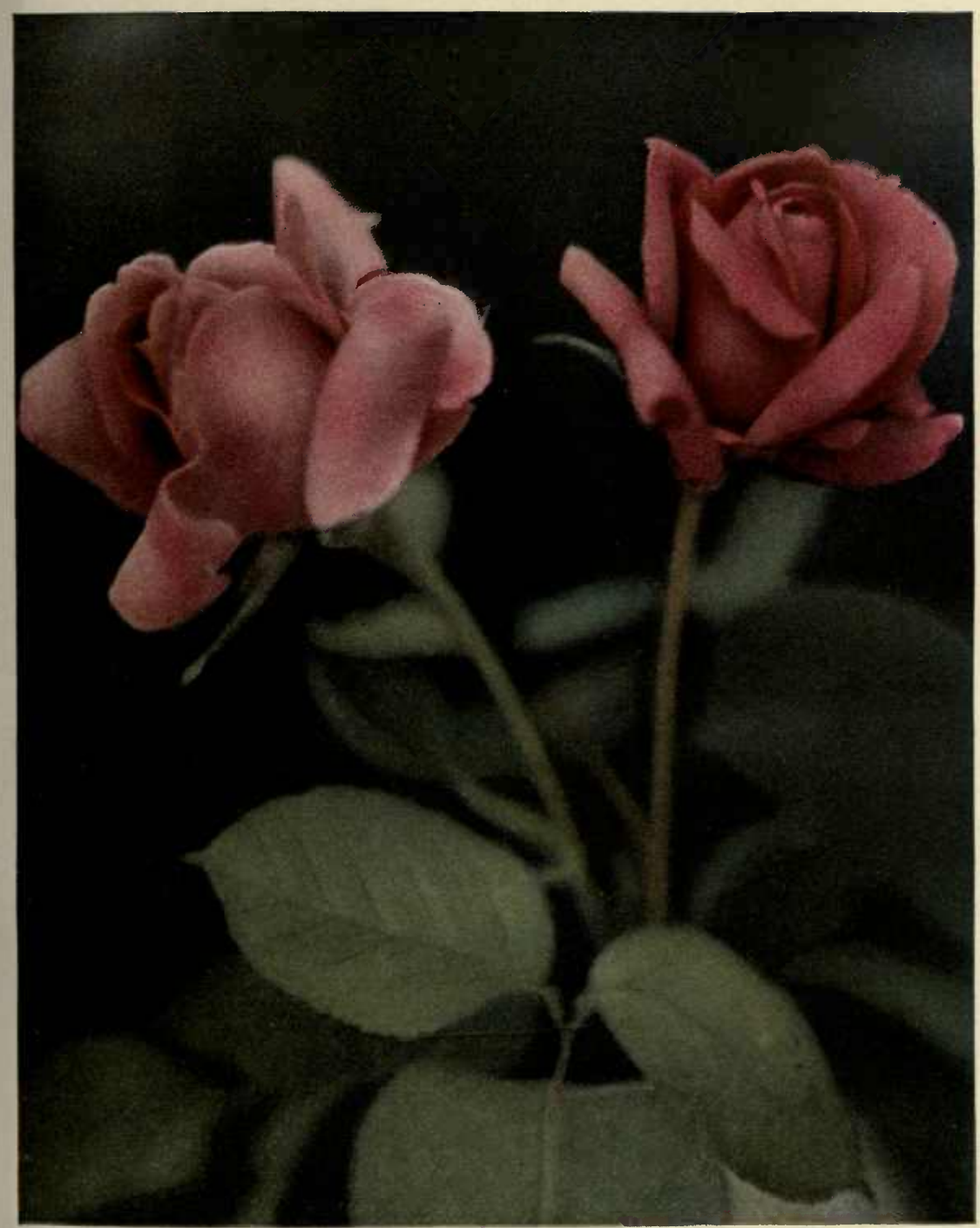

\section{ELIZABETH Hybrid Tea}

B. R. Cant \& Sovs 1911
C. W. COWAN Hybrid Tea

Alex. Dickson \& Sons 1912

Both fair growers with some autumn bloom 




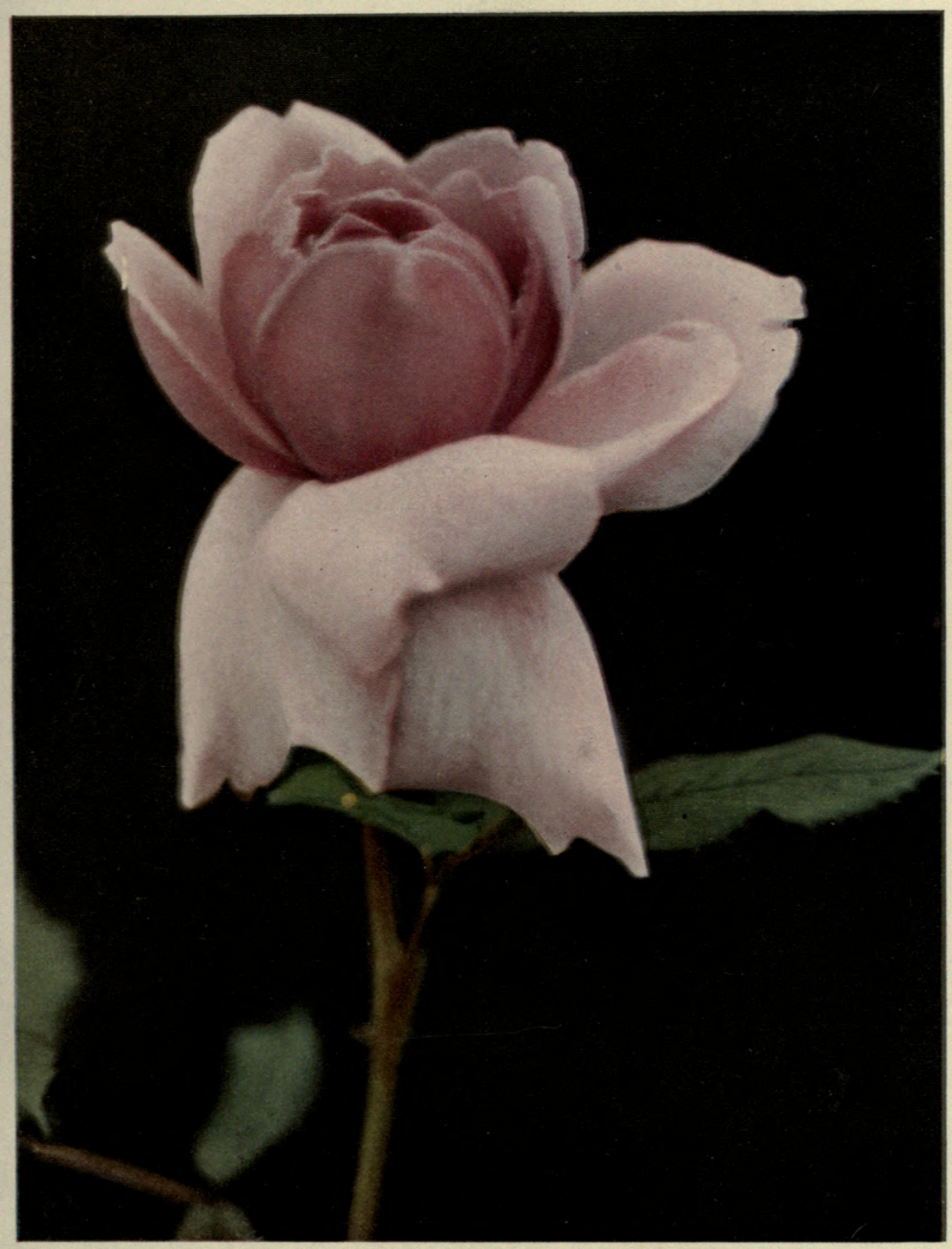

EVELYN DAUNTESSY Iybrid Tea

McGRedy \& Son 1911

Very weak grower in Middle Atlantic States 



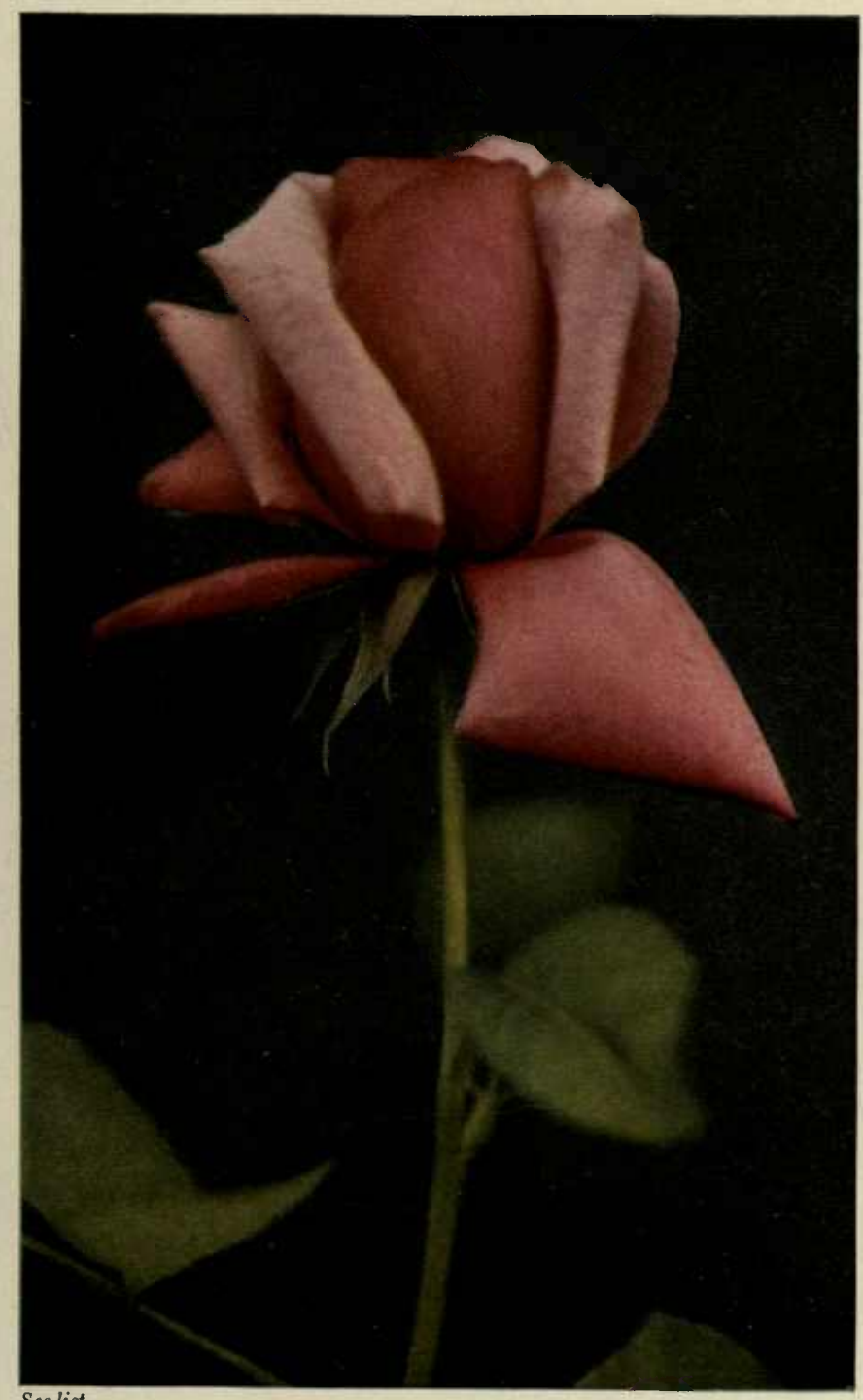

See list

FARBEN KÖNIGIN IIybrid Tea

HINTER 1902 



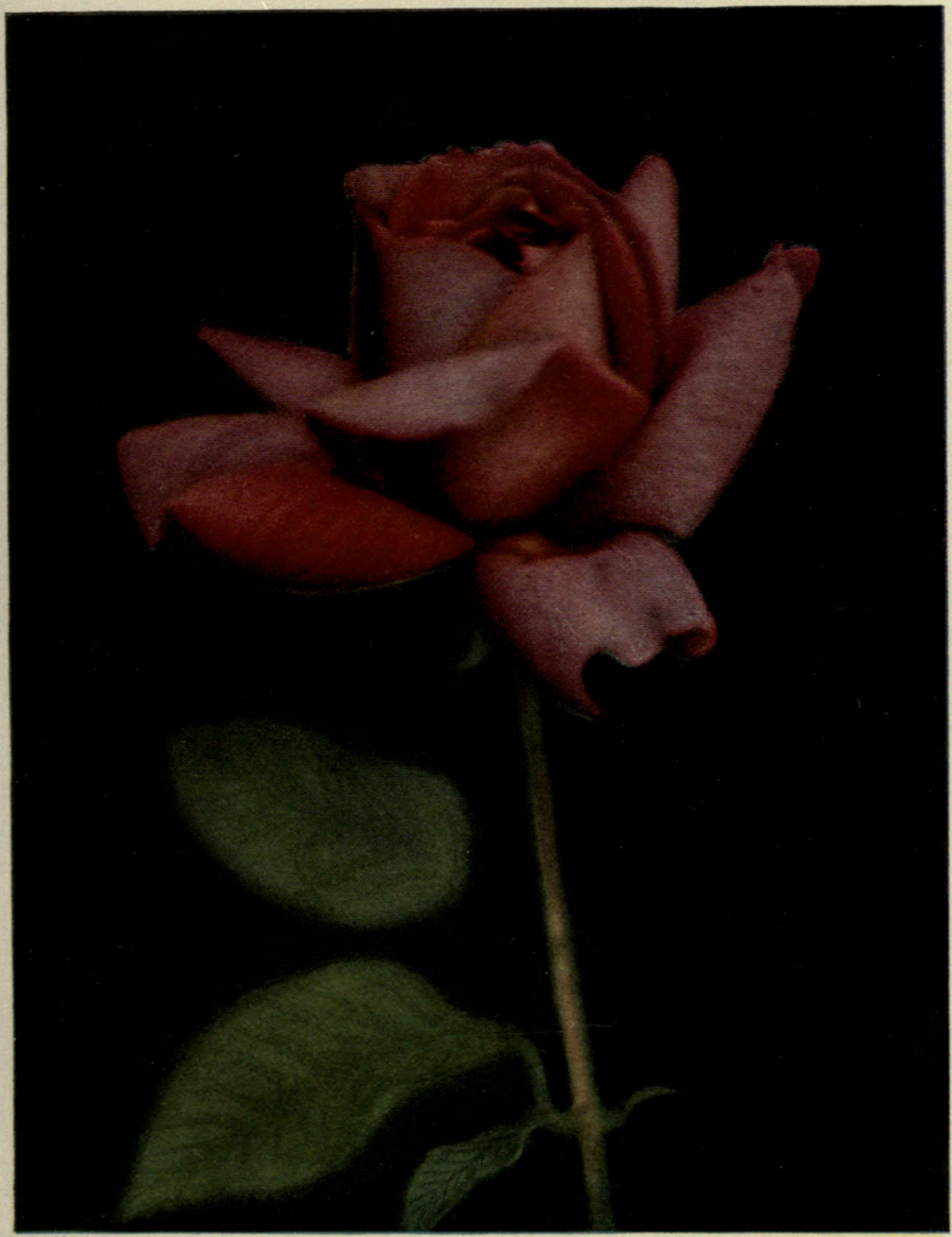

FREIHERR von MARSCHALL Tea

P. LAMBert 1904 



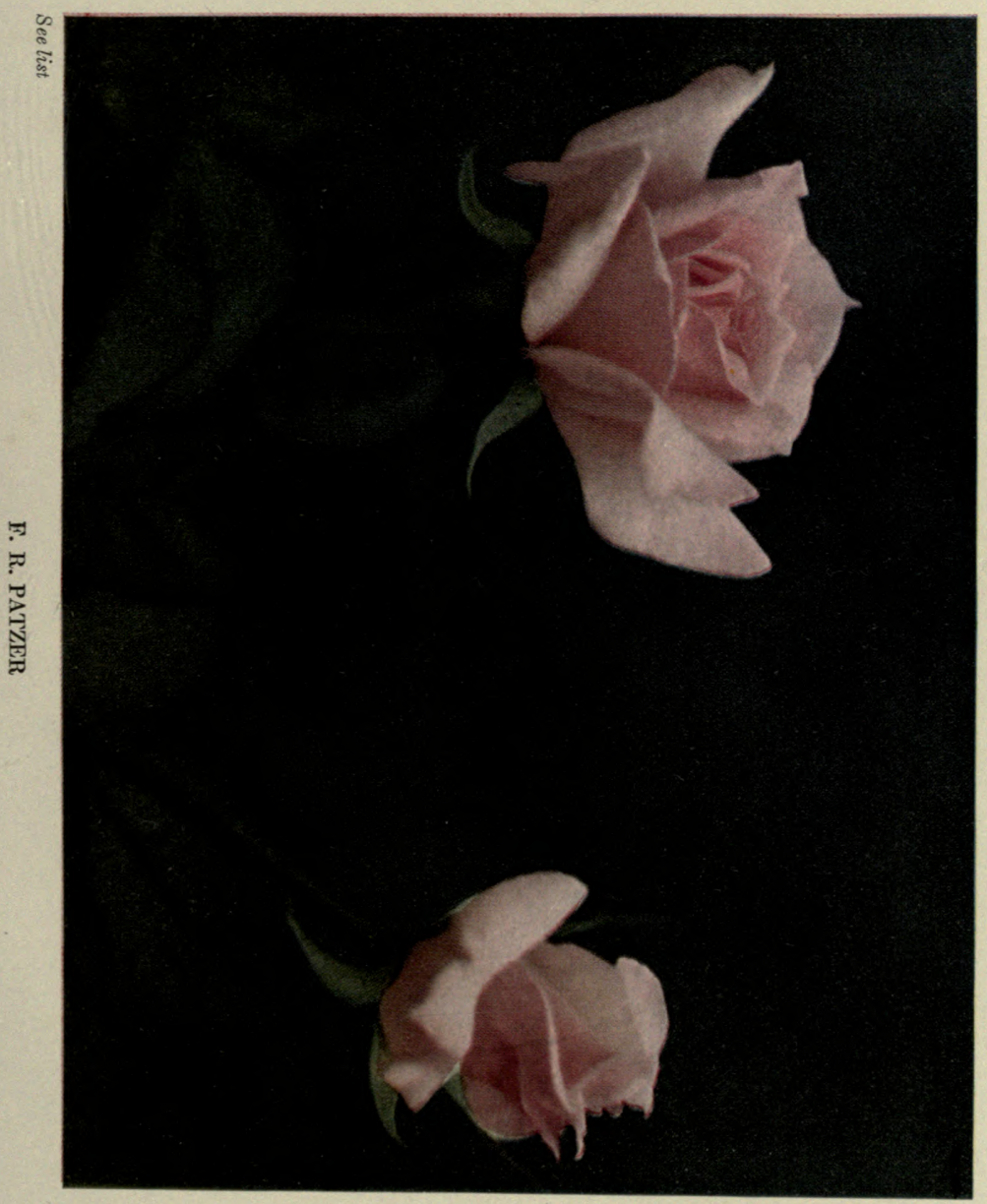





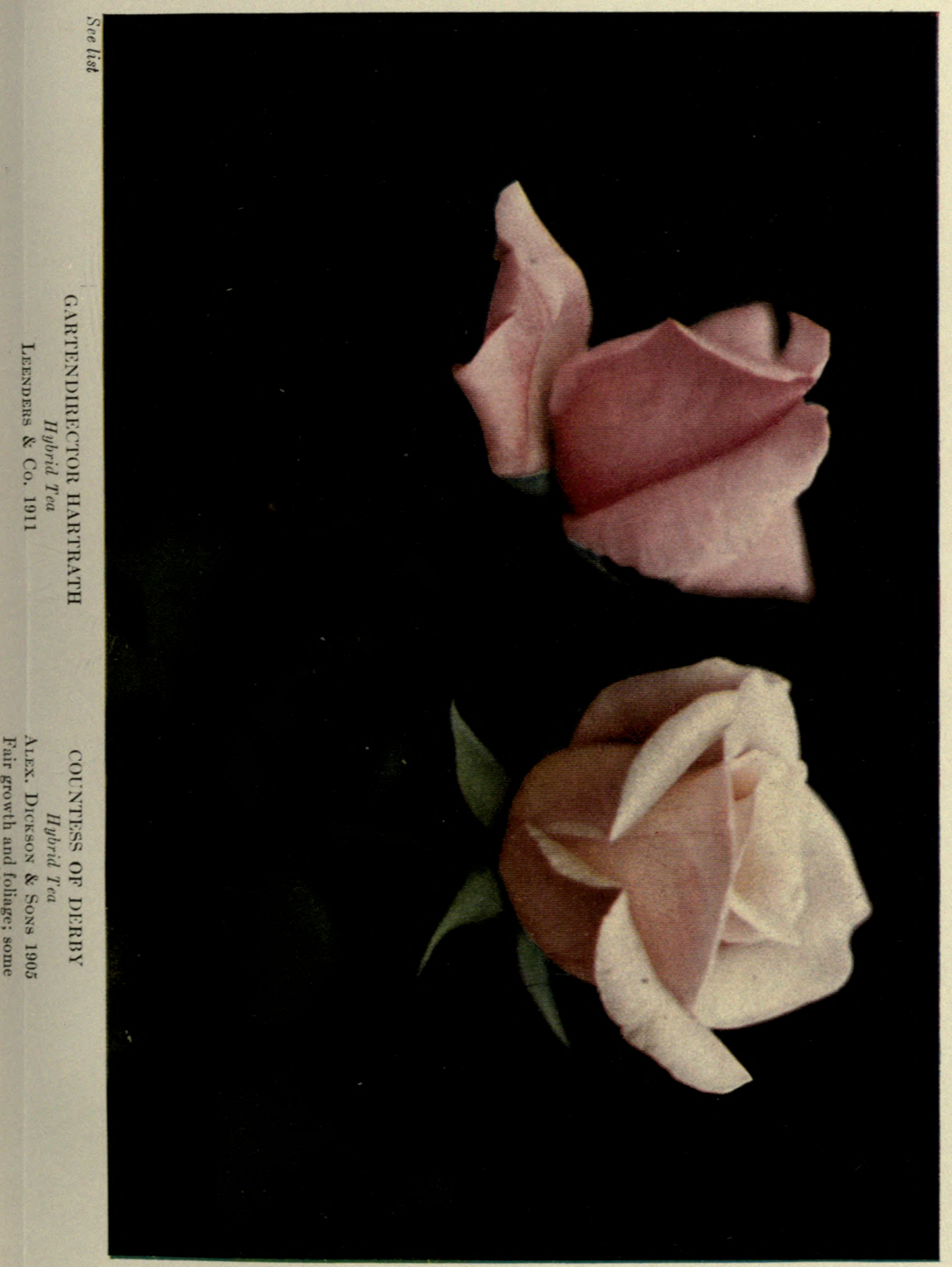





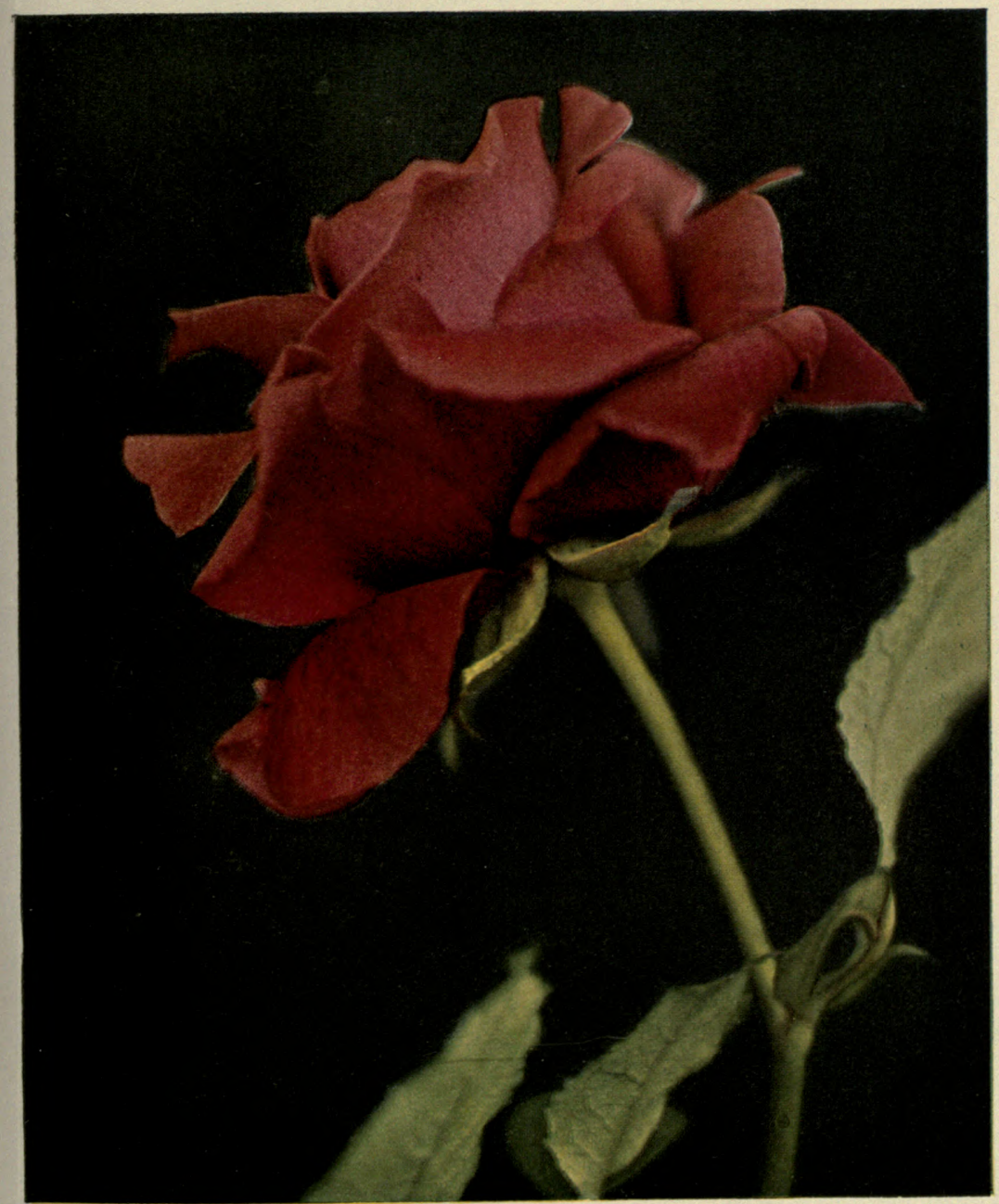

GEORGE DICKSON Hybrid Tea

Alex. Dickson \& Sons 1911 



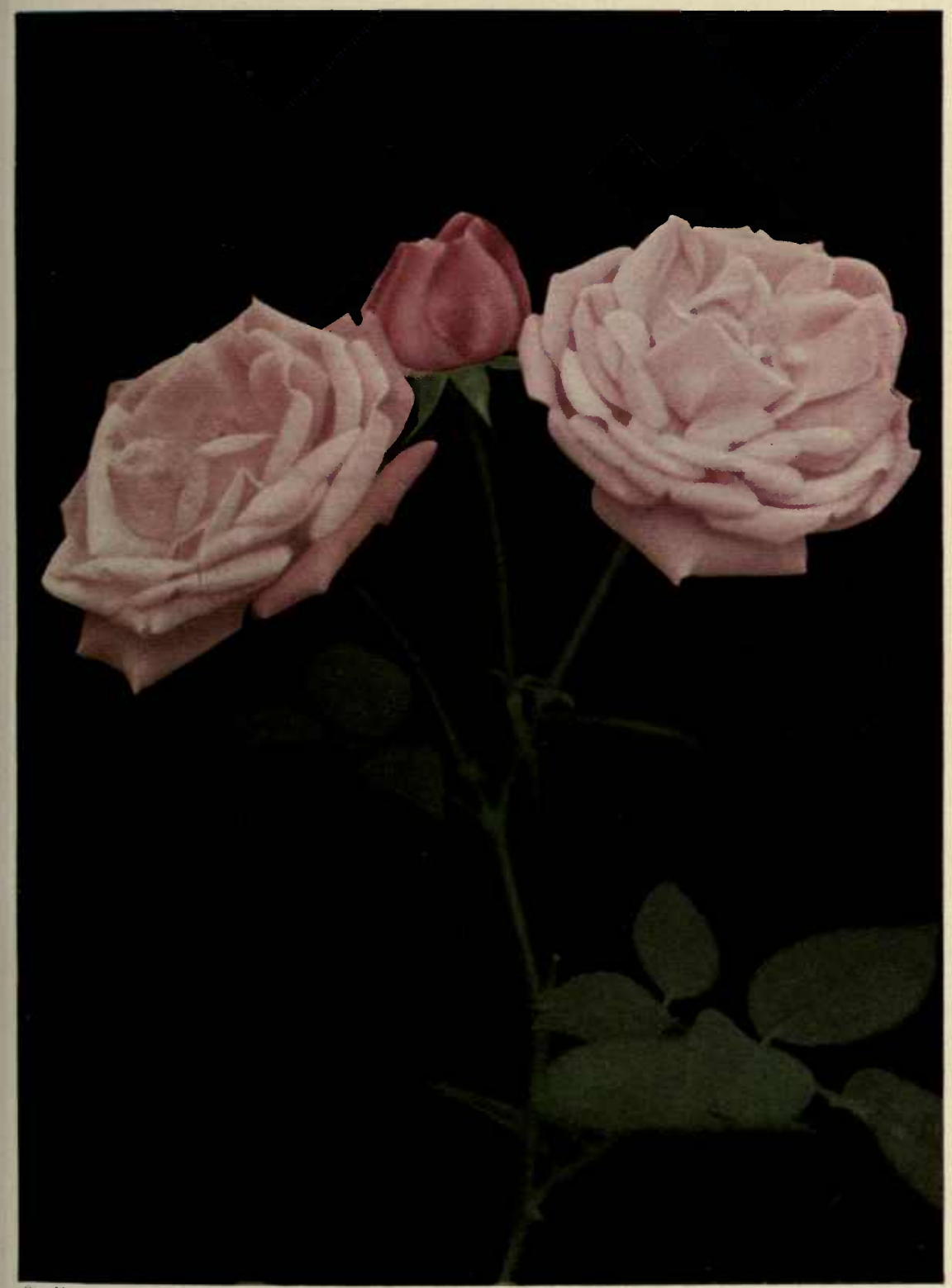





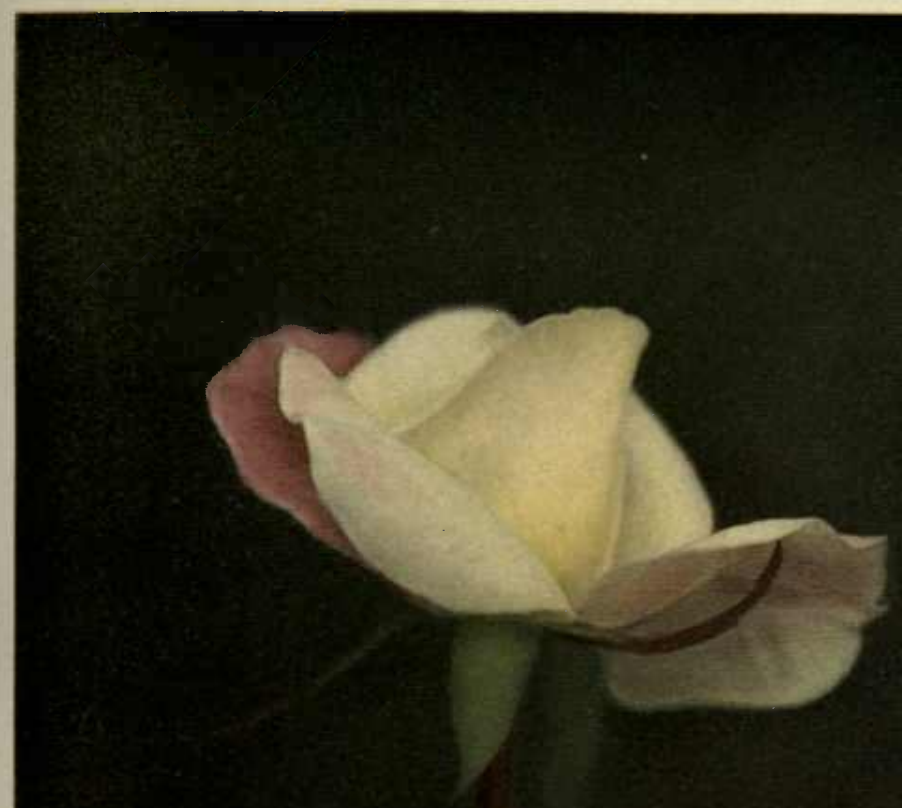





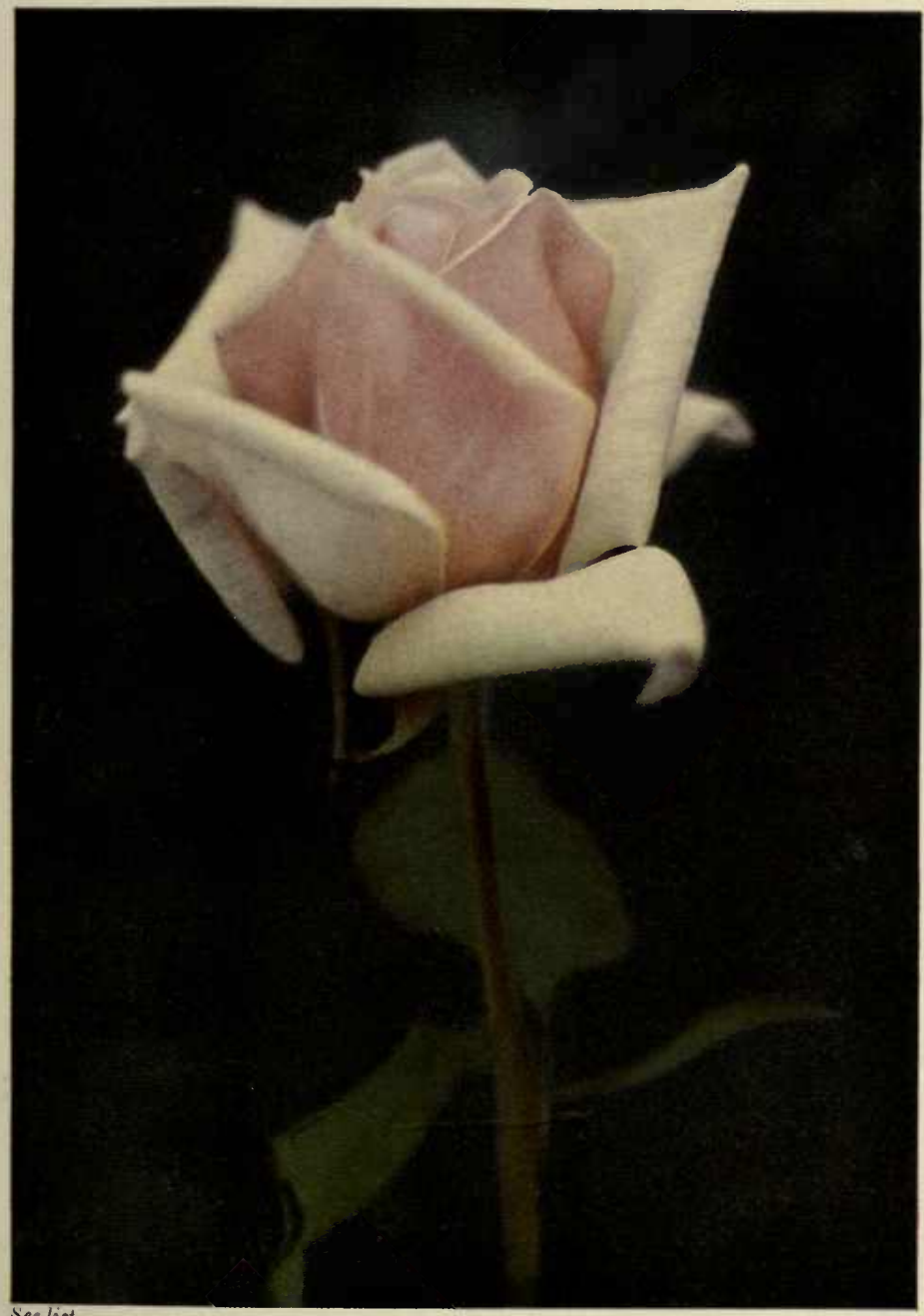

See list

JOSEPH HILL IIybrid Tea

Perset-Ducuer 1904 



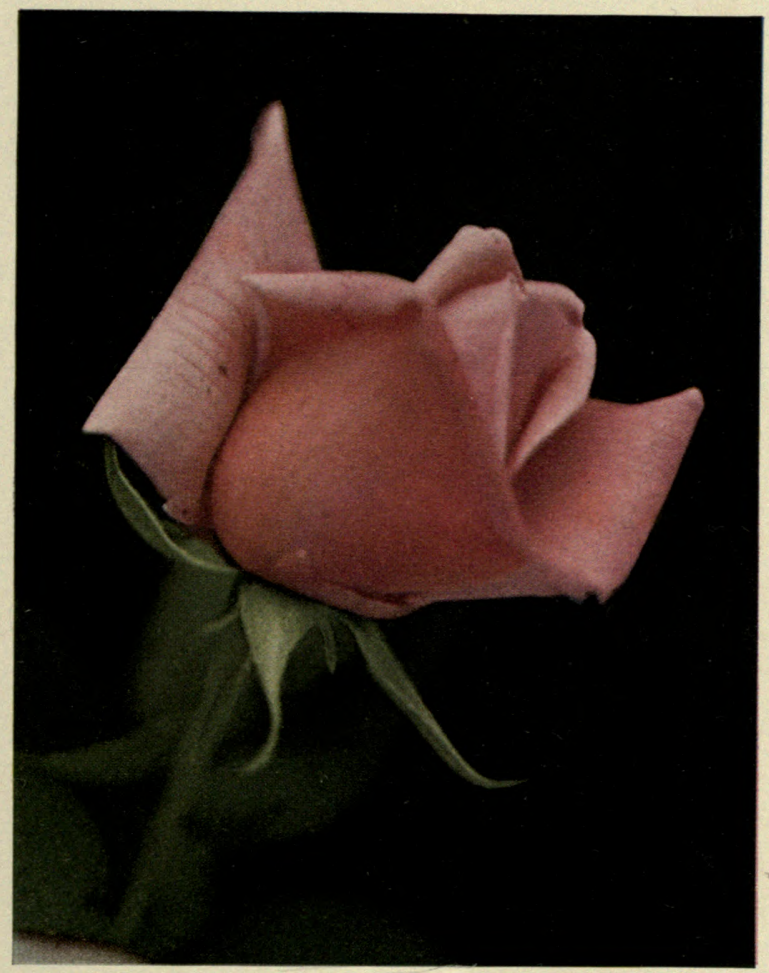

See list

LADY ASHTOWN Hybrid Tea

Alex. Dickson \& Sons 1911 



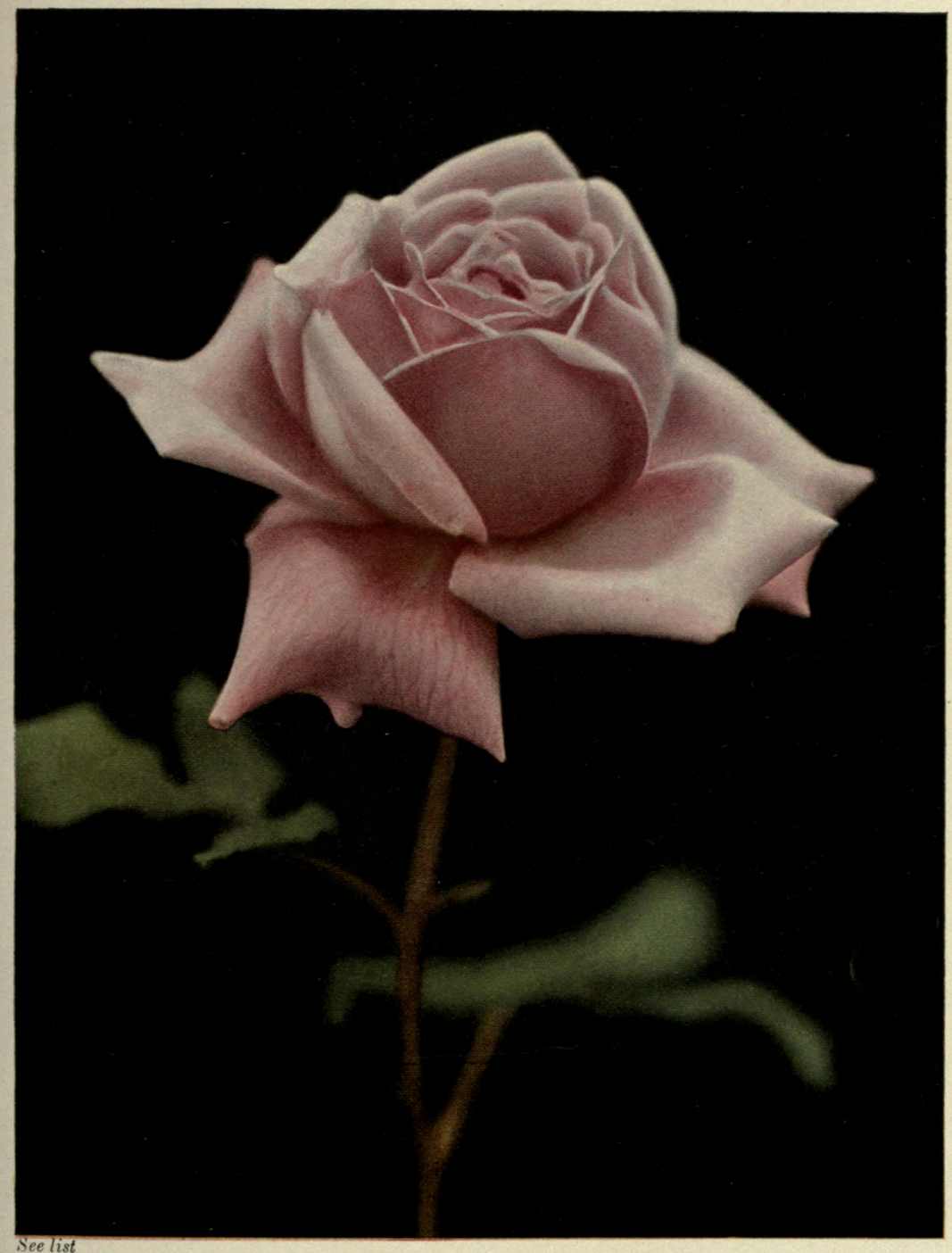





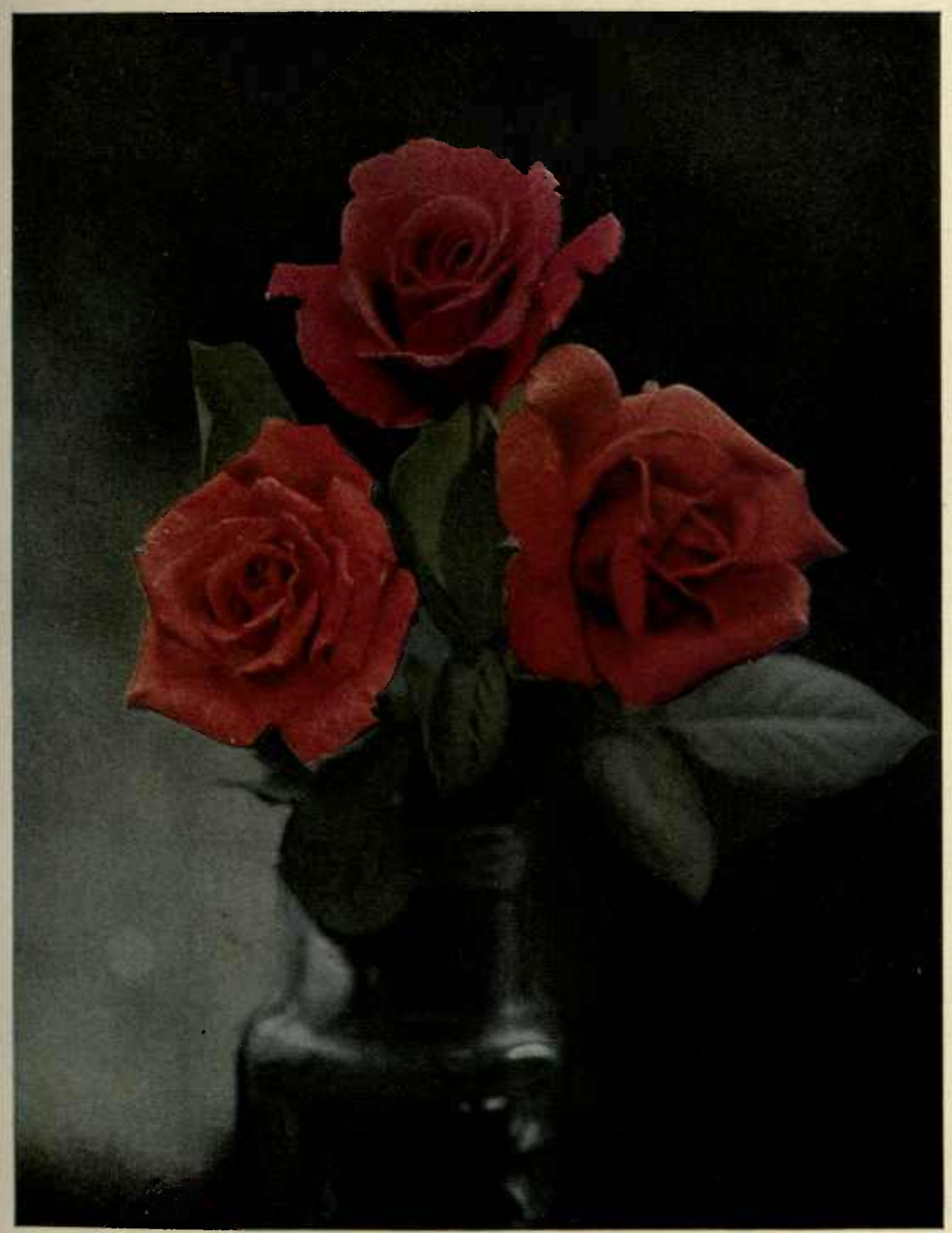

\section{LADY BATTERSEA Iybrid Tea}

PAUL \& Son 1901

Shy bloomer and weak grower. $\Lambda$ collector's rose. 



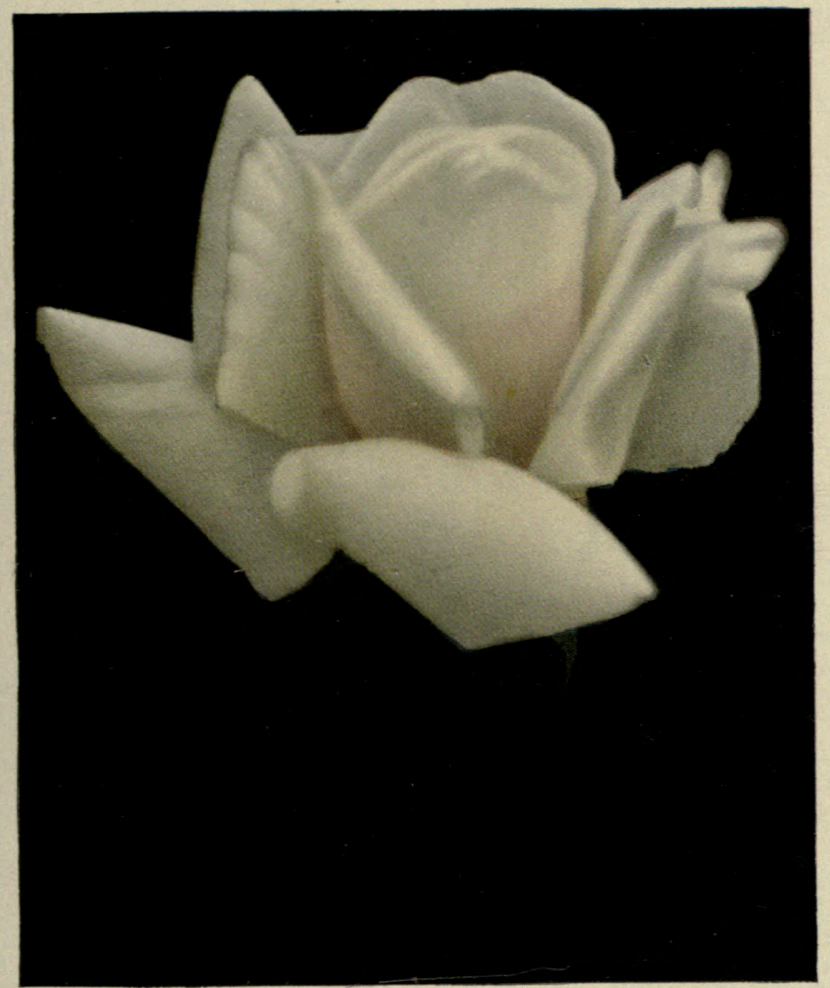

LADY deBATHE Hybrid Tea

B. R. CANT \& Sons 1911 




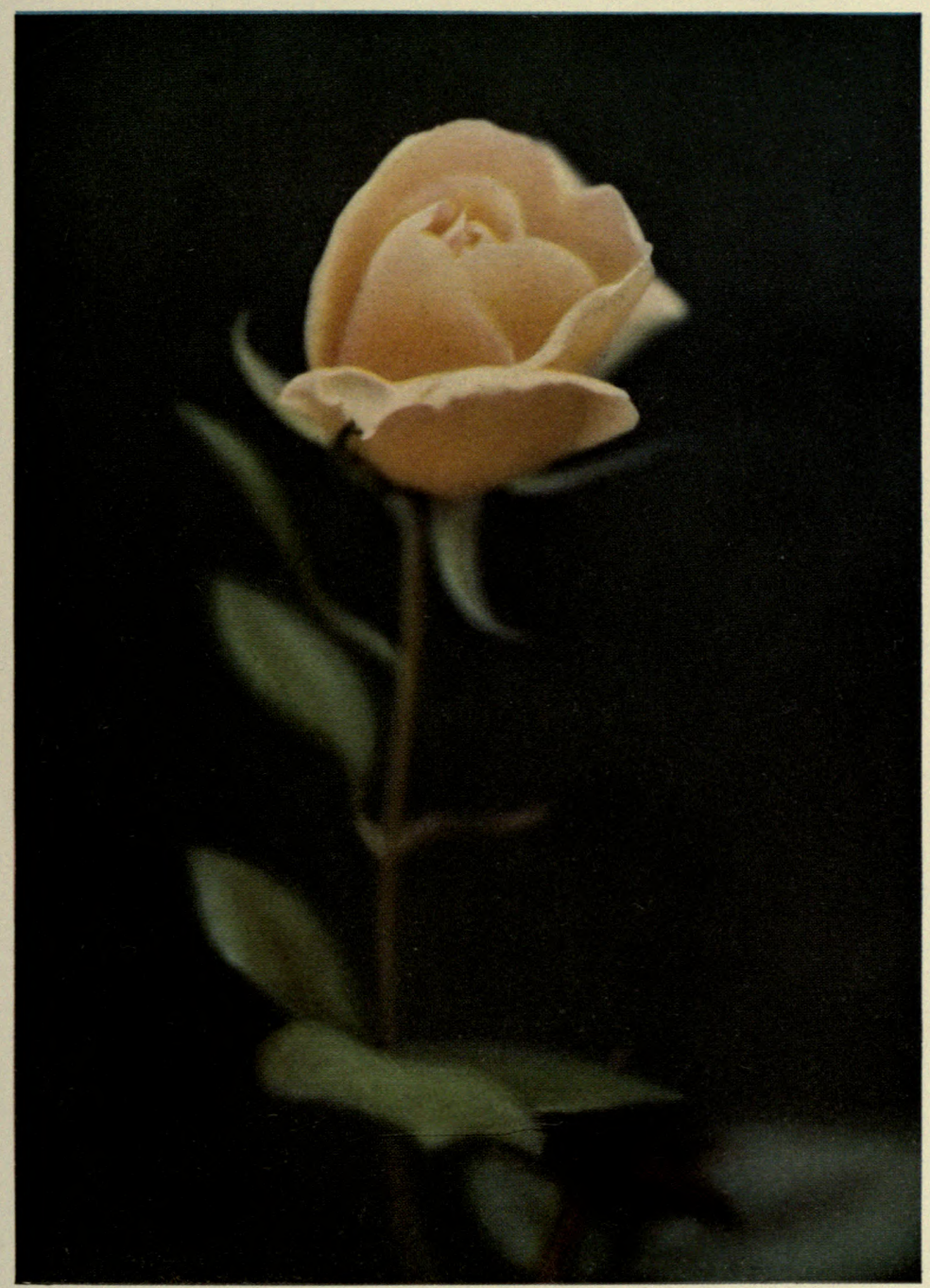

See list

LADY HILLINGDON Tea

Lowe \& Shawyer 1910 



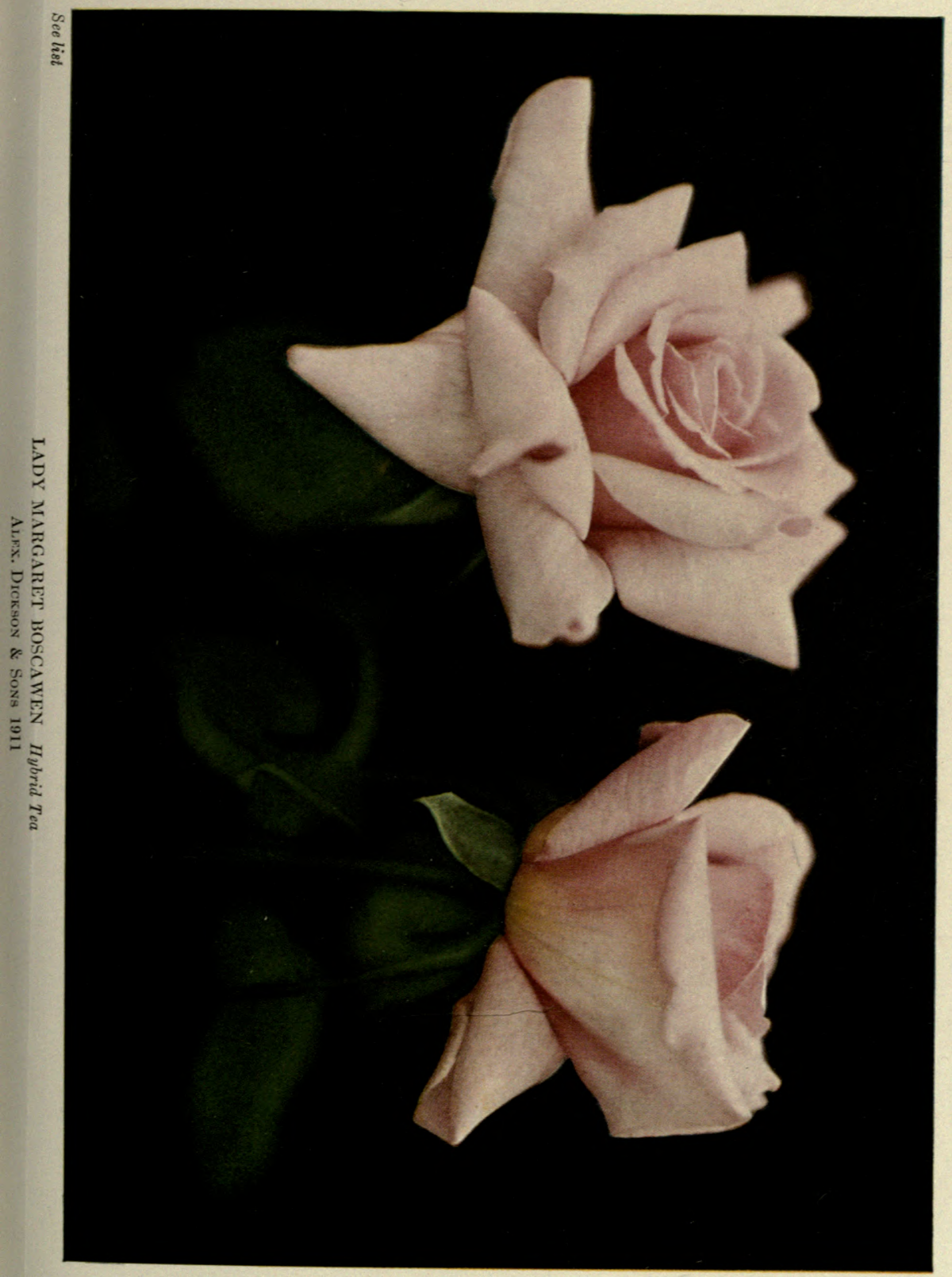





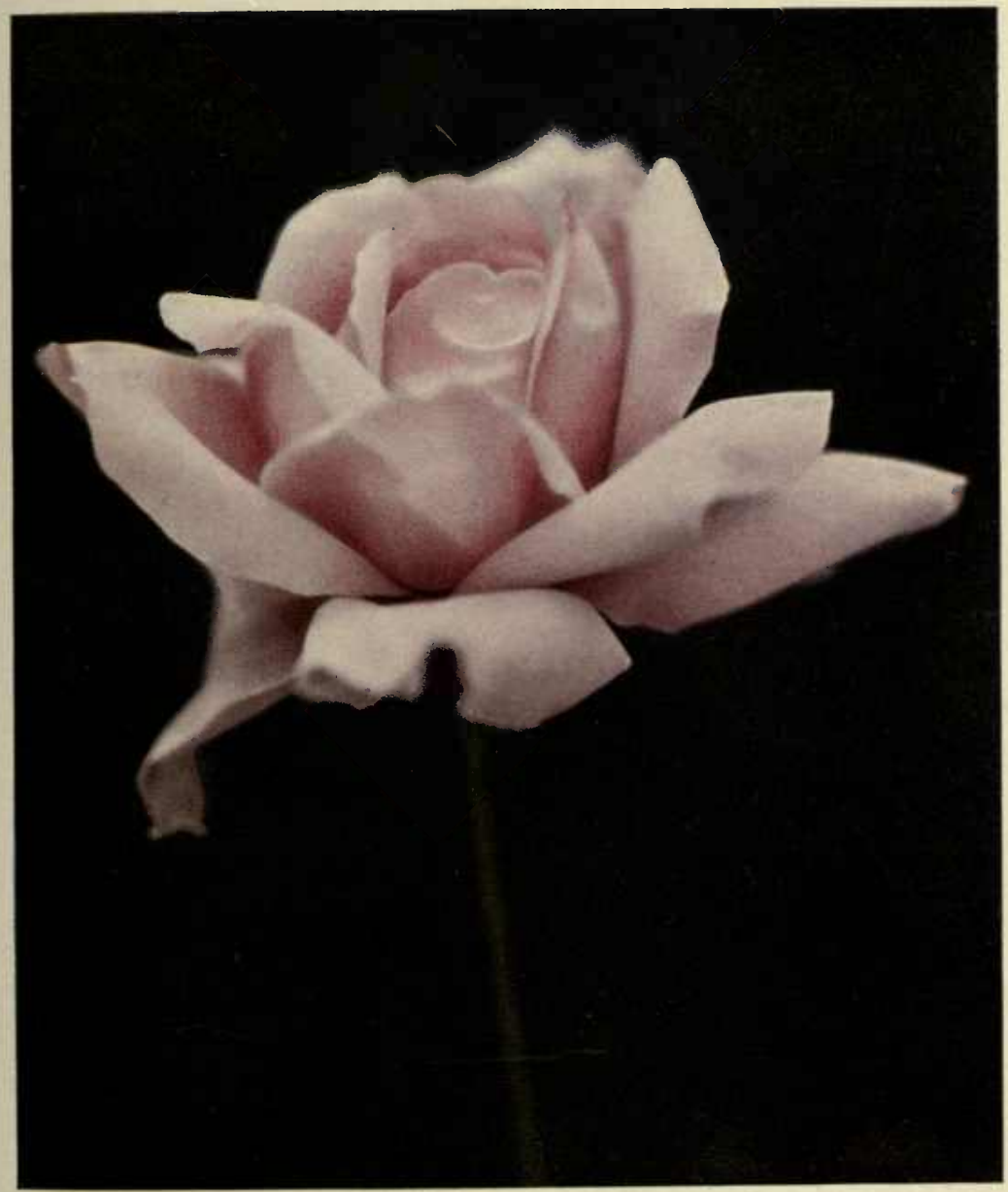

LADY MOYRA BEACCLERC Hybrid Tea

Alex. Dickson \& Soss 1901

Weak grower in Middle Atlantic Staies 



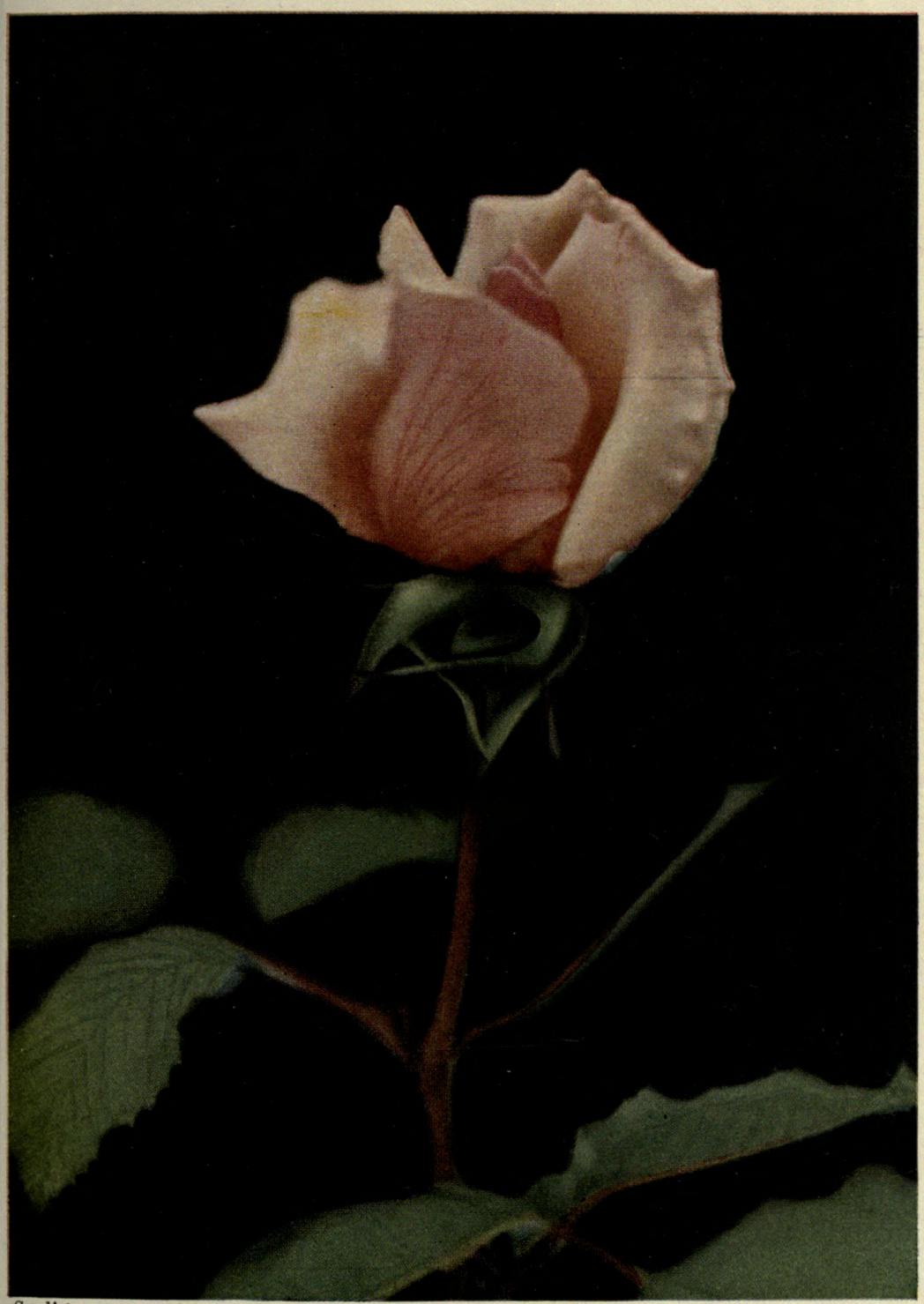

Hugh Dickson 1910 



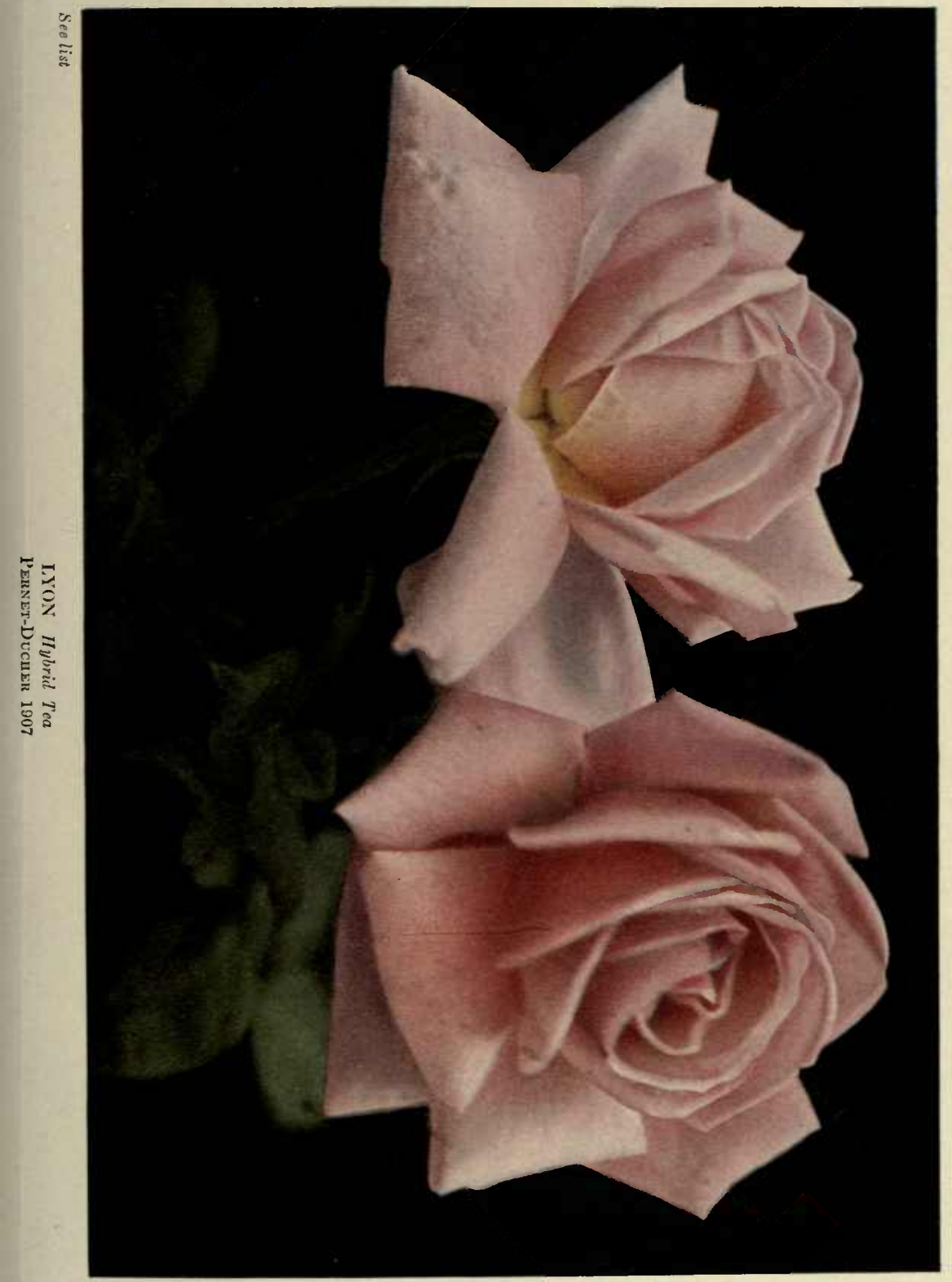





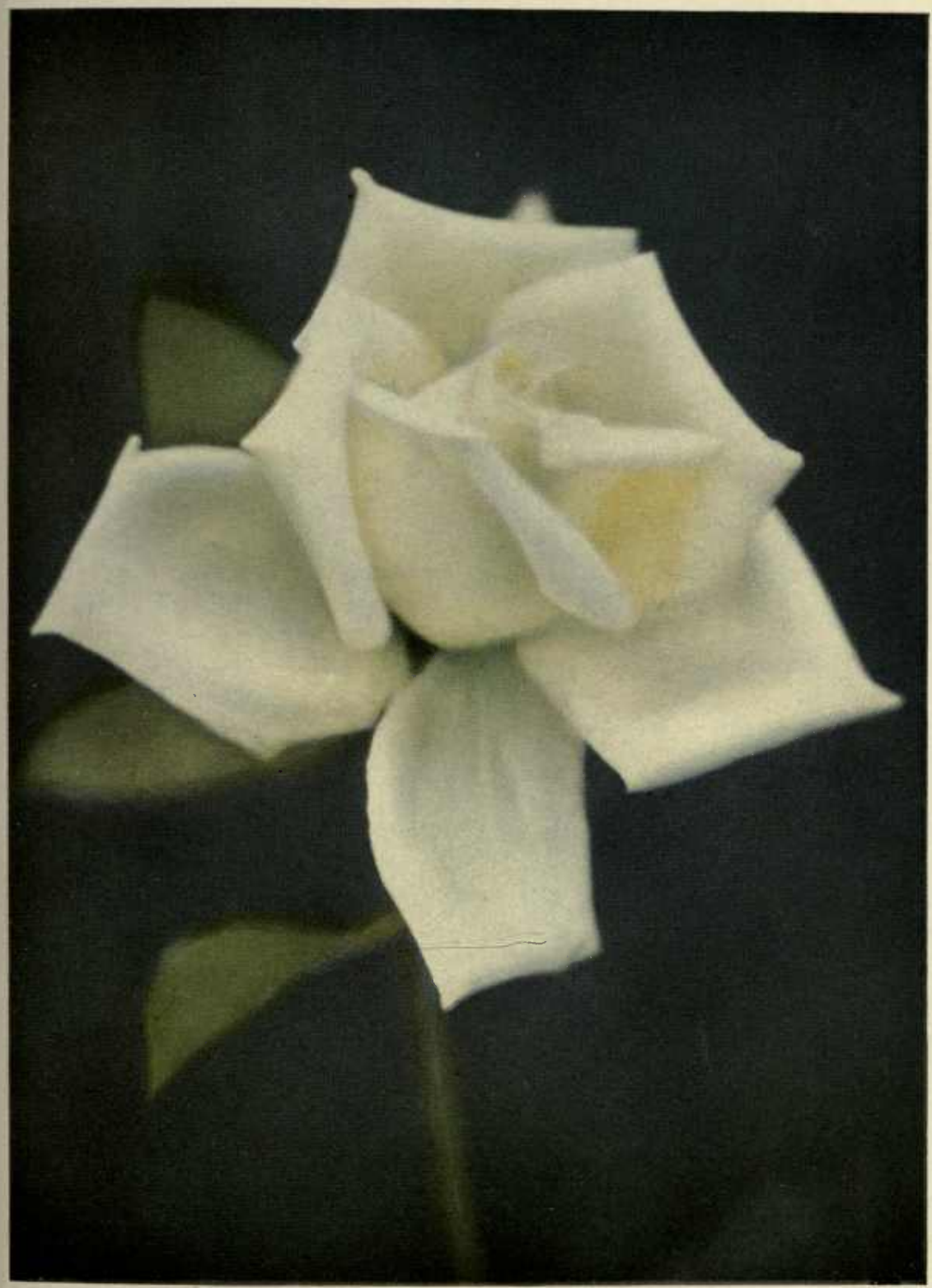





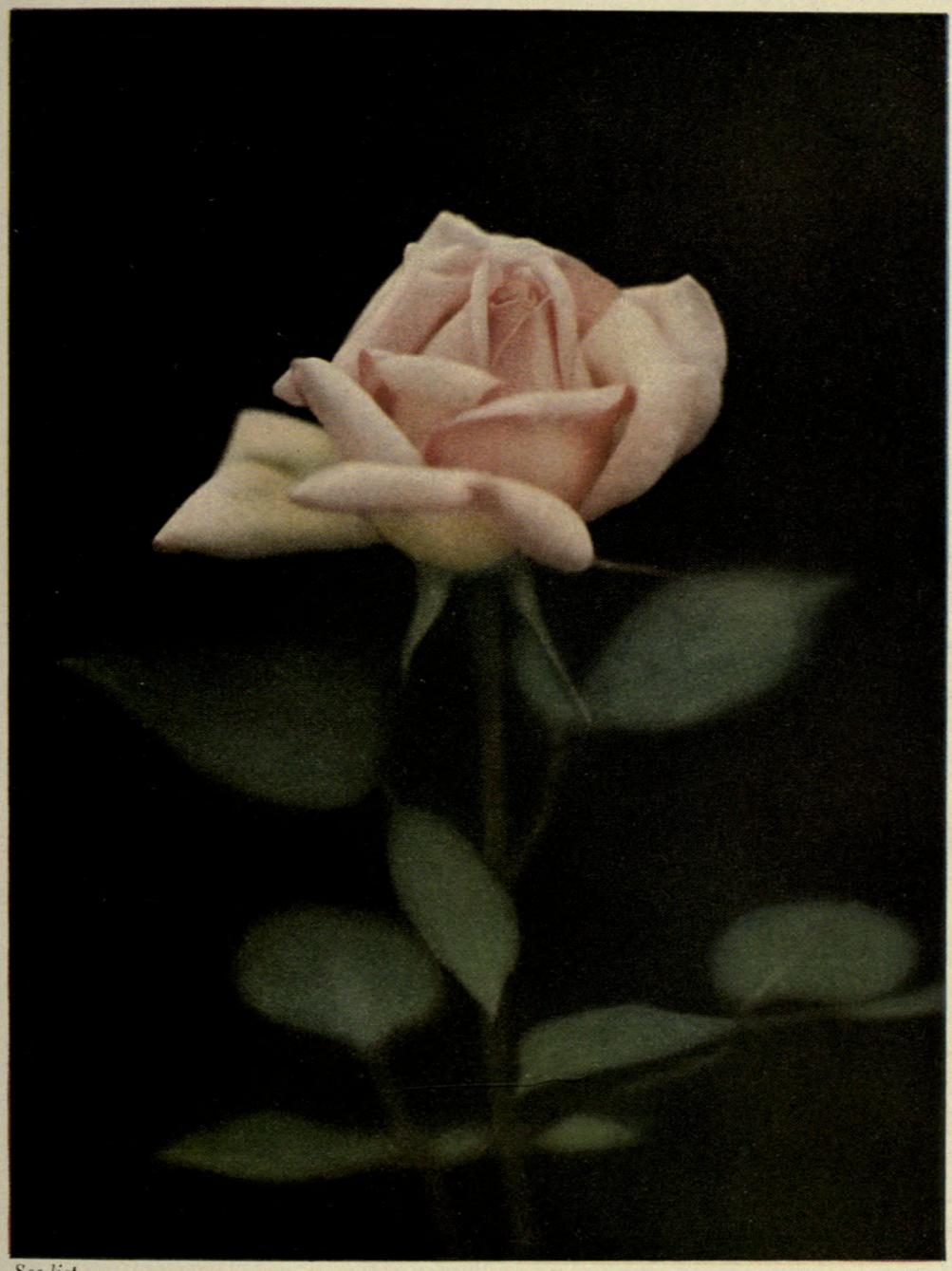

MADAME A. TUPINIER Hybrid Tea

A. Pedriolle 1910 



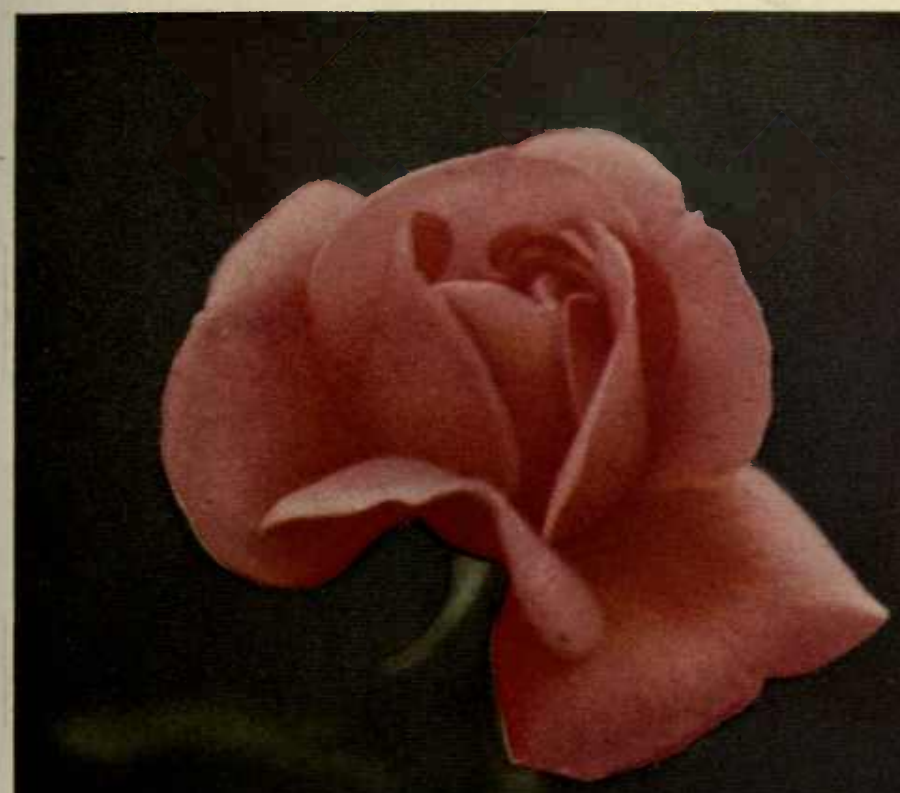






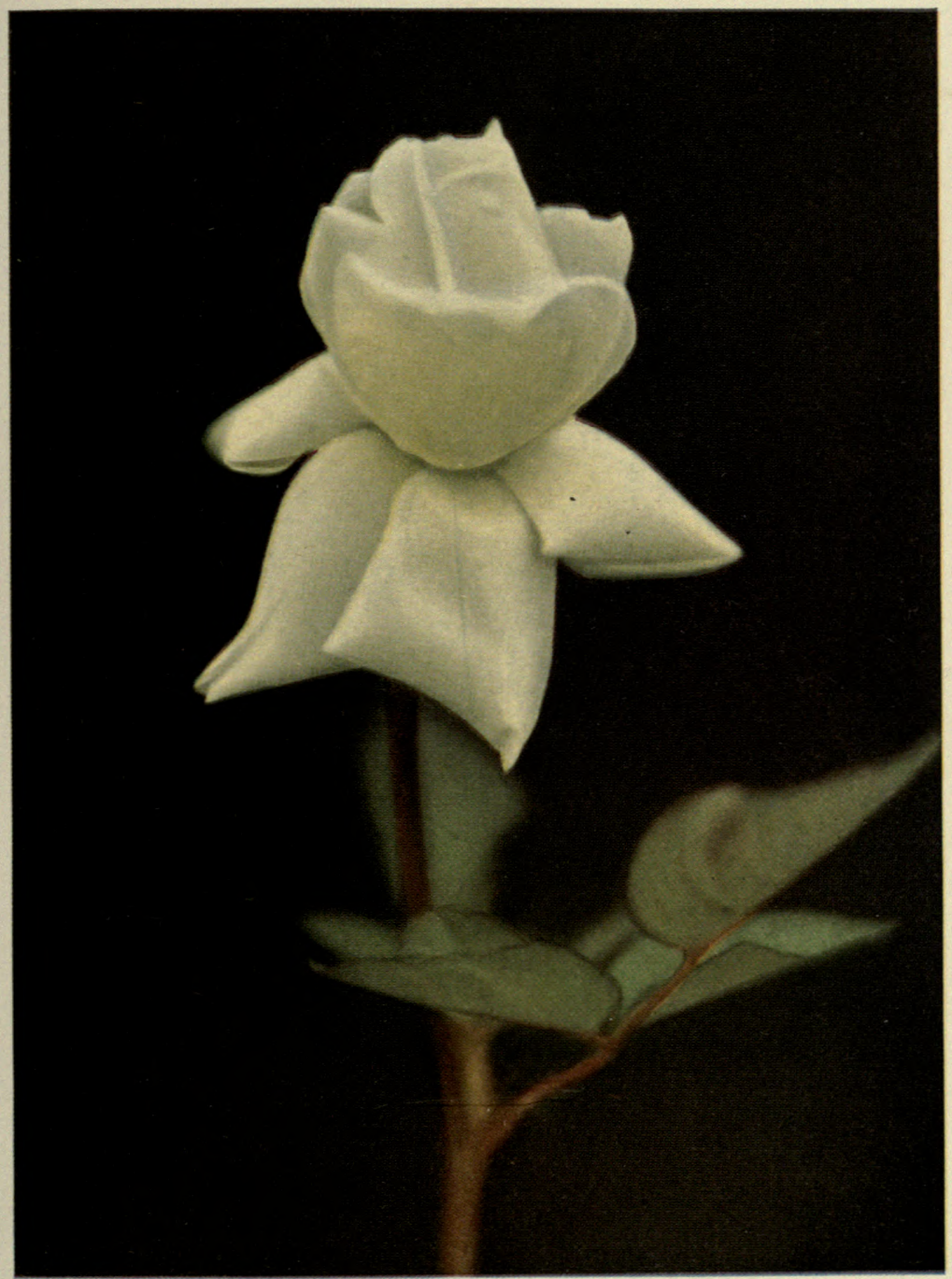

MADAME PAUL ROUCHON Hybrid Tea

PedRIOLLE 1912

Fair grower, some autumn bloom 



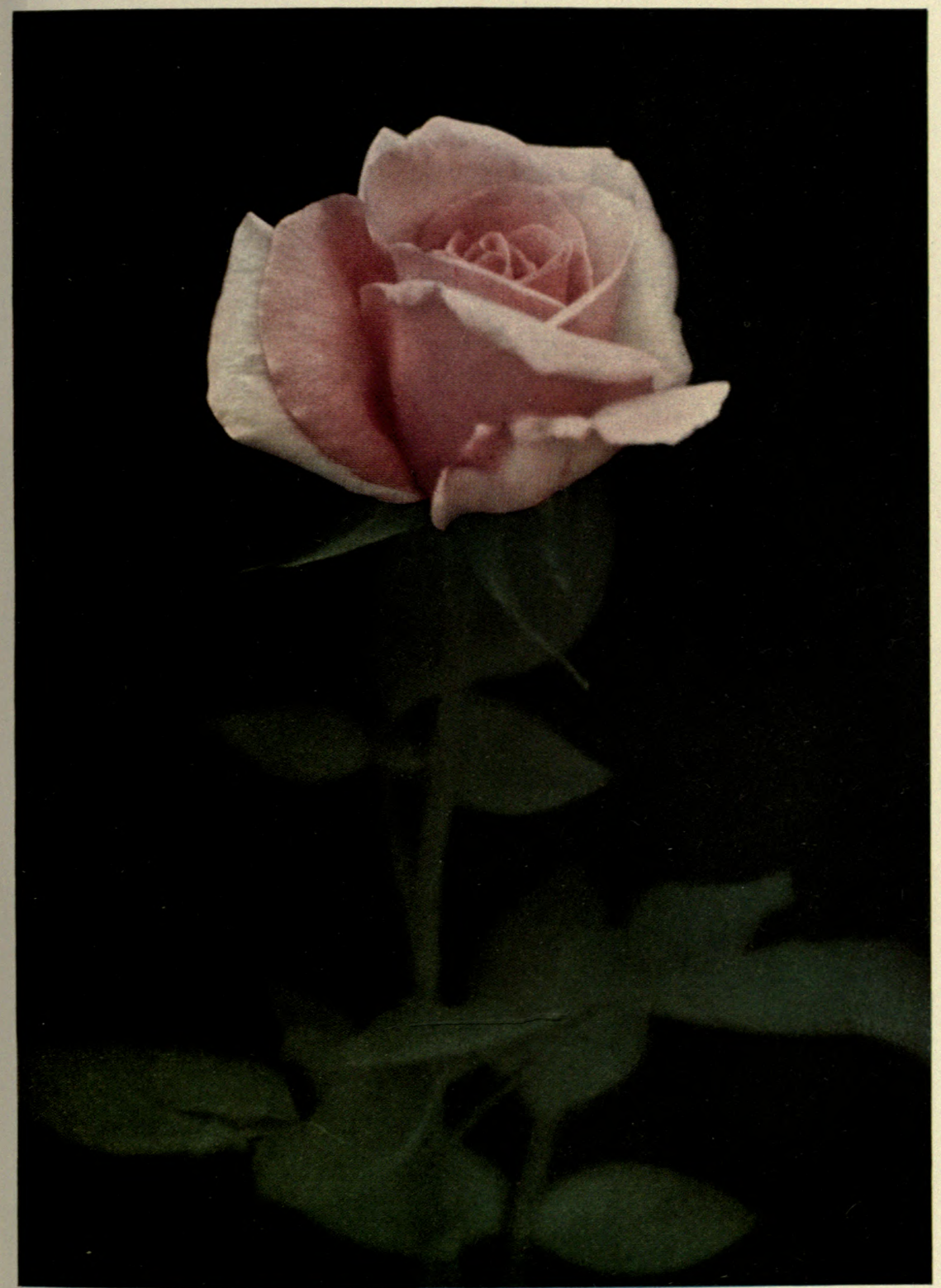





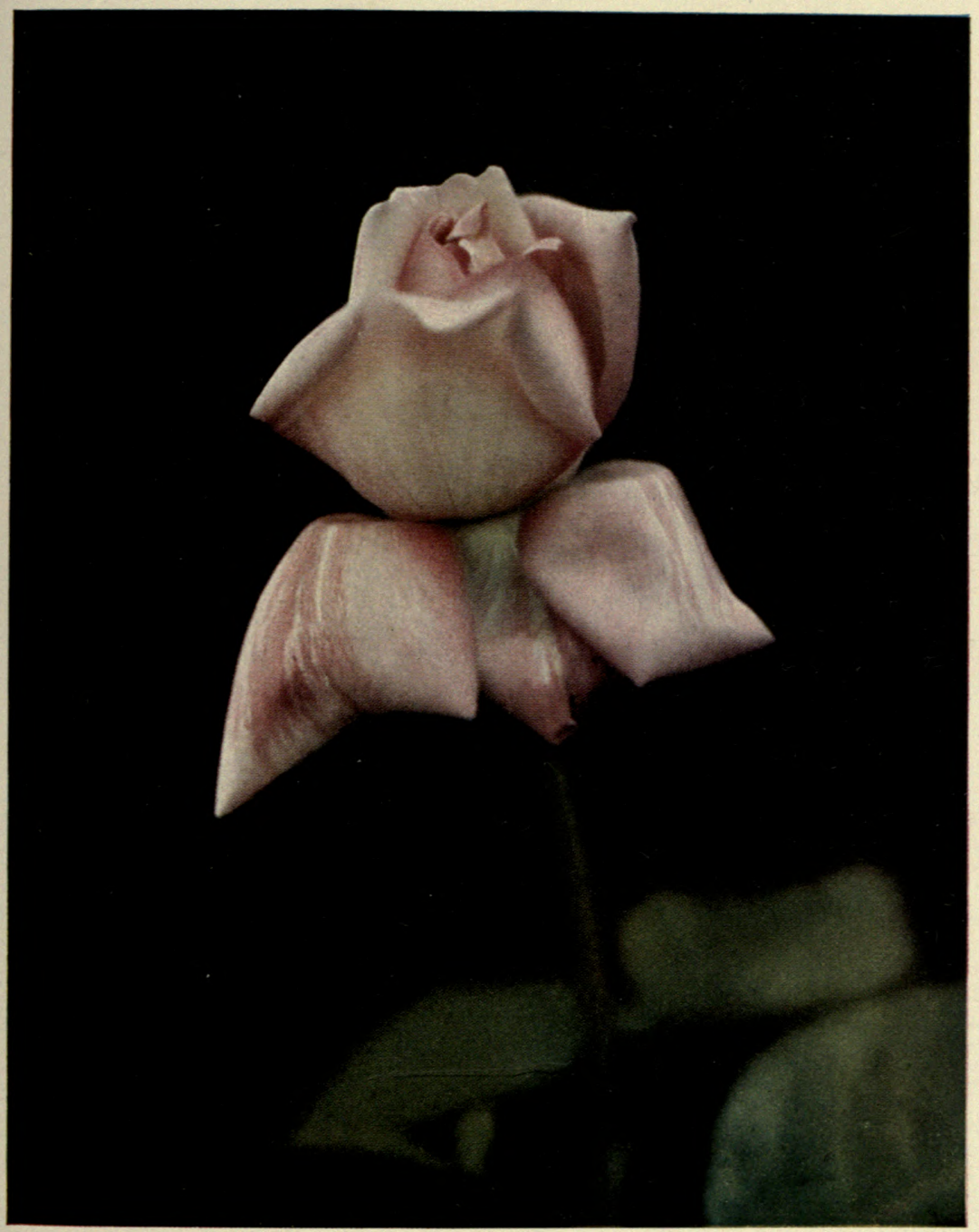

MADAME VERMOREL Tea

MARI 1901

Small grower; some autumn bloom 



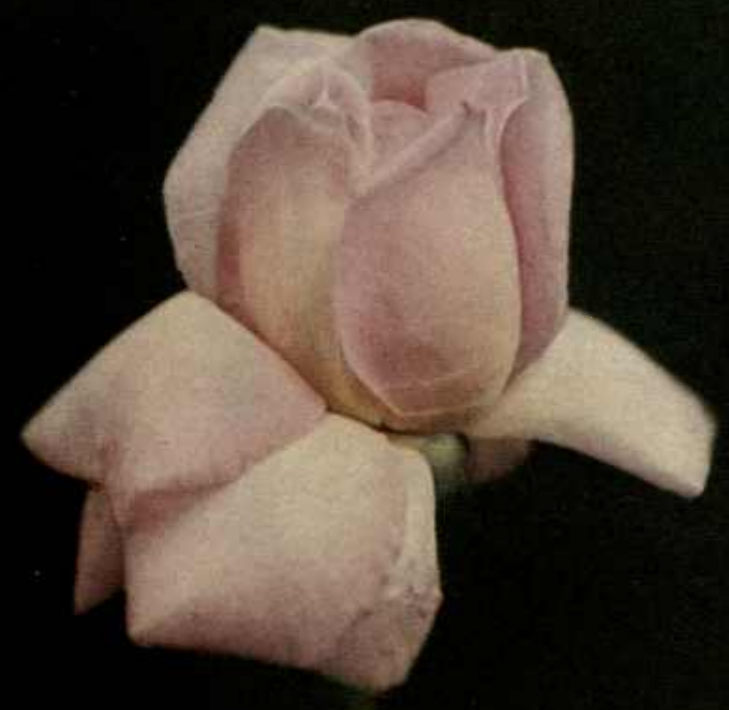

MADAME WAGRAM, COMTESSE deTURENNE Hybrid Tea B ERNAIX 1895

Some autumn bloom, weak grower in Middle Atlantic States 



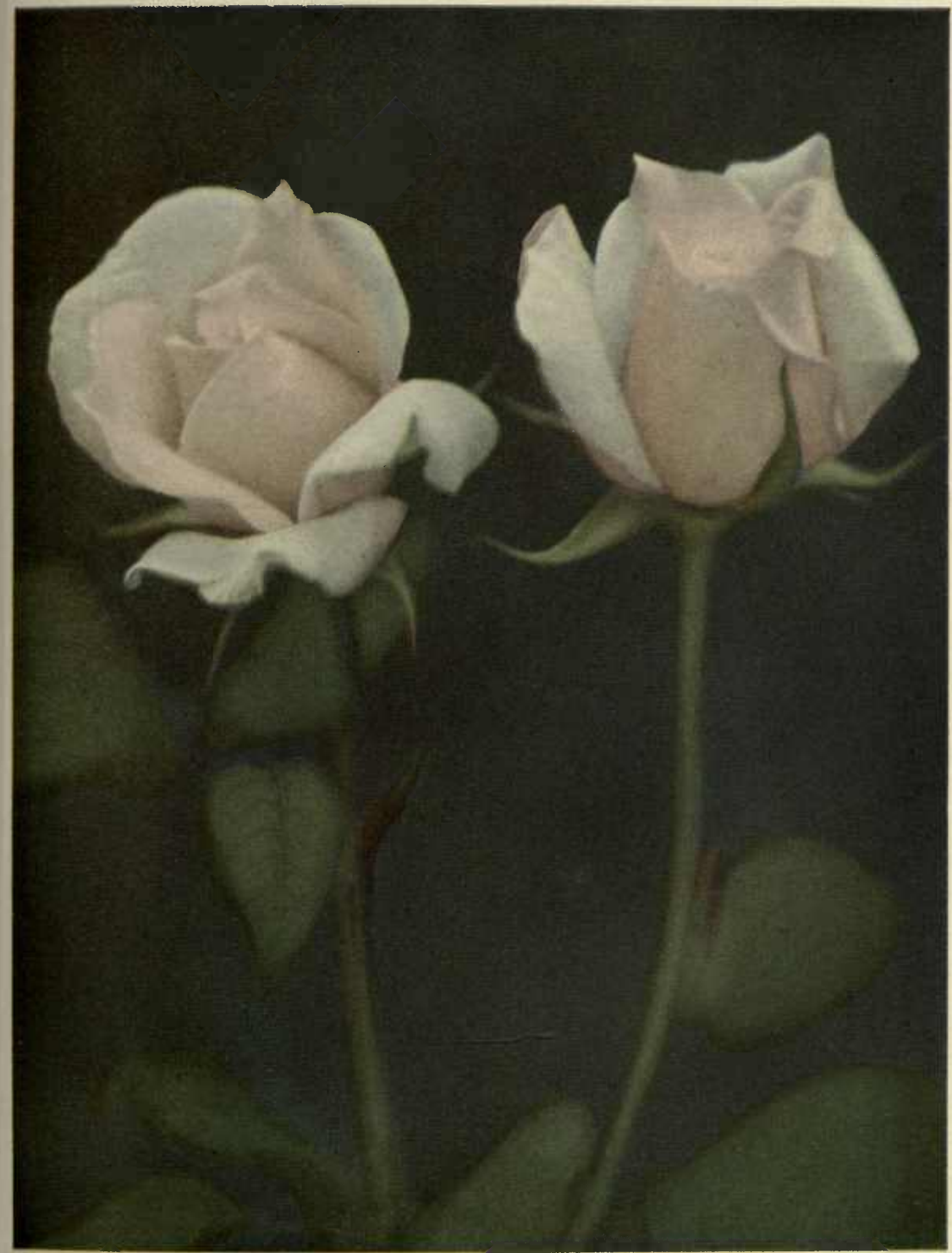

See list

MLLF. MARIE MASCURAND IIybrid Tea

BerNaIX 1909 



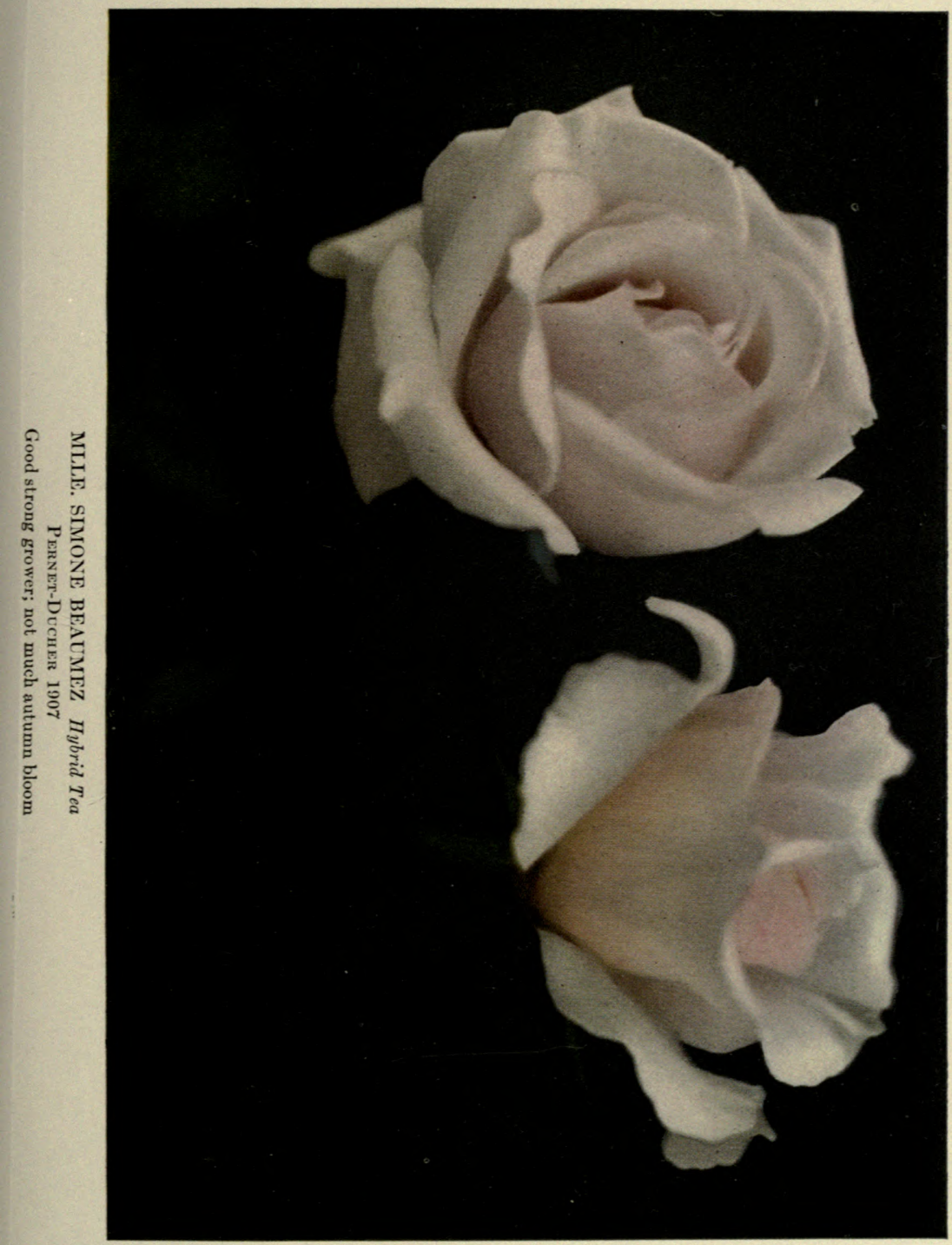





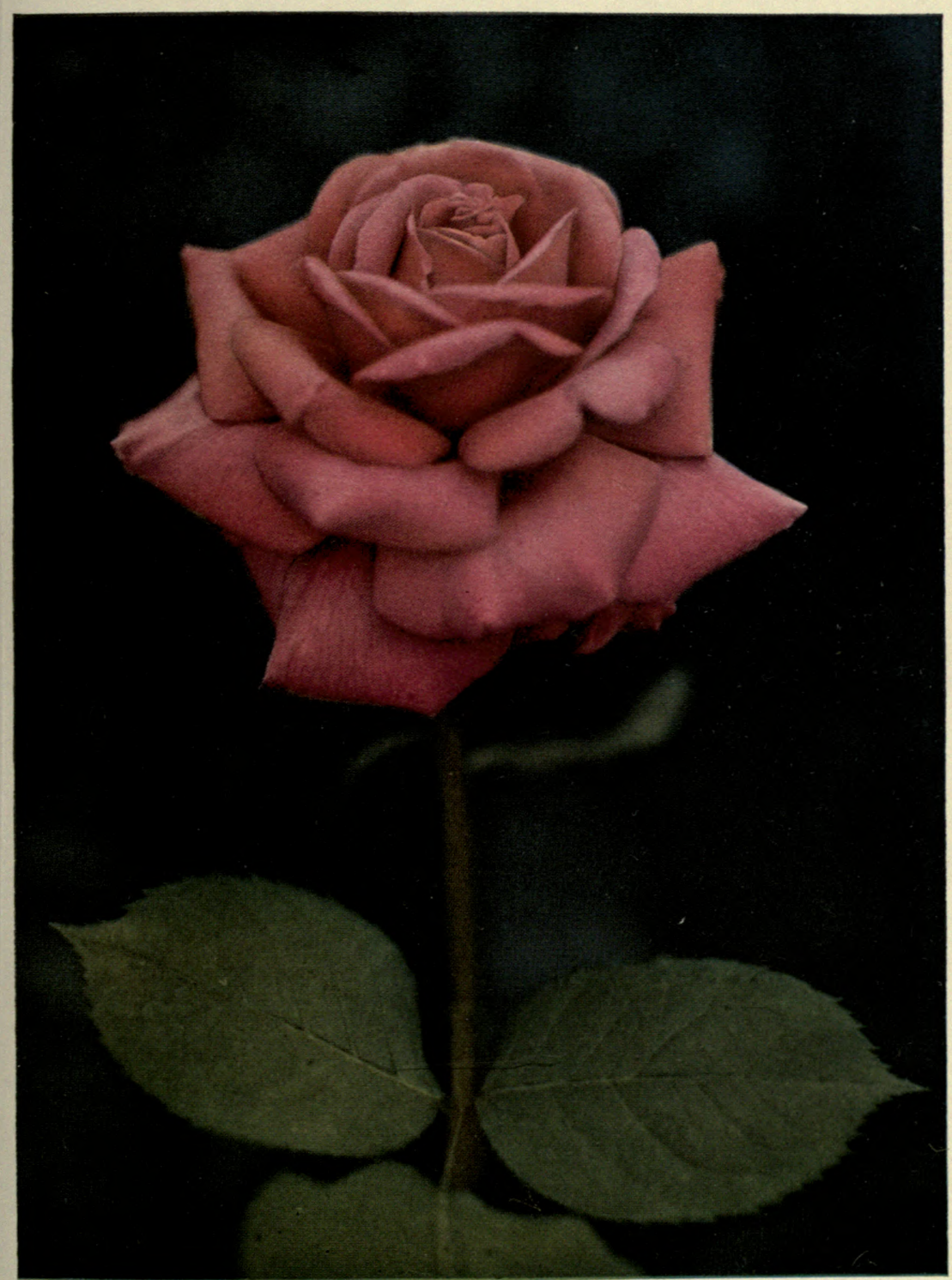
Alex. Dickson \& Sons 1909 



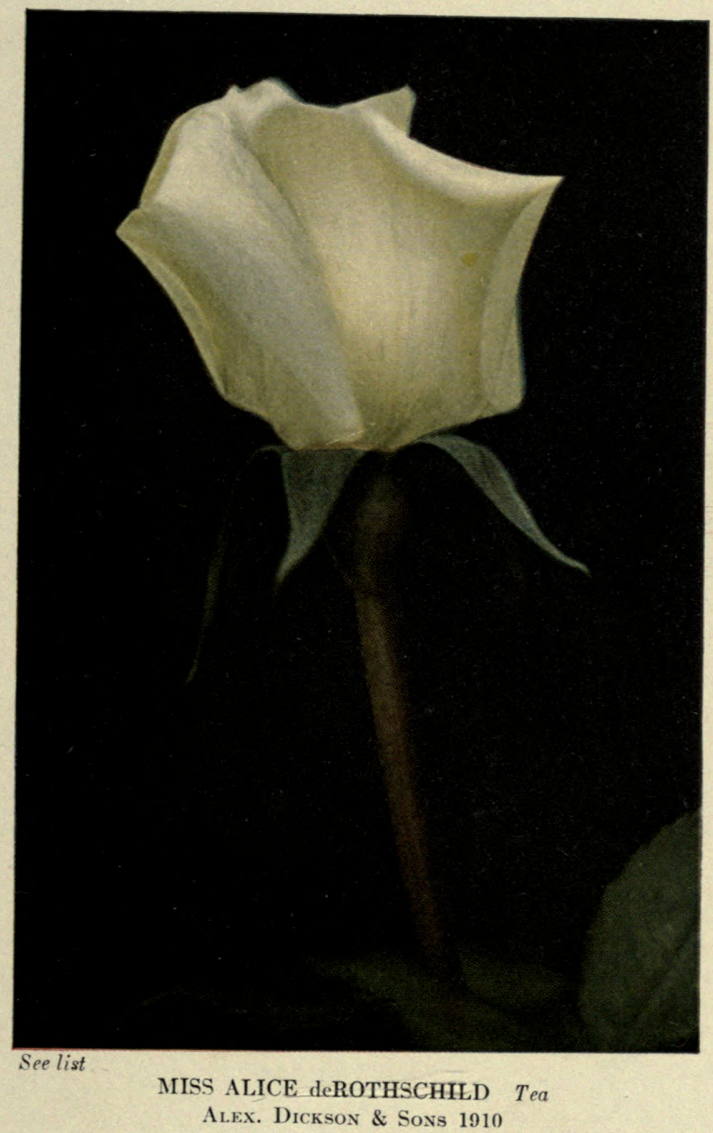





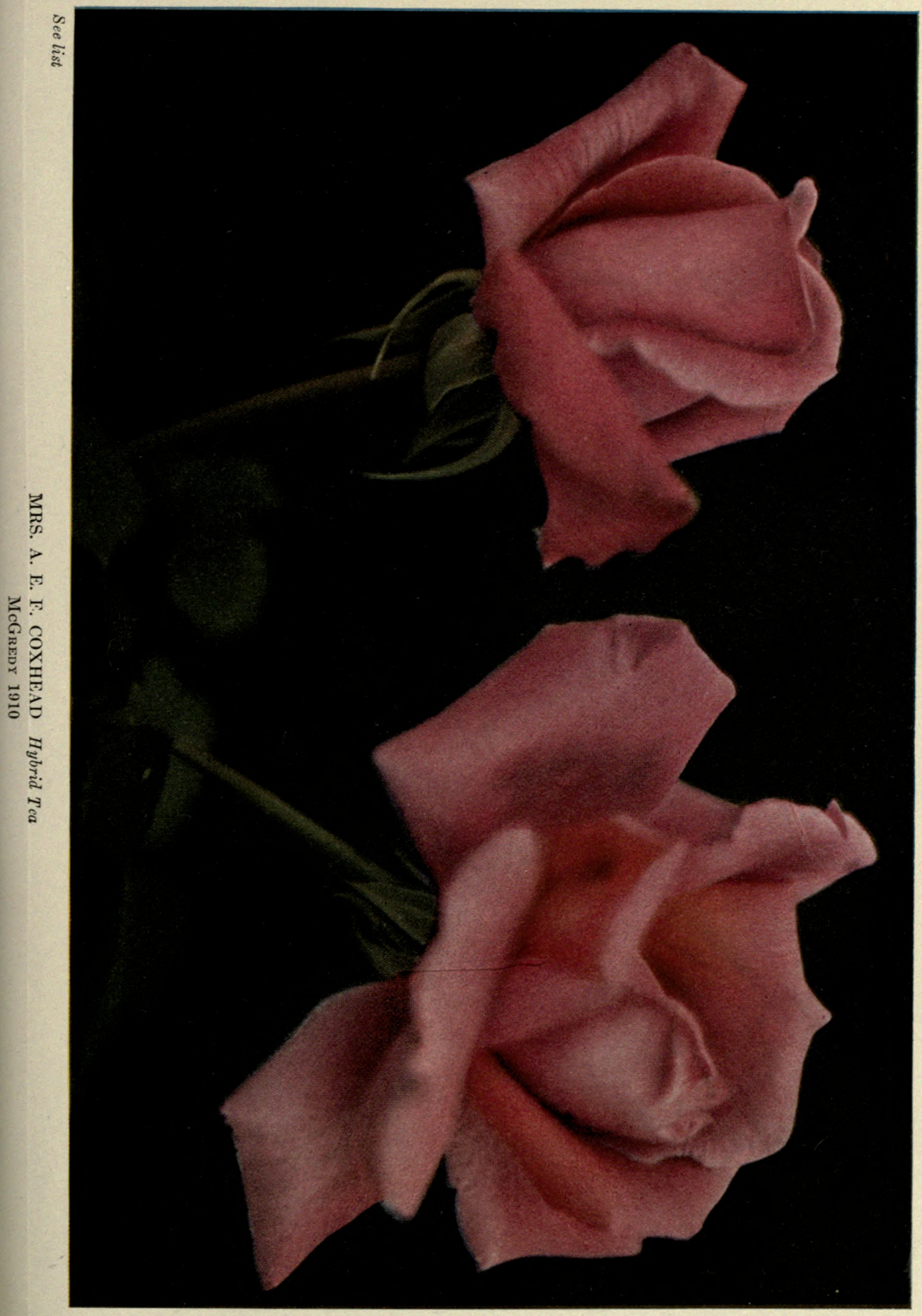





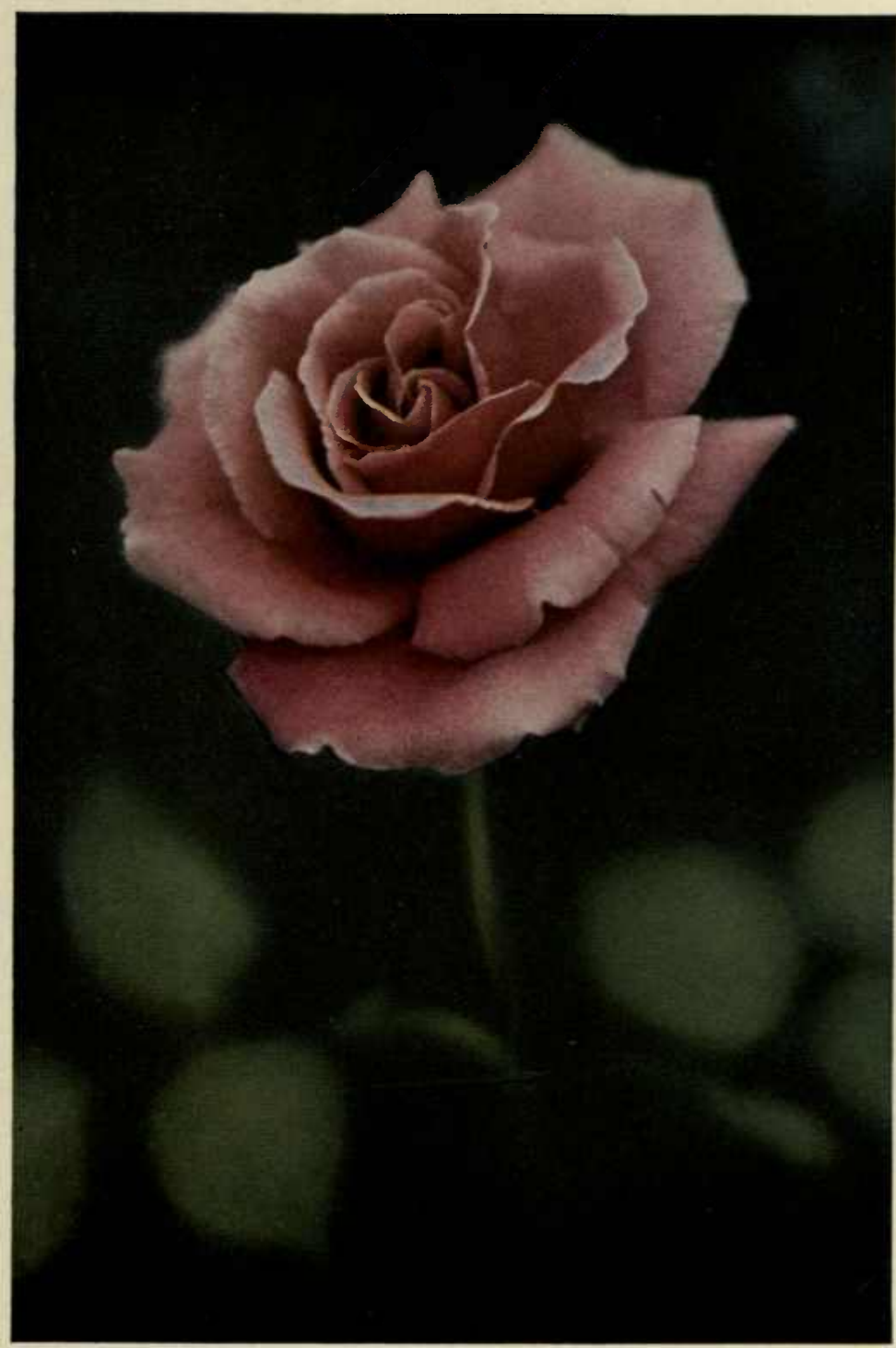

See list

MRS. CIIARLES C. HARRISON Tybrid Tea

Alex. Dicksos \& SoNs 1910 



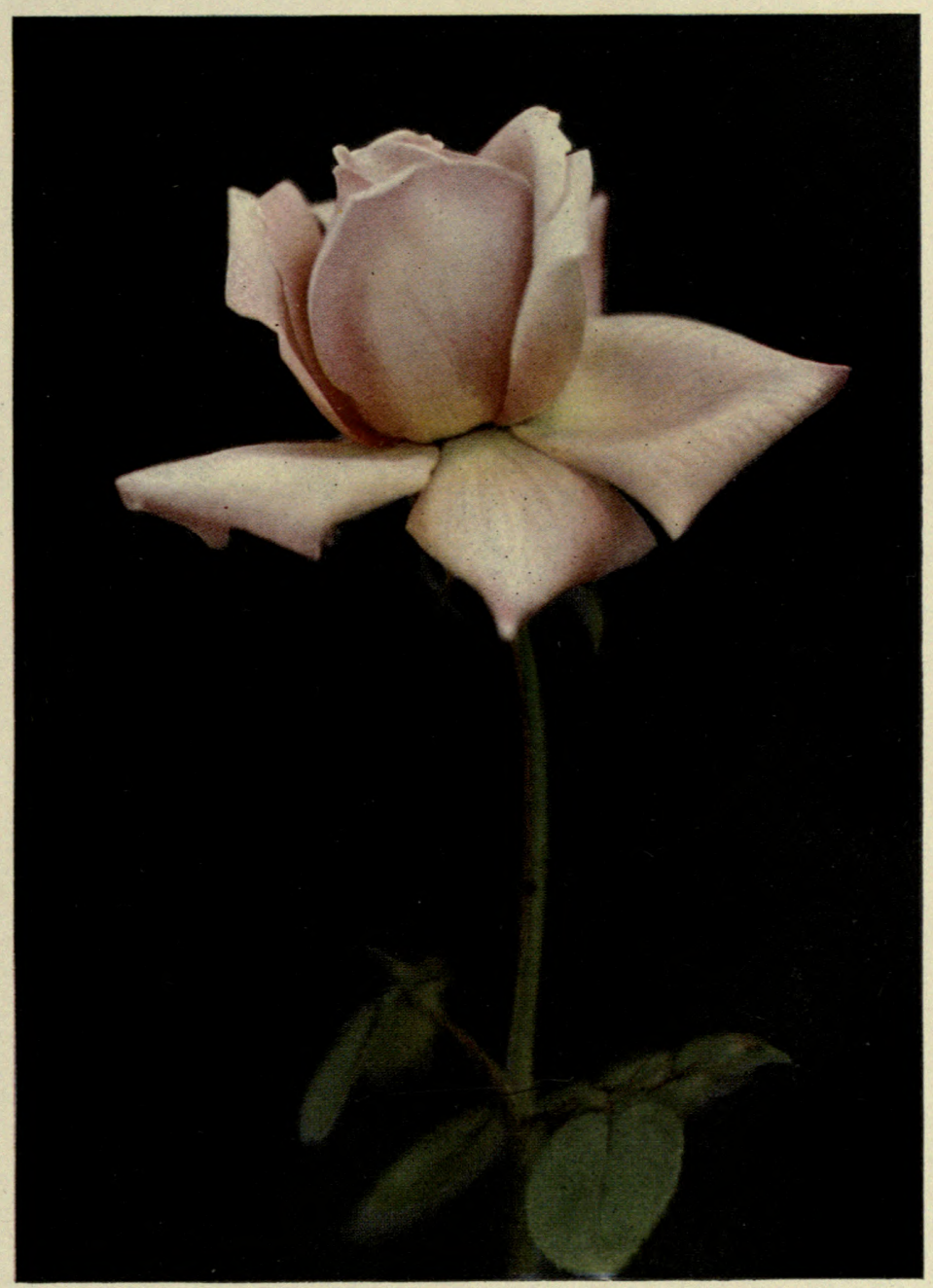

MRS. CHARLES E. ALLAN Hybrid Tea

Hugh Dickson 1911

Weak grower in Middle Atlantic States 




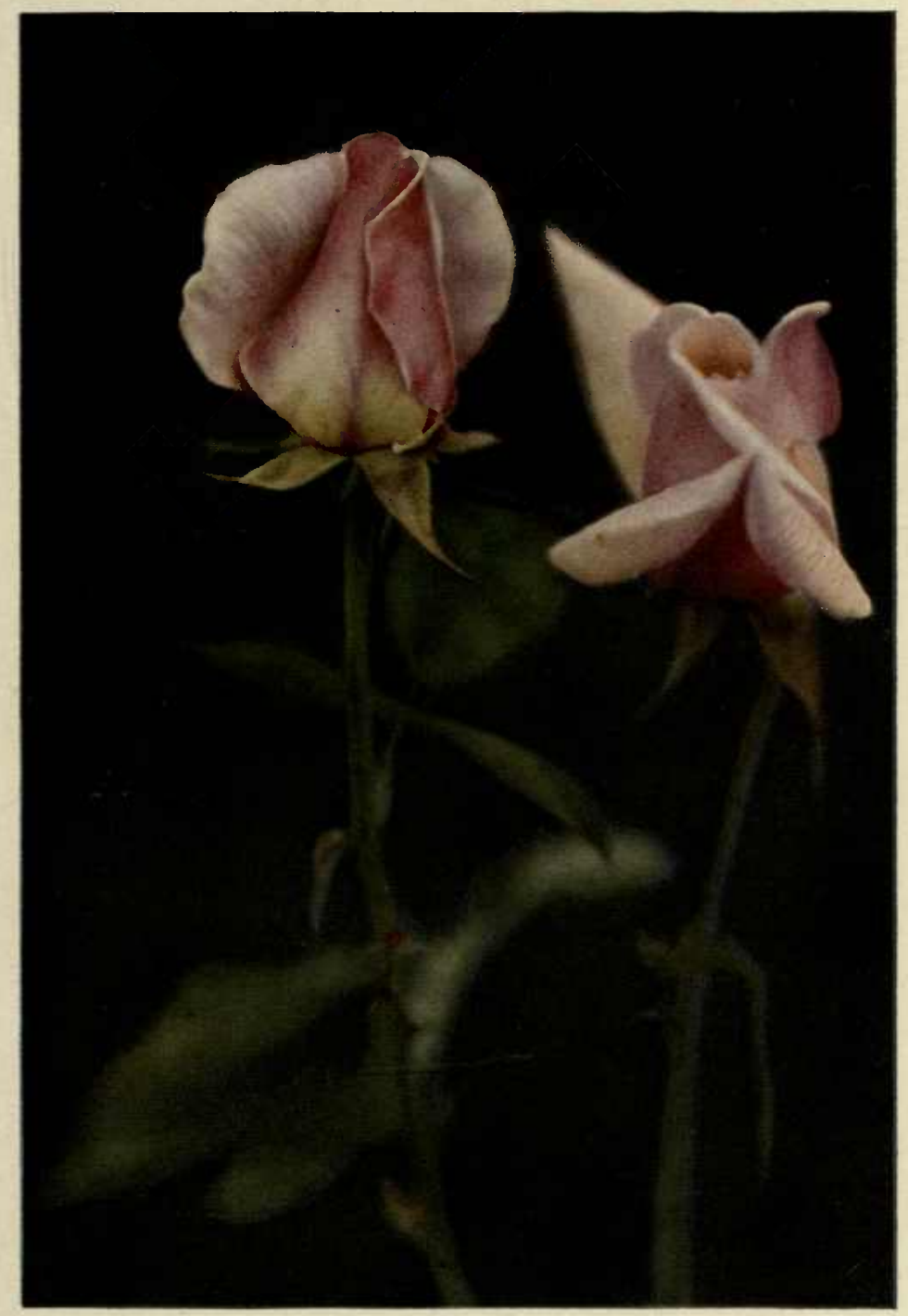

MRS. JAMES CRAIG IIybrid Tea

Hugir Dickson 1908

small grower, some autımn bloom 



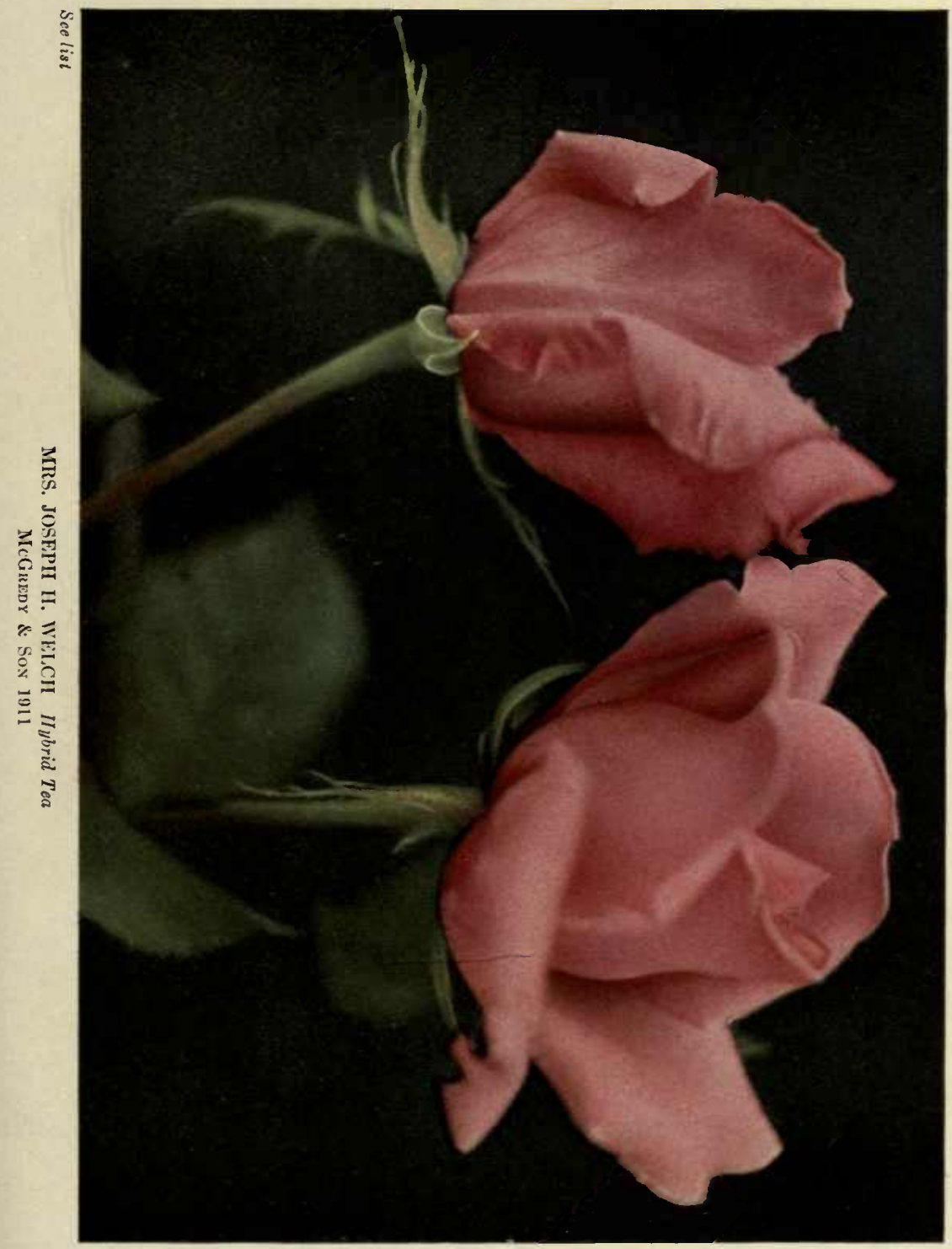




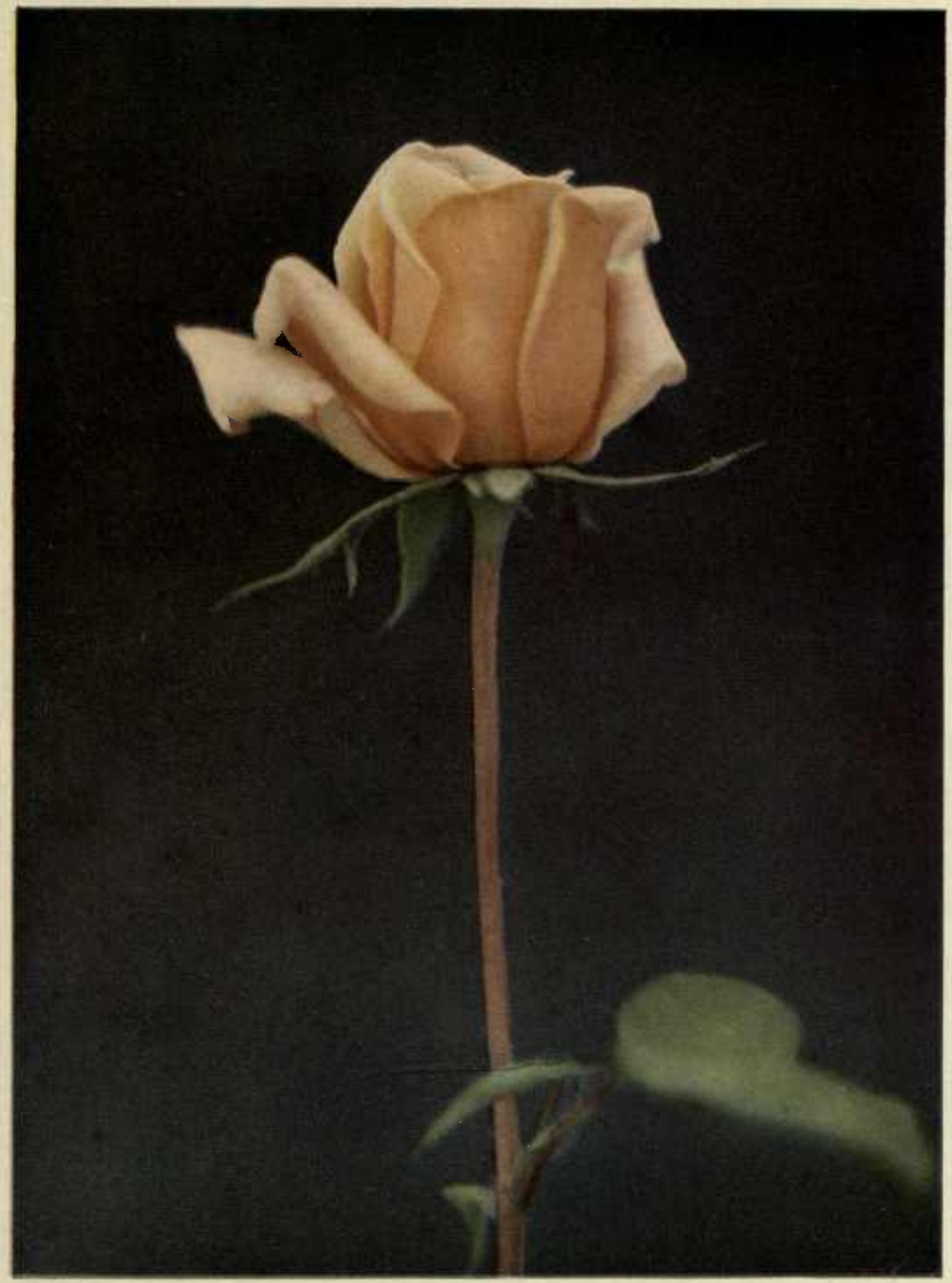

See list

MRS. I.EONARD PETRIE IIybrid Tea

Alex. Dickson \& Soxs 1910 



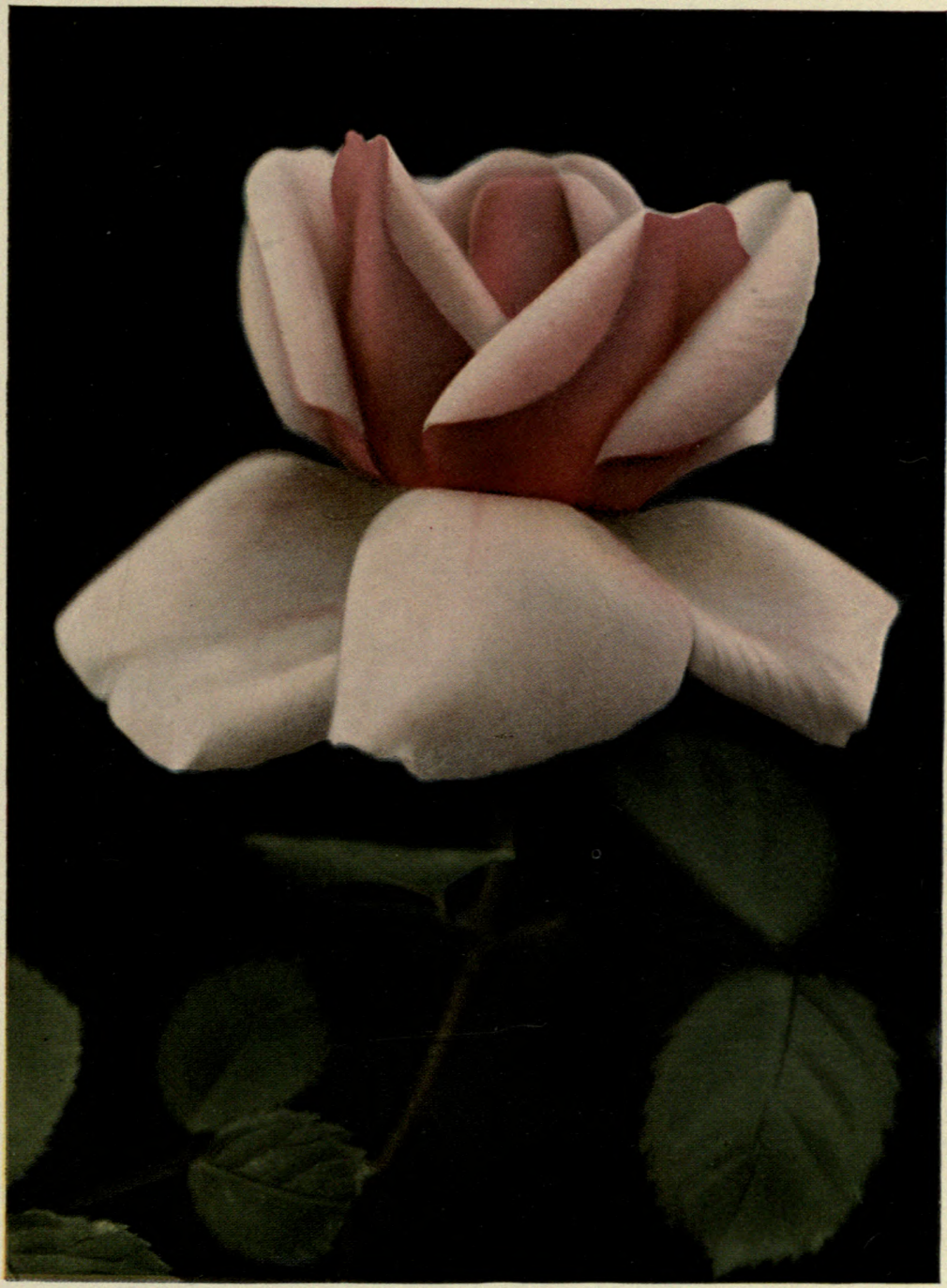

MRS. RICHARD DRAPER Hybrid Tea

Hugh Dickson 1912

Only fair growth, some autumn bloom; poor foliage 

B. $3 x^{2}+2+2=$ 


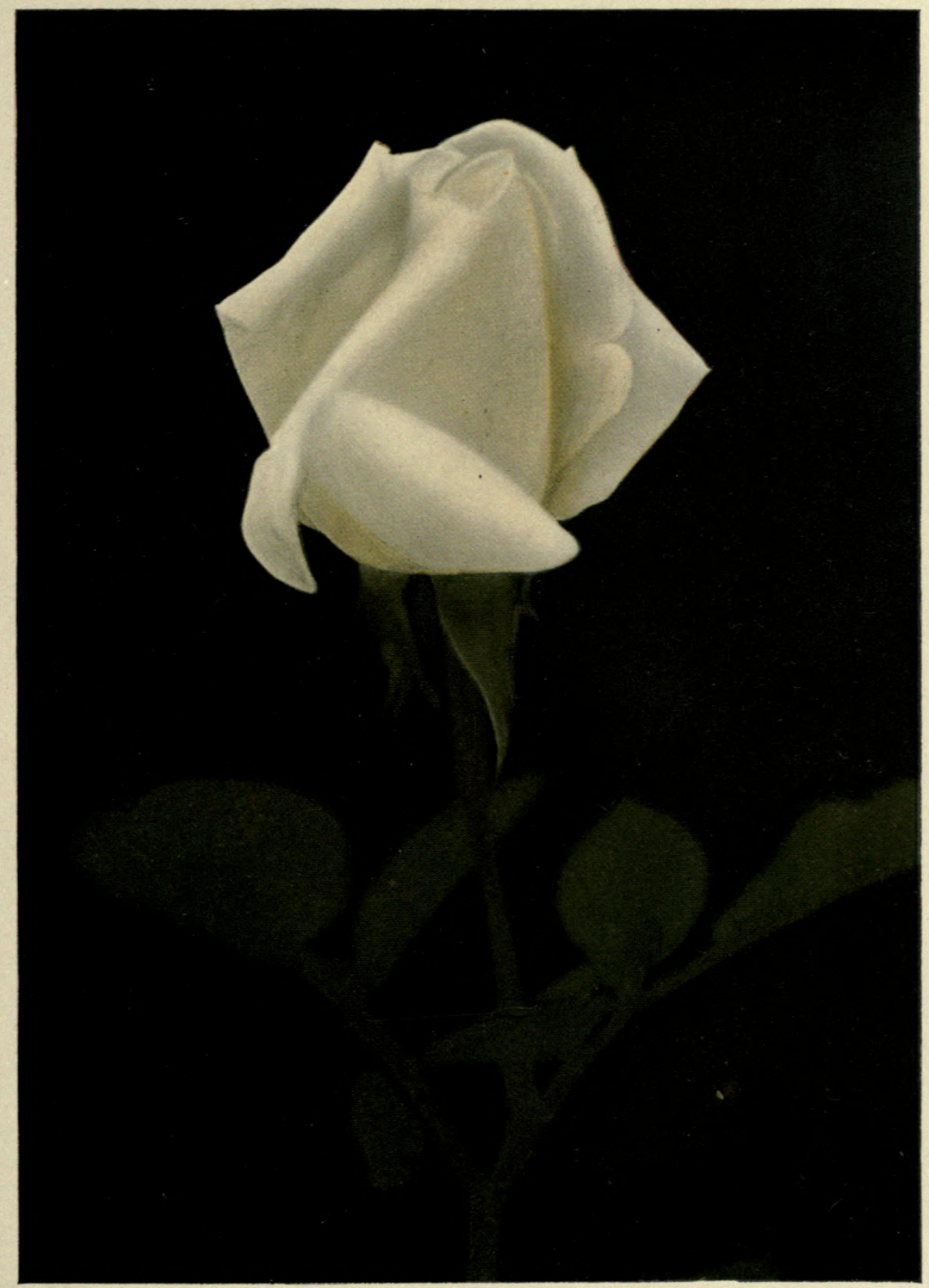





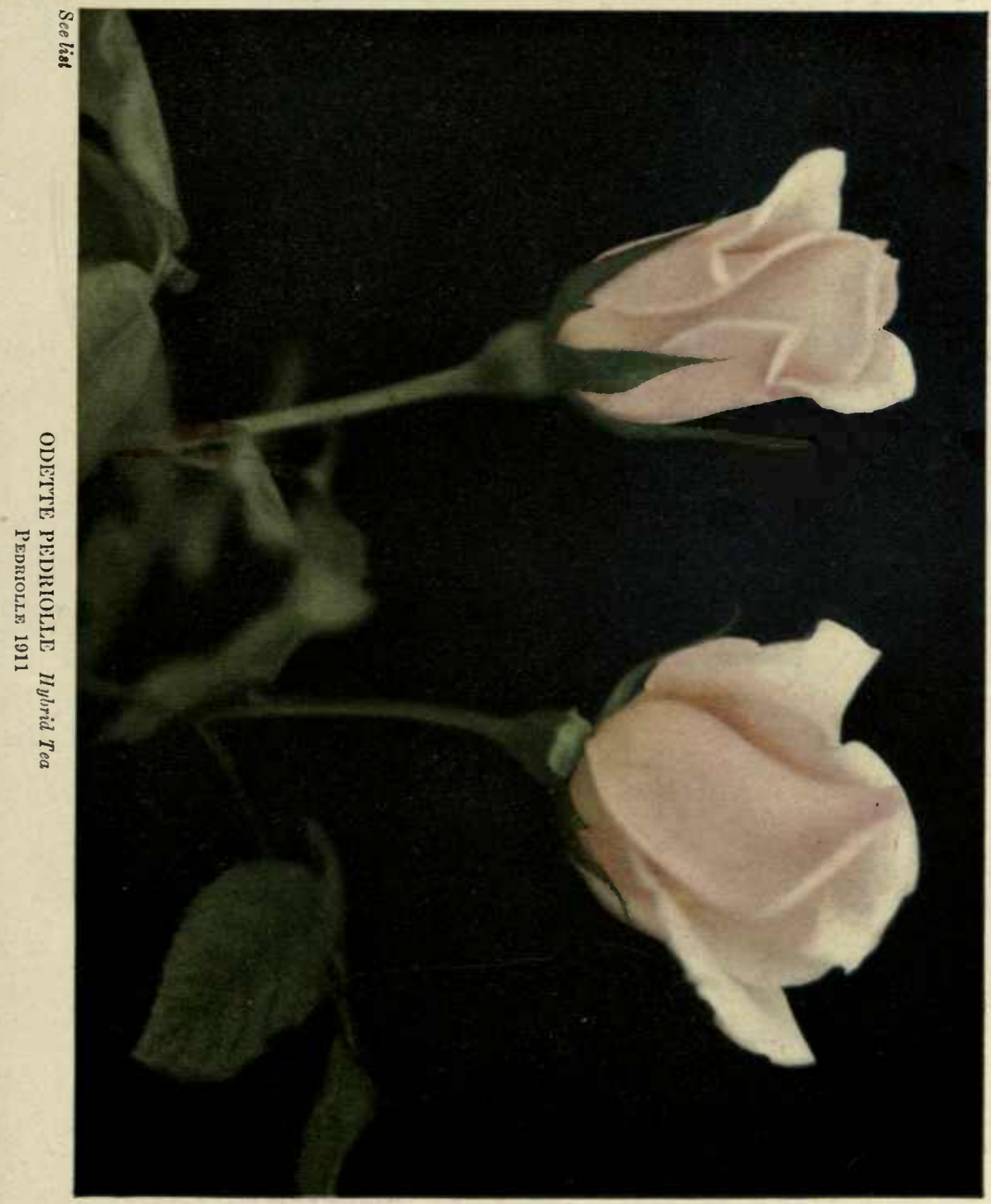





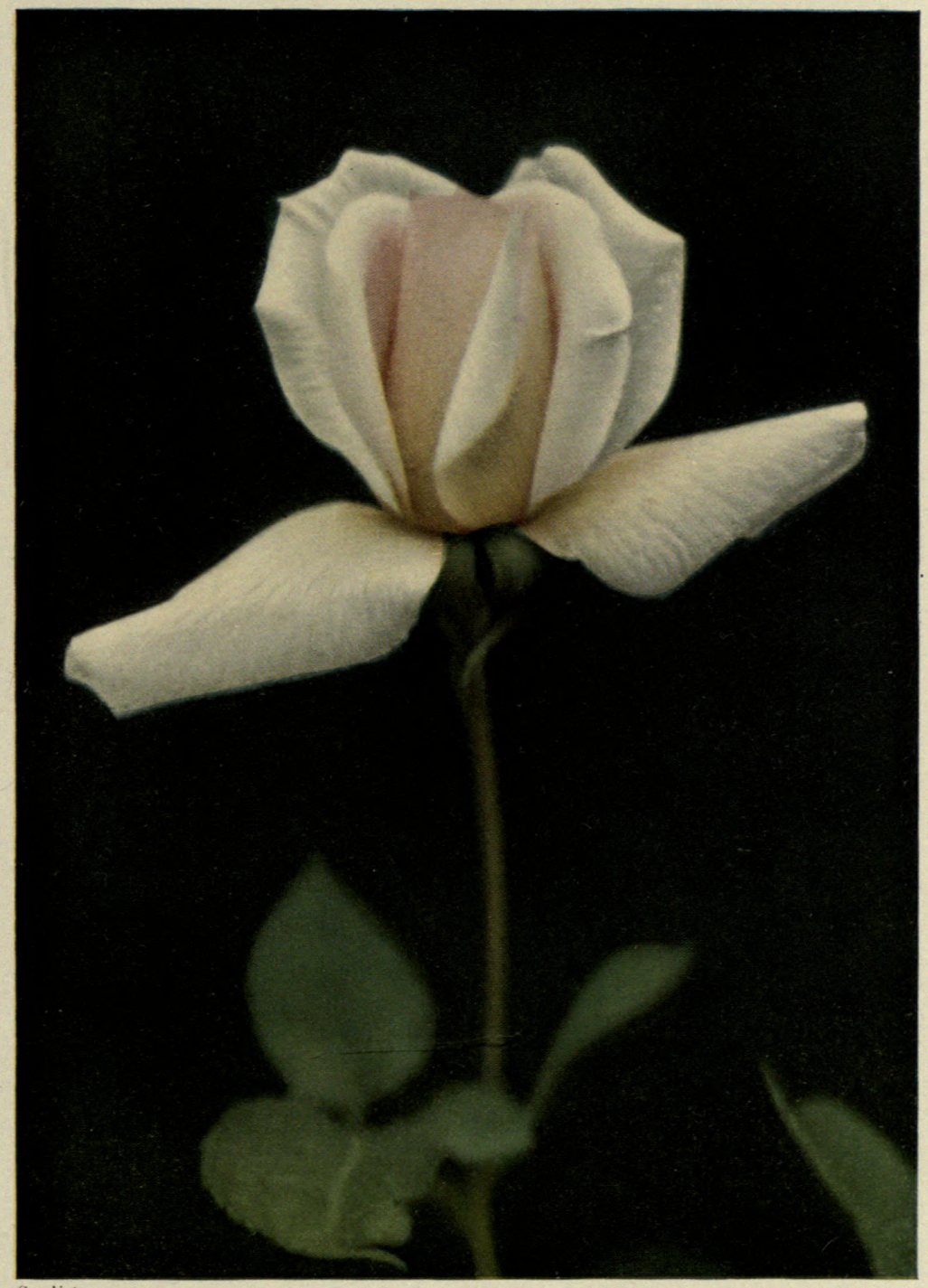

WM. PAUL 1912 



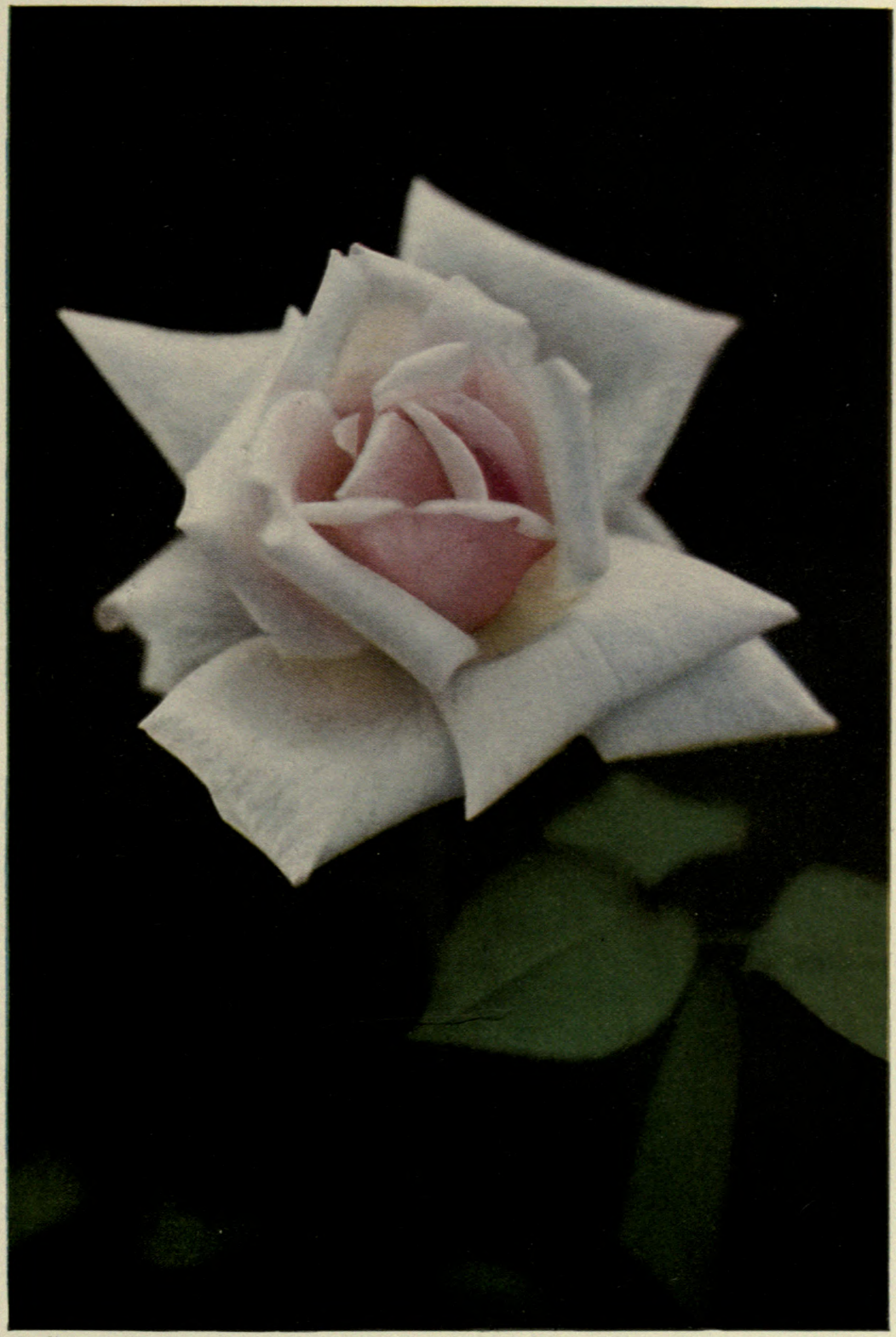

W. HINNER 1903 



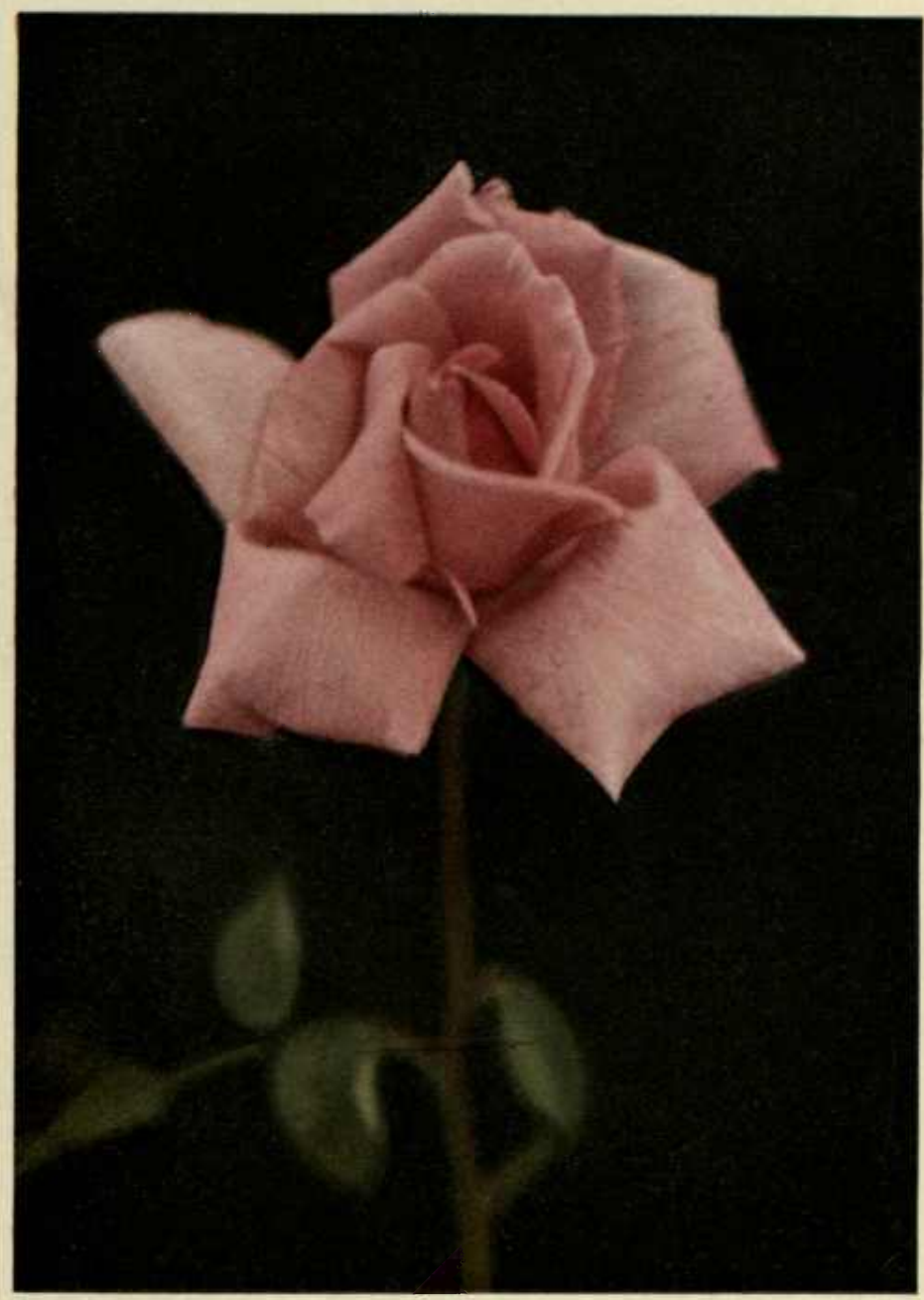

See list

PRESIDENT W. H. TAFT Hybrid Tea

Wis. PAEL \& Sox 1910 



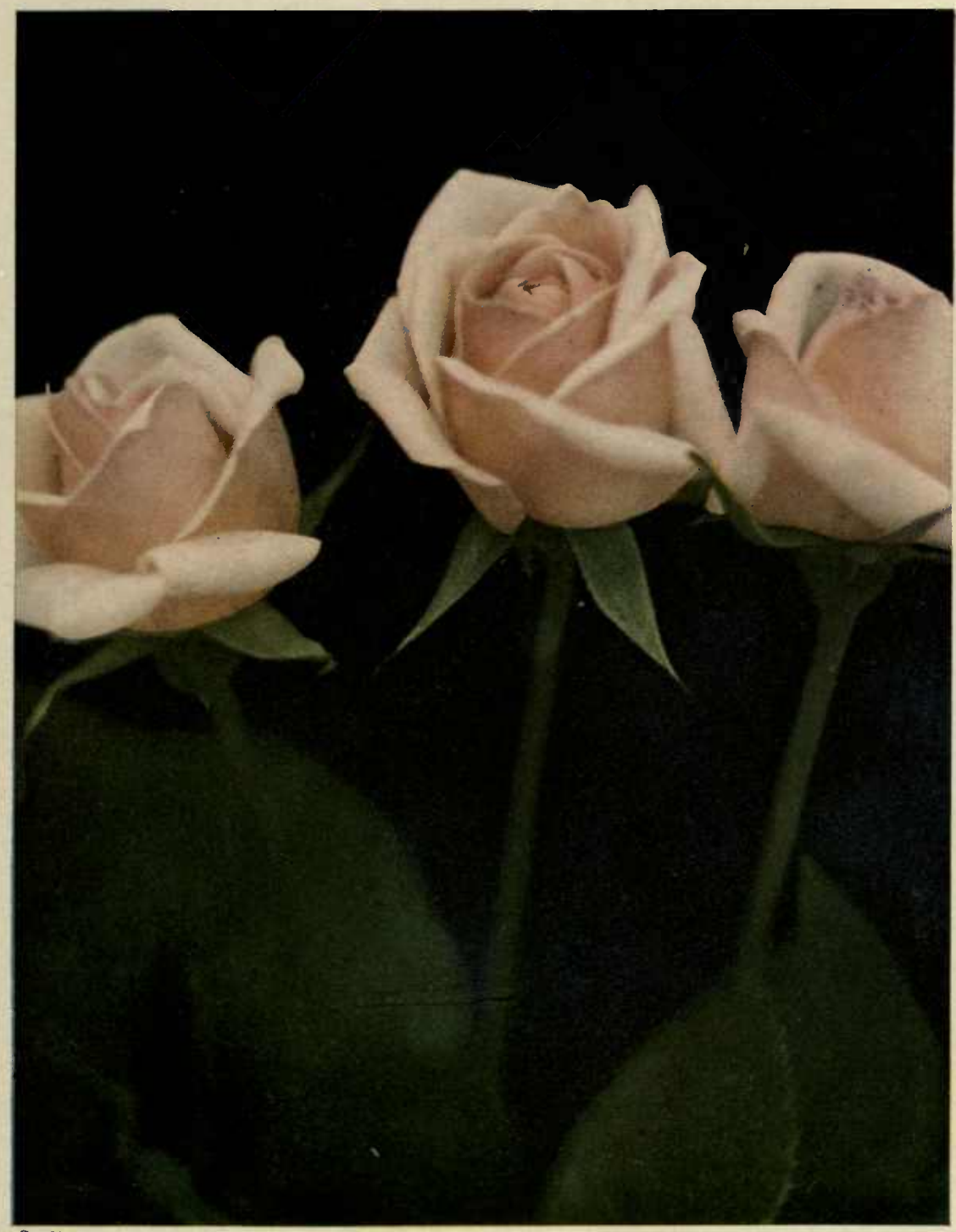

PRINCE de BULGARIE Hybrid Tea

Pernet-Ducher 1902 



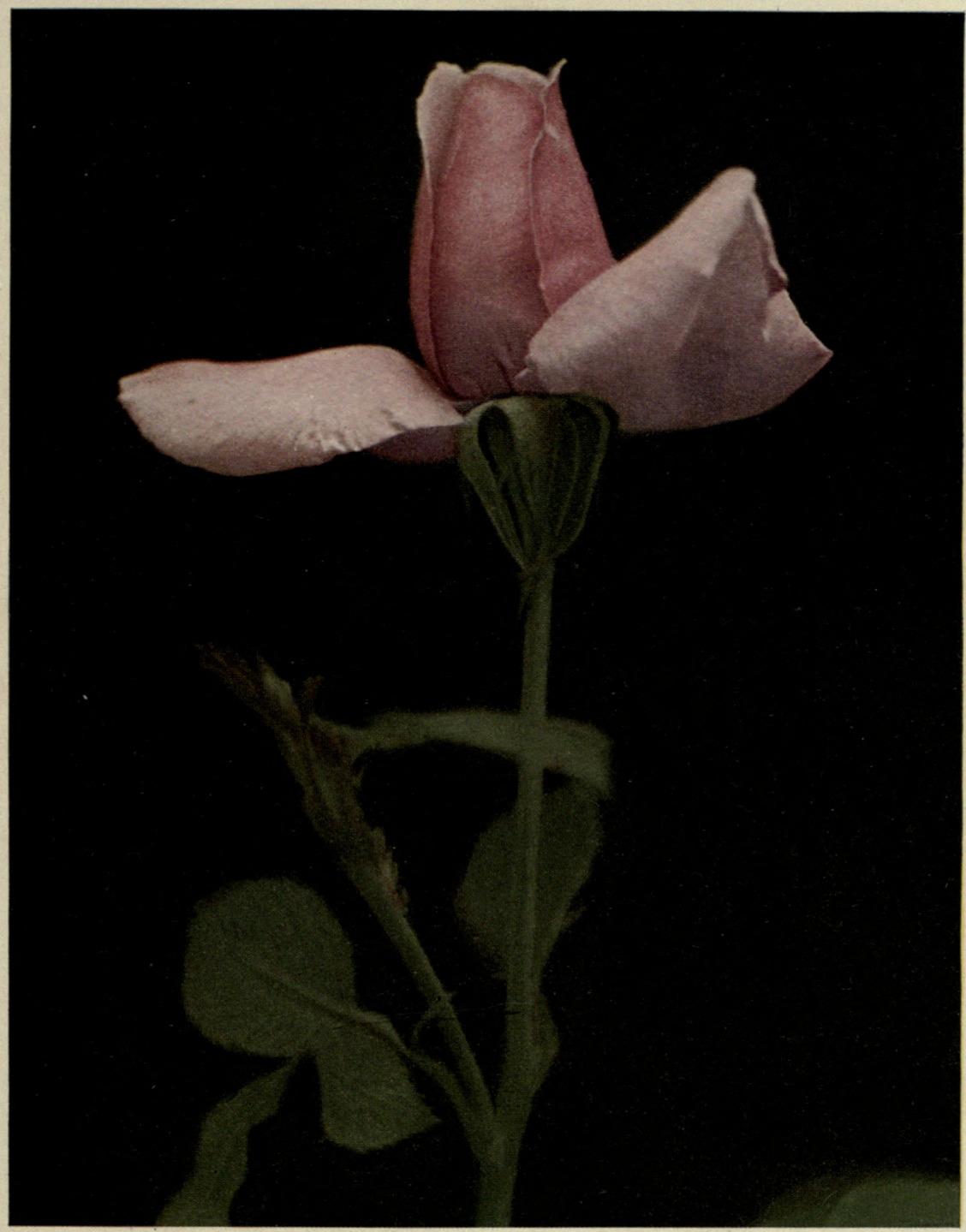

RADIANCE Hybrid Tea

JoHN Соок 1912 



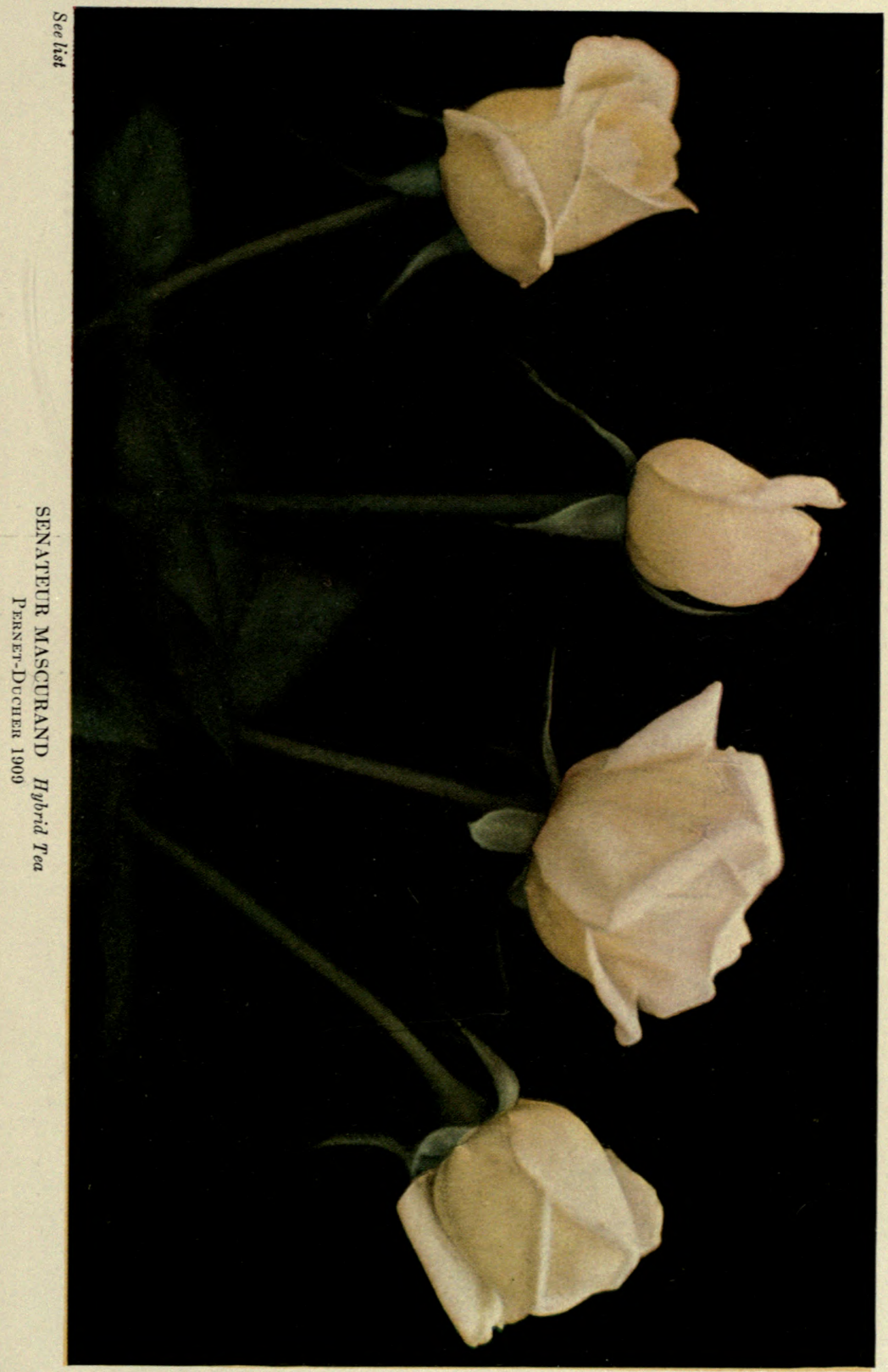






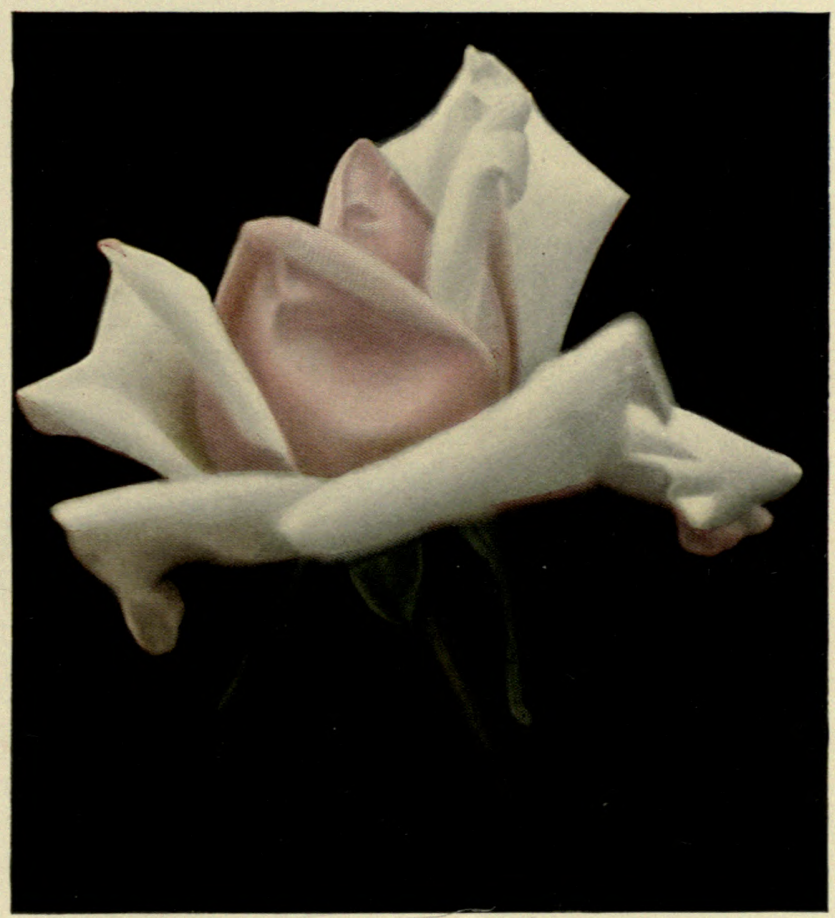

ST. HELENA Hybrid Tea

B. R. CANT \& Sons 1912

Not hardy in Middle Atlantic States 



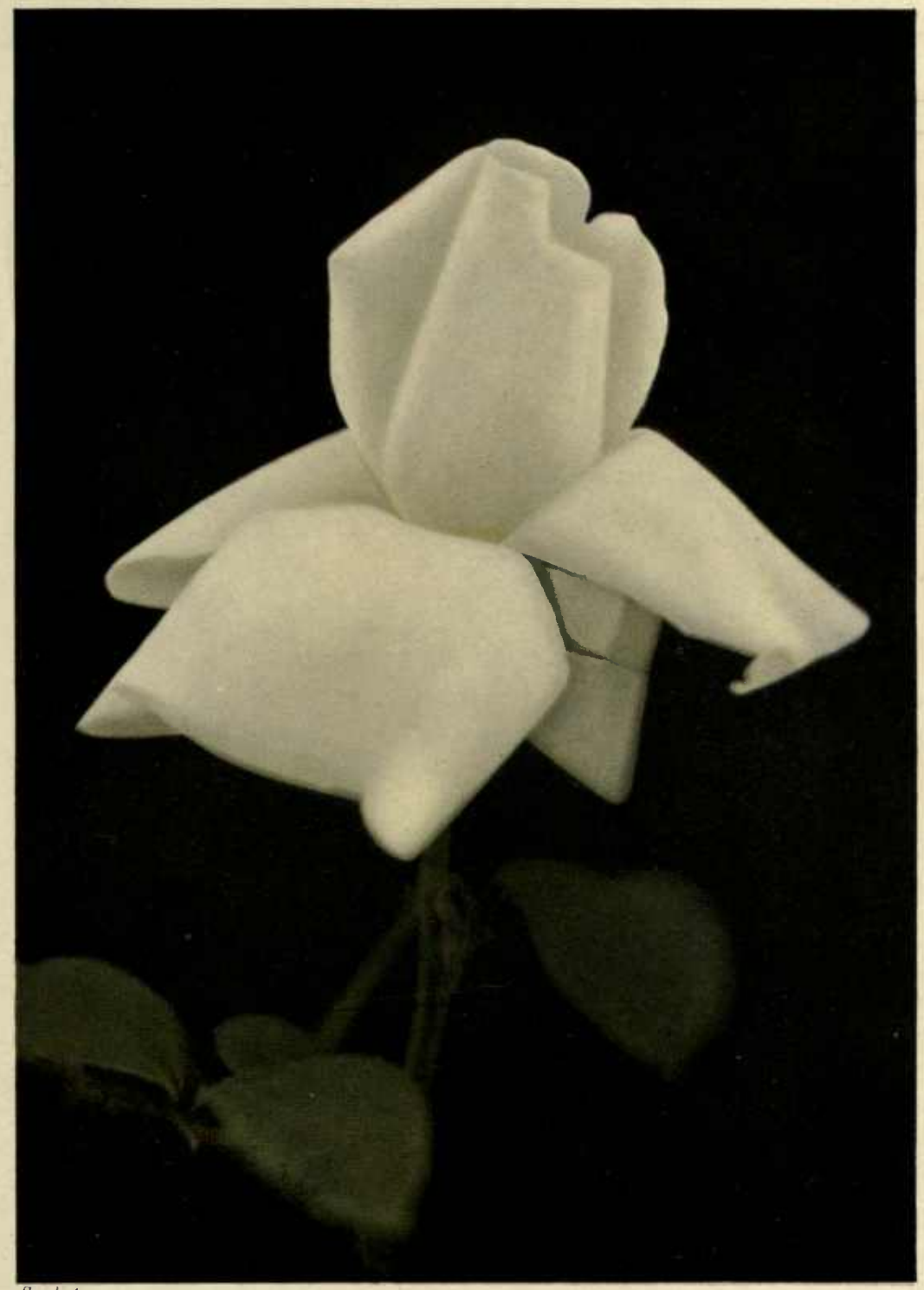

WHITE KILLARNEY IIybrid Tea

WabAN Rose Co. 1909 



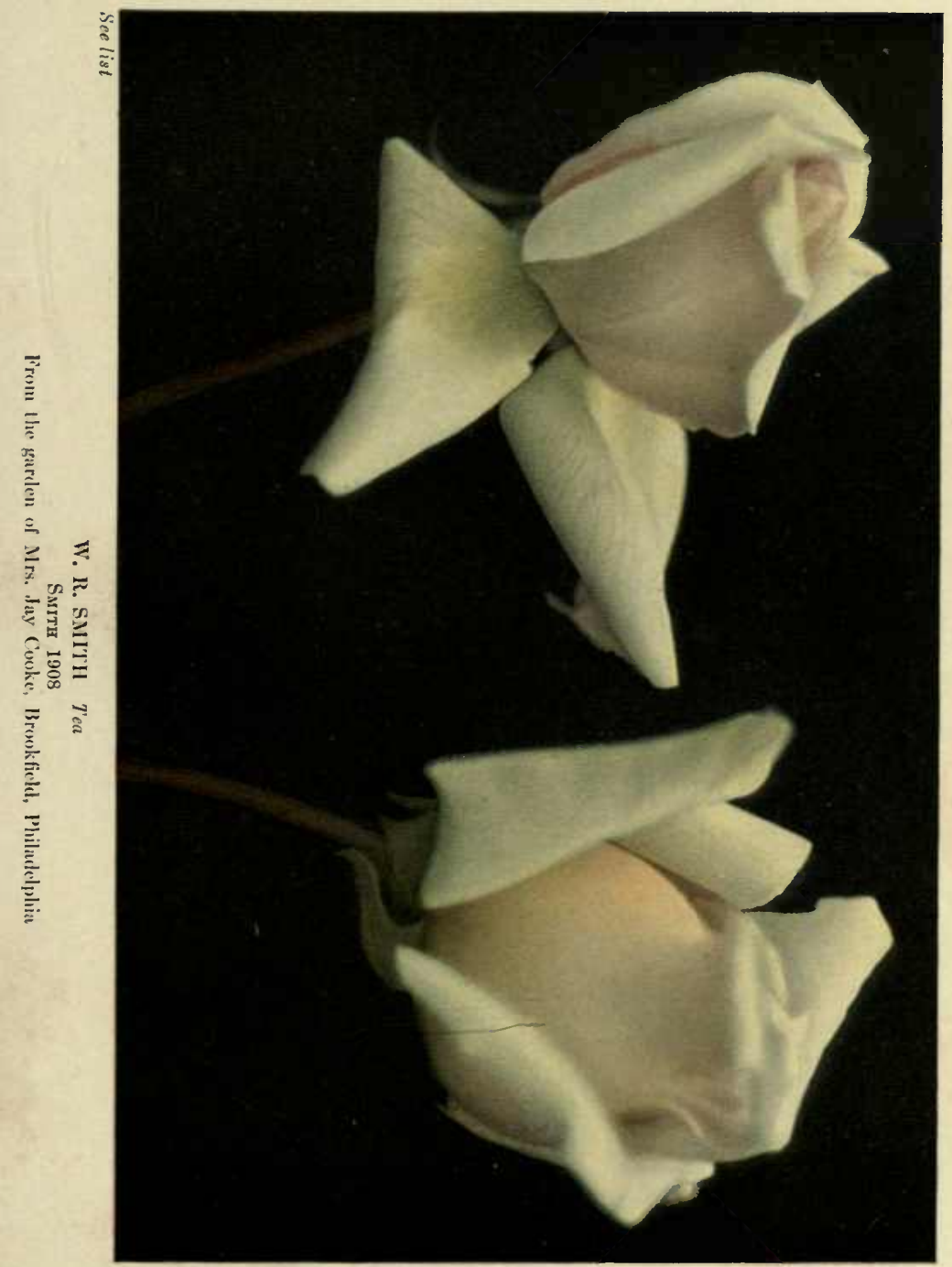





